\title{
Microwave-Assisted Intramolecular Ullmann Diaryl Etherification as the Post-Ugi Annulation for Generation of Dibenz $[b, f][1,4]$ oxazepine Scaffold
}

Jianyu Shi, ${ }^{\text {a† }}$ Jinlong Wu, ${ }^{\mathrm{a}}$ Chengsen Cui, ${ }^{\mathrm{b}}$ and Wei-Min Dai ${ }^{\mathrm{a}, \mathrm{b} *}$

${ }^{\mathrm{a}}$ Laboratory of Asymmetric Catalysis and Synthesis, Department of Chemistry, Zhejiang University, Hangzhou 310027, P. R. of China

${ }^{\mathrm{b}}$ Laboratory of Advanced Catalysis and Synthesis, Department of Chemistry, The Hong Kong University of Science and Technology, Clear Water Bay, Kowloon, Hong Kong SAR, P. R. of China

E-mail: chdai@zju.edu.cn; chdia@ust.hk

\section{Supporting Information}

1. Copies of ${ }^{1} \mathrm{H}$ and ${ }^{13} \mathrm{C}$ NMR spectra of 12a-i, 13a-m, 14a-i, and $15 \mathbf{a}-\mathbf{m}$............... S2

2. Copies of HRMS data, and ${ }^{1} \mathrm{H}$ and ${ }^{13} \mathrm{C}$ NMR spectra of resynthesized 15a and 15i..... S158

[The residue of $\mathrm{CHCl}_{3}$ introduced during NMR sample preparation gives the signals at 8.21 (for ${ }^{1} \mathrm{H}$ ) and 79.2 (for ${ }^{13} \mathrm{C}$ ) ppm, respectively, in DMSO- $d_{6 \cdot}{ }^{1}$ ]

\footnotetext{
† Current address: Department of Medicinal Chemistry, UniTris Biopharma Co., Ltd., 399 Cailun Road, Shanghai 201203, P. R. of China.

${ }^{1}$ Gottlieb, H. E.; Kotlyar, V.; Nudelman, A. J. Org. Chem. 1997, 62, 7512-7515.
} 

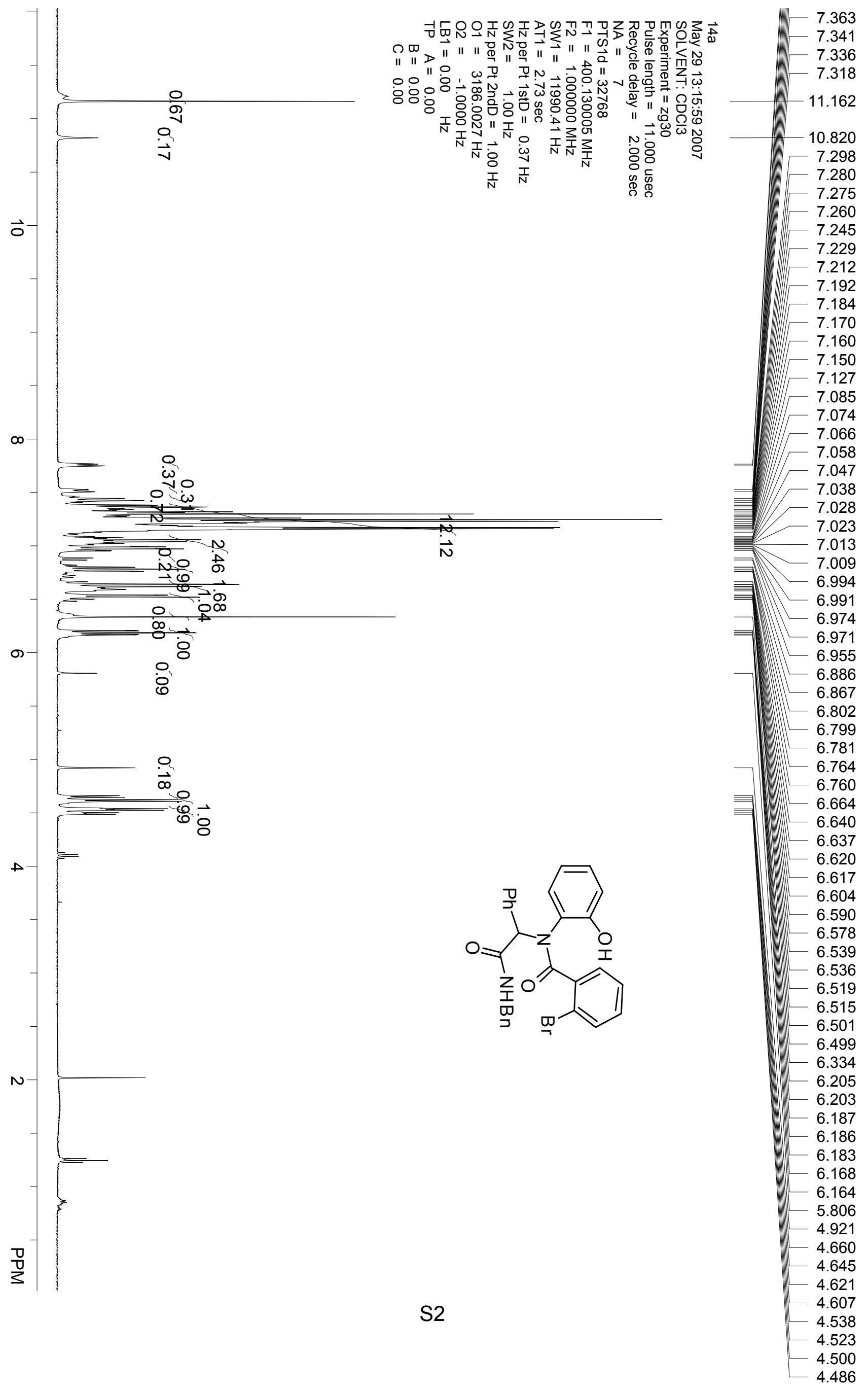


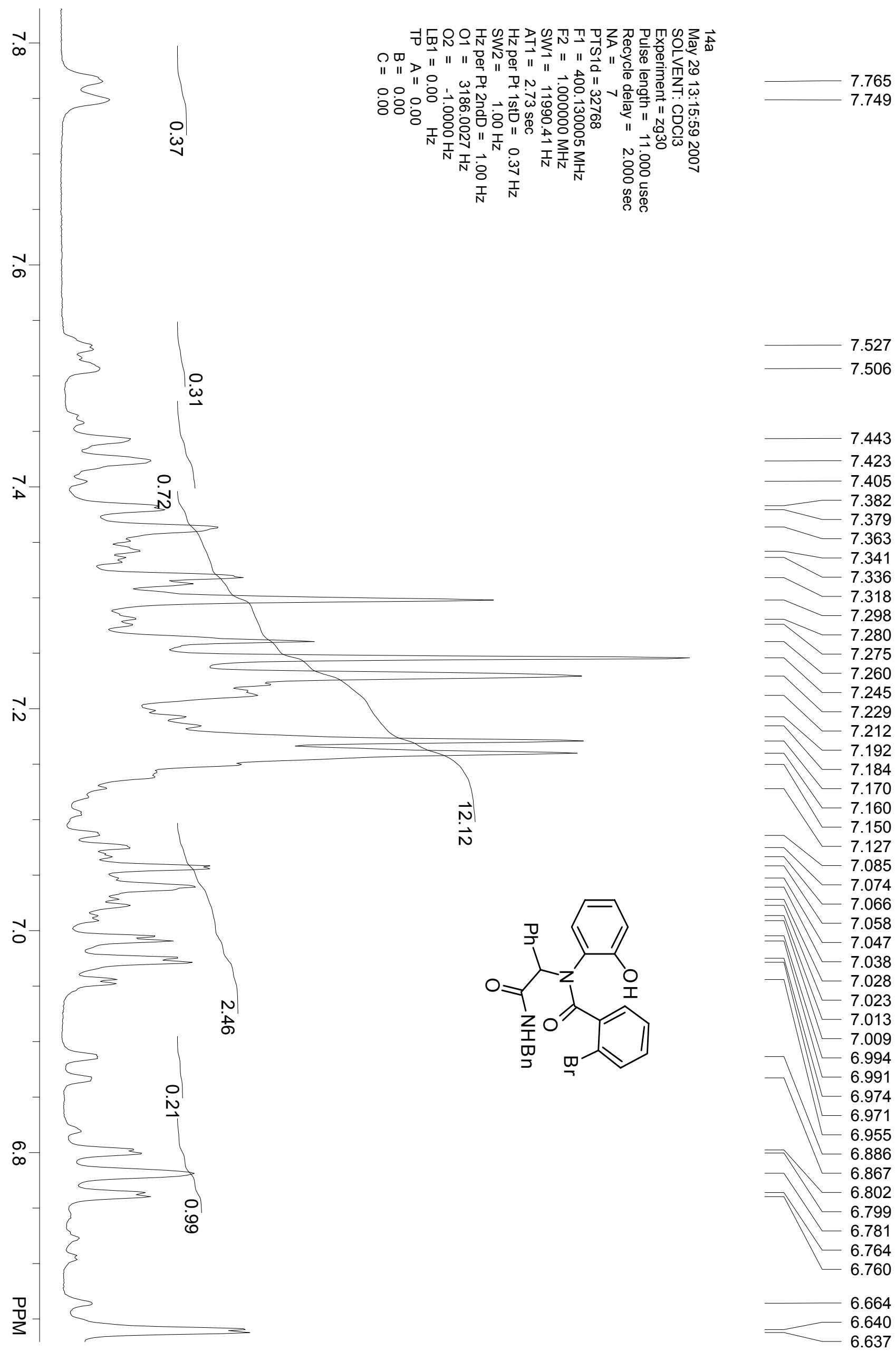



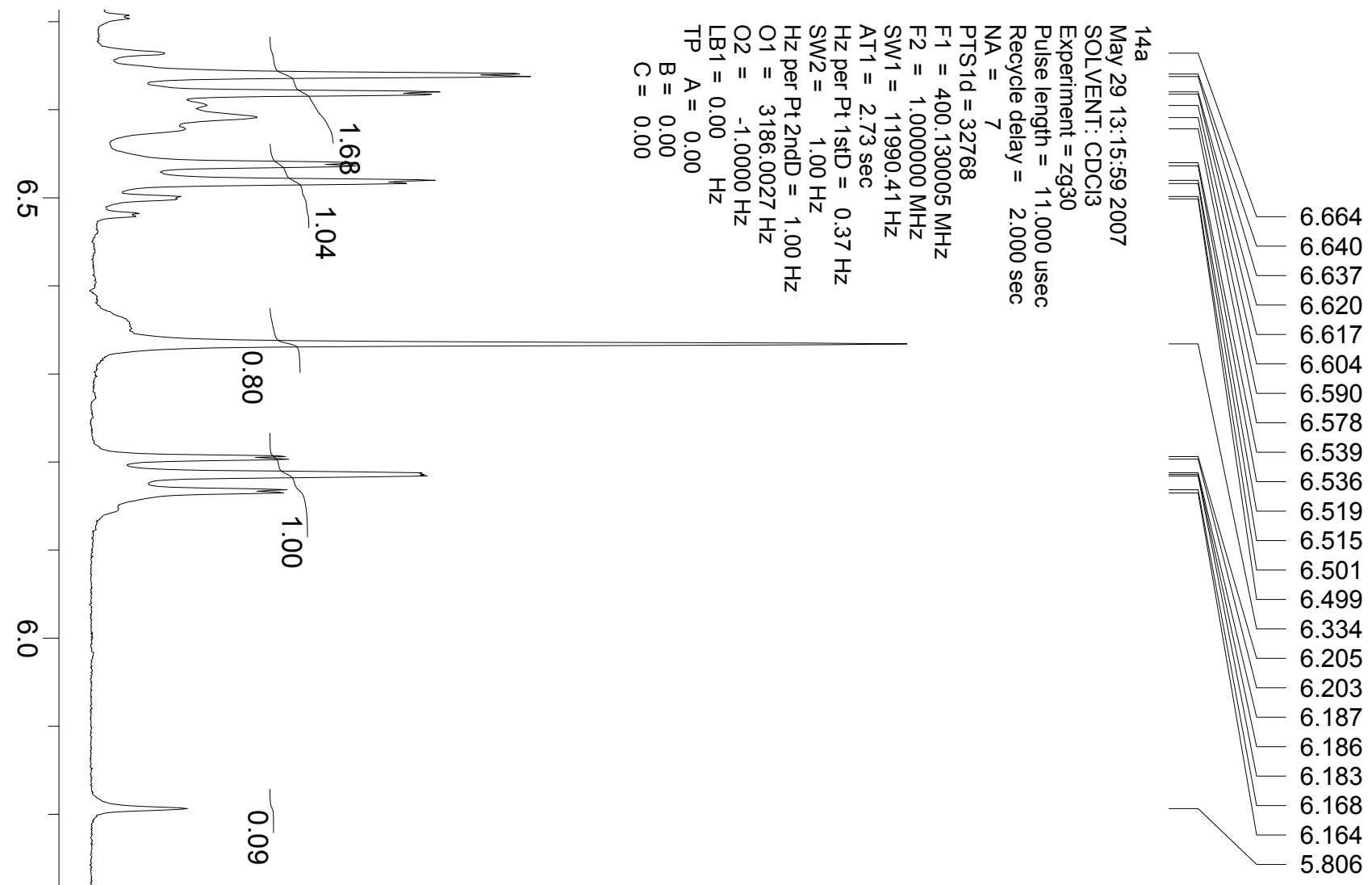

잉

용

6.640

6.637

6.617

6.604

6.578

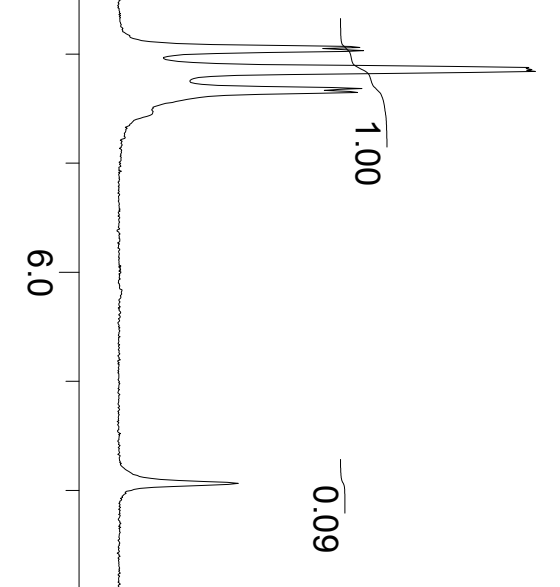

6.539
.536

.519

6.515

6.501

6.334

6.205

6.203

6.187

6.183

6.168

5.806

or

$\vec{\infty}$

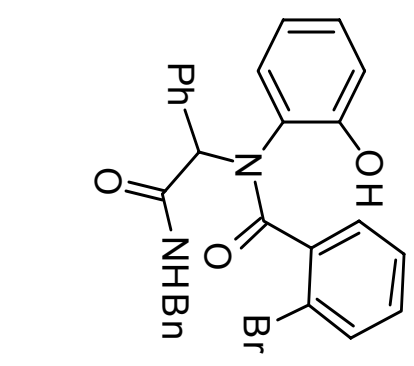

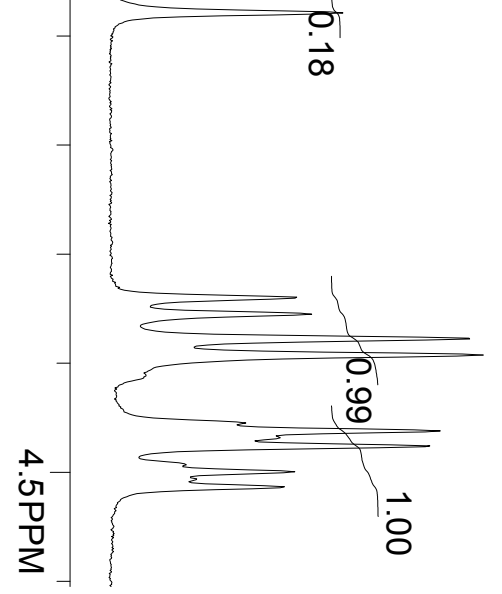



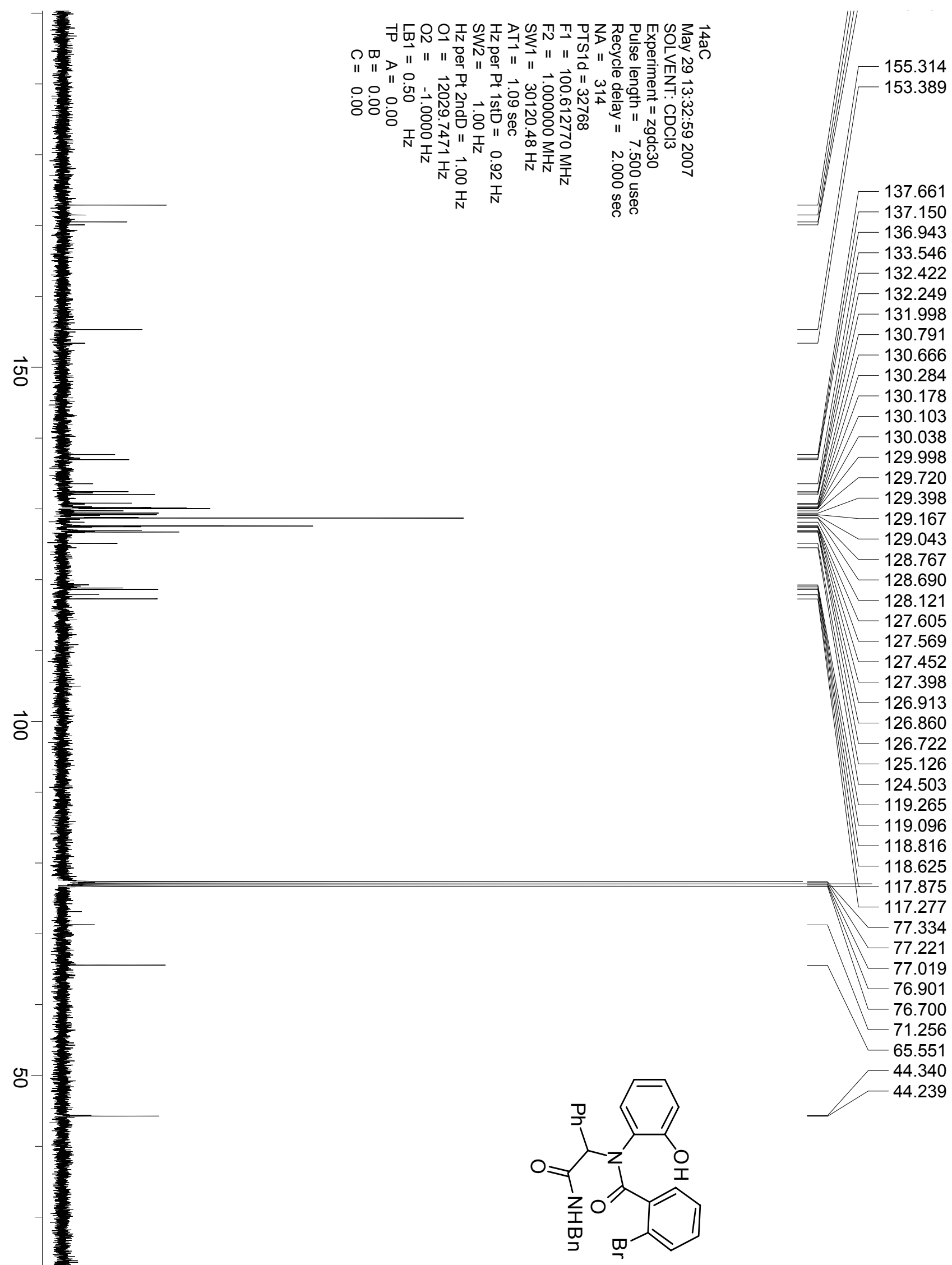

$\stackrel{0}{0}$ 


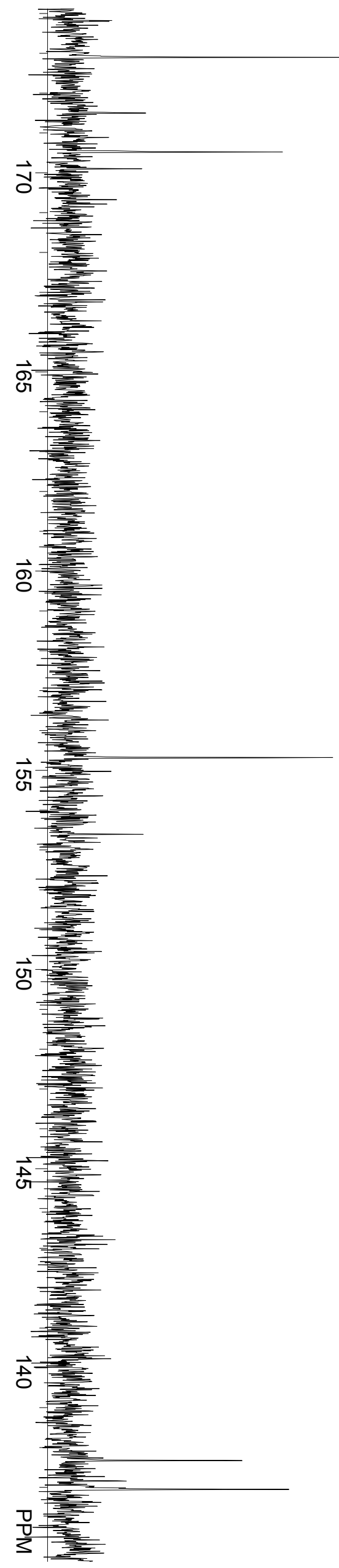

172.897

$0 \pi$ D N N

" " $>0$ "

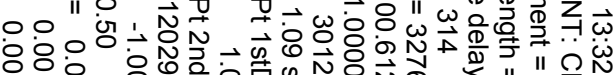

171.496

T啨"

N

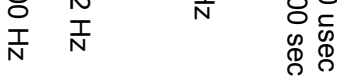




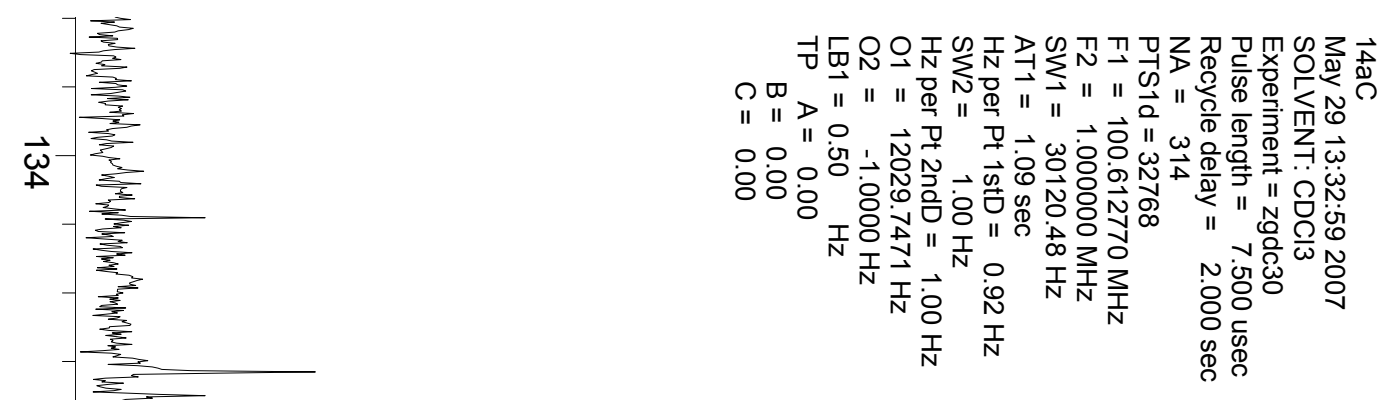

$\stackrel{\omega}{N}$

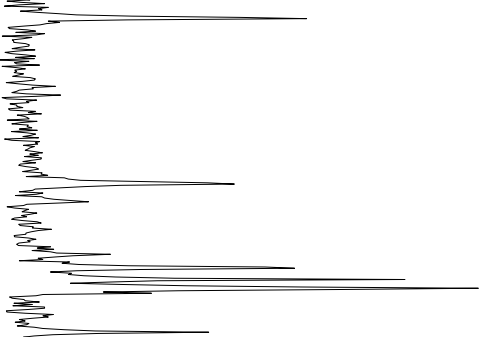

130.791

130.666

130.284

130.178

130.103

130.038

129.998

129.720

129.398

129.167

129.043

128.767

128.690

128.121

127.605

127.569

127.452

127.398

126.913

126.860

126.722

N

心-

3

N

$\triangle$

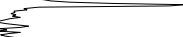

125.126

124.503 


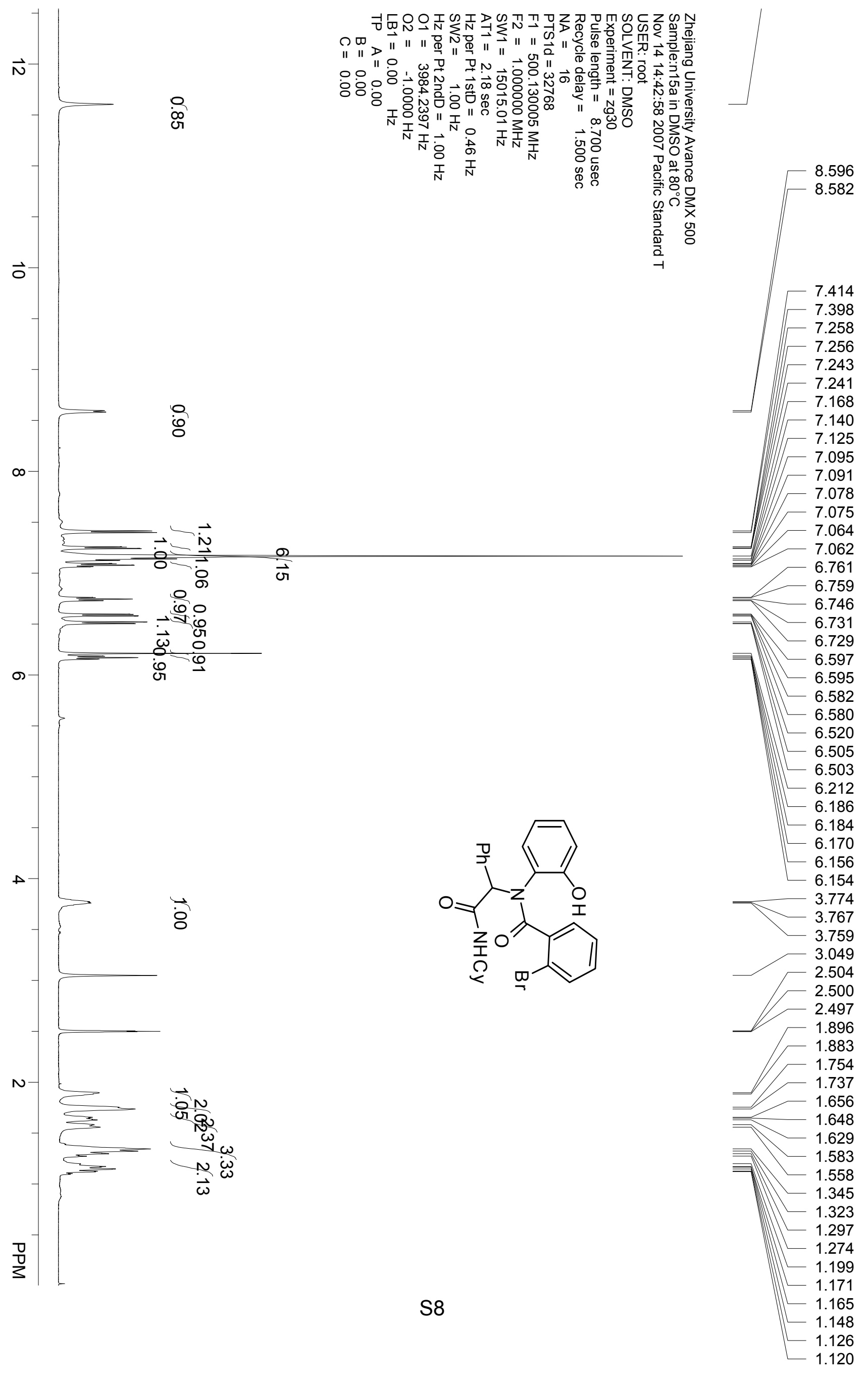




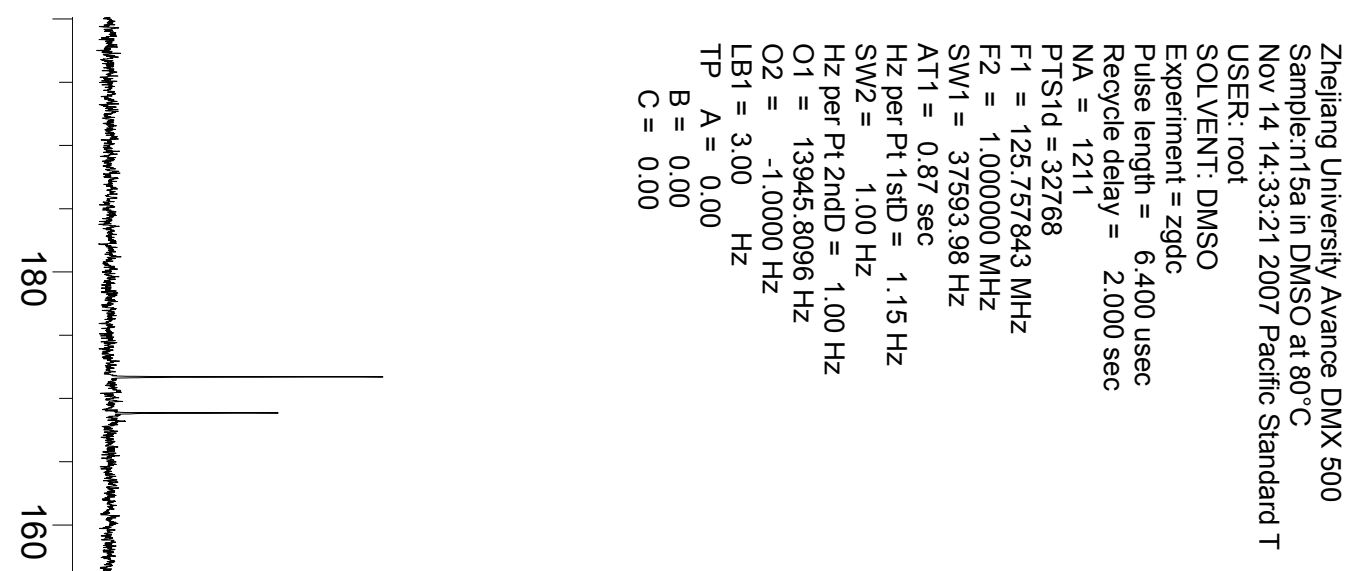

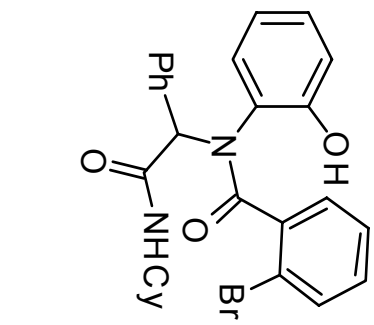




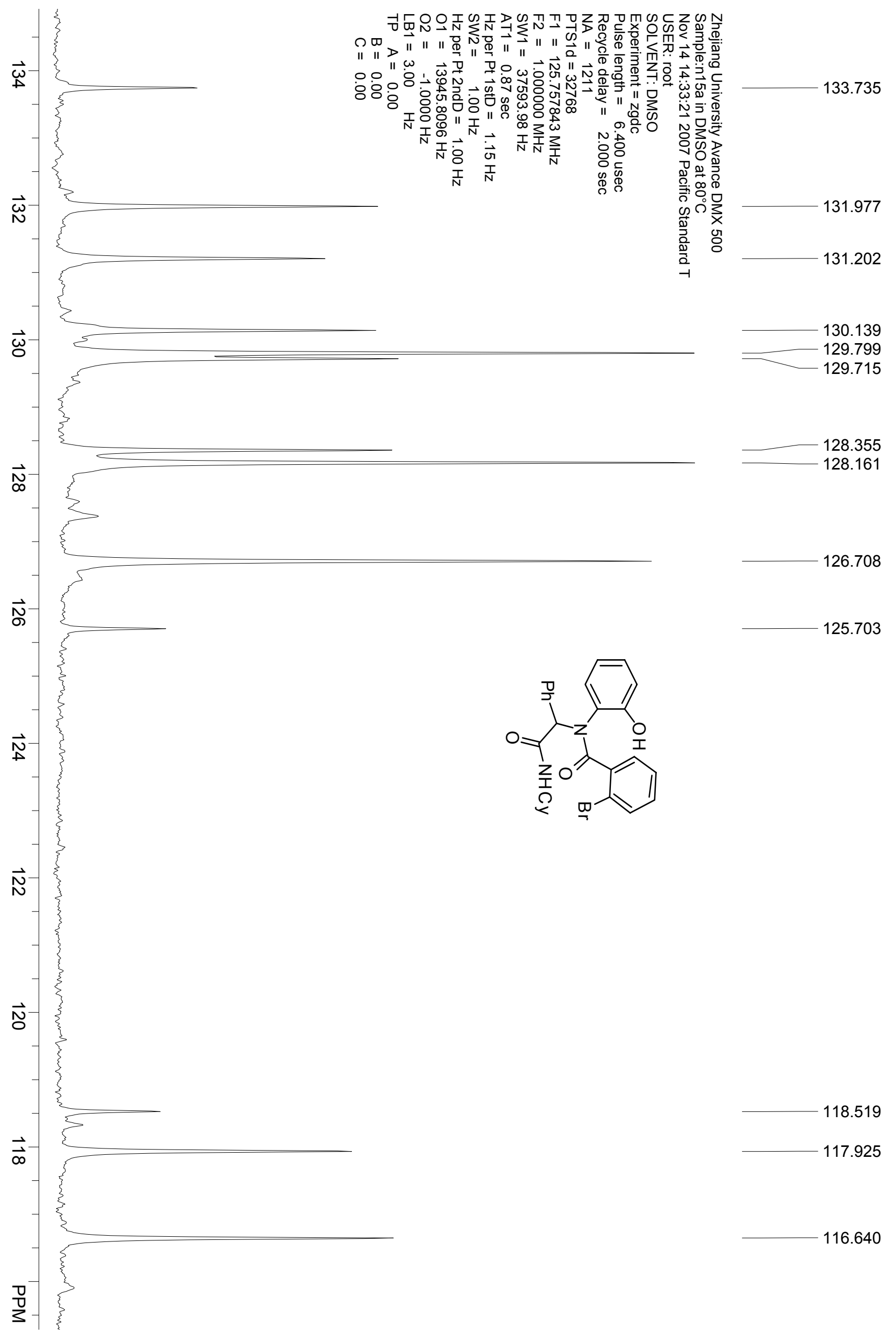



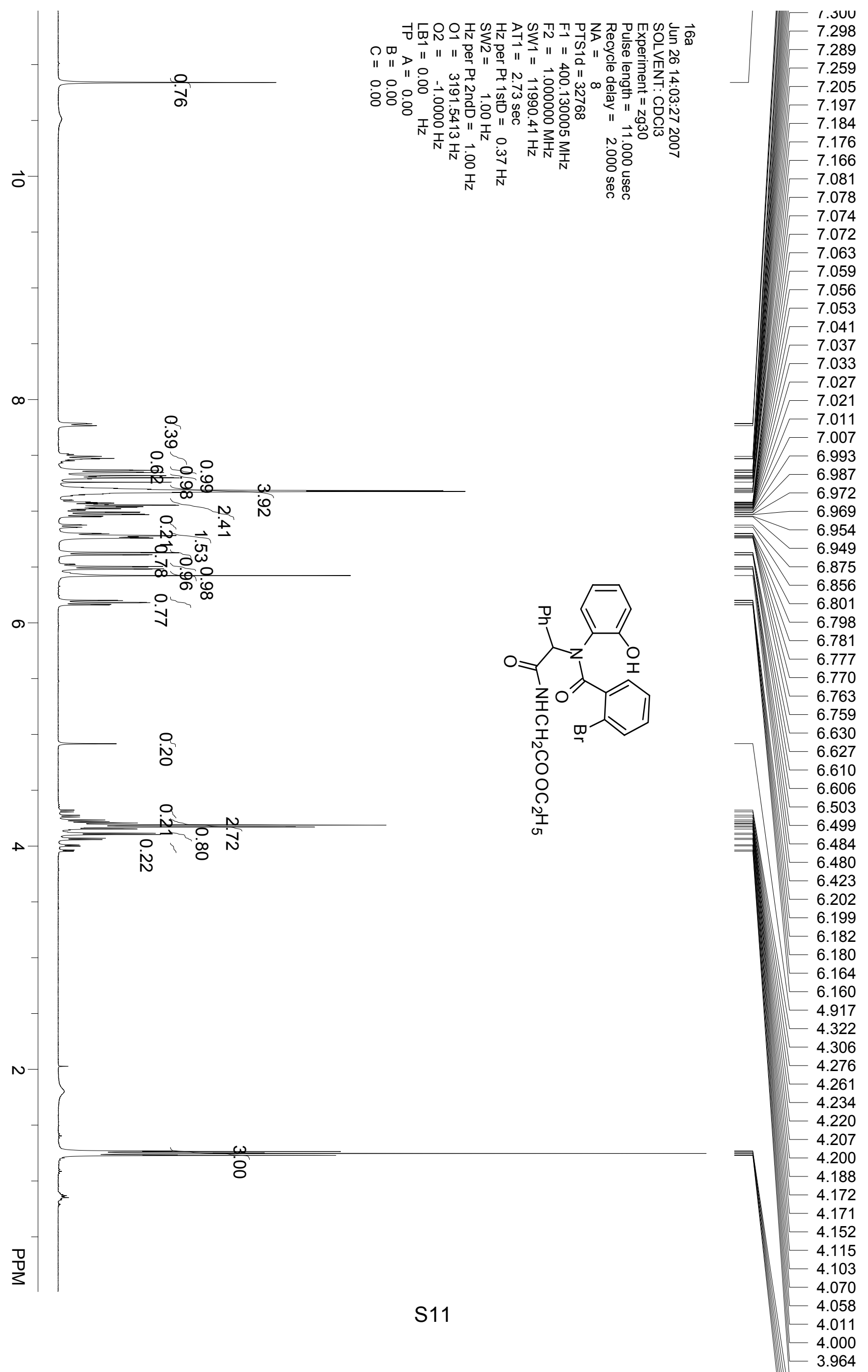


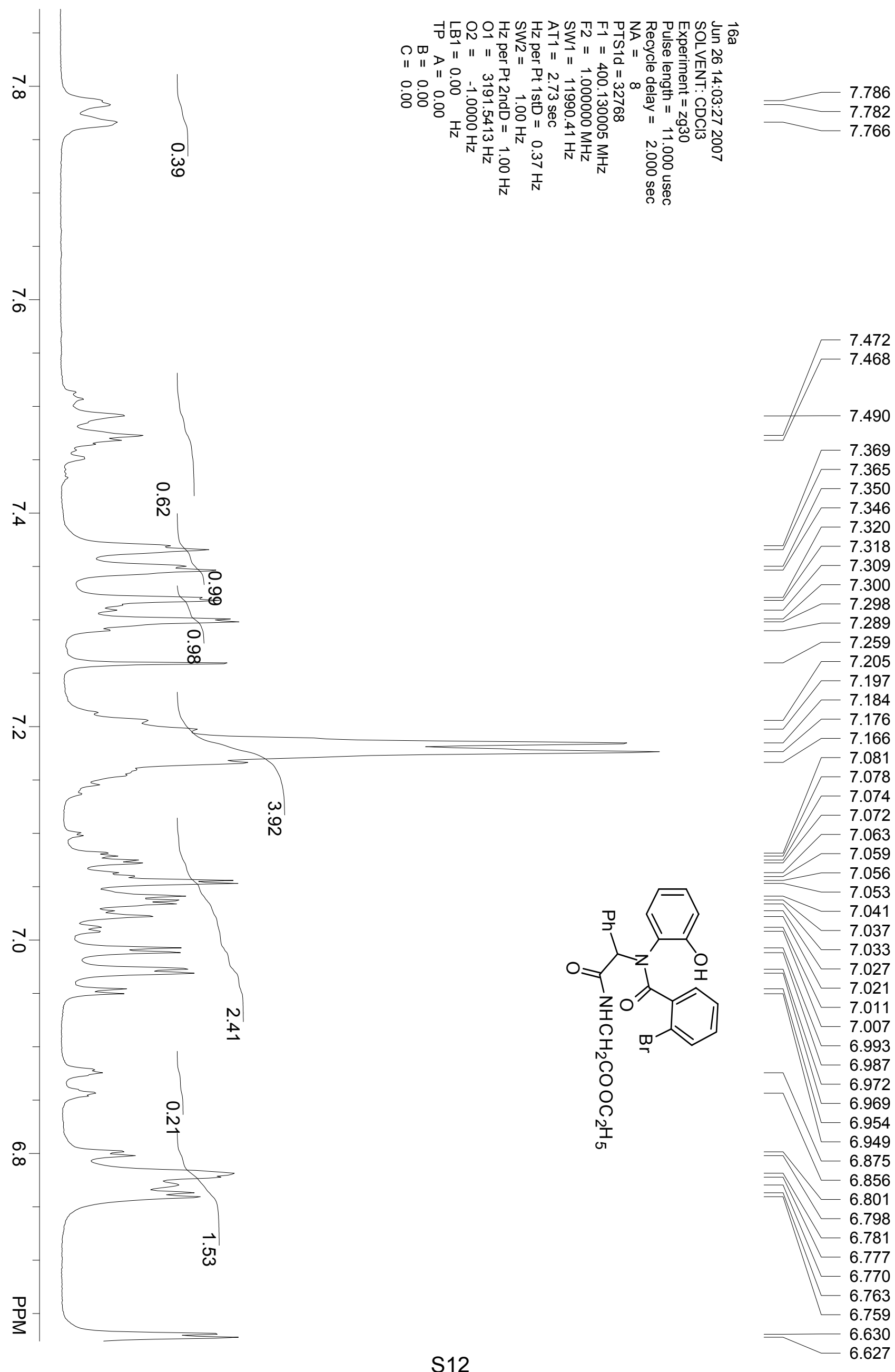




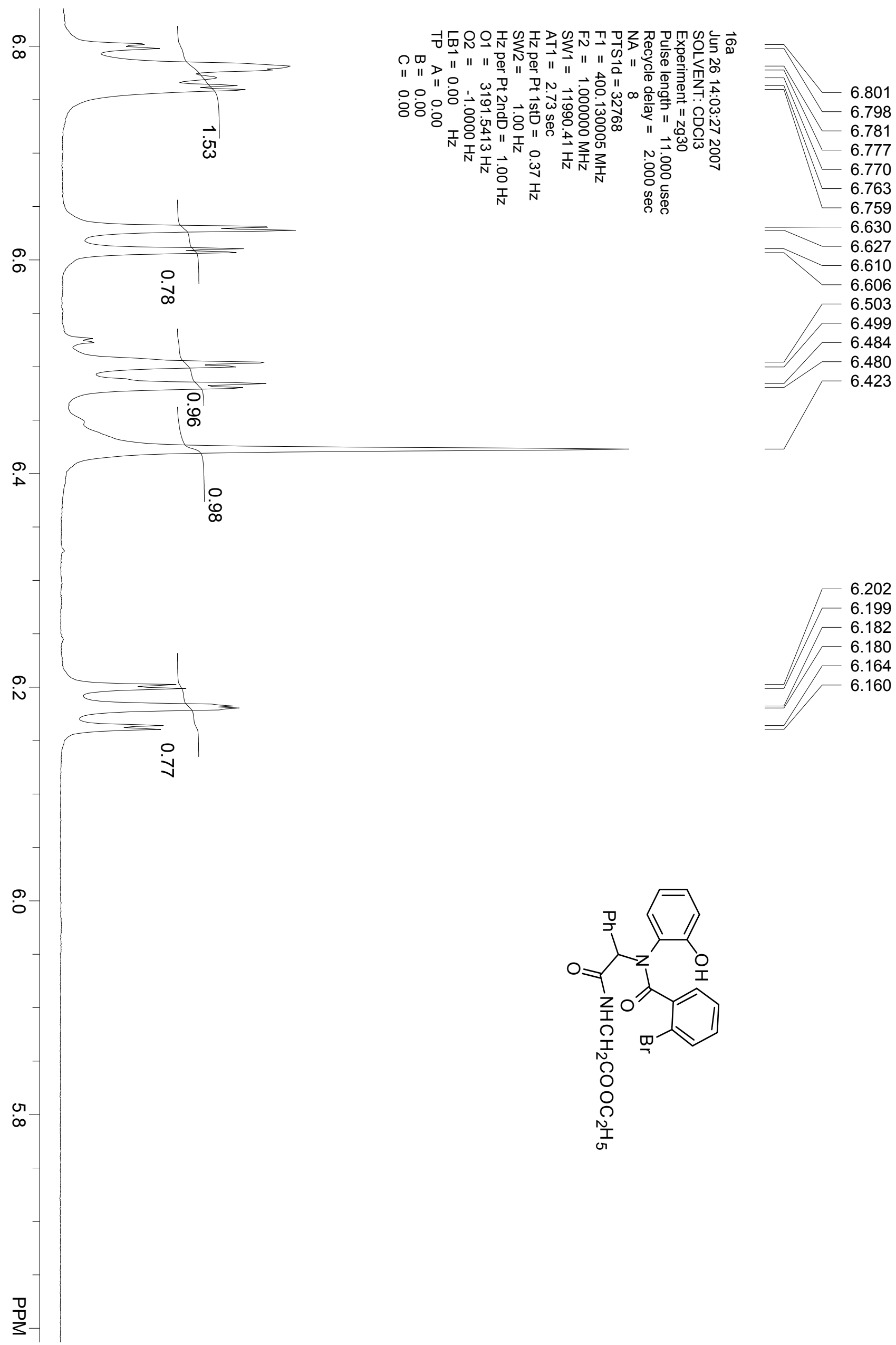




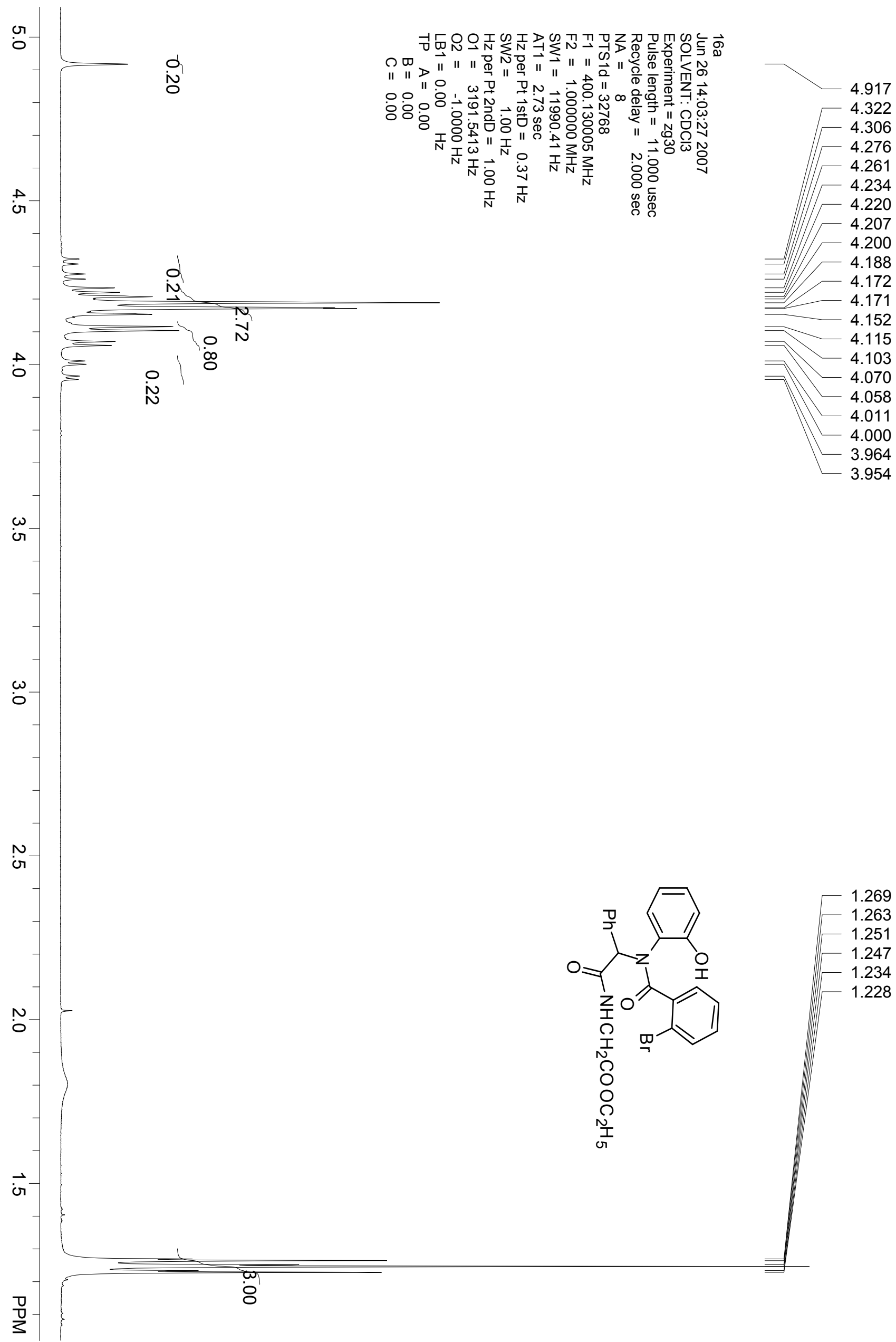



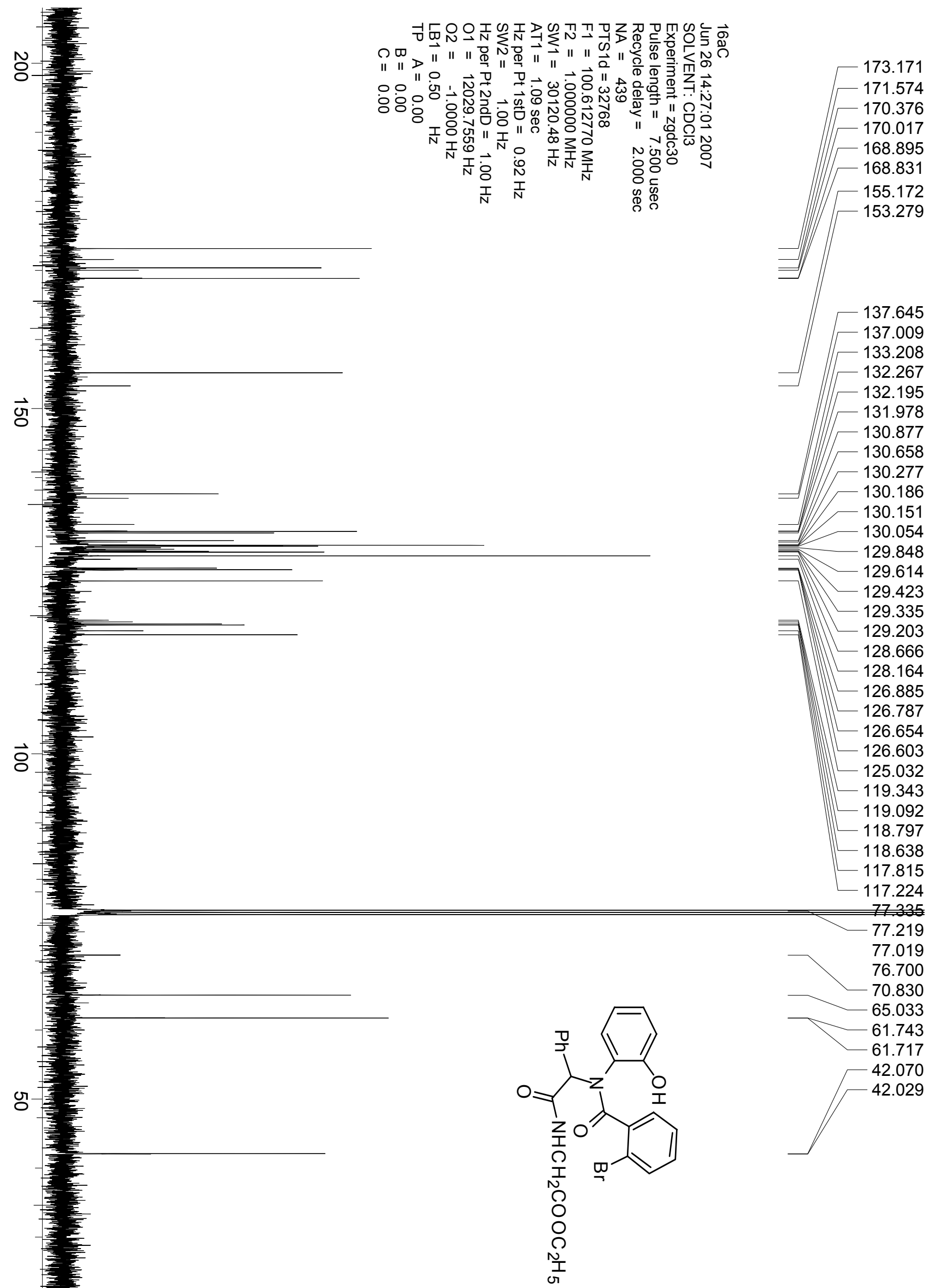


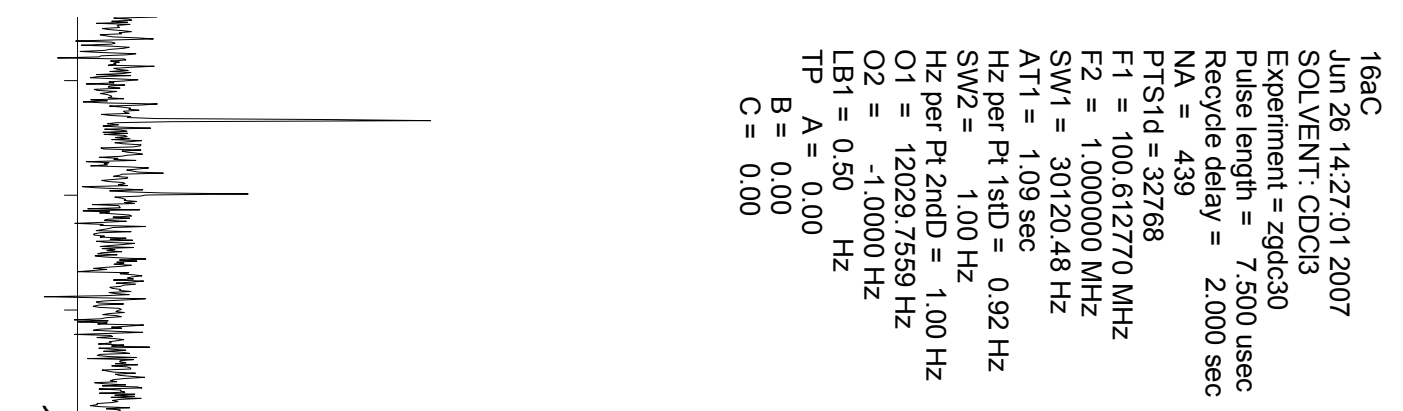
137.645 137.009

$\widehat{N}$

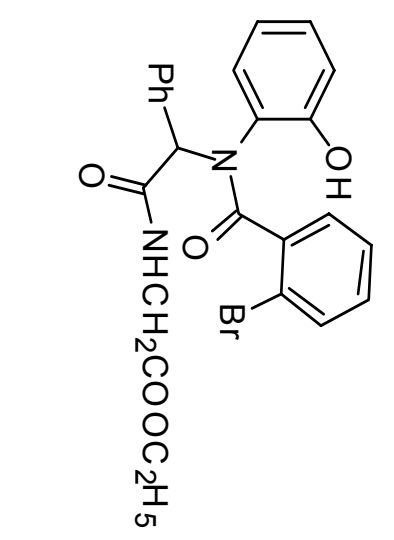




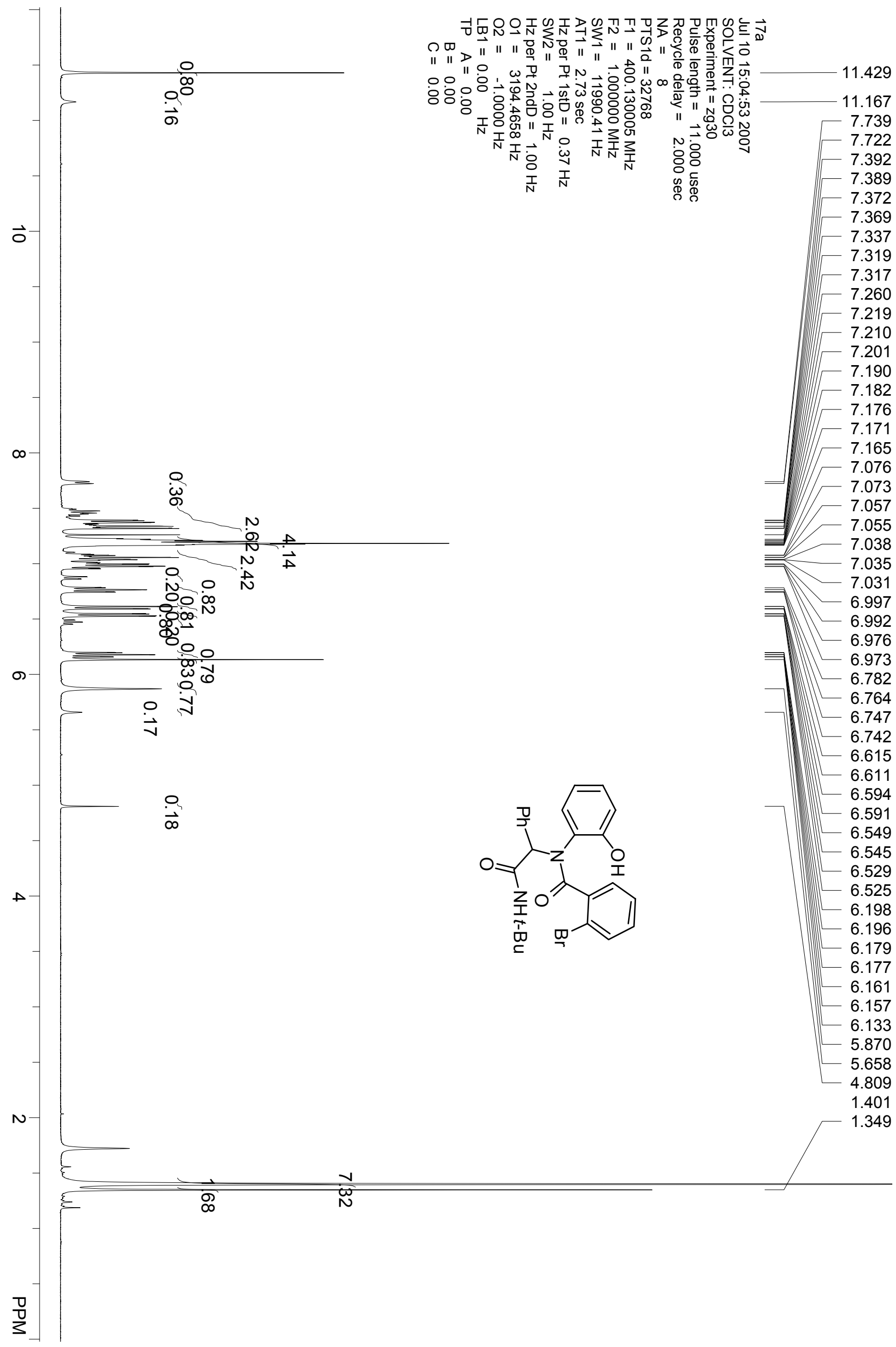




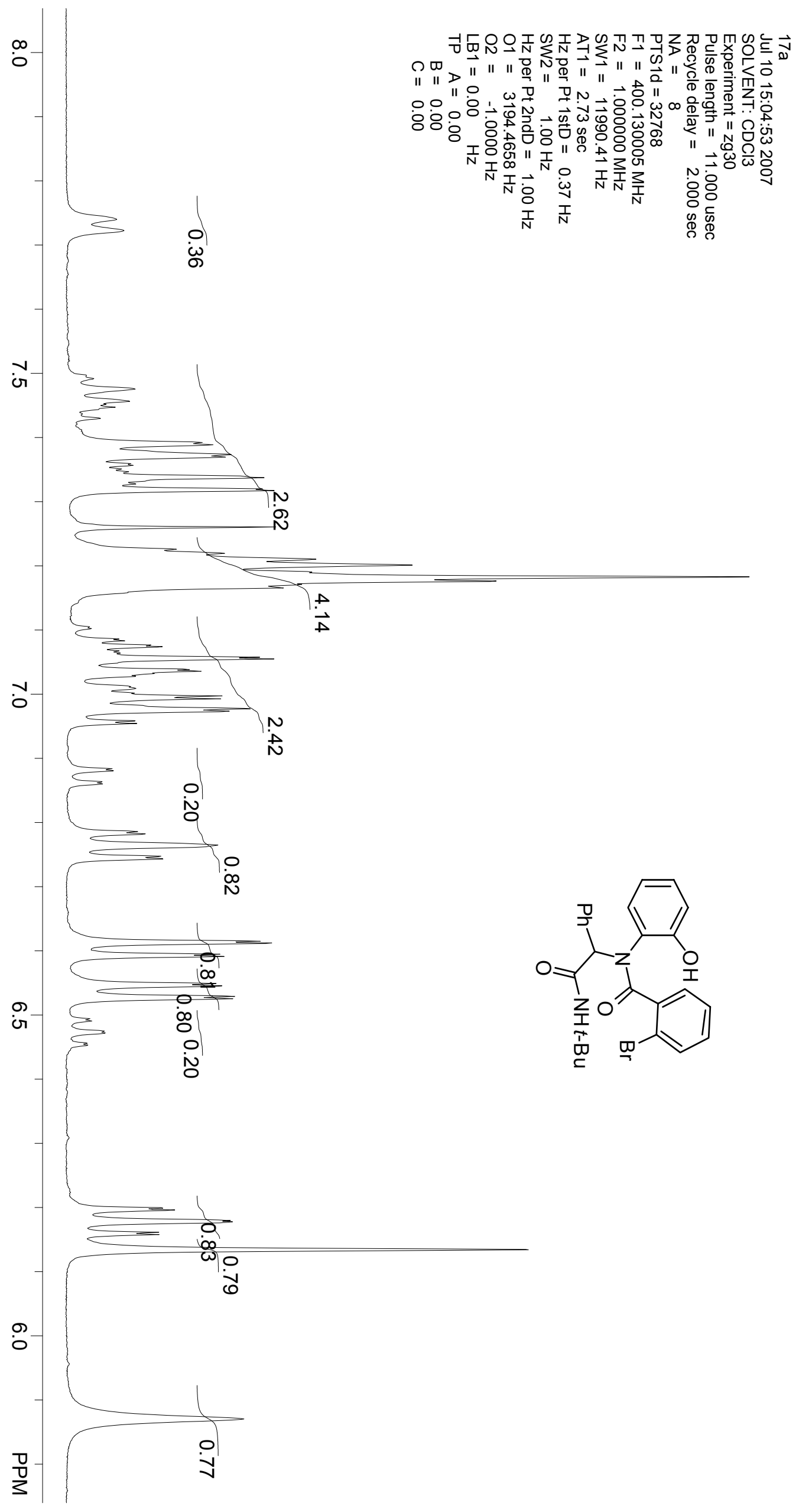




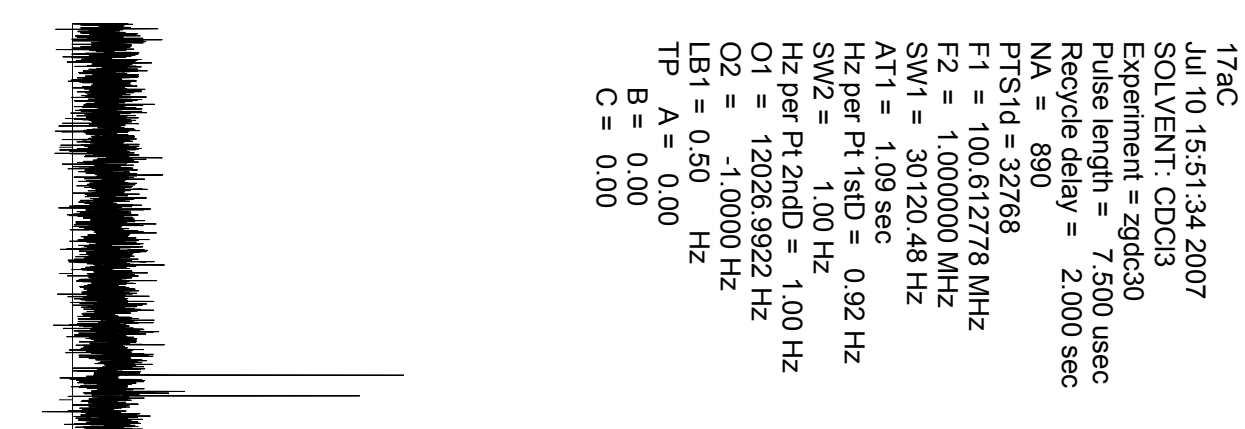

118.857

118.446

$\overrightarrow{8}$

$-117.114$

76.670

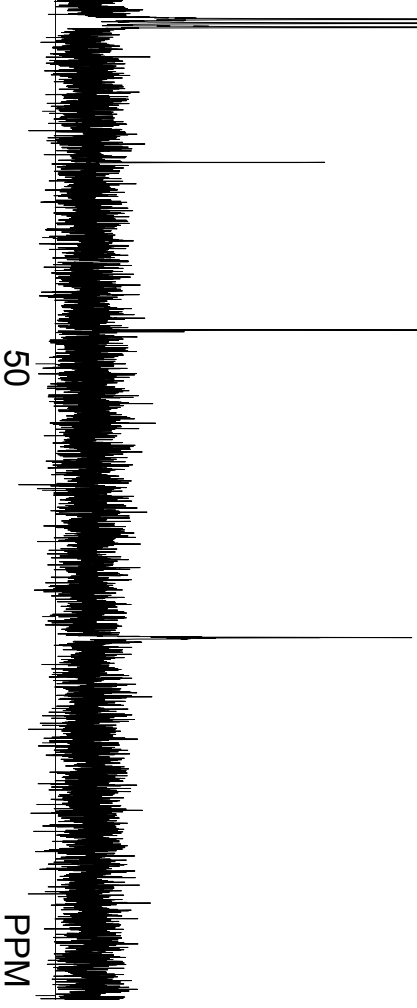

65.968

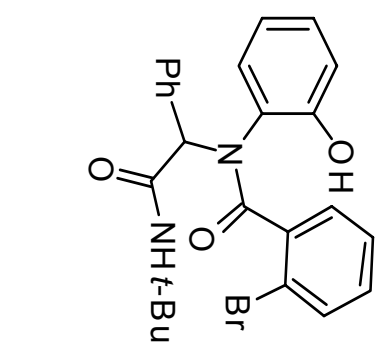

52.700 


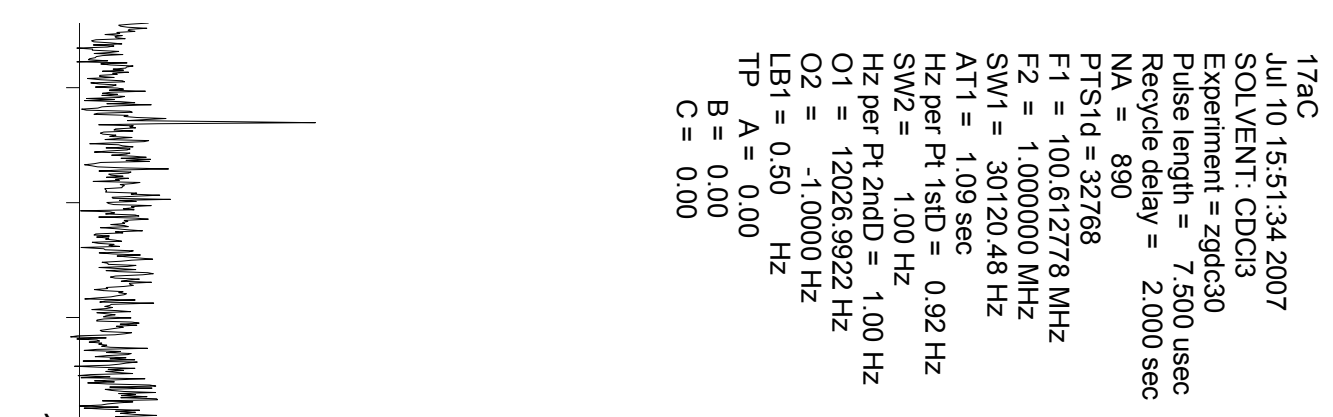

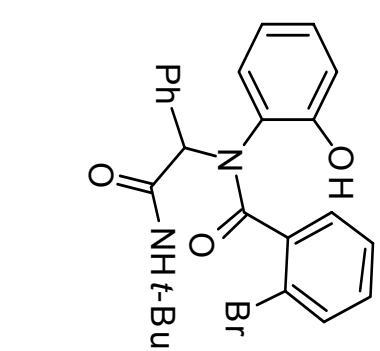




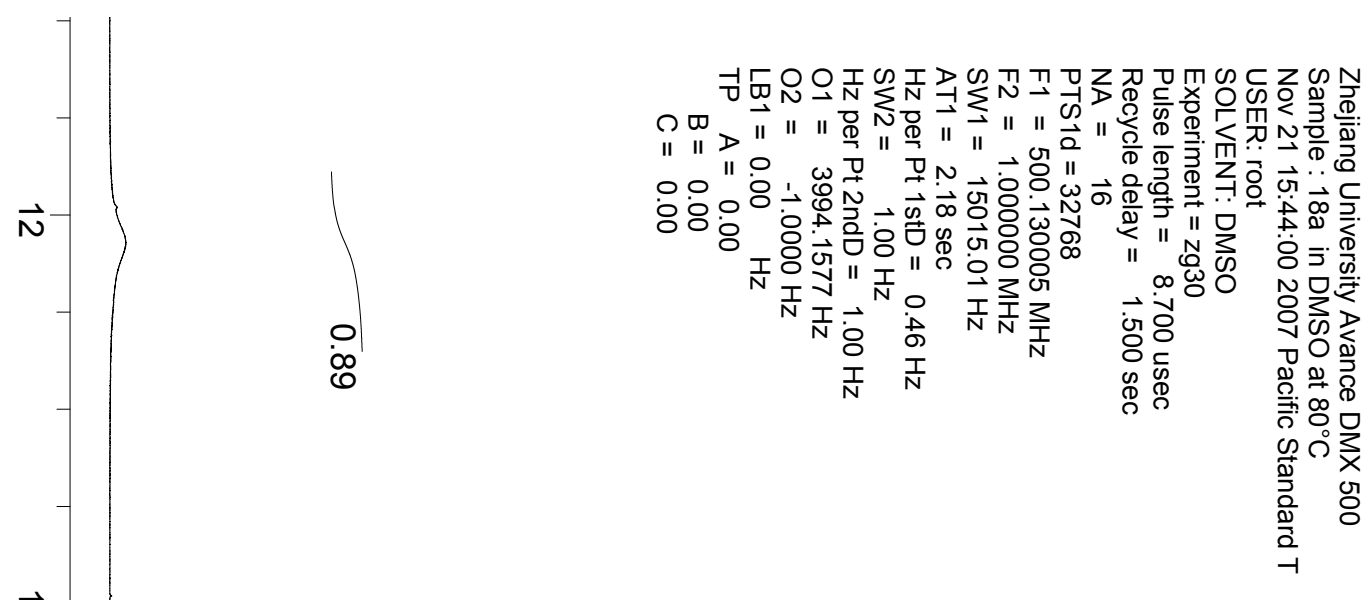

$\overrightarrow{0}$
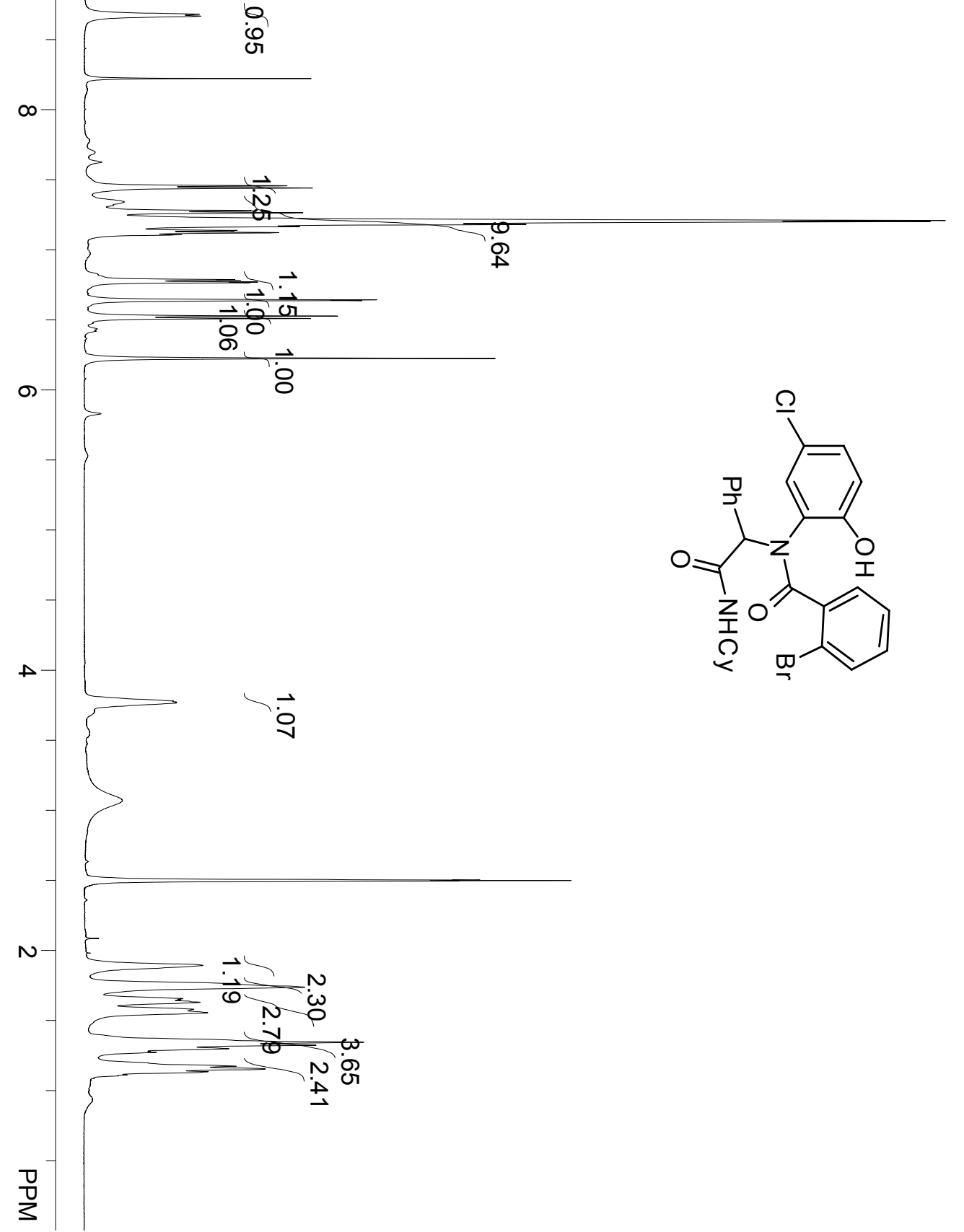

$-7.135$

7.122
-7.107

7.107

6.787

6.782

$-6.770$

6.765

6.642

6.636

$-6.525$

- 6.508

- 6.224

- 3.777

3.770

- 3.764

2.501

$-2.498$

$-2.495$

1.892

1.737

1.655

1.628

1.579

1.554

1.344

1.322

1.298

$-1.272$

1.173

1.152

1.134

$\frac{0}{3}$

1.111 


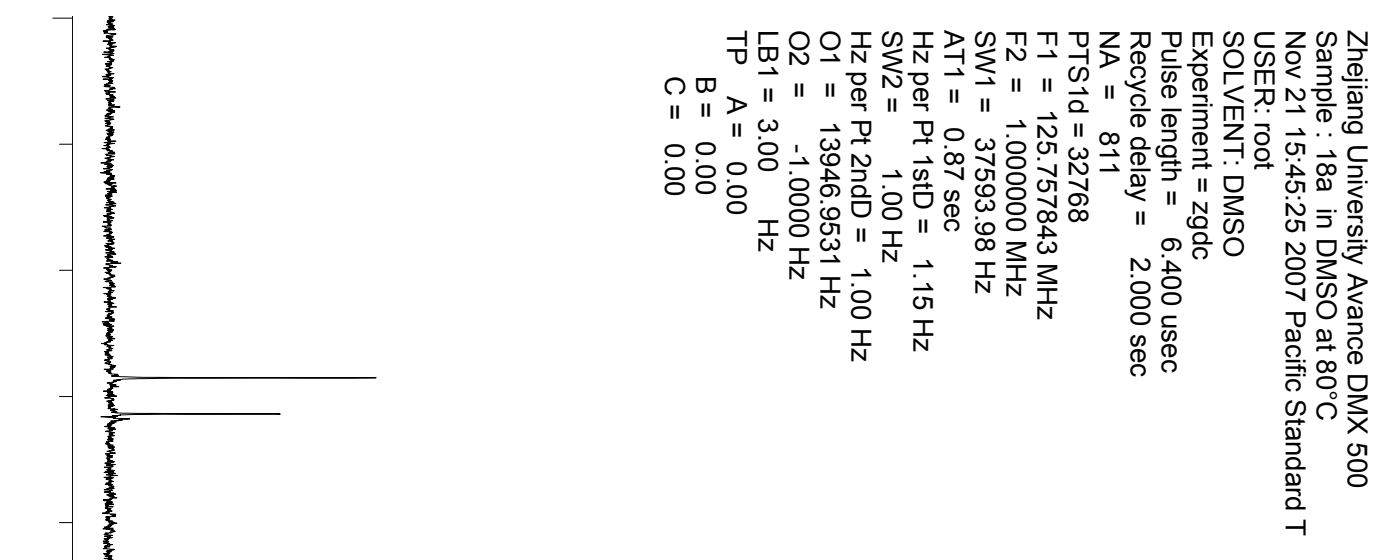

171.471

168.604

154.775

방

$\overrightarrow{8}$

$\frac{\Omega}{\frac{\Omega}{\omega}}$

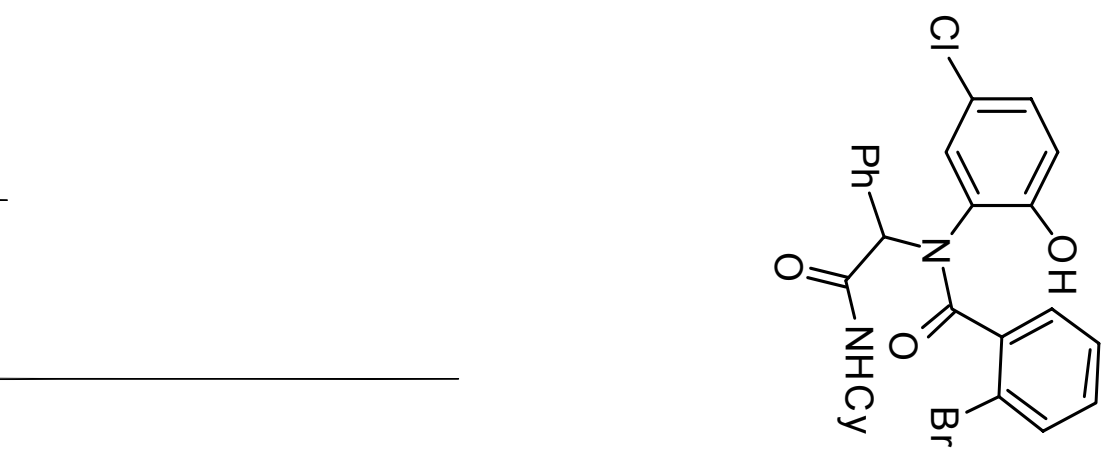

133.484

132.071

137.936

130.874

130.471

129.759

129.616

128.647

128.330

$-126.856$

126.564

120.965

118.407

118.035

잉

40.492

48.914

40.416

40.327

40.240

40.158

39.988

39.828

39.658

39.485

31.838

31.787

25.152

$-24.320$

24.229

0
3 


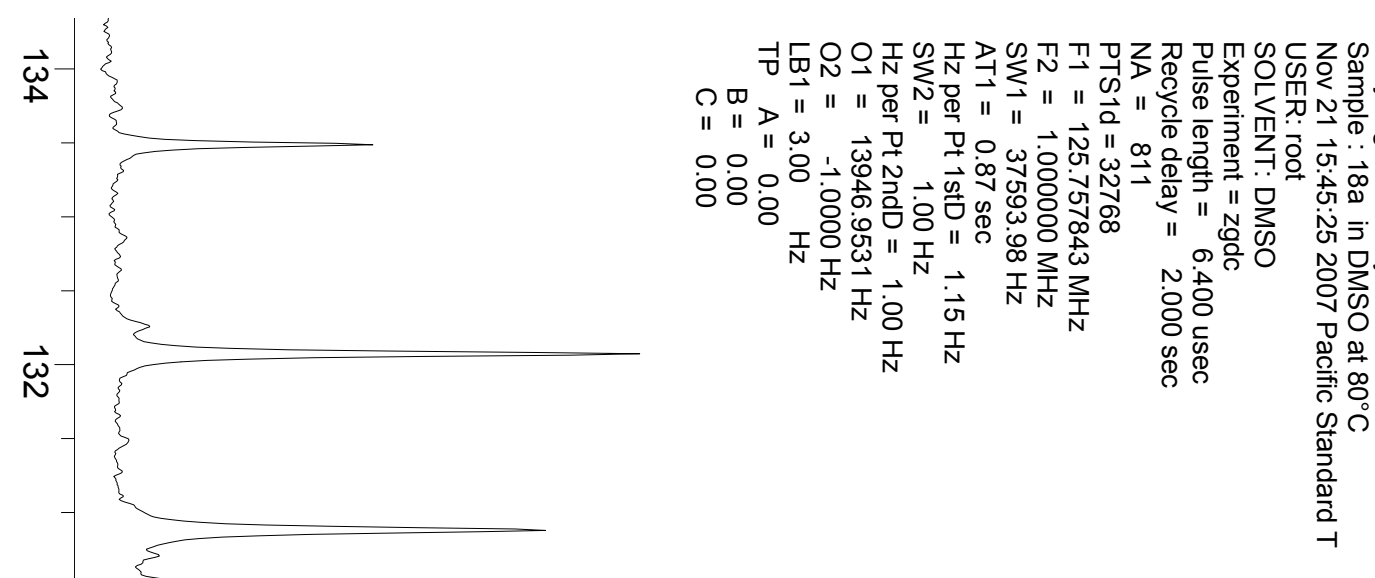<smiles>O=C(O)C(=O)C(=O)Oc1ccccc1[O-]</smiles>

$\overrightarrow{0}$

$\vec{N}$

$\vec{N}$

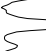
T

인

$\frac{\overrightarrow{9}}{\overrightarrow{0}}$ 


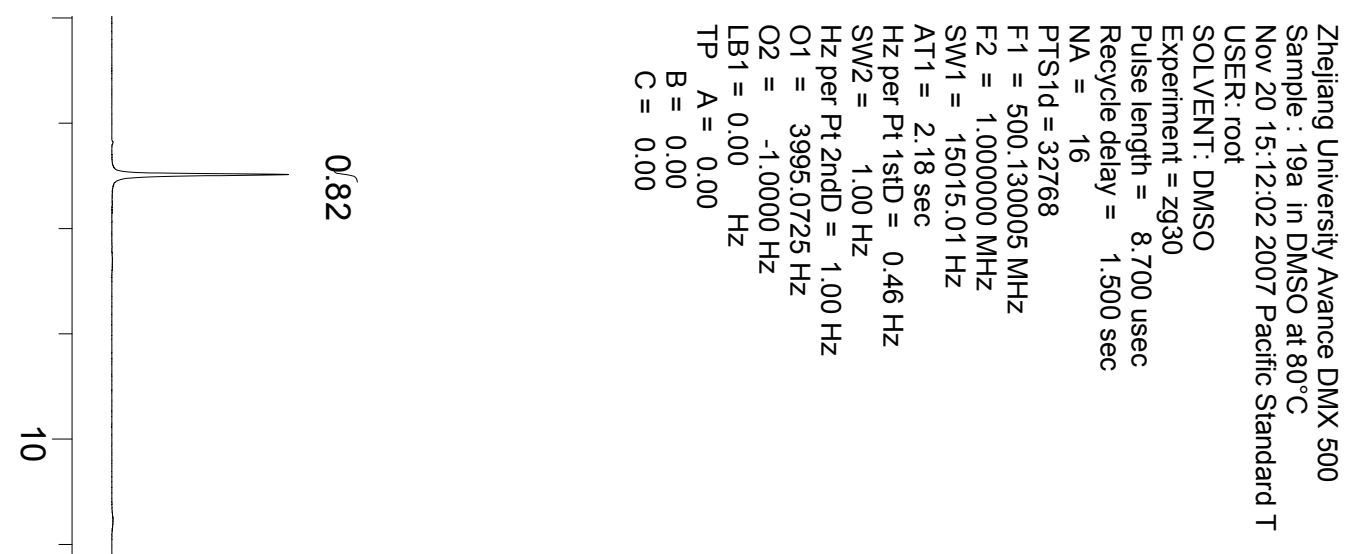

$\infty-\quad \frac{T}{\omega} \quad r .378$
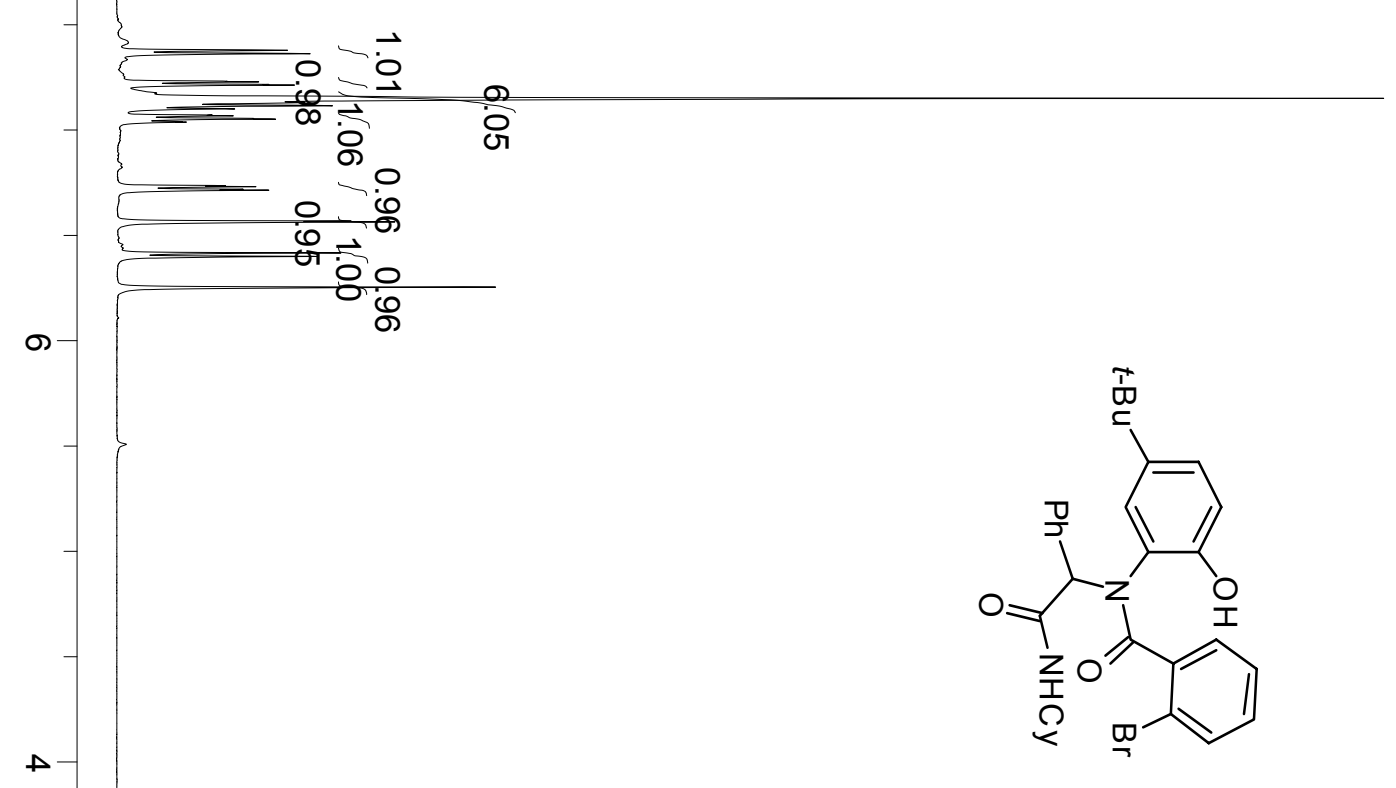

7.115

7.101

$-7.071$

훙

$\frac{T}{\mathrm{O}}$ 


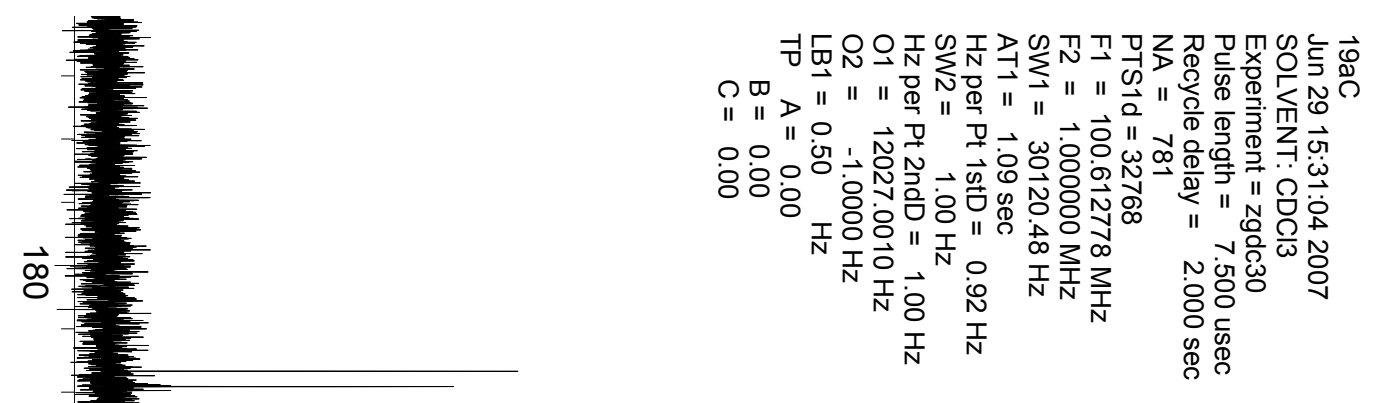

171.646

(2.618

128.321

126.866

126.667

126.457

124.448

118.784

응

116.407

77.286

76.962

76.639

○

76.639

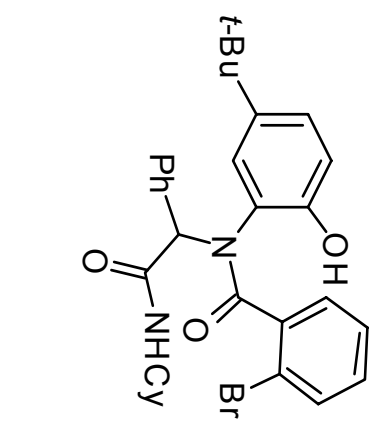

65.035

49.554

33.433

32.407

32.356

30.817

25.293

24.680

N

24.525 


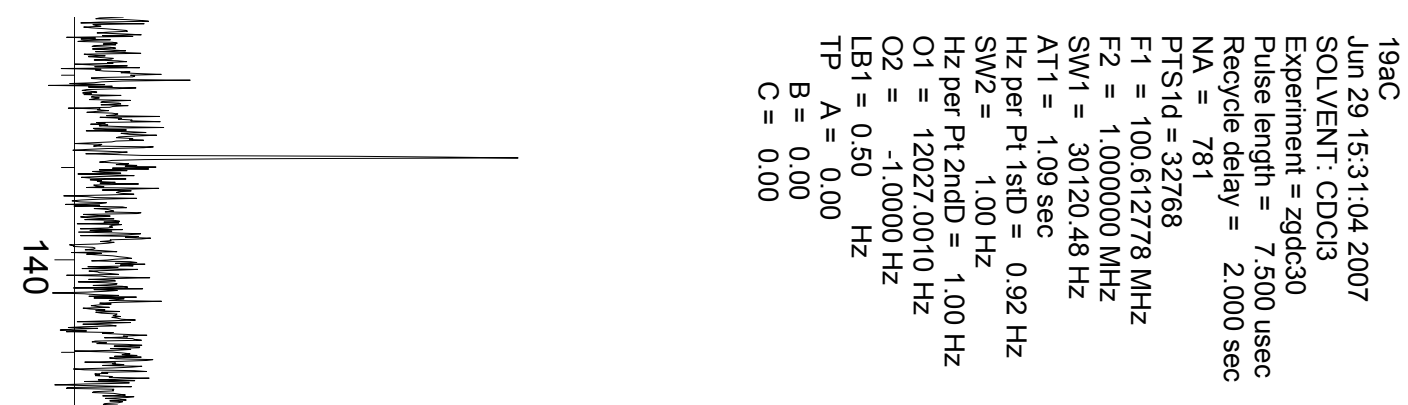

$\vec{\omega}$

$\vec{w}$

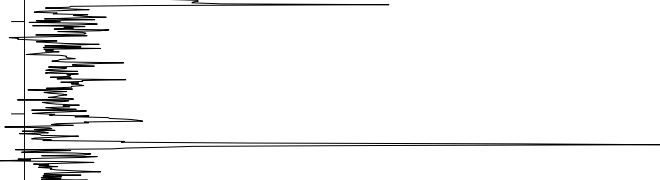

130.033 129.832

128.876

128.618

128.321

126.866

126.667

126.457

$\vec{N}$

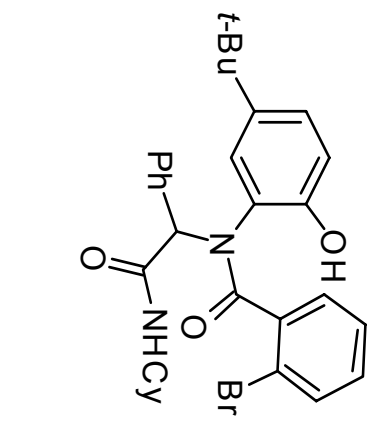

124.448

118.784

$\vec{O}$

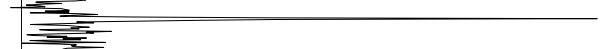




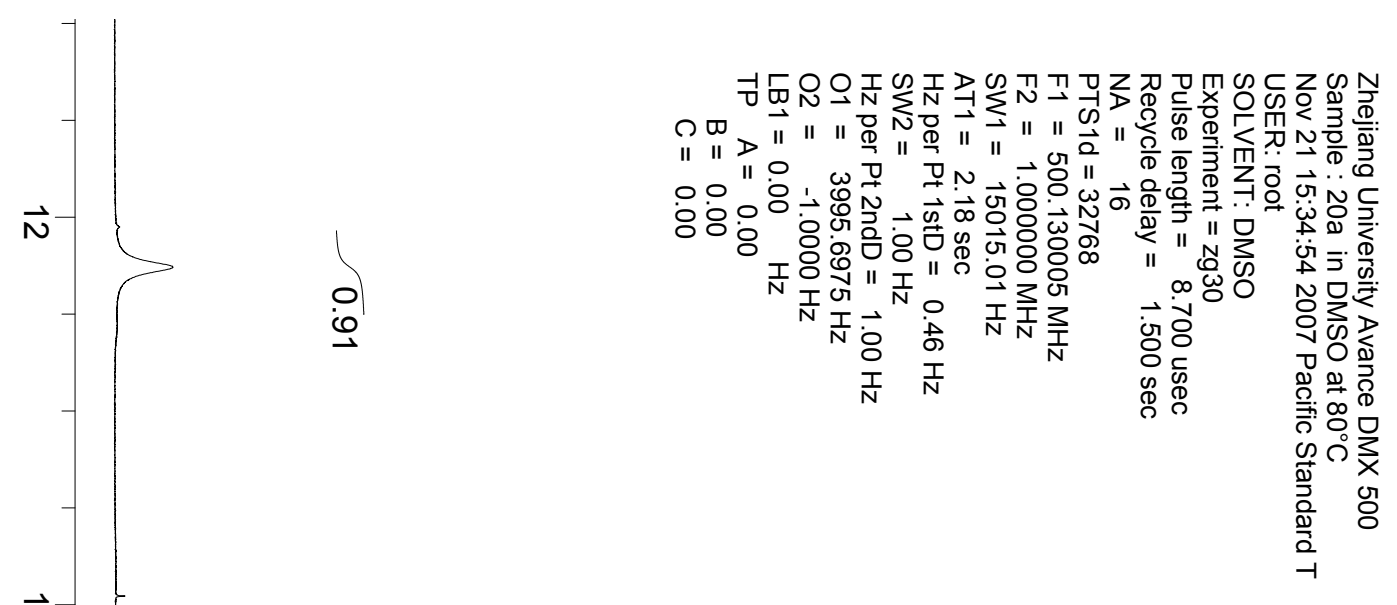

$\overrightarrow{0}$

$\vec{\infty}$

$\stackrel{\infty}{\omega}$

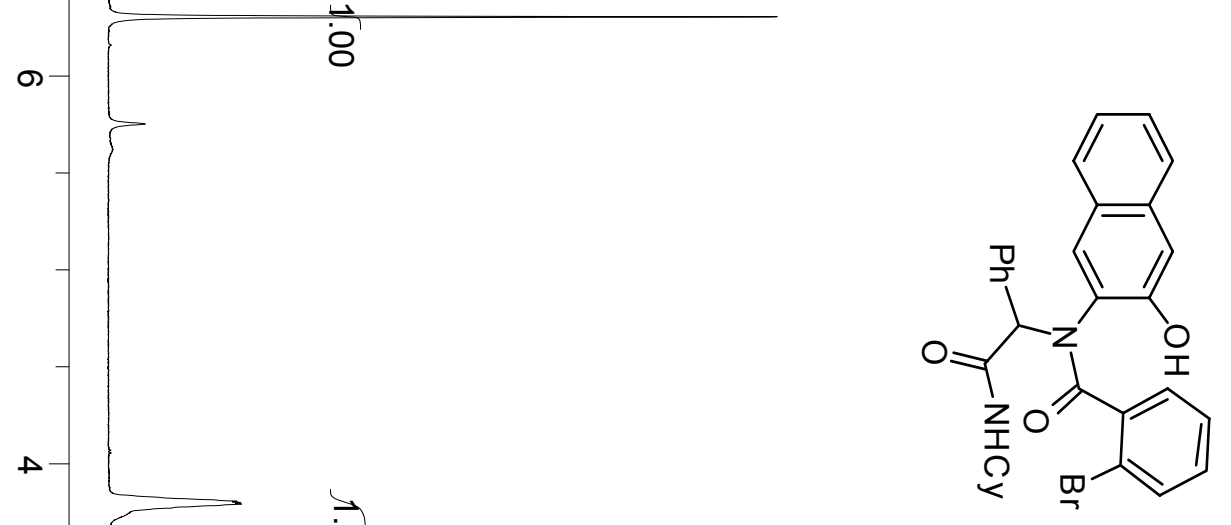

क् 


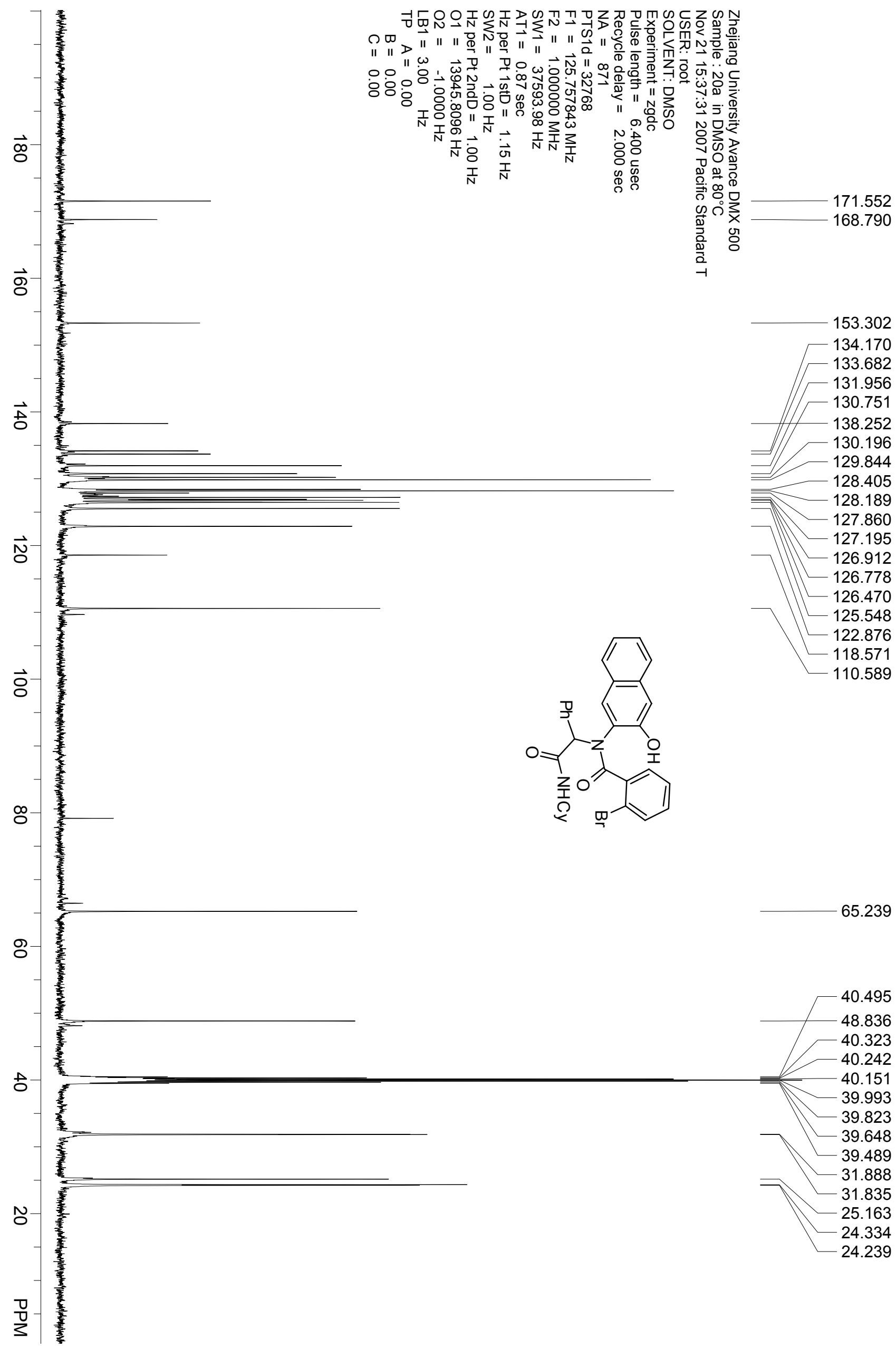




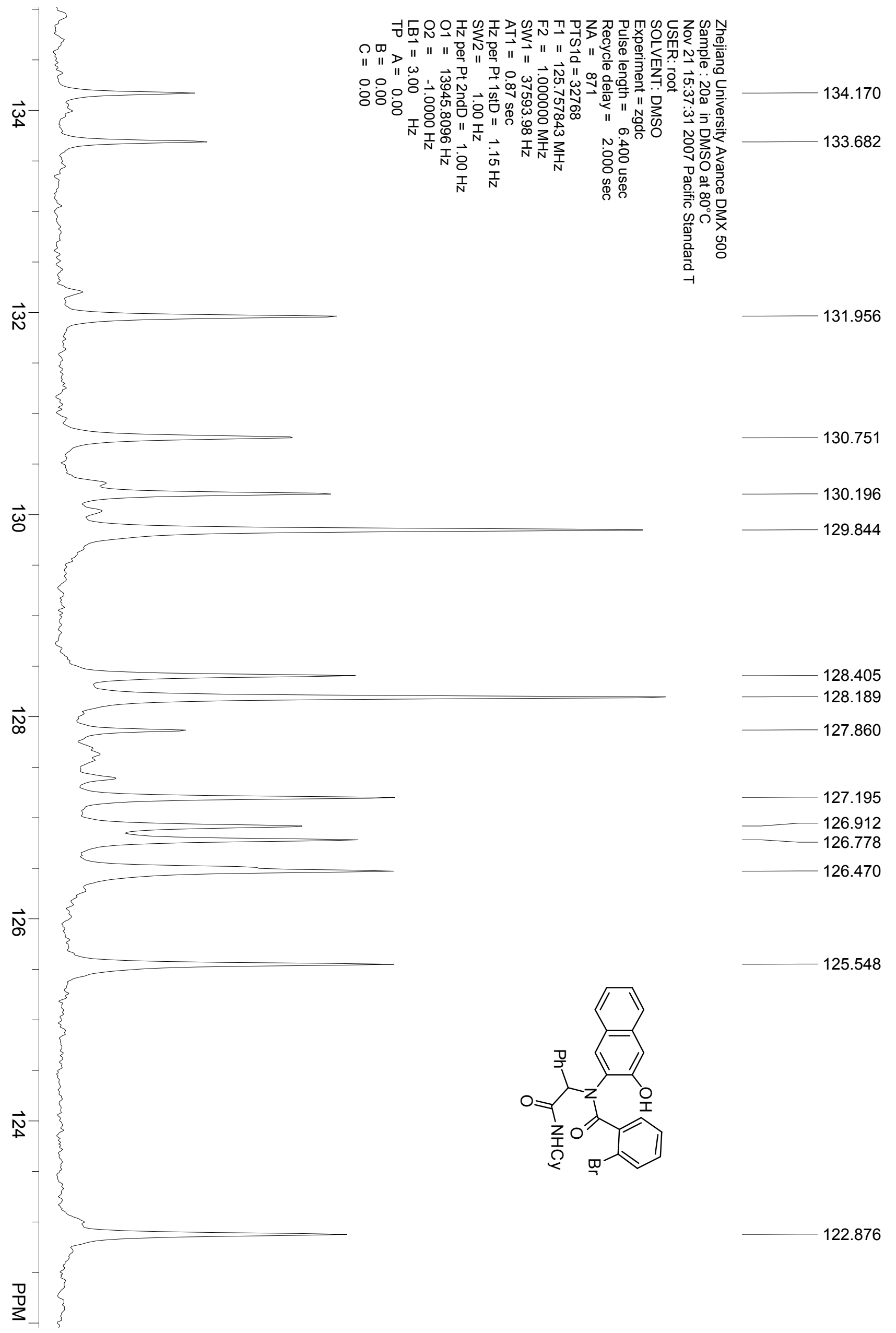




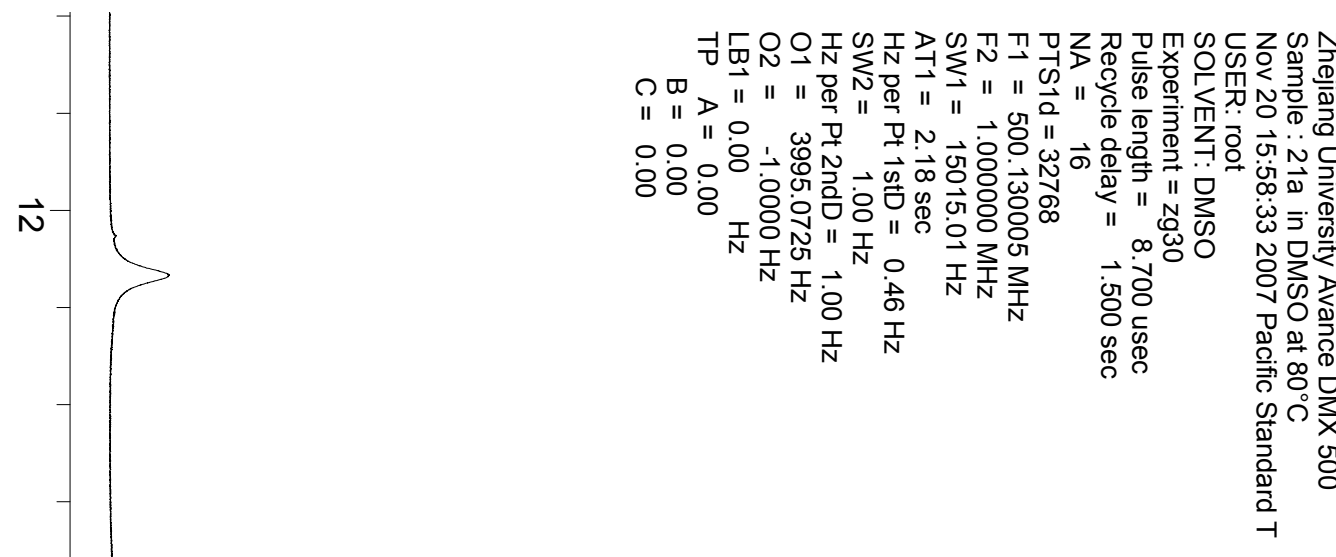

$\overrightarrow{0}$

$\frac{\rho}{\frac{\rho}{\rho}}$

$-\quad \stackrel{0}{\stackrel{\infty}{\rightarrow}}$

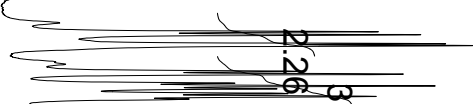

7.312

7.300

7.263

7.249

7.203

7.188

7.174

7.149
-7.135

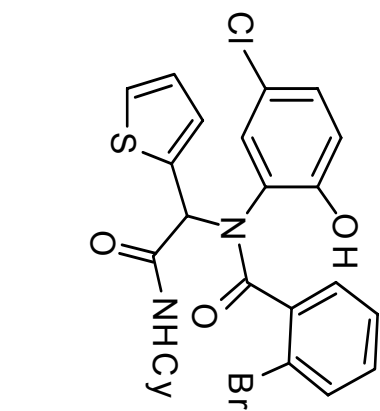

7.135

7.121

7.078

7.011

7.006

6.868

6.859

6.852

6.820

6.815

6.576

6.559

6.420

6.034

3.744

3.737

3.731

2.503

2.498

2.497

के

1.883

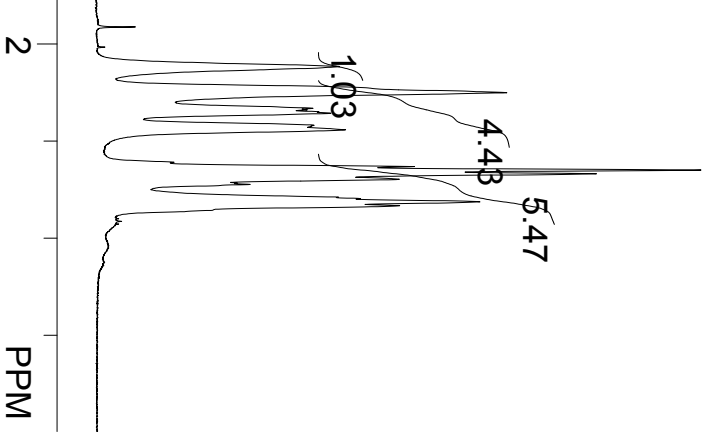

1.748

1.668

1.650

1.642

1.580

1.557

1.369

1.350

1.332

1.303

1.277 


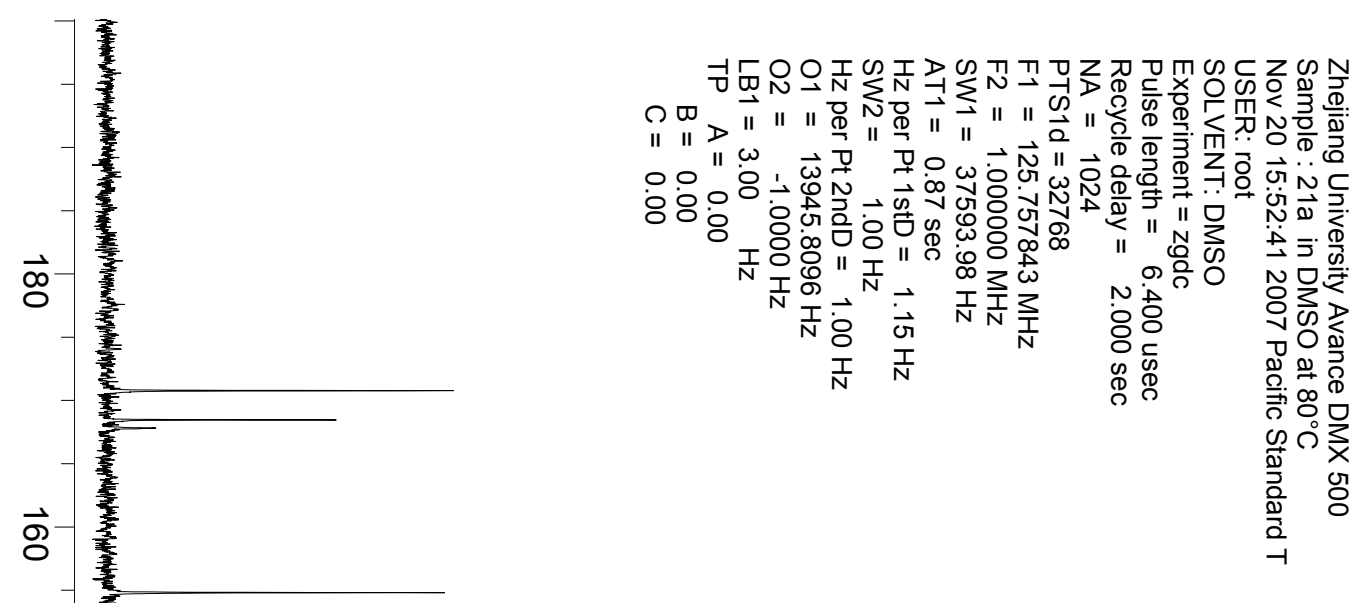

170.771

168.460

154.806

134.717

132.117

137.733

130.661

130.542

129.868

129.703

128.264

126.880

126.831

126.790

126.308

$-121.107$

118.403

118.082

$\overrightarrow{8}$

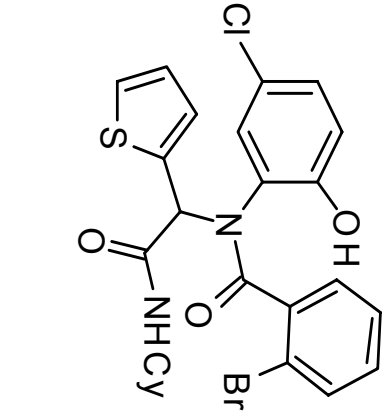

59.983

임

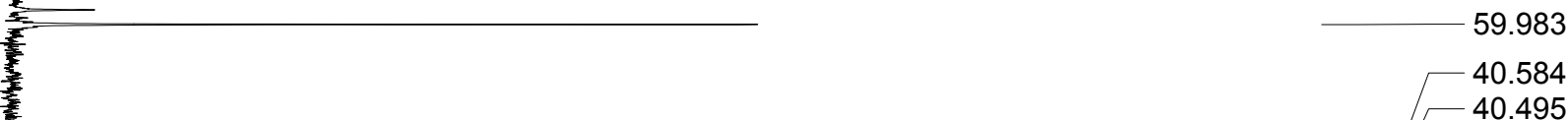

40.495

48.953

$-40.404$

40.324

40.244

D

差

40.149

39.990

39.824

39.656

$-39.485$

N

31.746

31.669

25.146

24.259

24.172

$\stackrel{0}{0}$ 

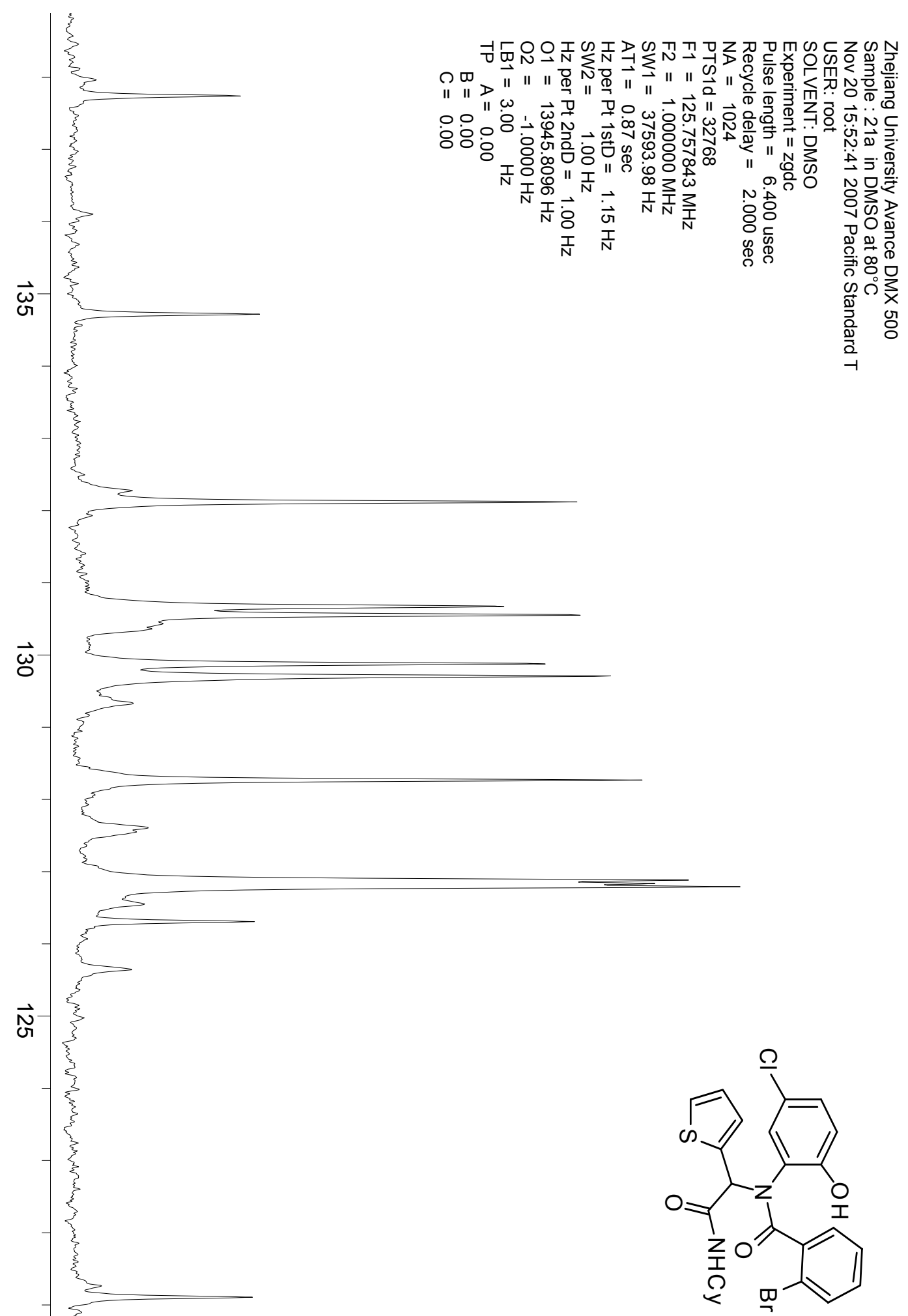


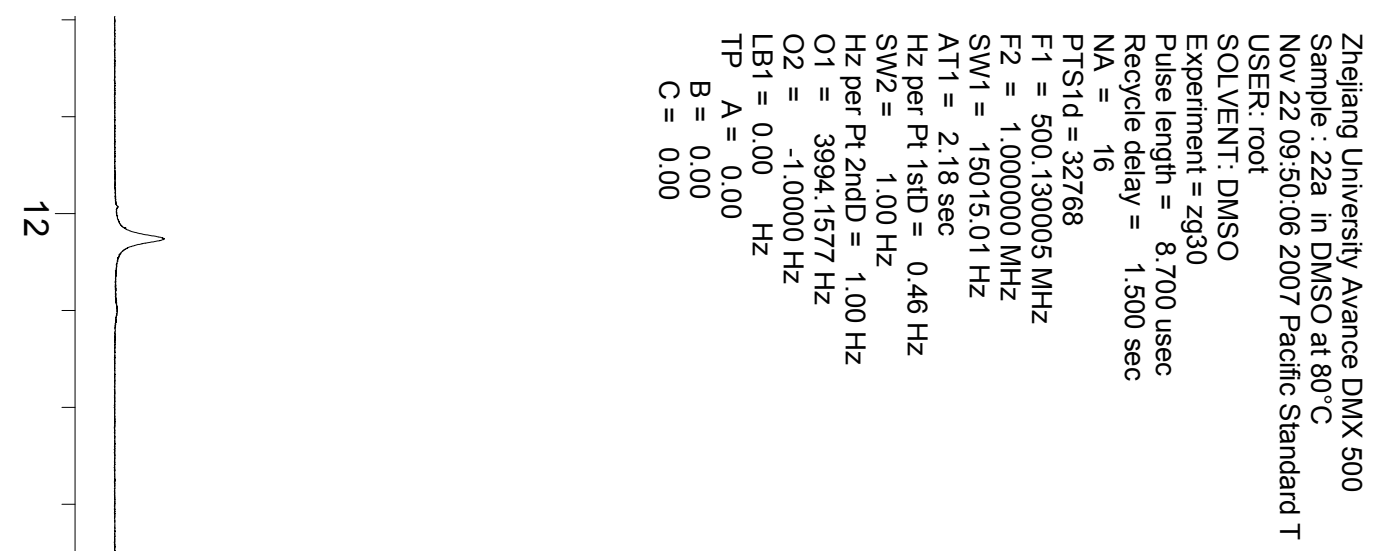

$\vec{o}$<smiles>O=[Os]=O</smiles>
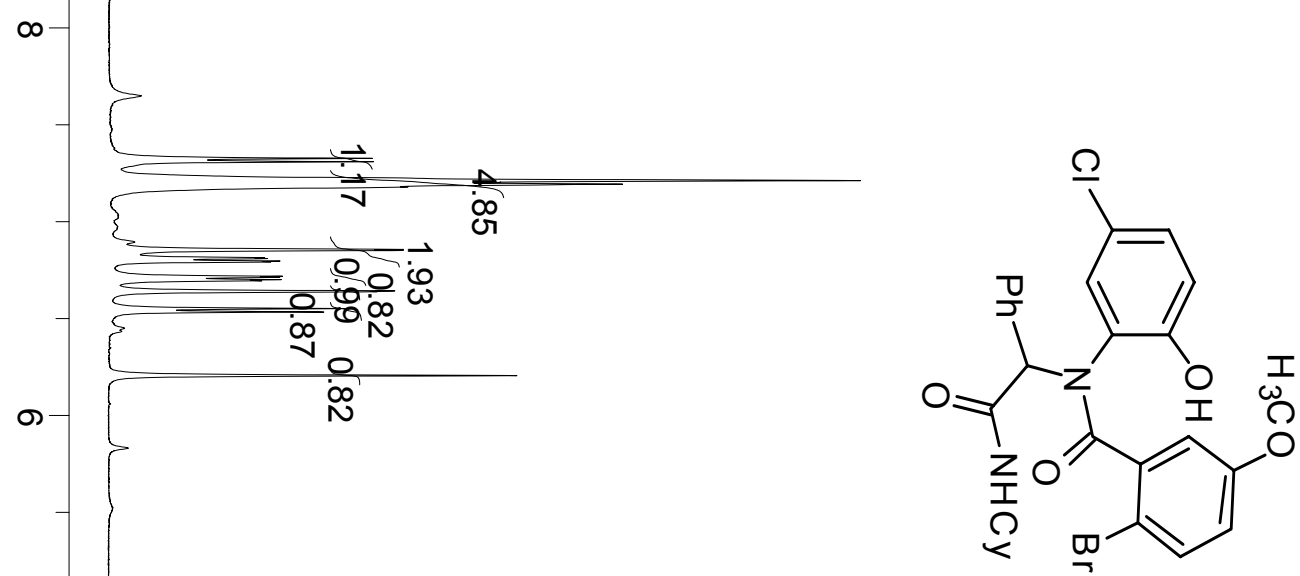

7.194

7.179

$-6.857$

6.852

6.814

$-6.810$

$-6.797$

$-6.792$

$-6.718$

6.712

6.701

$-6.695$

$-6.643$

$-6.638$

6.551

6.534

6.206

3.771

3.763

3.759

3.661

3.054

2.502

$\frac{T}{N}$
0

2.498

$\frac{\square}{0}$

i

$N$

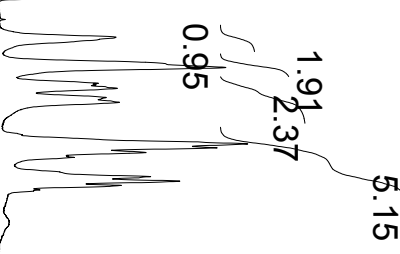




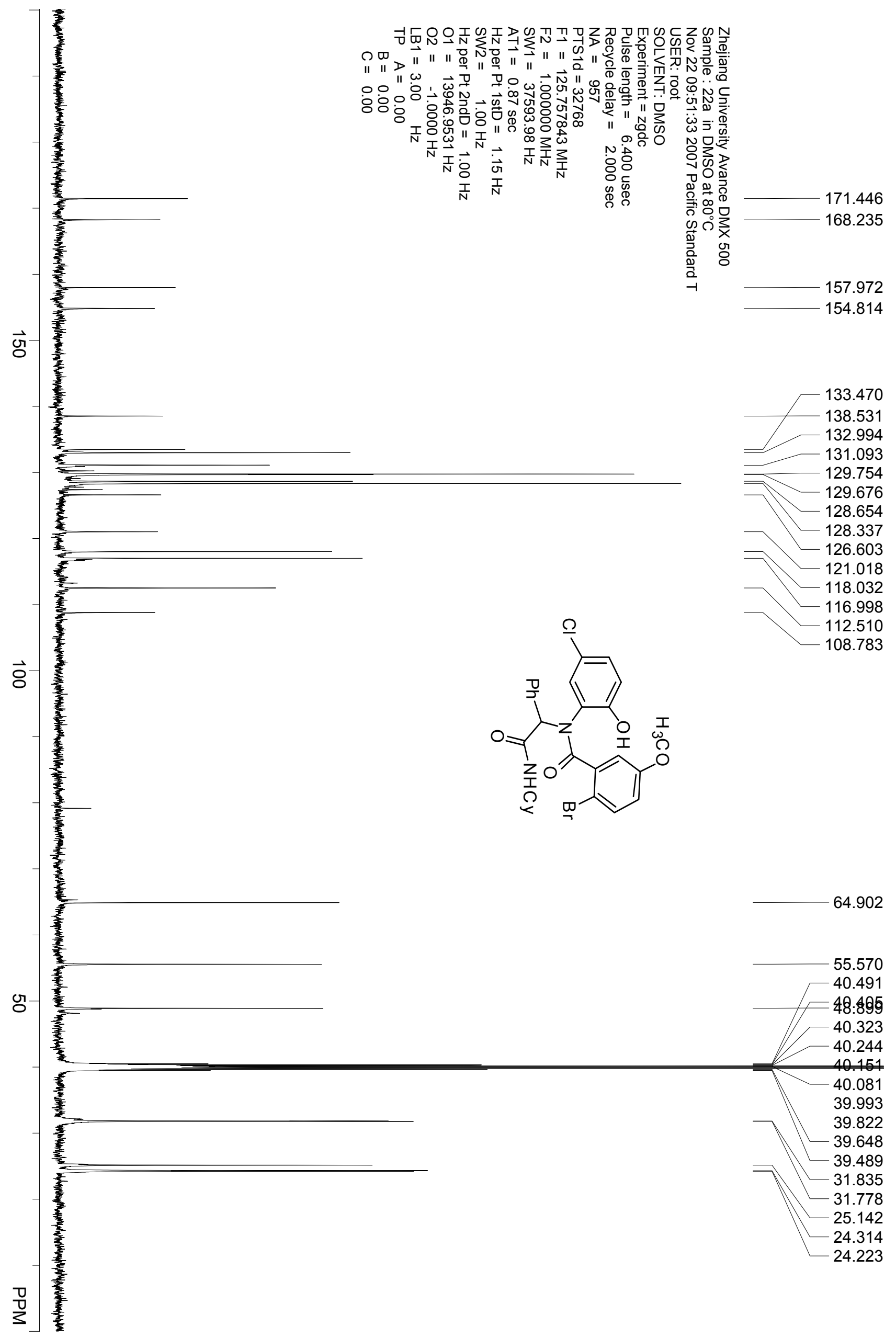




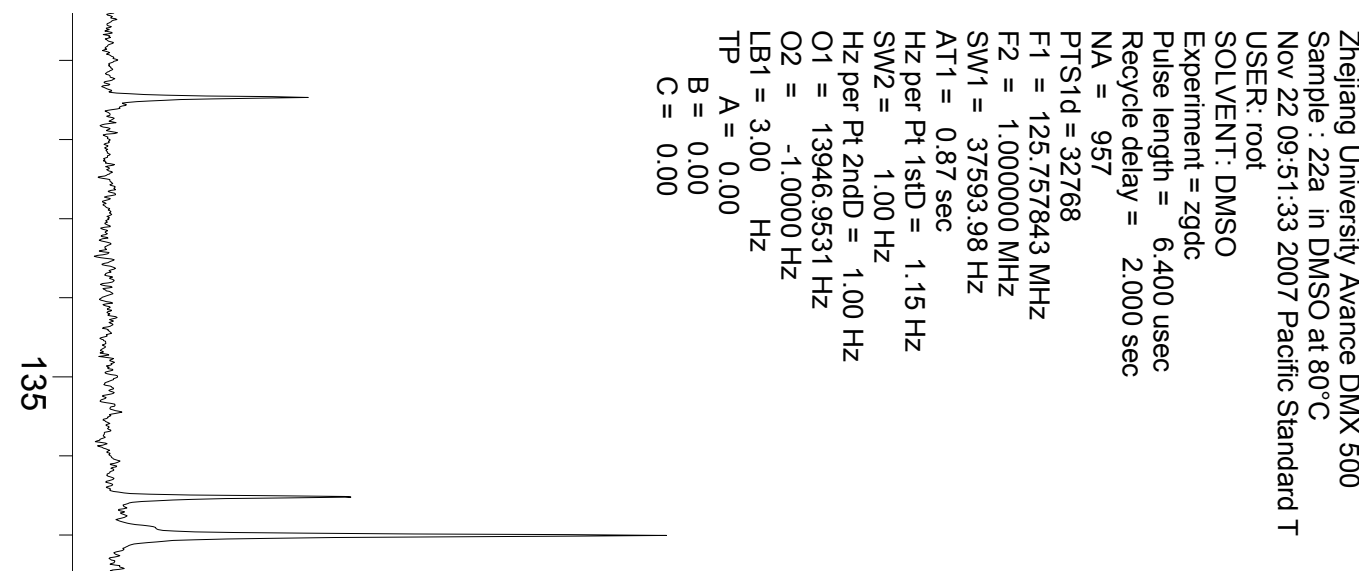

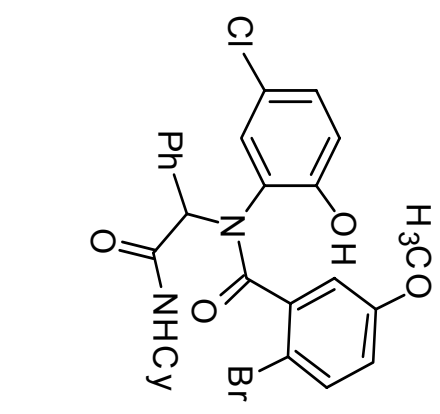



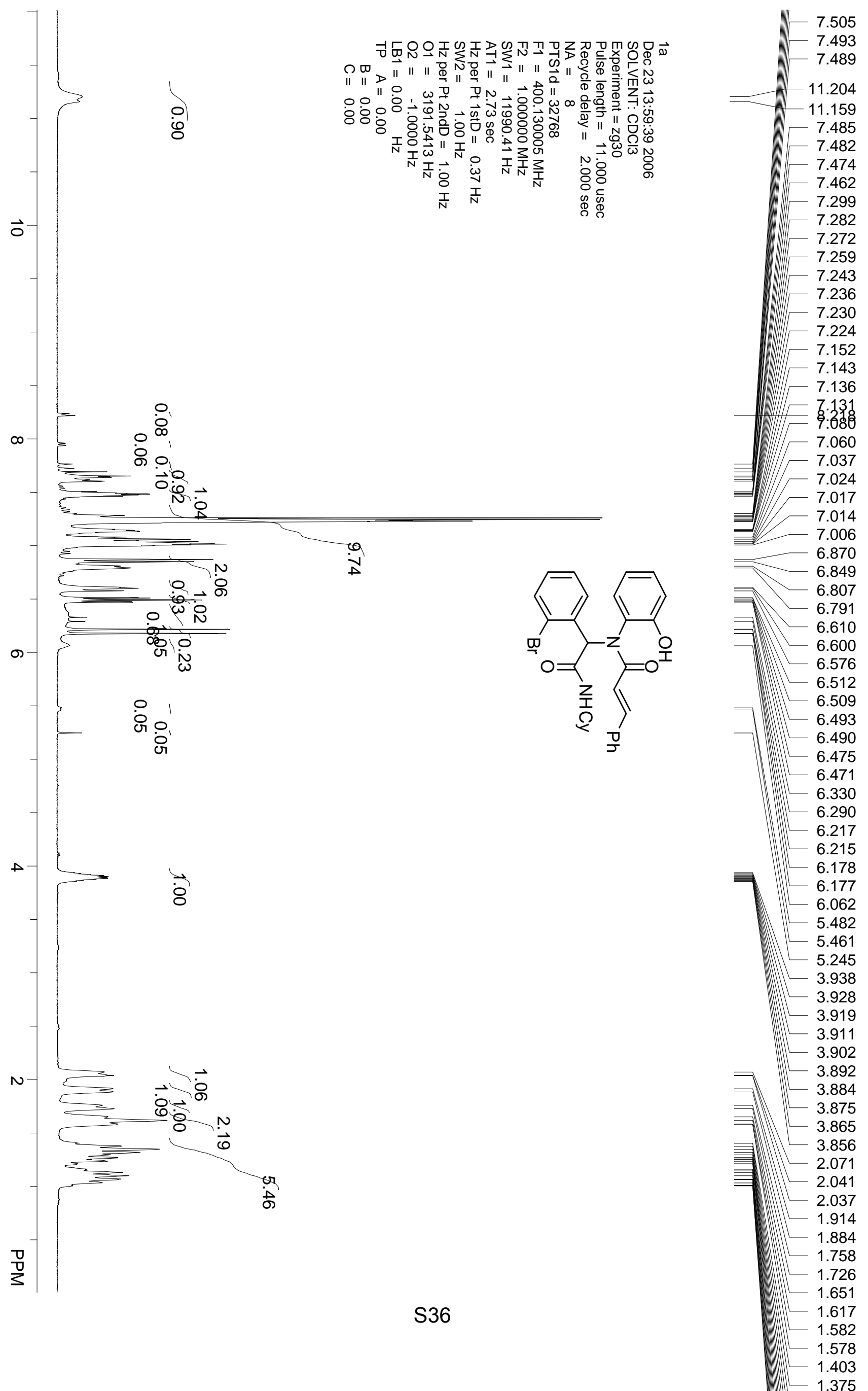


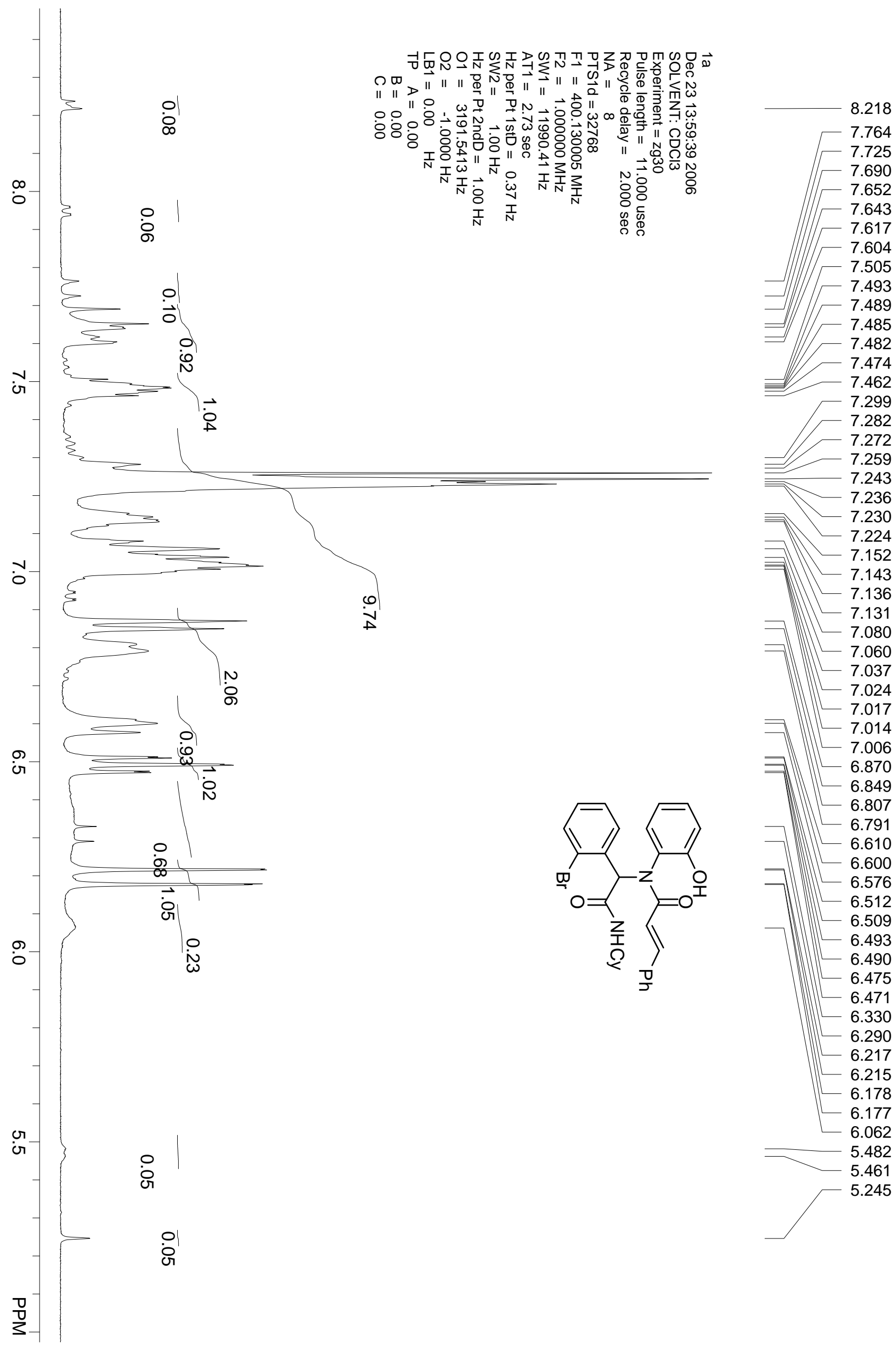




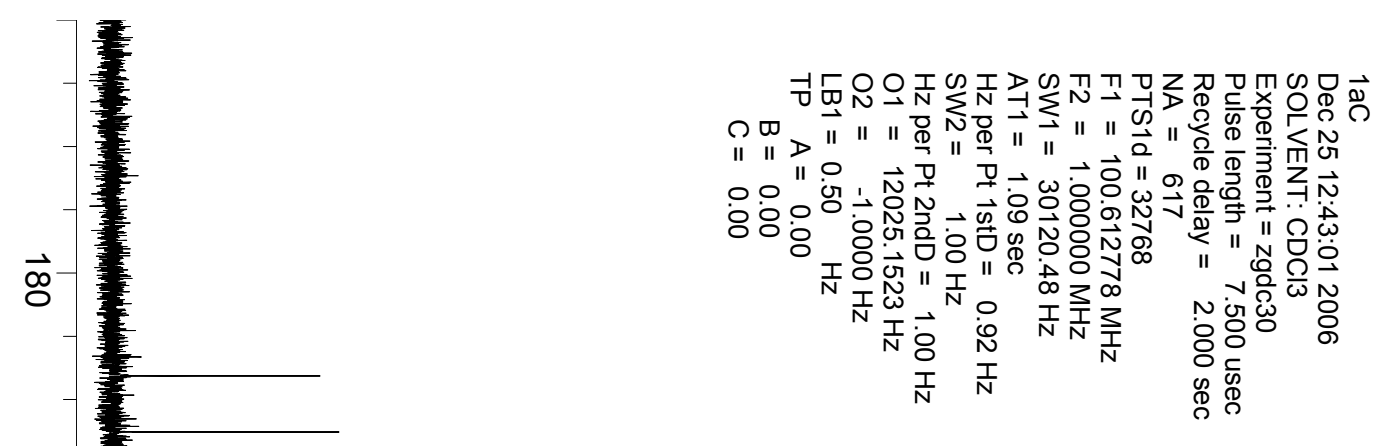

$\vec{\circ}$

$\circ$ 155.821

143.265

134.849

133.538

132.828

130.752

130.466

130.421

129.625

128.503

127.941

127.722

126.512

124.757

119.024

117.601

117.470

77.306

77.192

76.990

边

76.674

$-64.690$

8

o
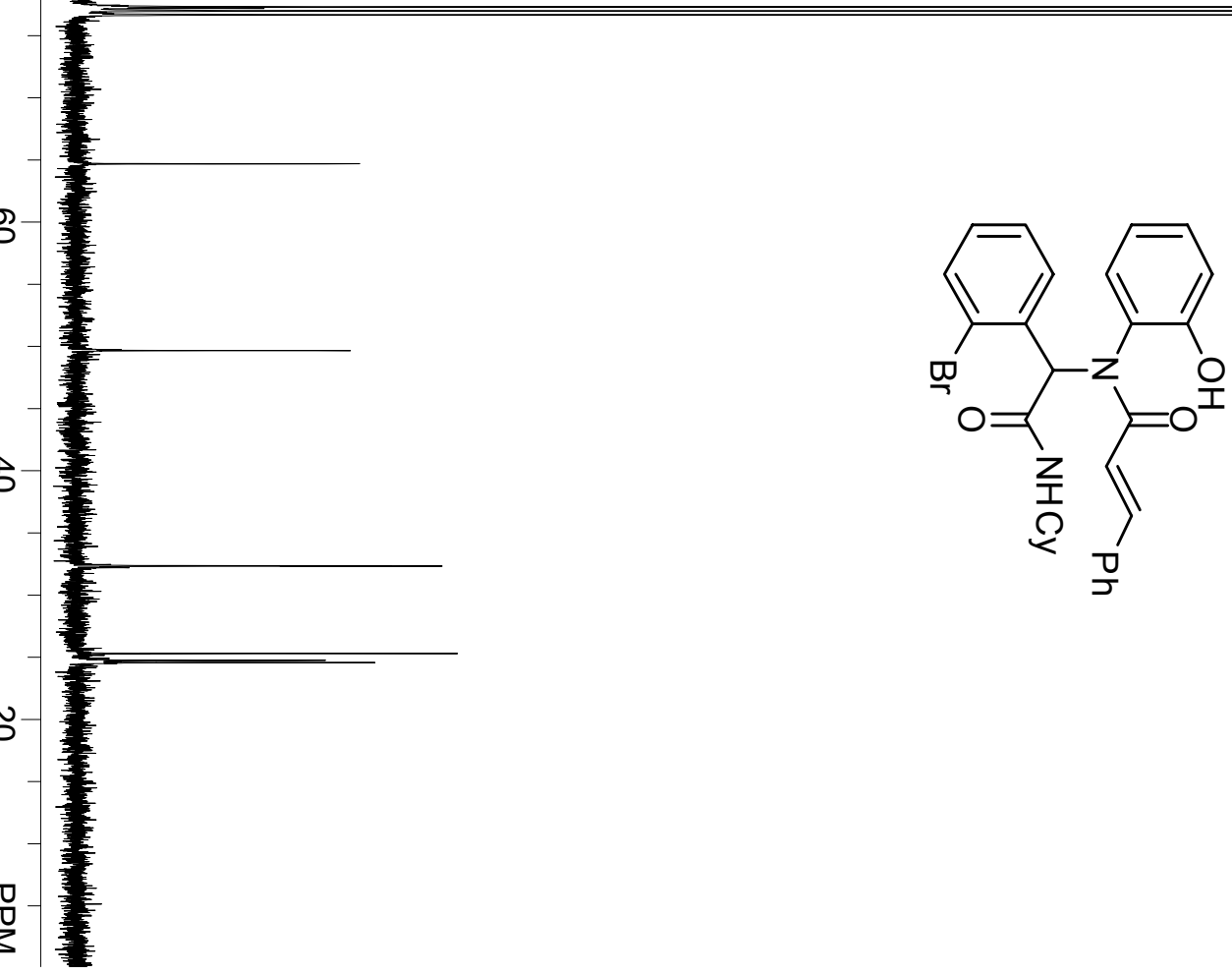

49.660

32.361

32.335

25.309

24.745

24.575 

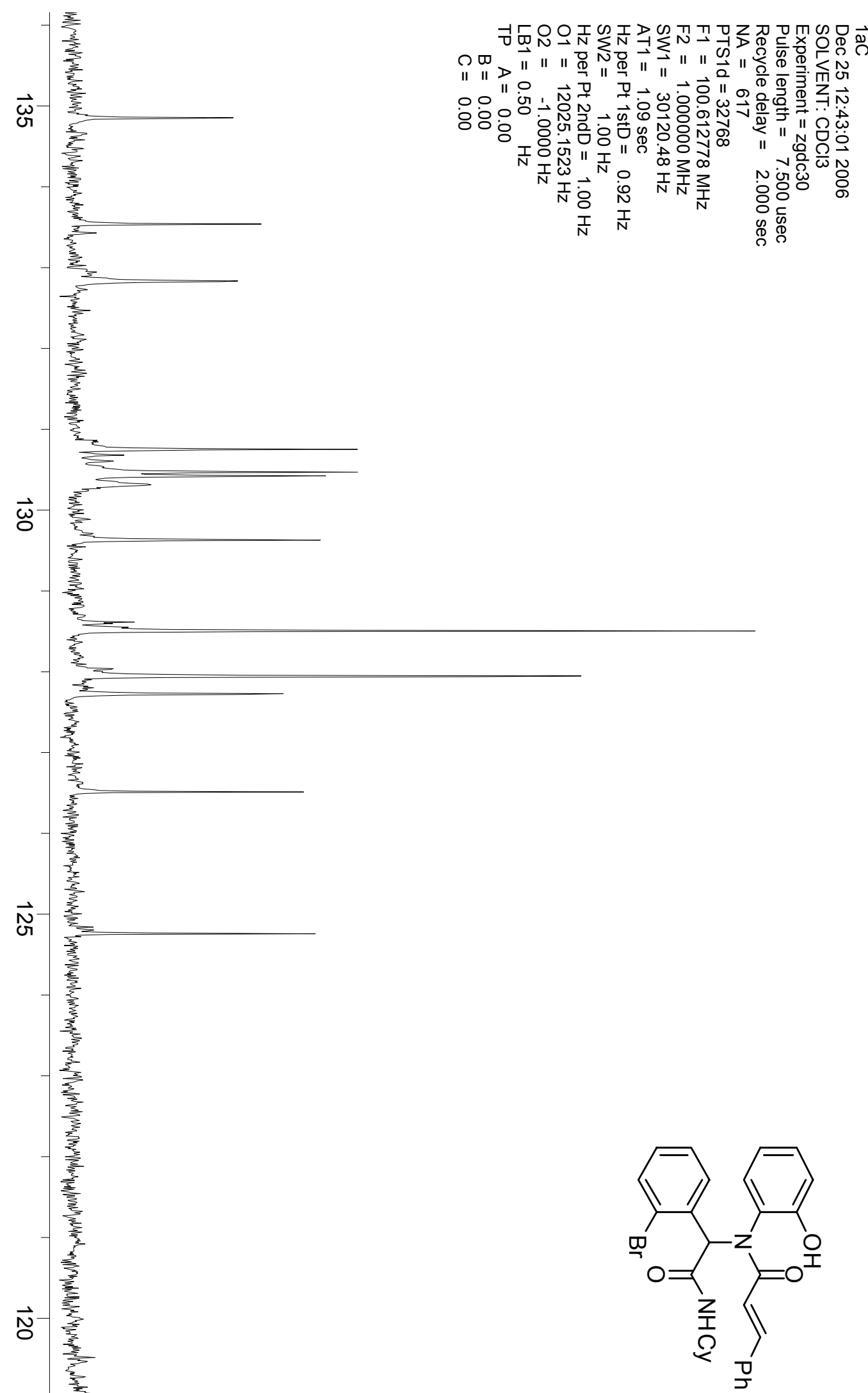

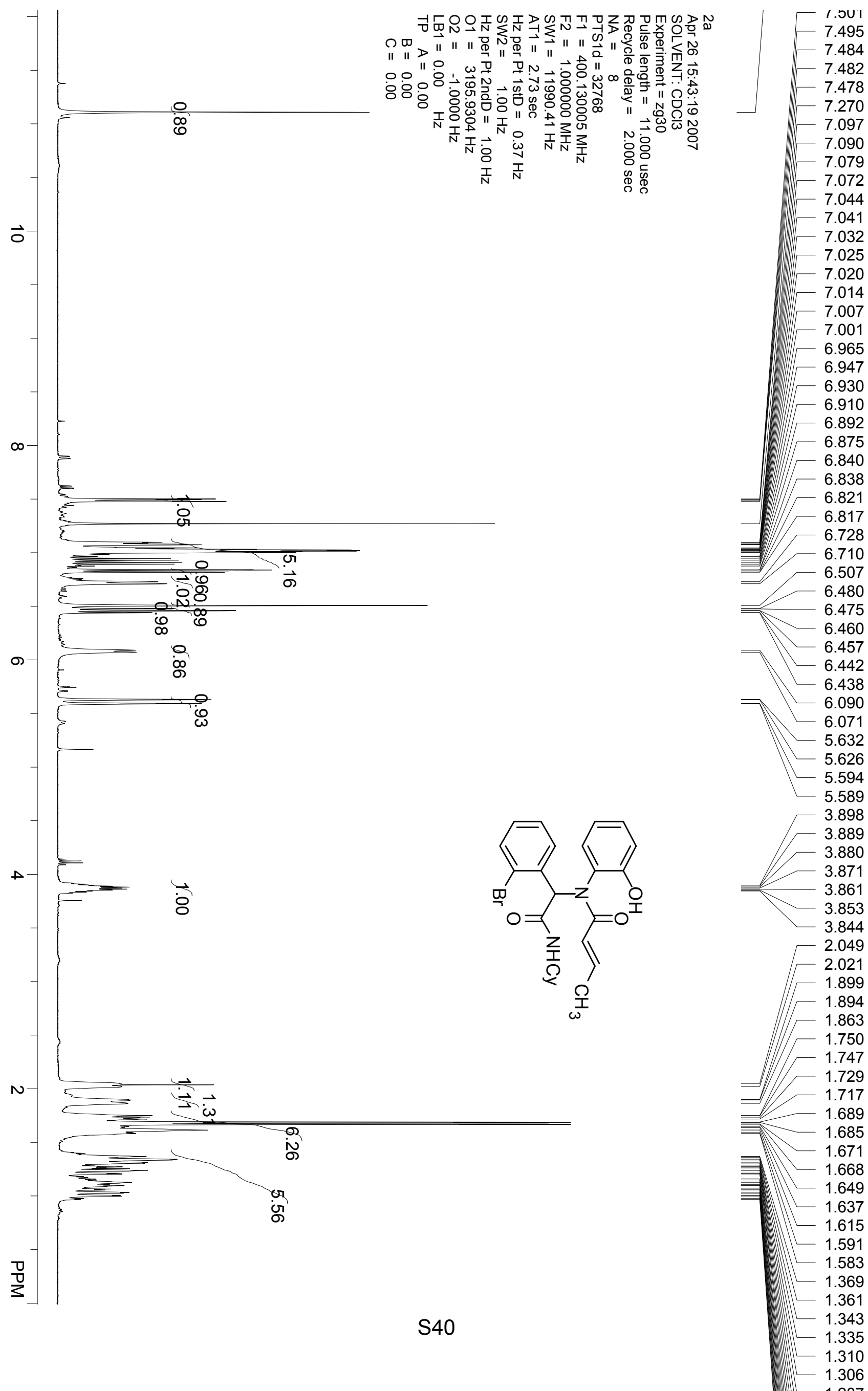


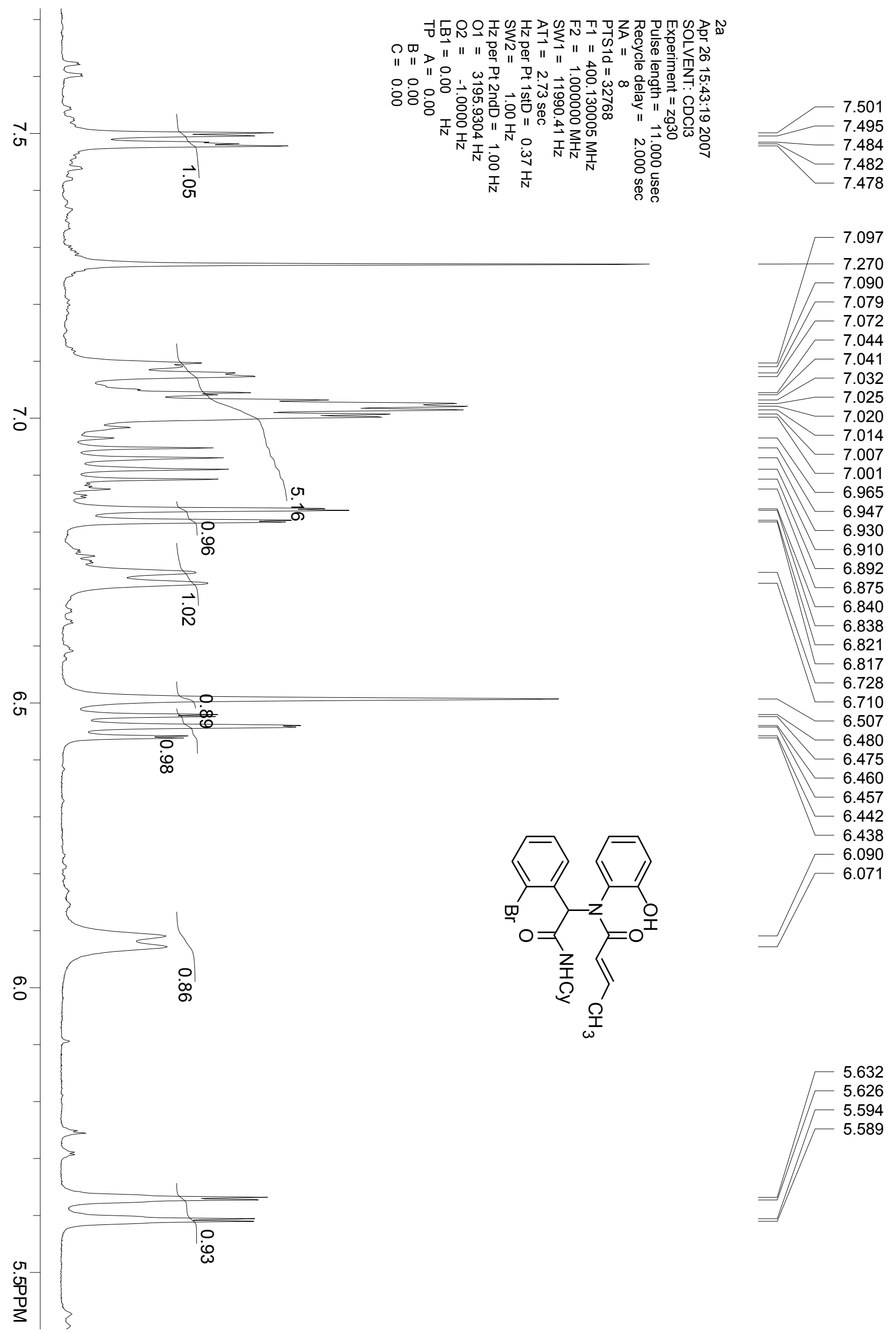




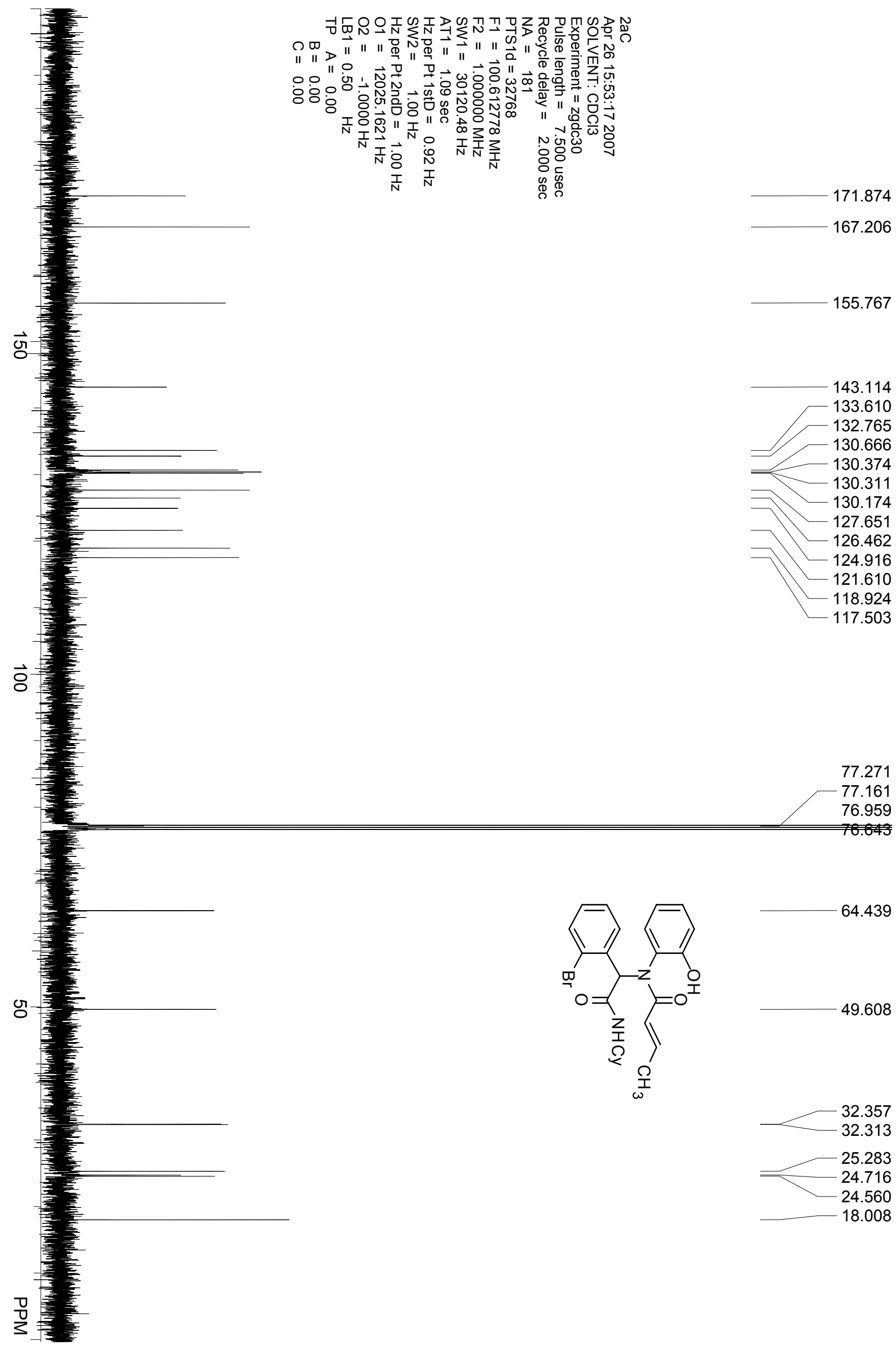




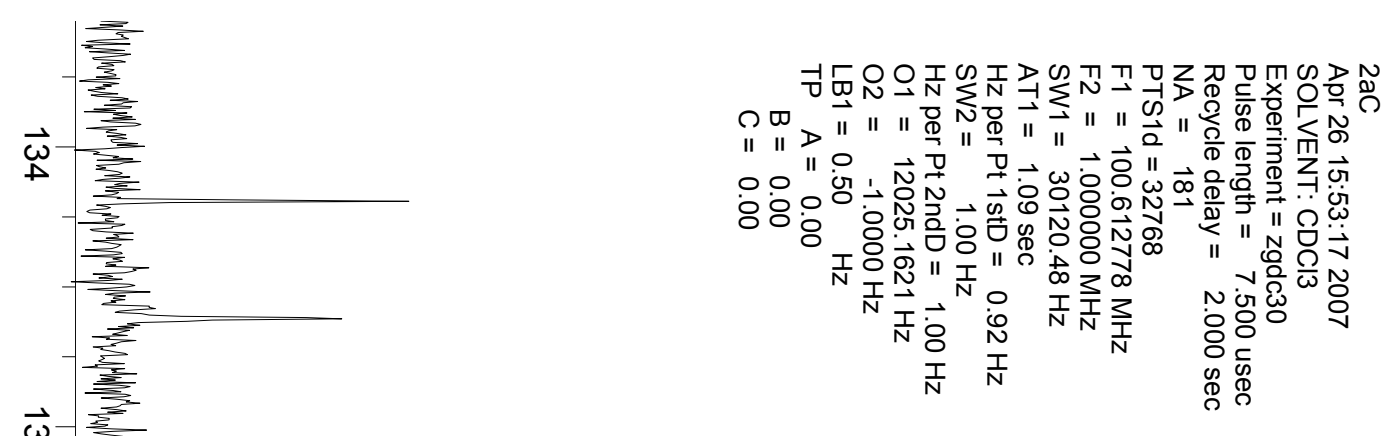

$\vec{N}$

127.651

126.462

$\vec{N}$

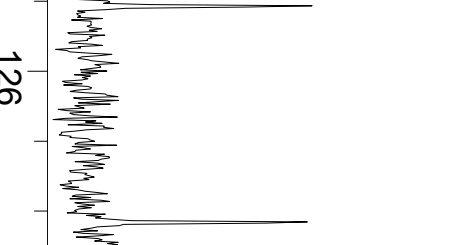

124.916

$\vec{N}$

○<smiles>[CH]C(=O)C([Z](C(=O)[O-])c1ccccc1[O-])c1ccccc1[O-]</smiles> 


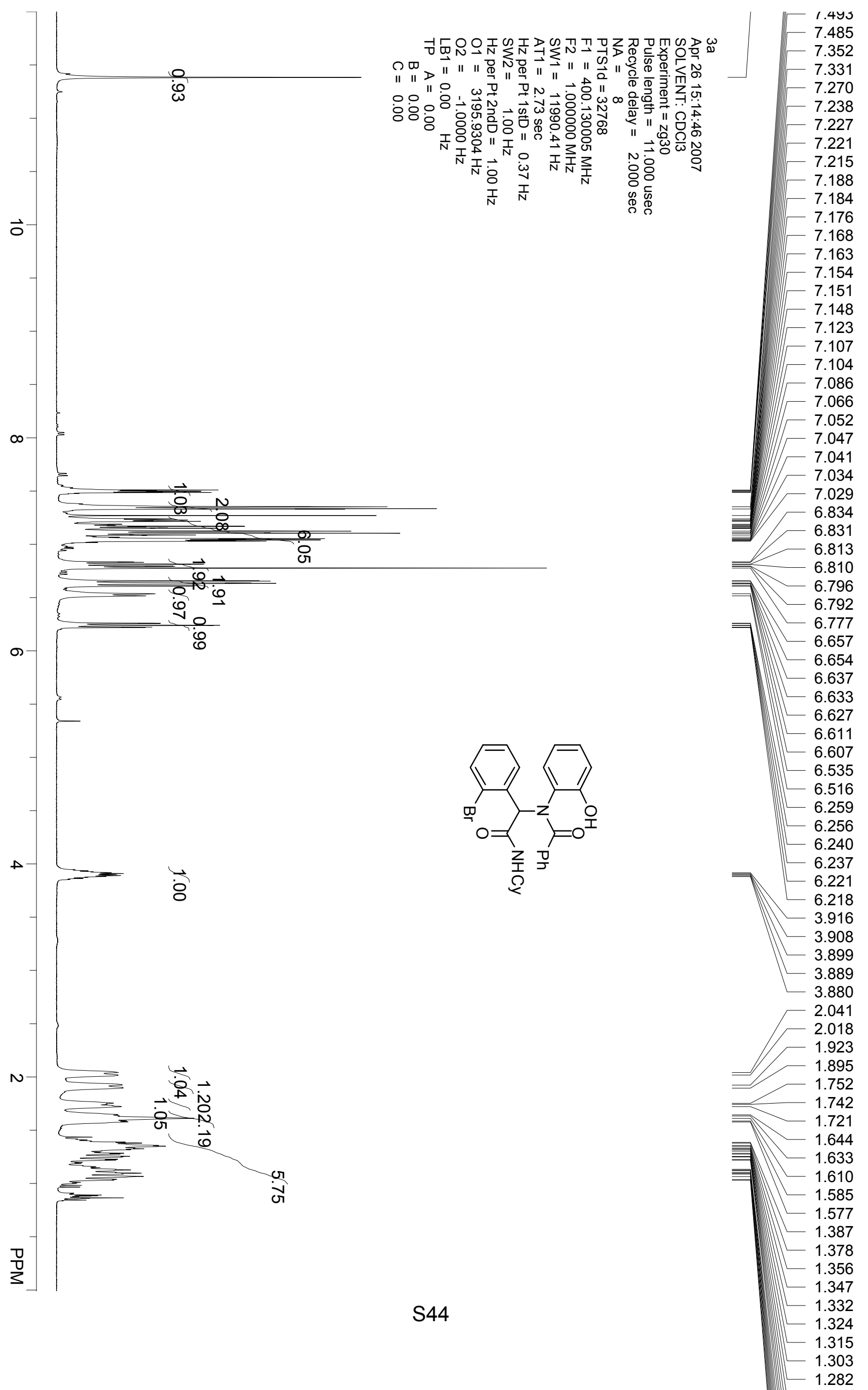




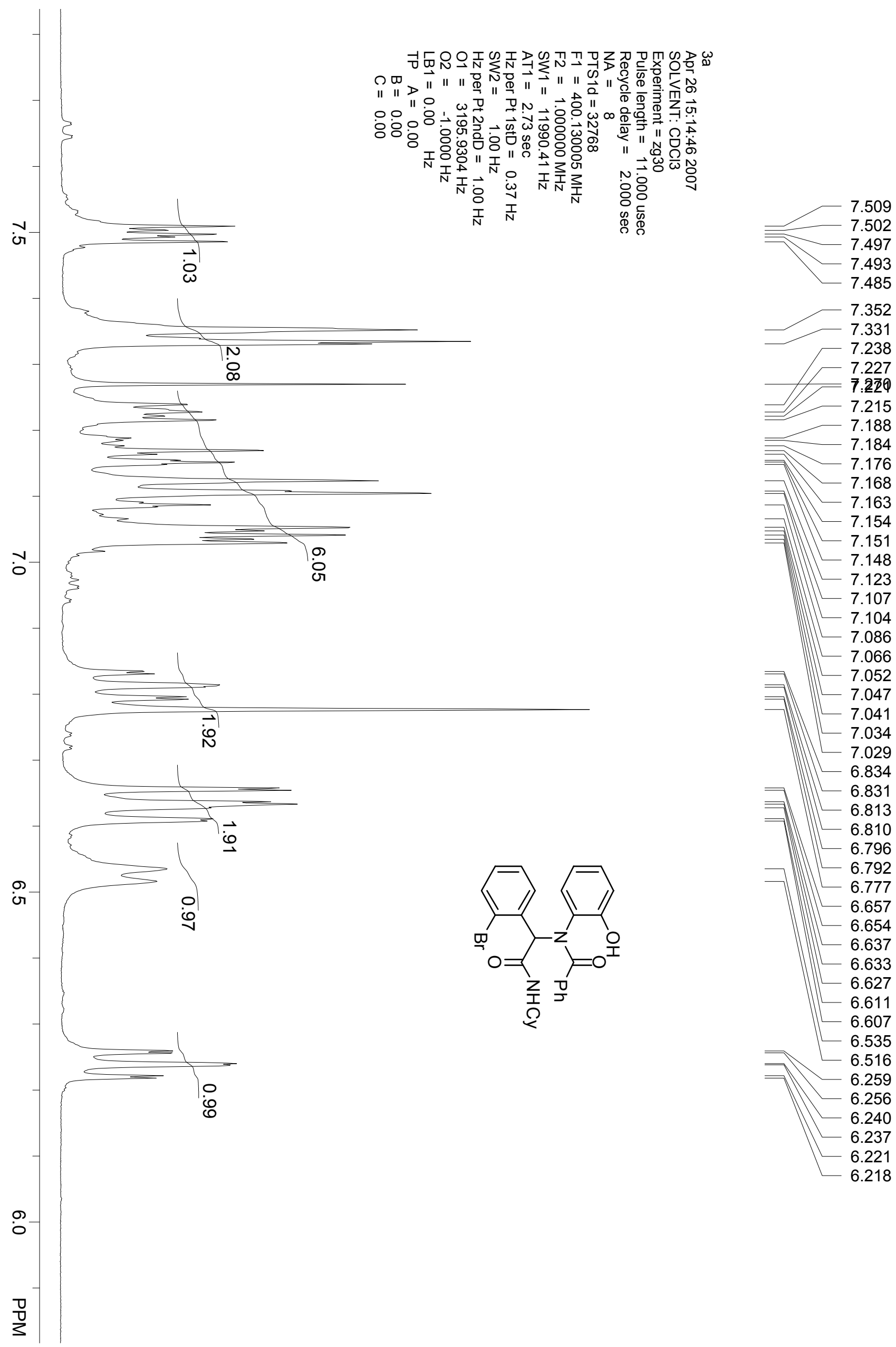




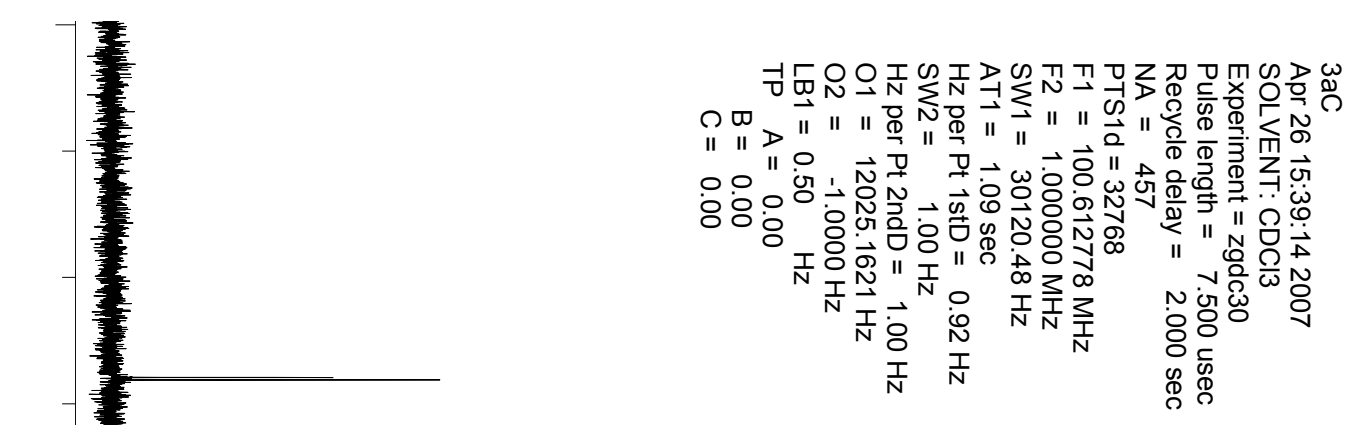

172.070 171.883

155.364

$\overrightarrow{0}$

135.499

133.373

132.788

130.952

130.502

130.439

129.834

129.444

127.690

127.462

127.096

126.576

126.292

118.568

117.210

77.287

76.979

76.664

잉

$\overrightarrow{0}$

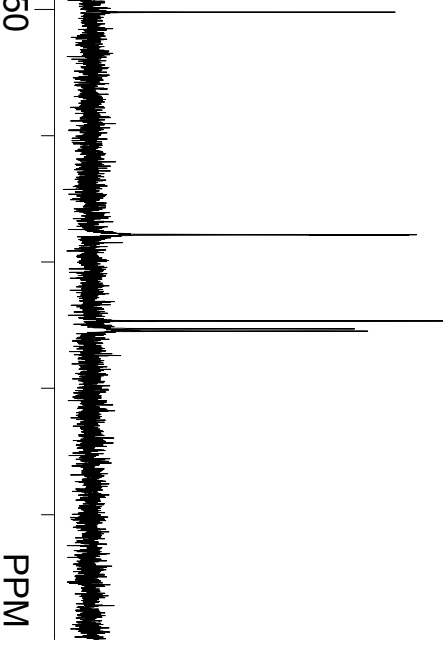

64.930

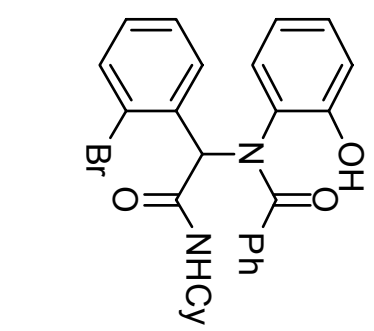

49.758

32.129

$-32.100$

25.295

24.677

$-24.491$ 

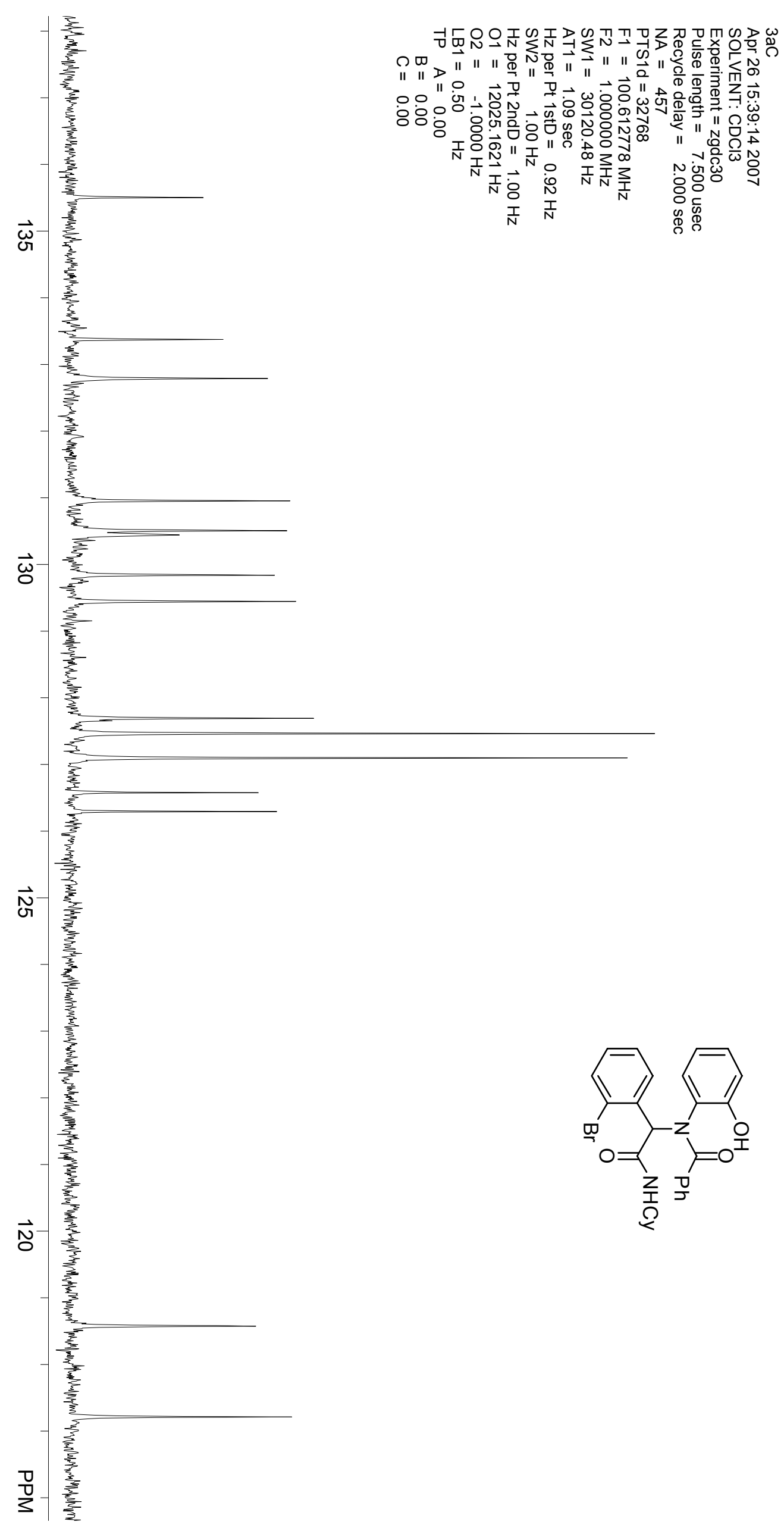


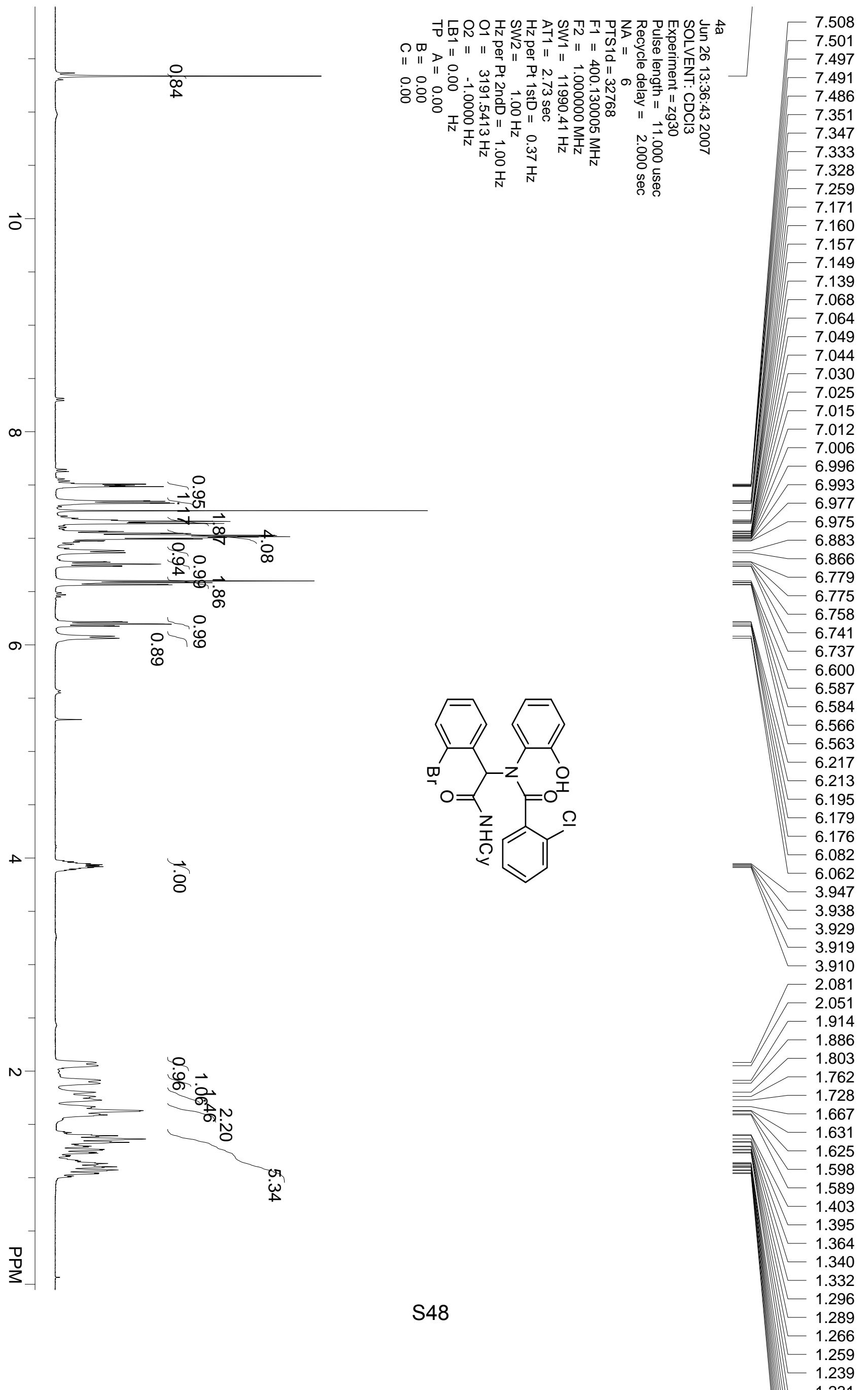




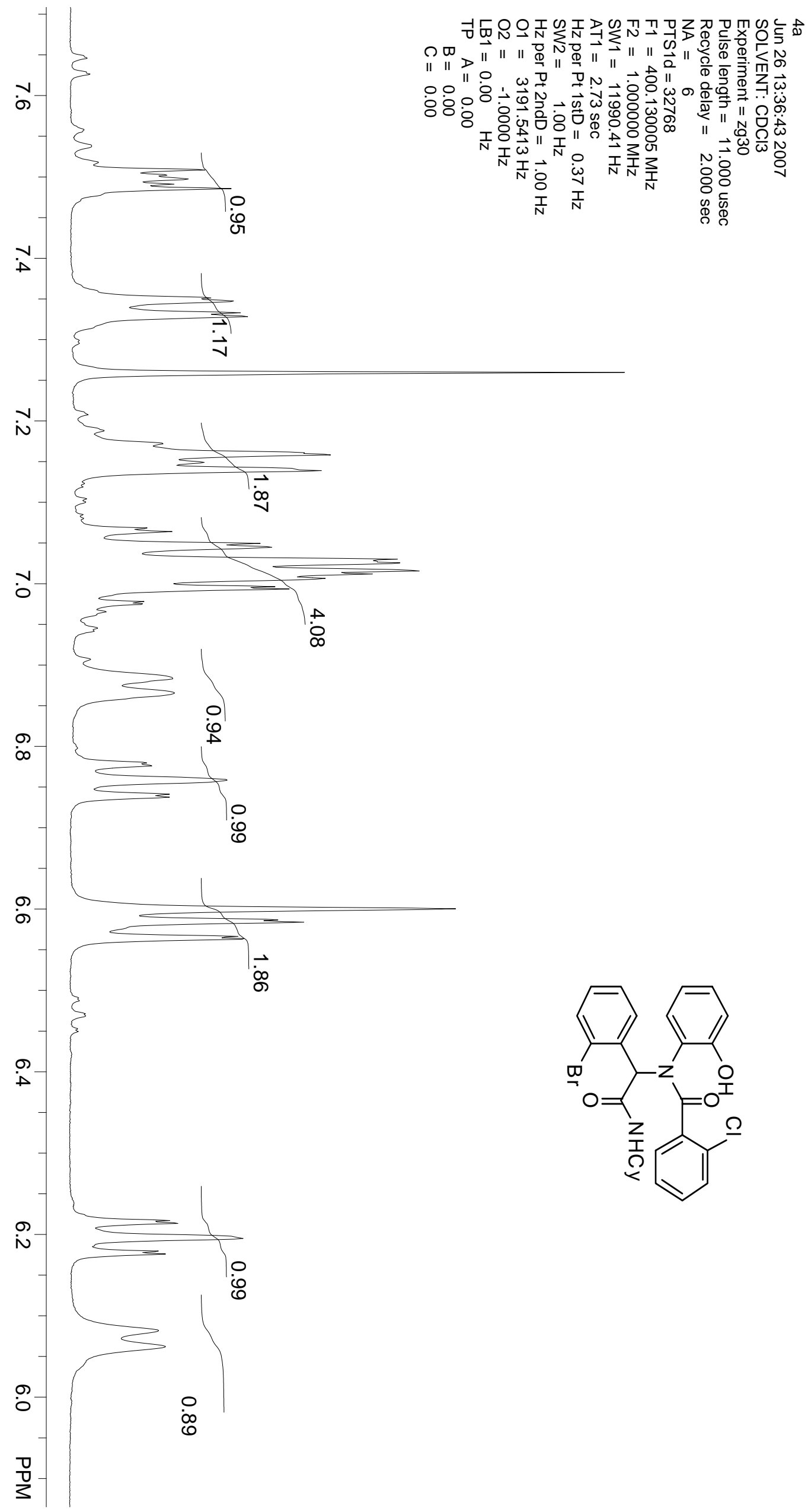

6.741

$-6.737$

6.600

6.587

6.584

$-6.566$

6.563

6.217

6.213

6.195

6.179

6.176

6.082

6.062 


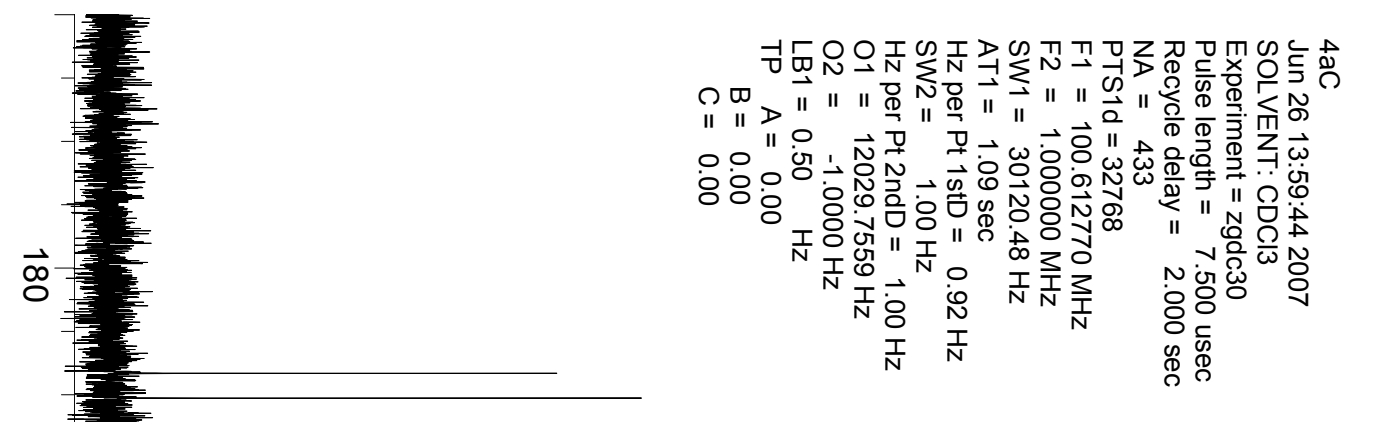

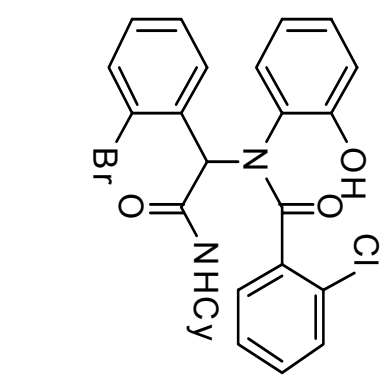




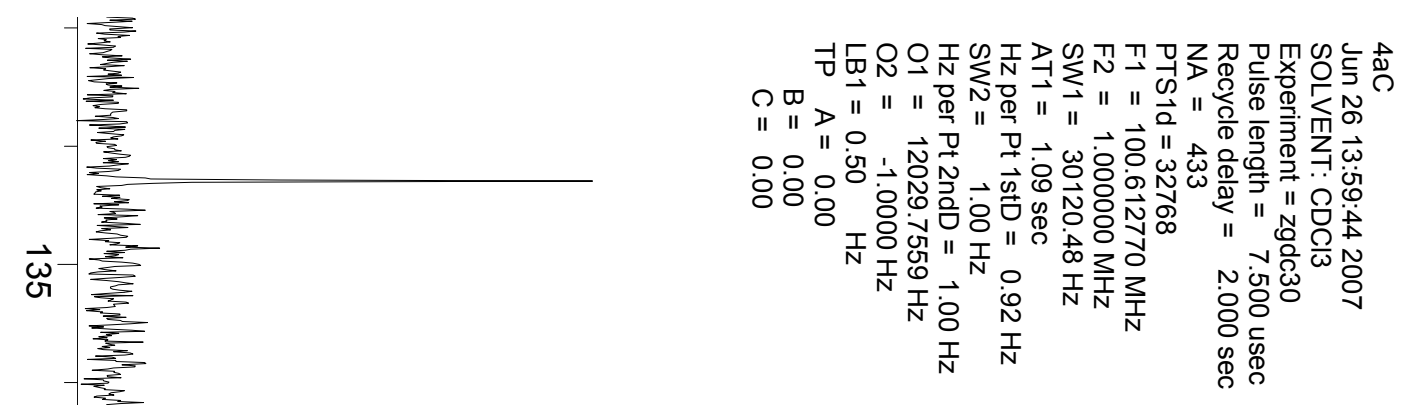

$\vec{\omega}$

ह

130.219

130.062

129.851

129.714

128.960

127.760

126.807

126.608

126.045

$\vec{N}$

125.086

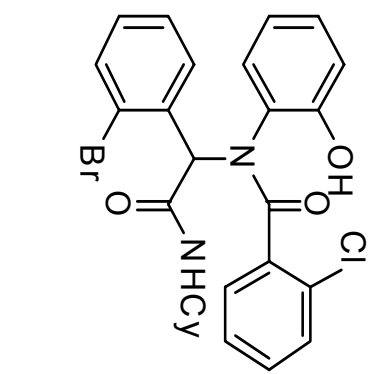

118.578

117.048

$\stackrel{0}{7}$

0 

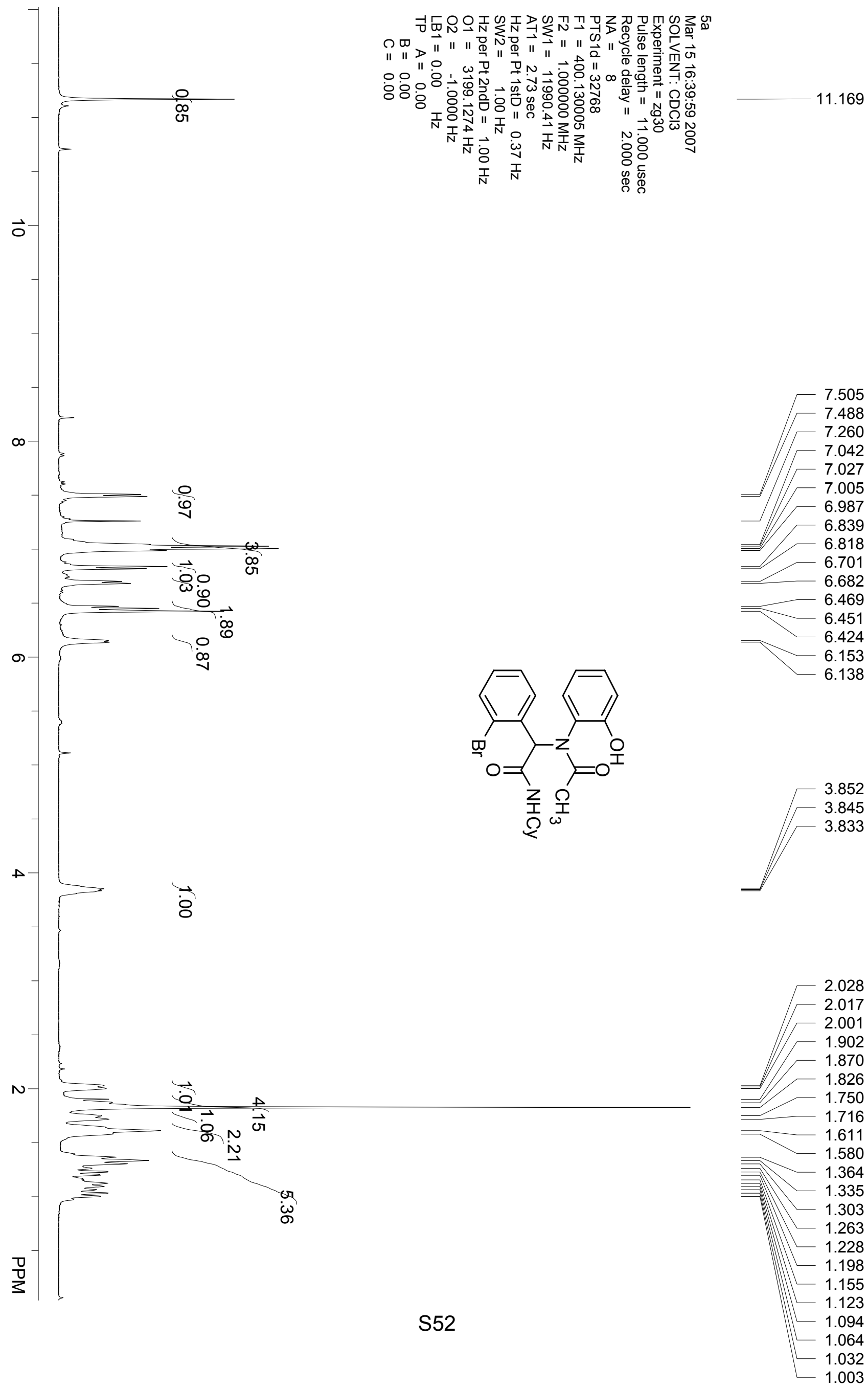

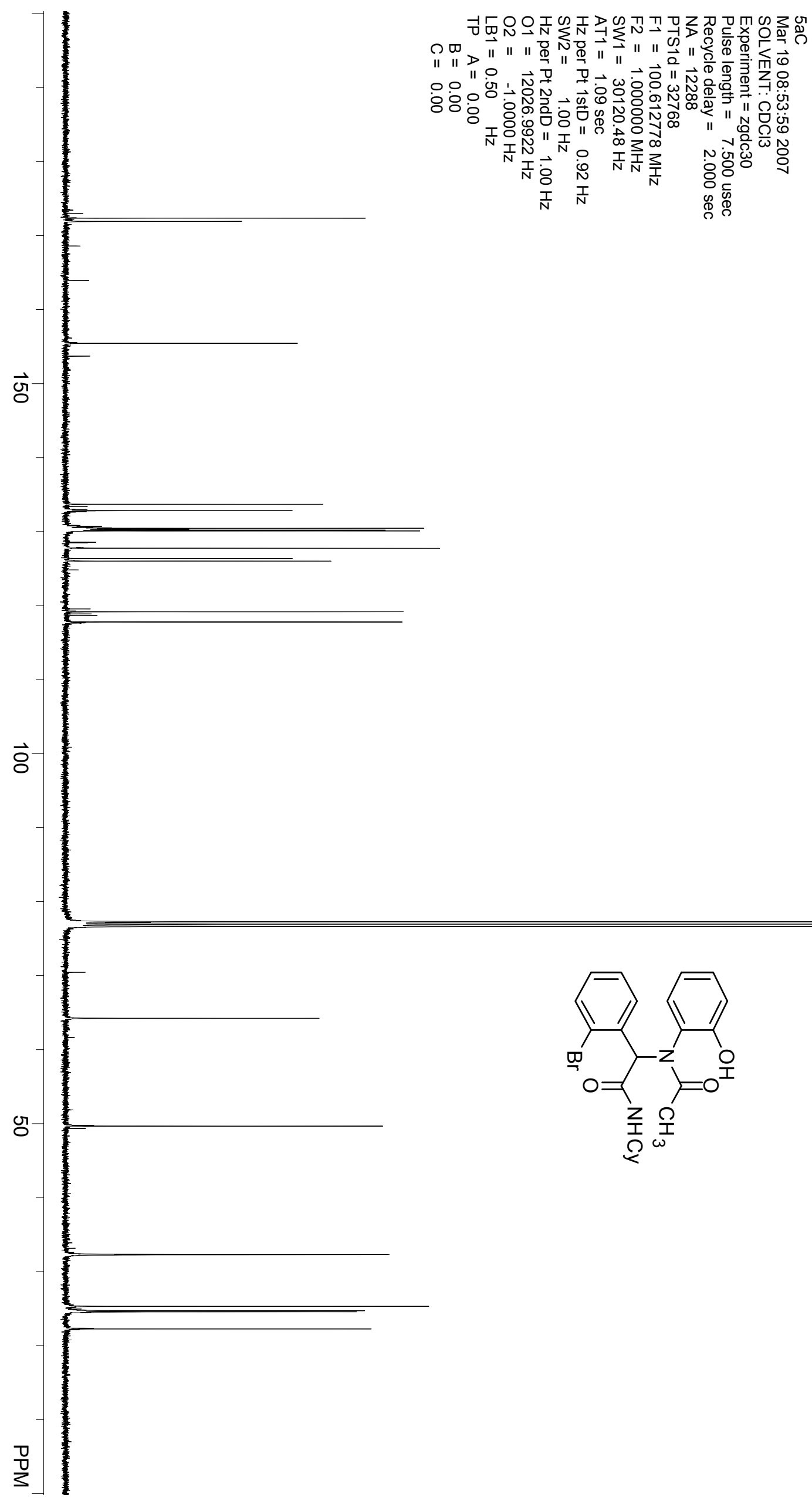

133.683

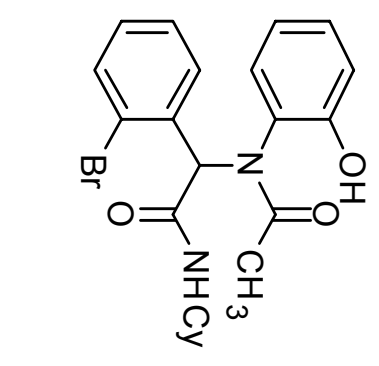

64.242 

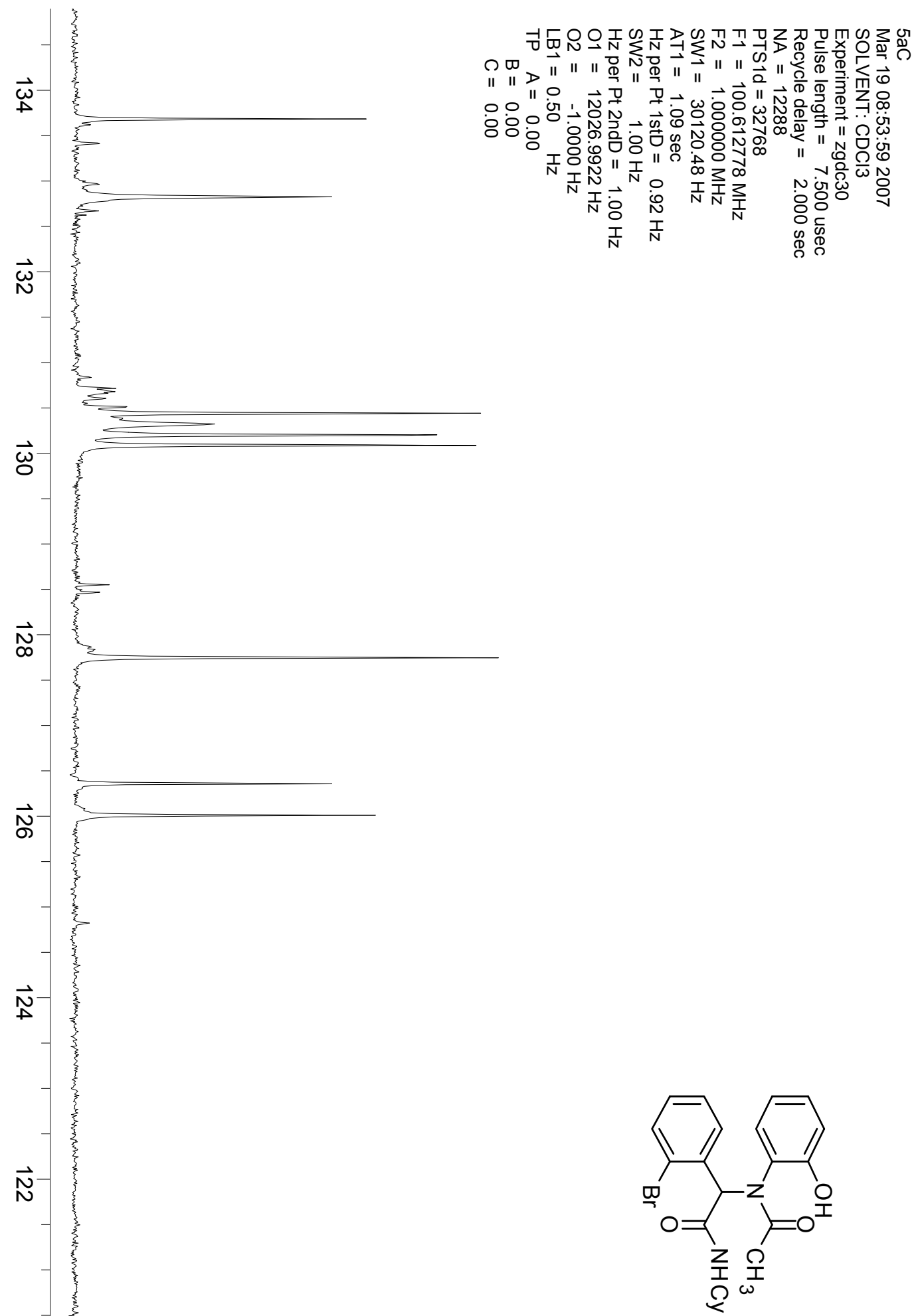

$\vec{N}$

$\vec{\infty}$ 

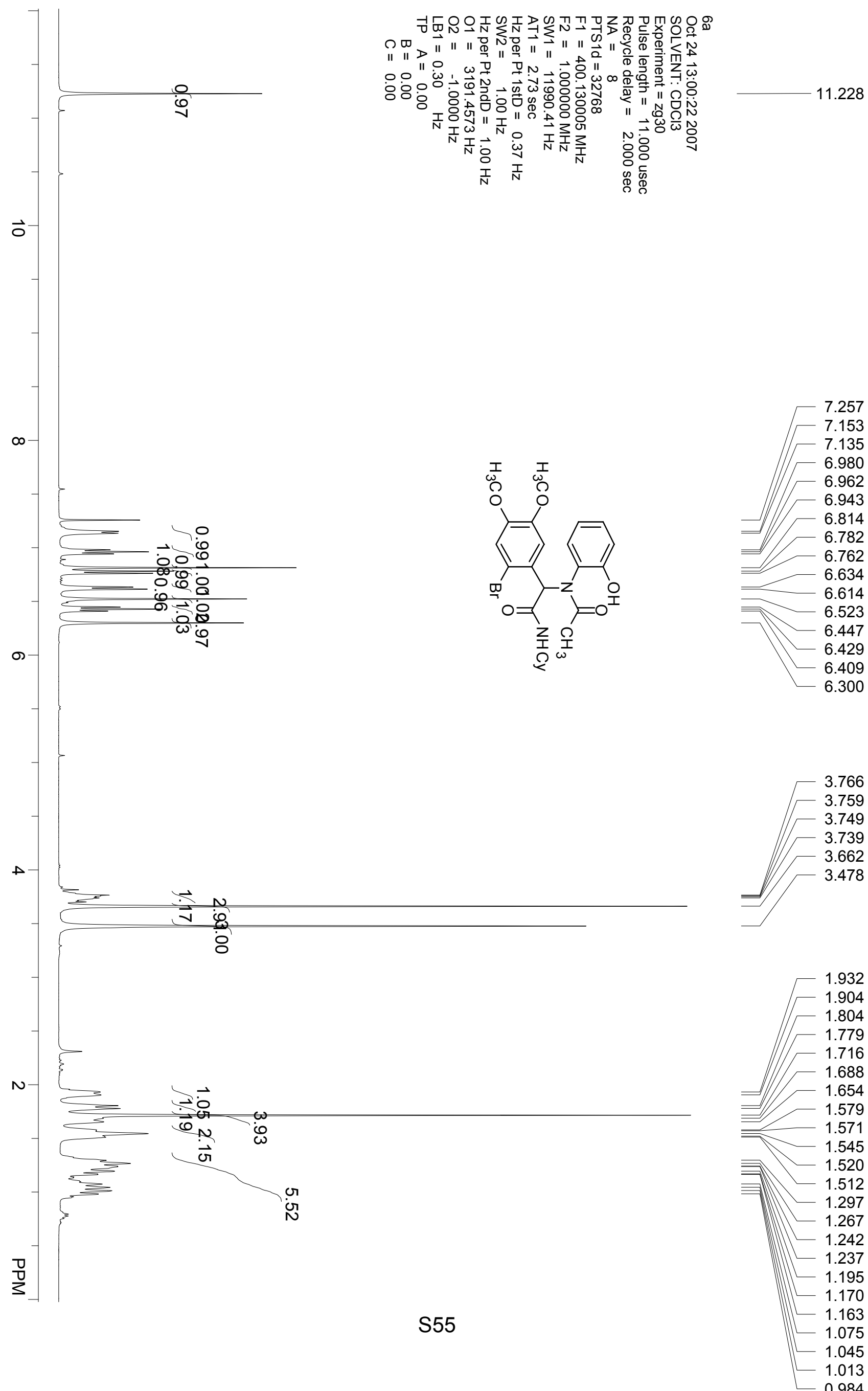

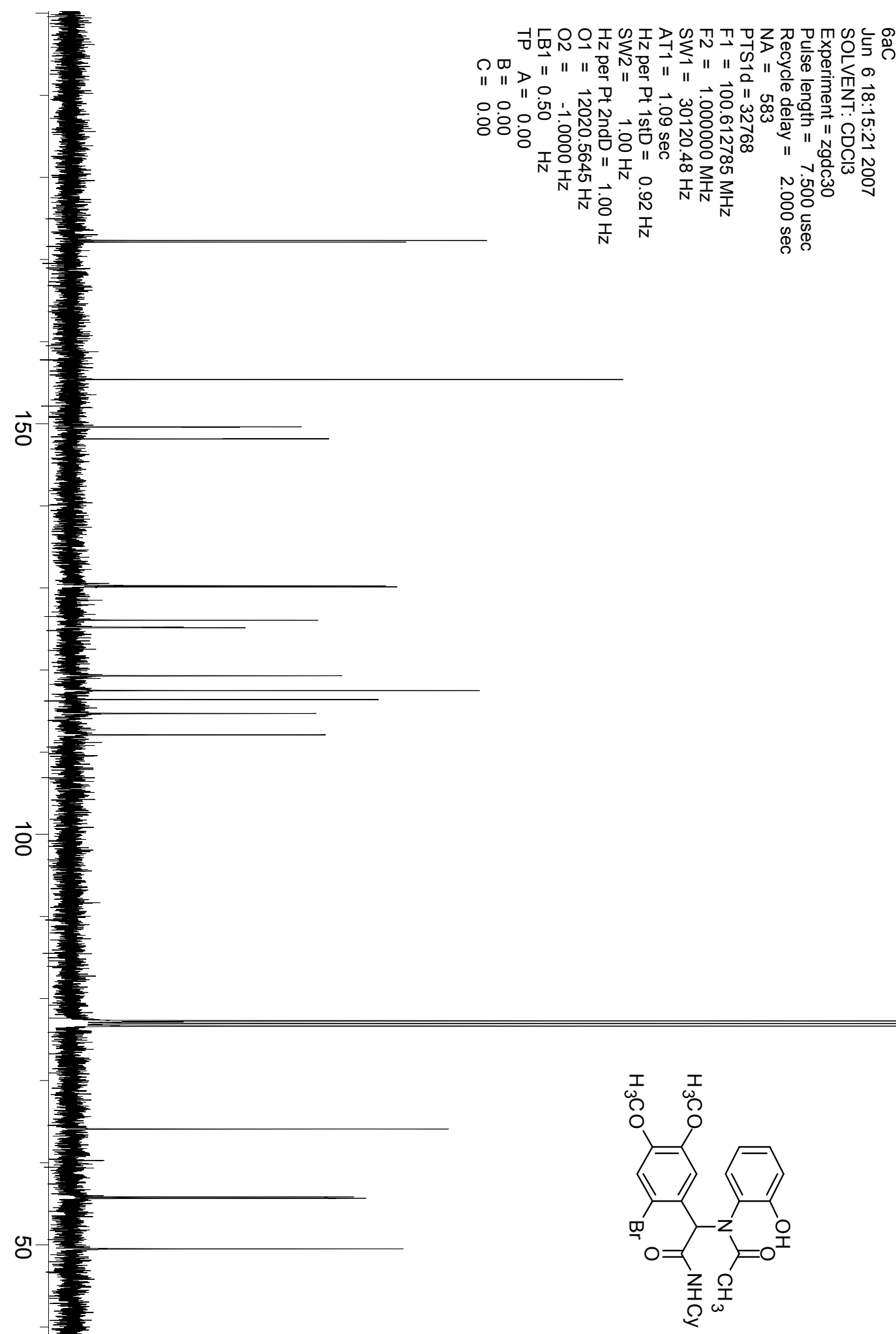

64.111

55.844

55.678

49.504

32.193

32.145

32.113

32.055

25.234

24.632

24.502

22.282 


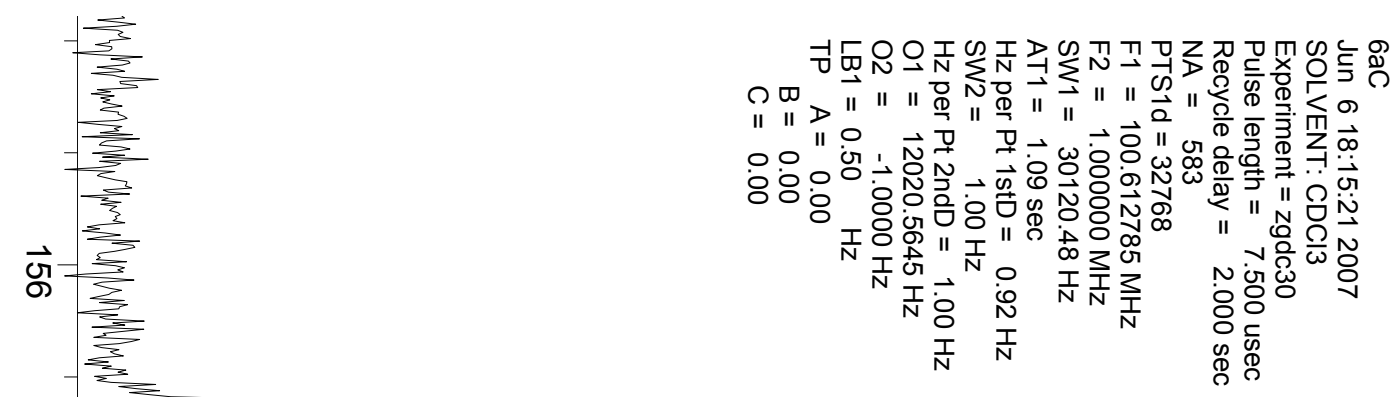

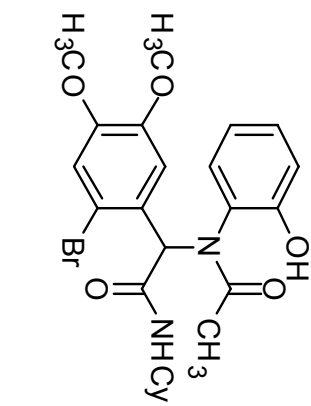




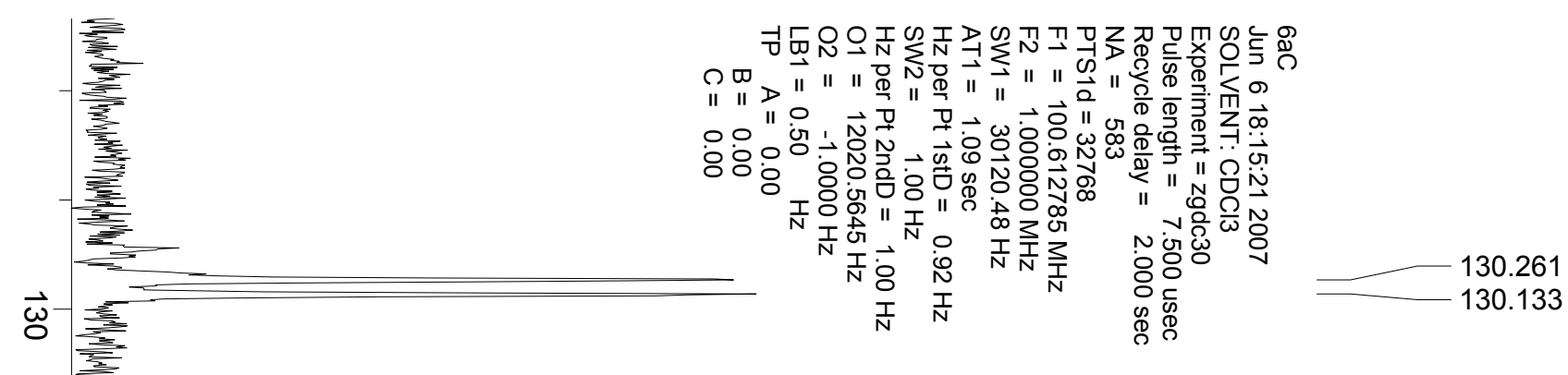

$\vec{N}$
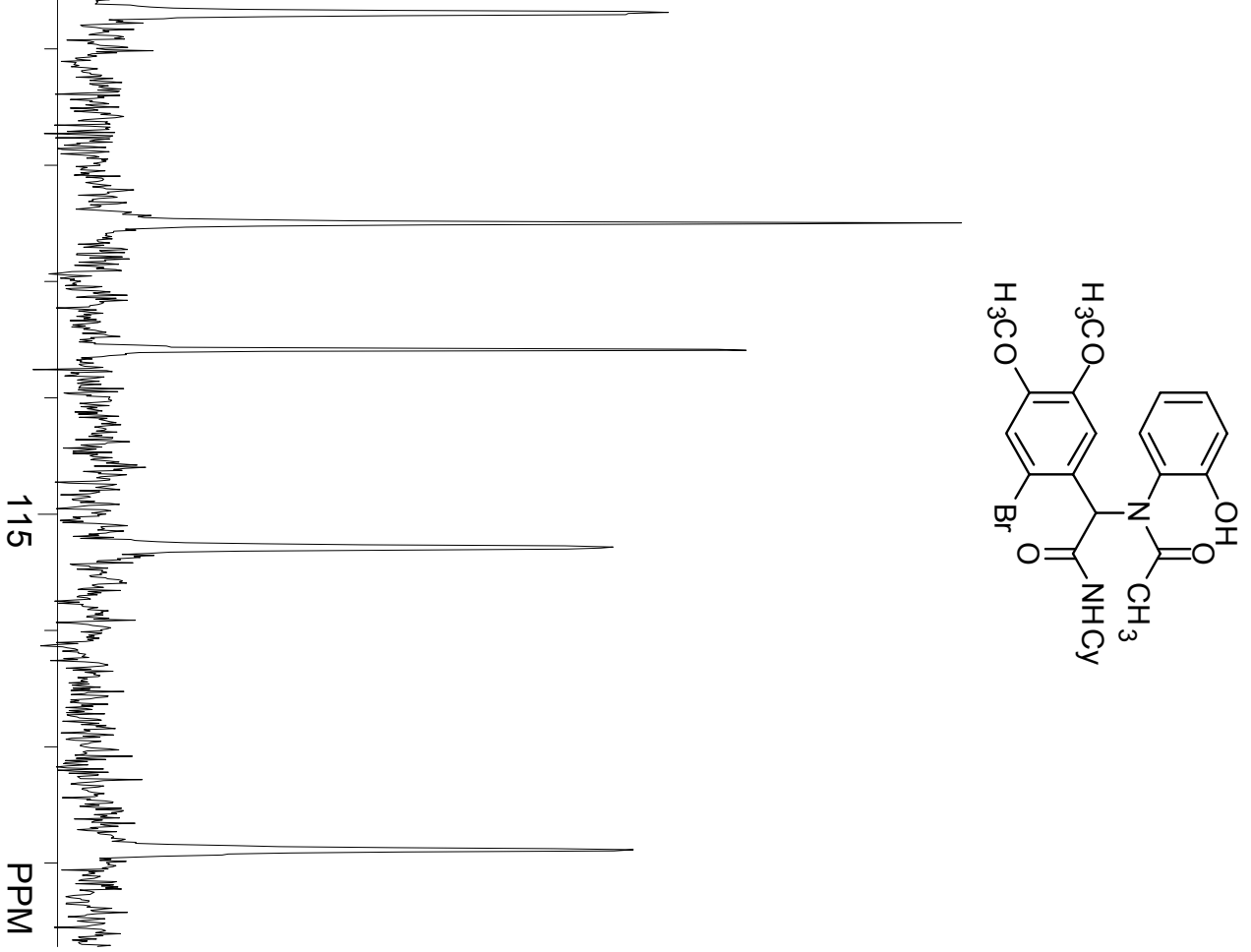


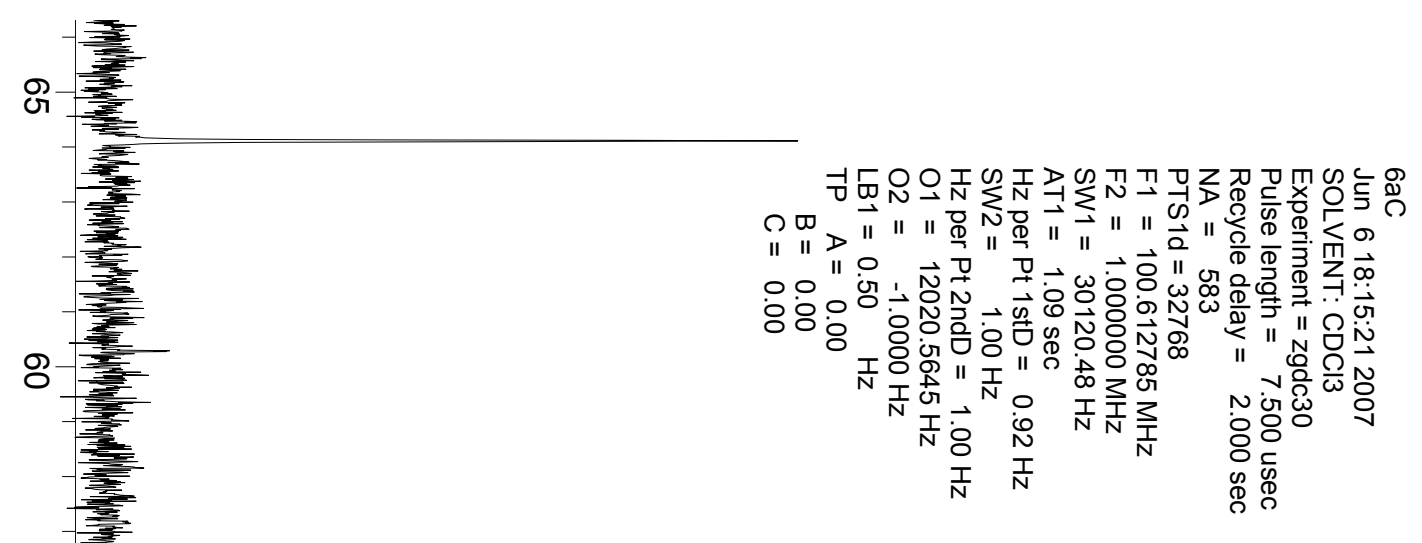

55.844

G

55.678

g

49.504

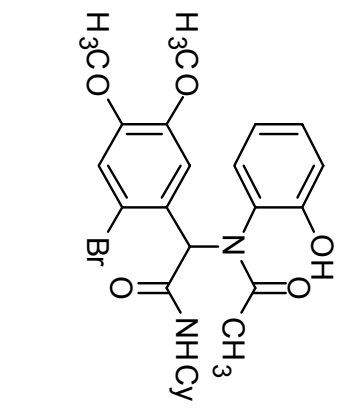

w

32.193

32.145

32.113

32.055

w

$\sqrt{-\frac{\sqrt{\frac{1}{3}}}{\sqrt{\frac{1}{n}}}}$ 


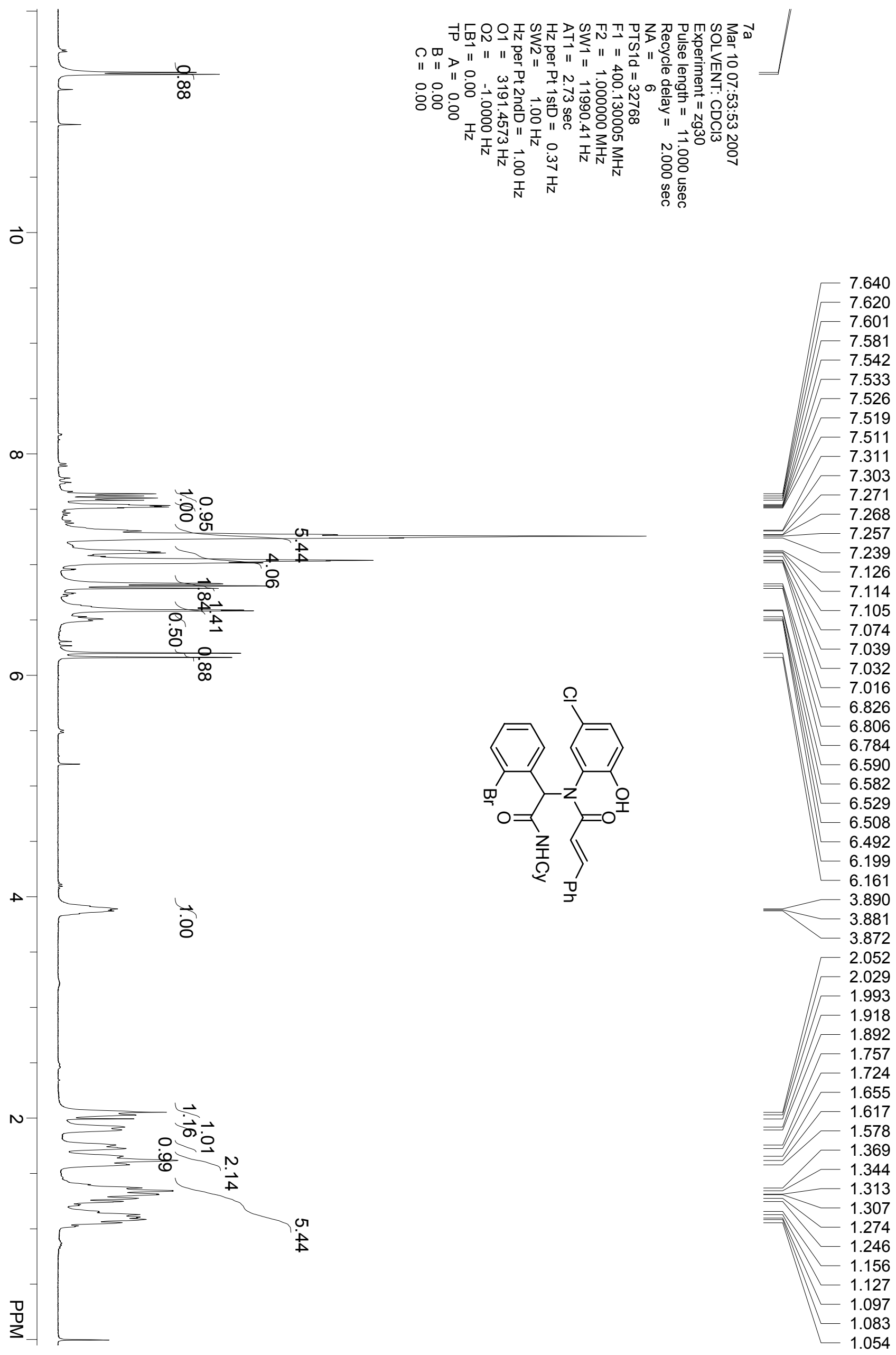




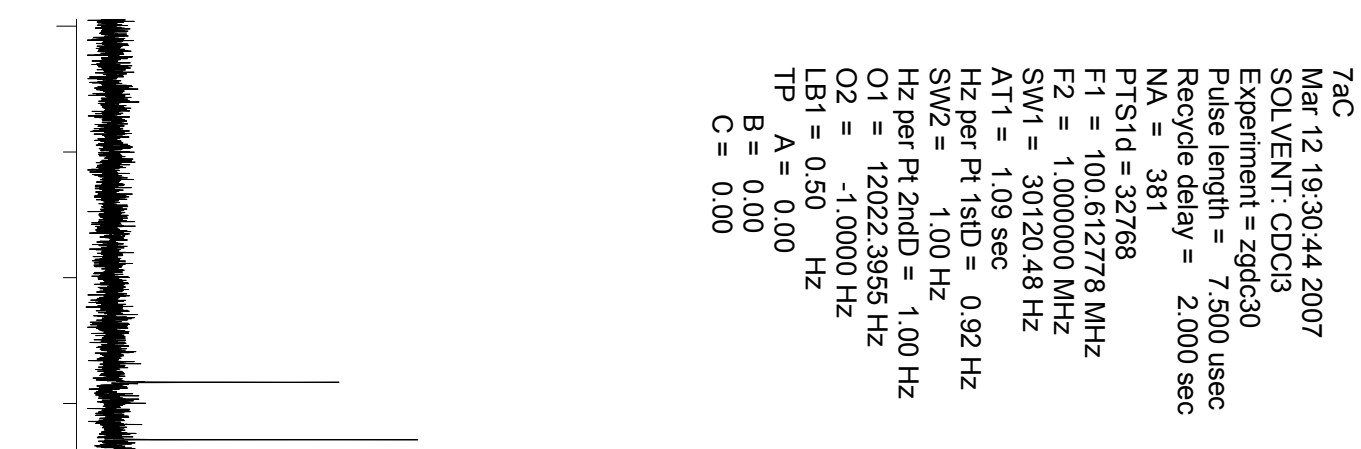




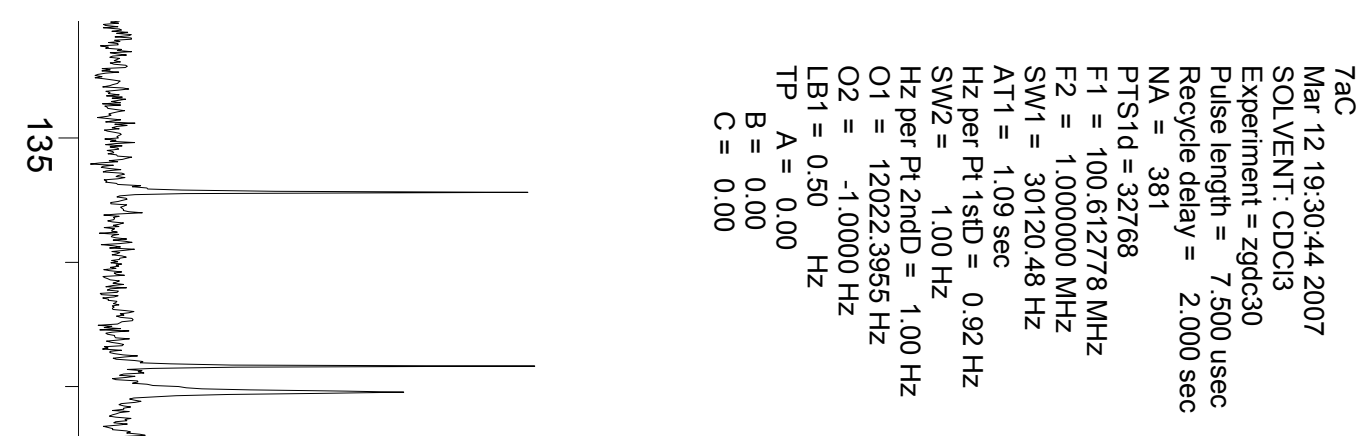

134.560

133.164

132.951

130.745

130.512

130.275

130.062

$\vec{\omega}$

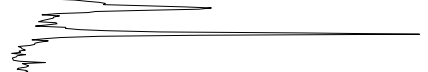

129.852

128.539

128.010

127.834

126.476

125.558

$\vec{N}$

는

$\overrightarrow{0}$

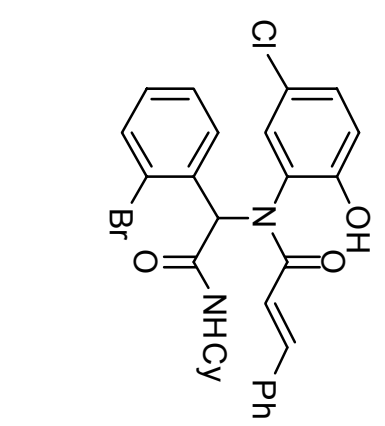

122.986

118.730 

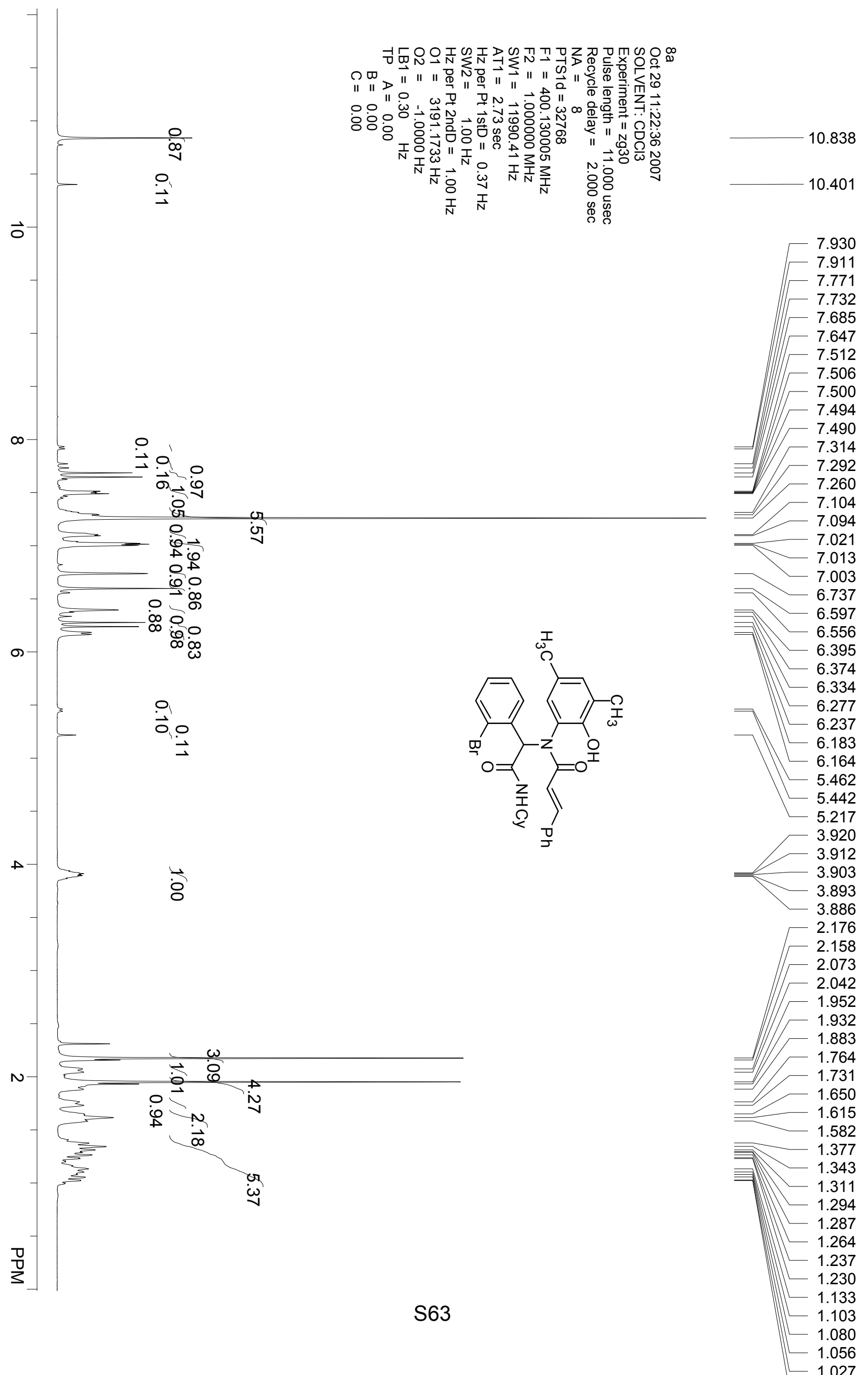

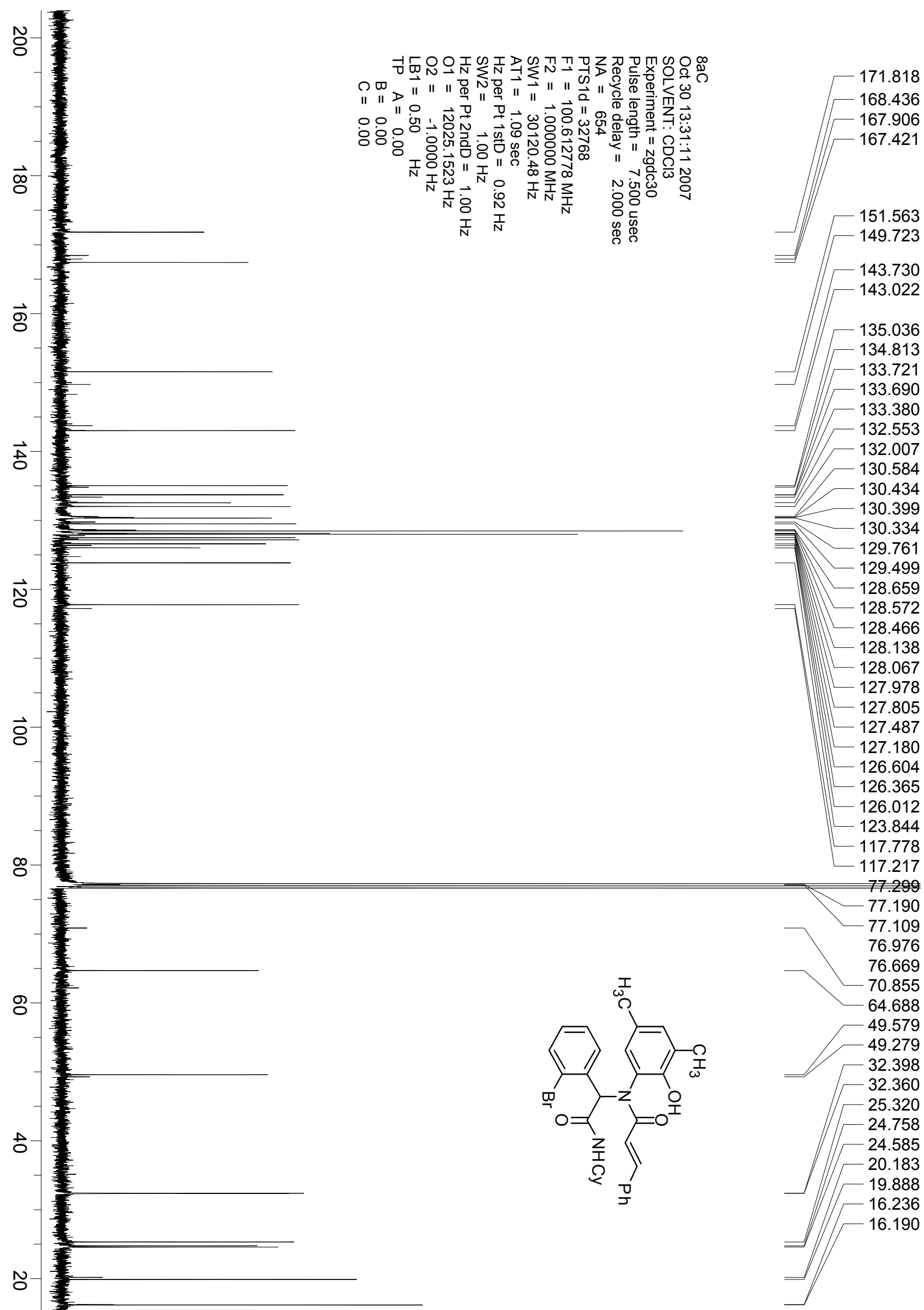


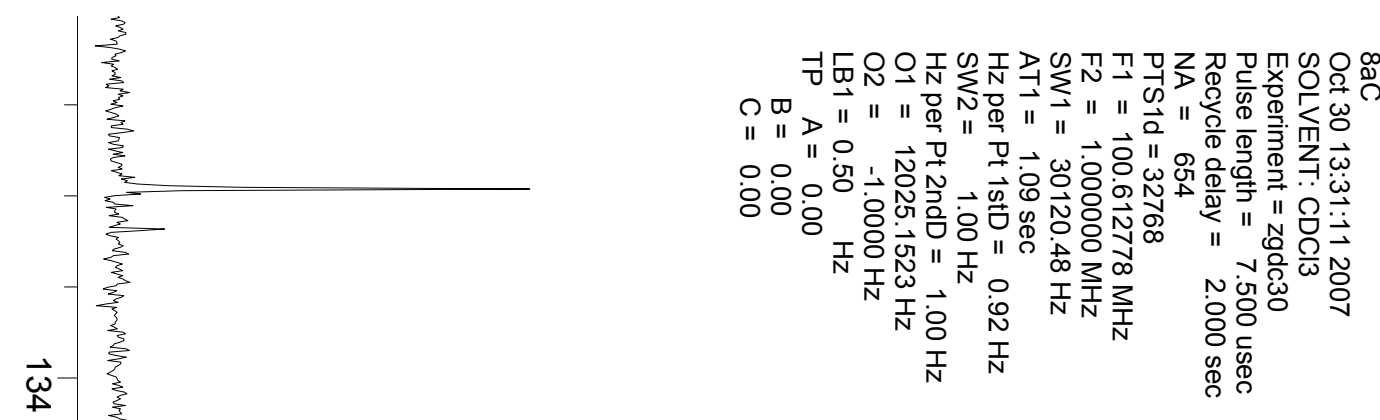

$\vec{\omega}$
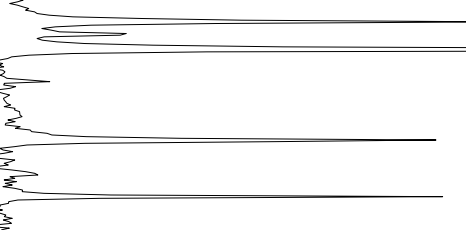

128.659

128.572

128.466

128.138

128.067

127.978

127.805

127.487

127.180

126.604

126.365

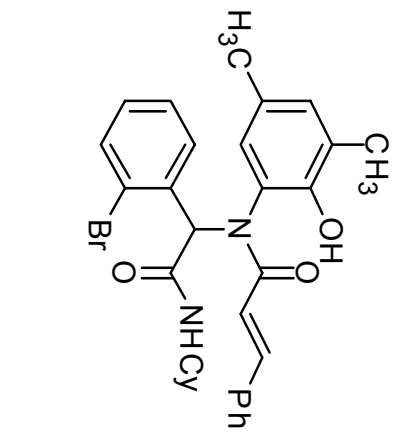

126.012 


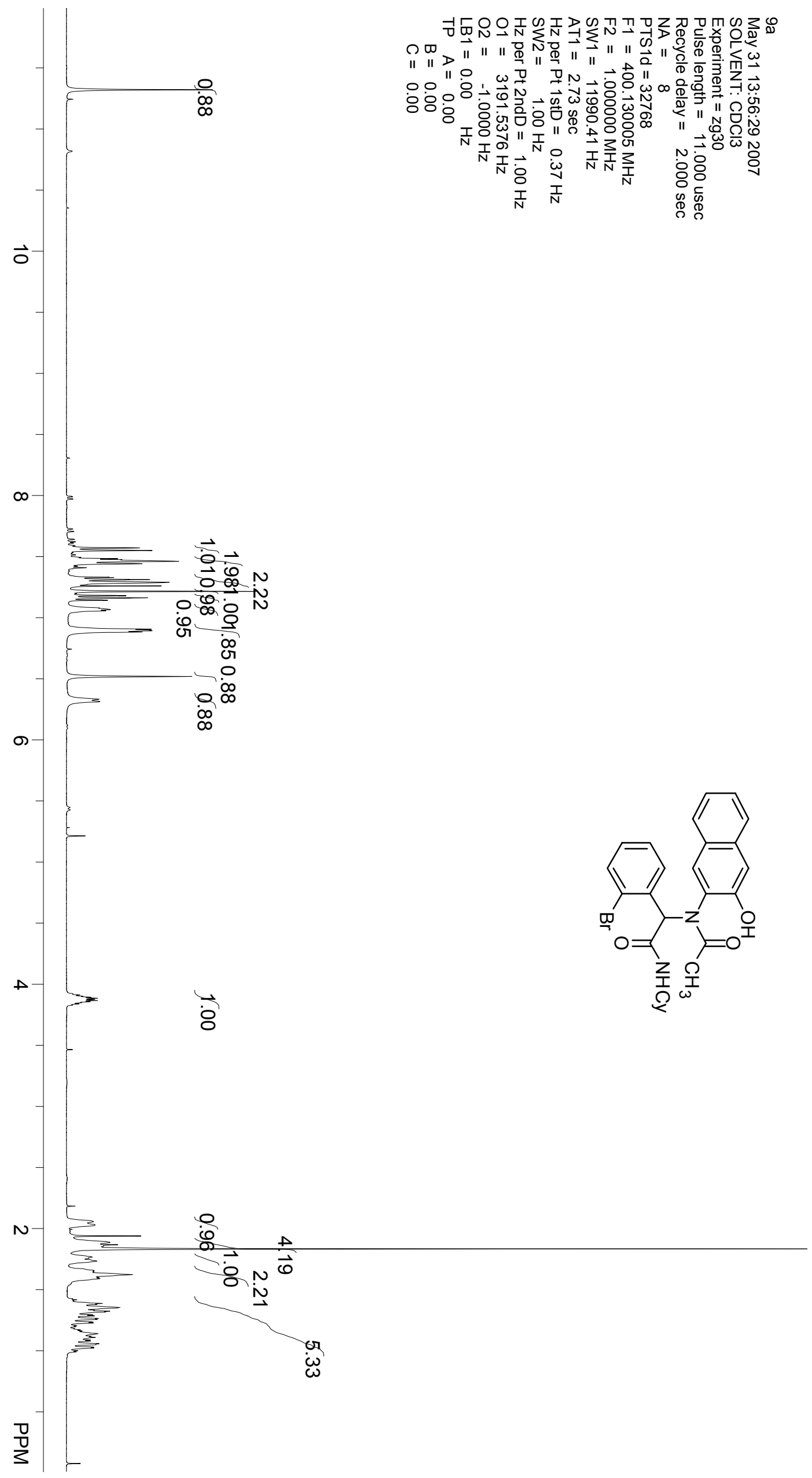




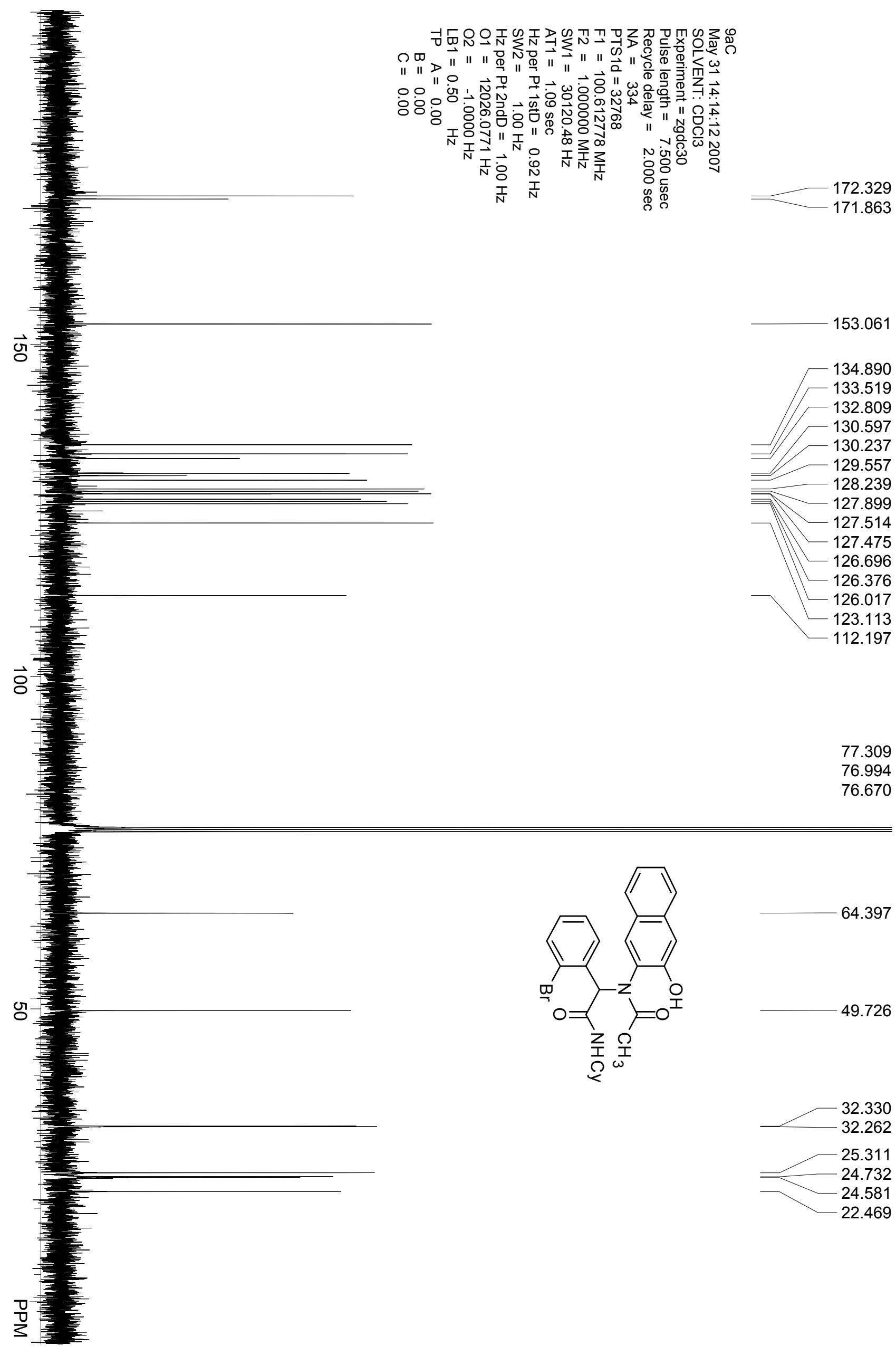



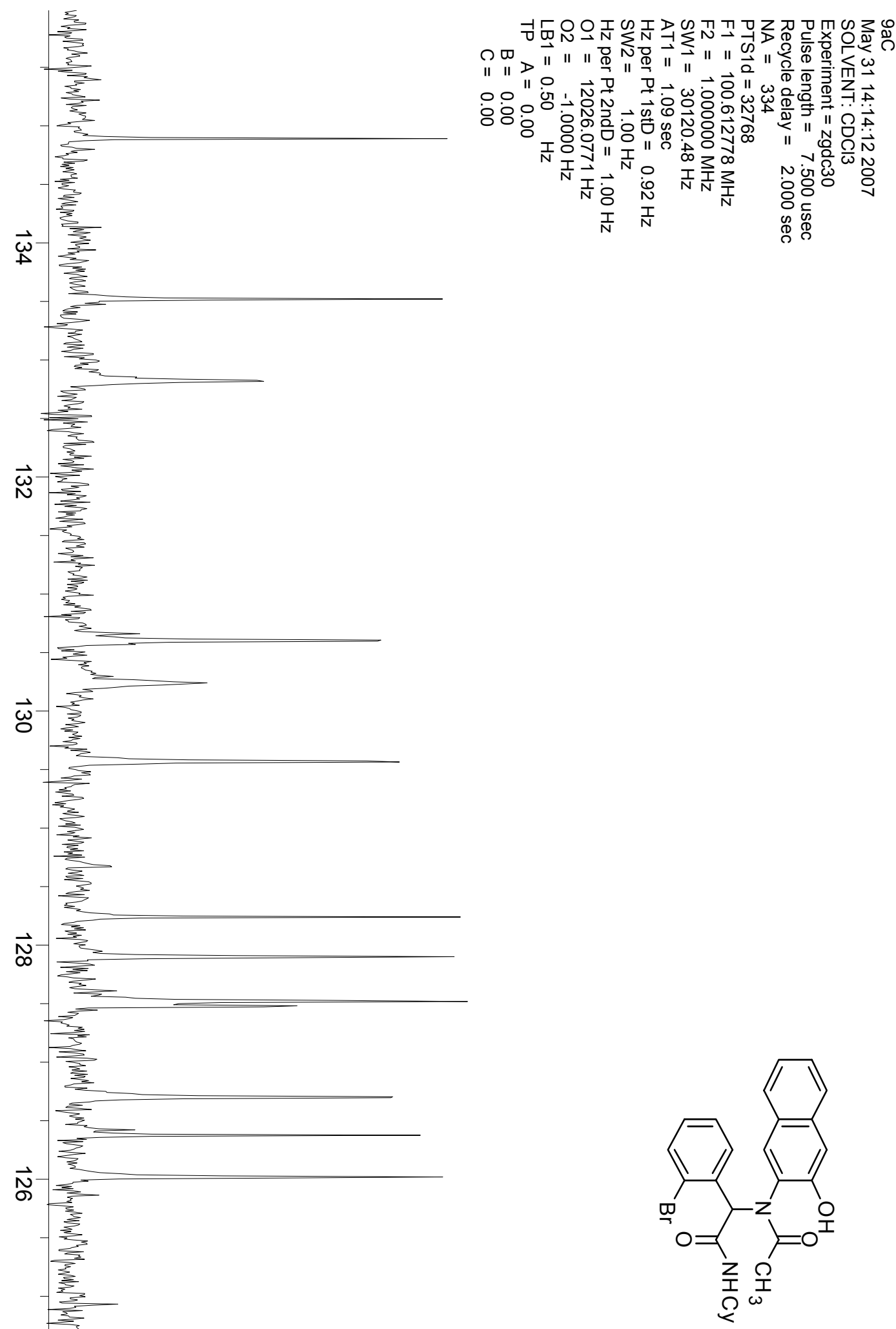

126.696

126.376

N

ह

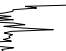

$\vec{N}$

$\vec{\perp}$

泡 


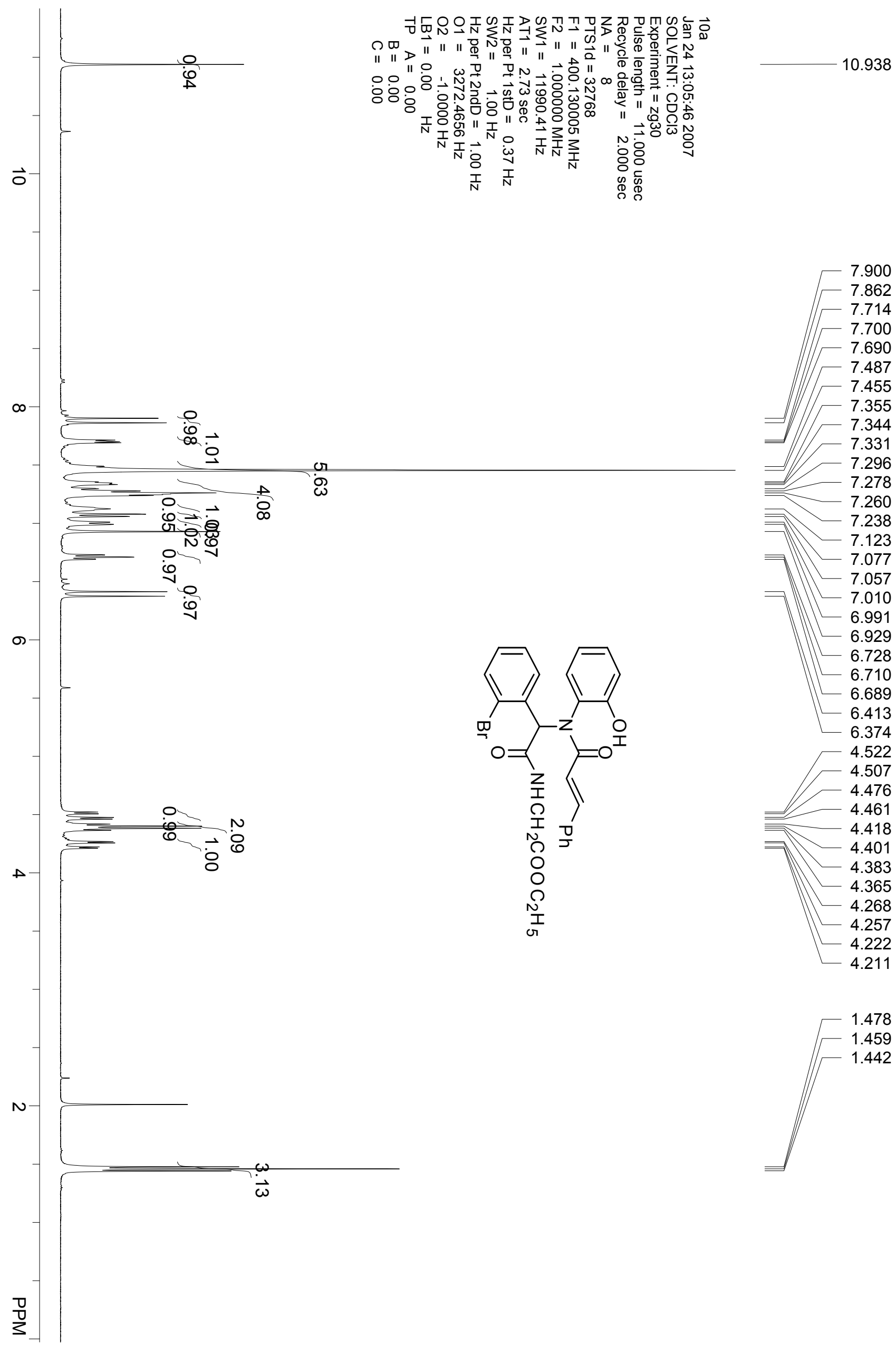



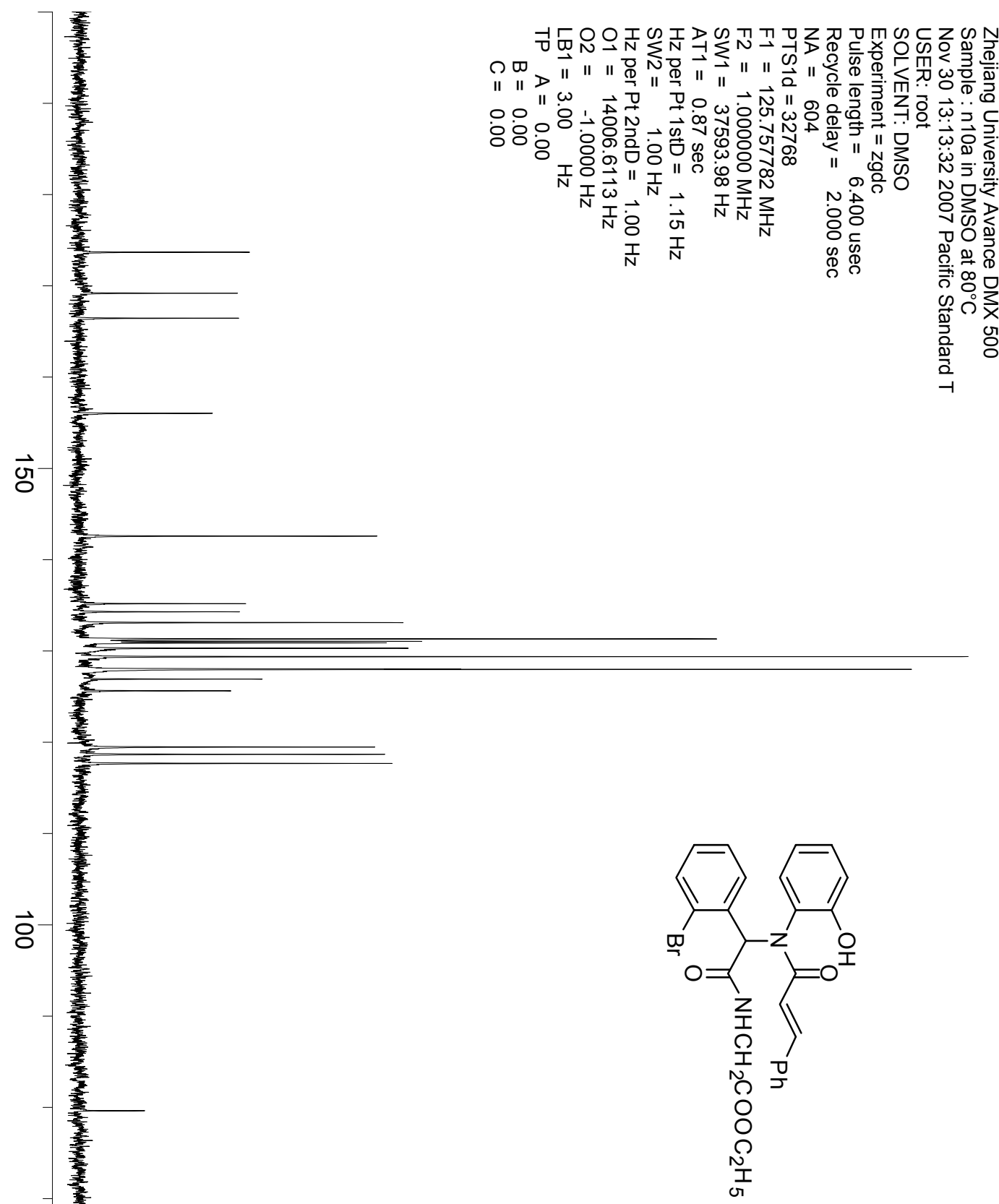

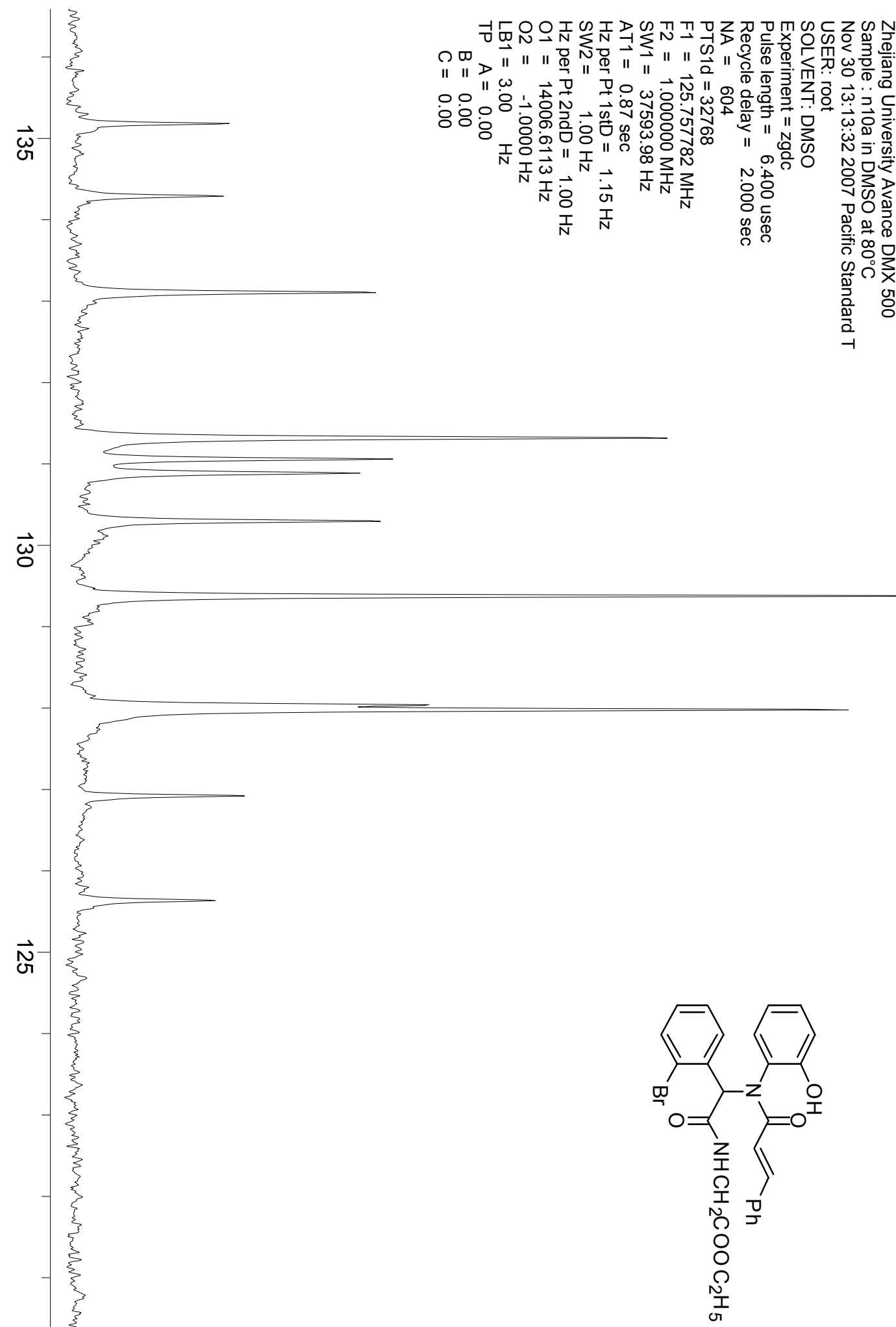


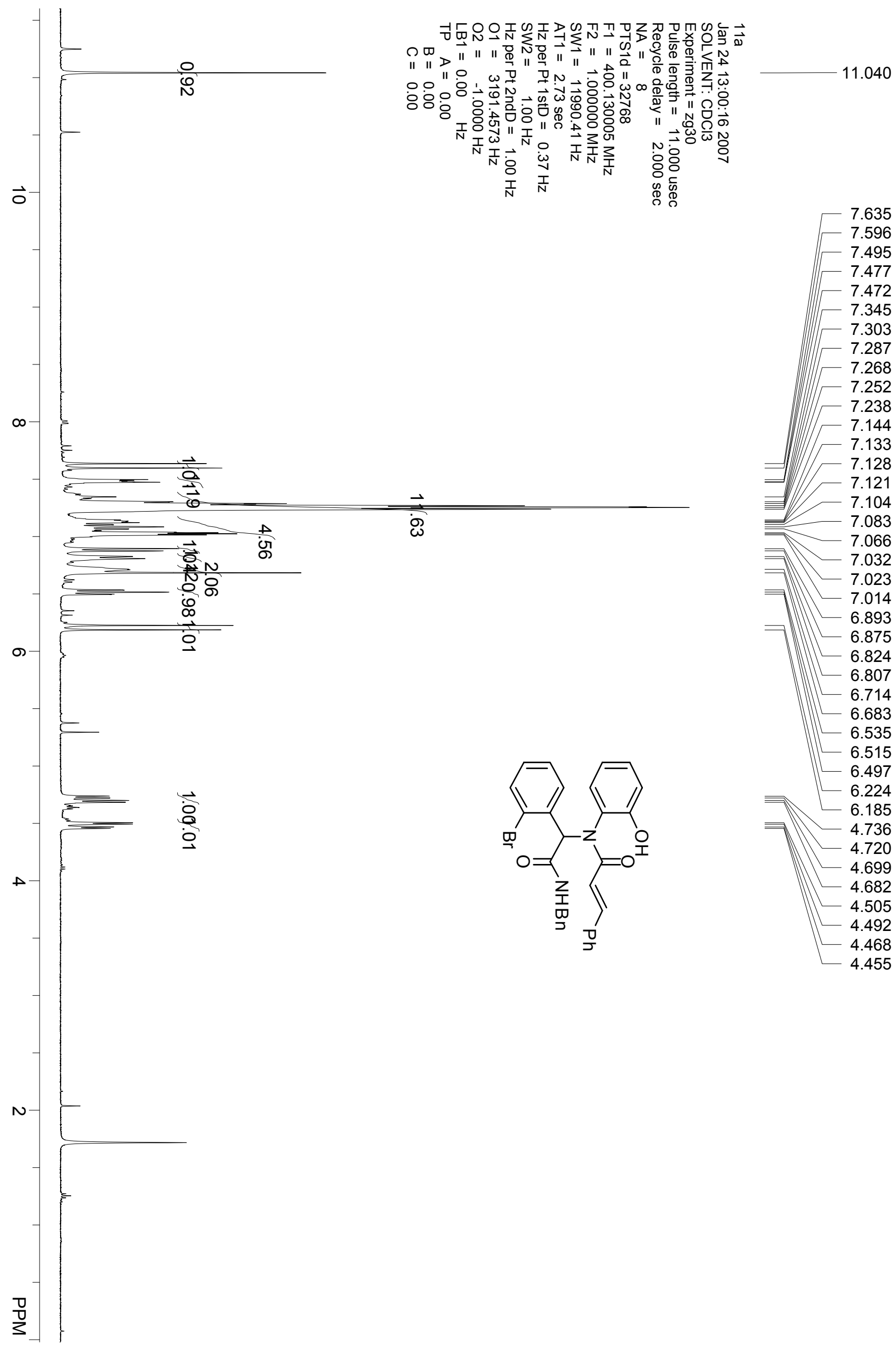




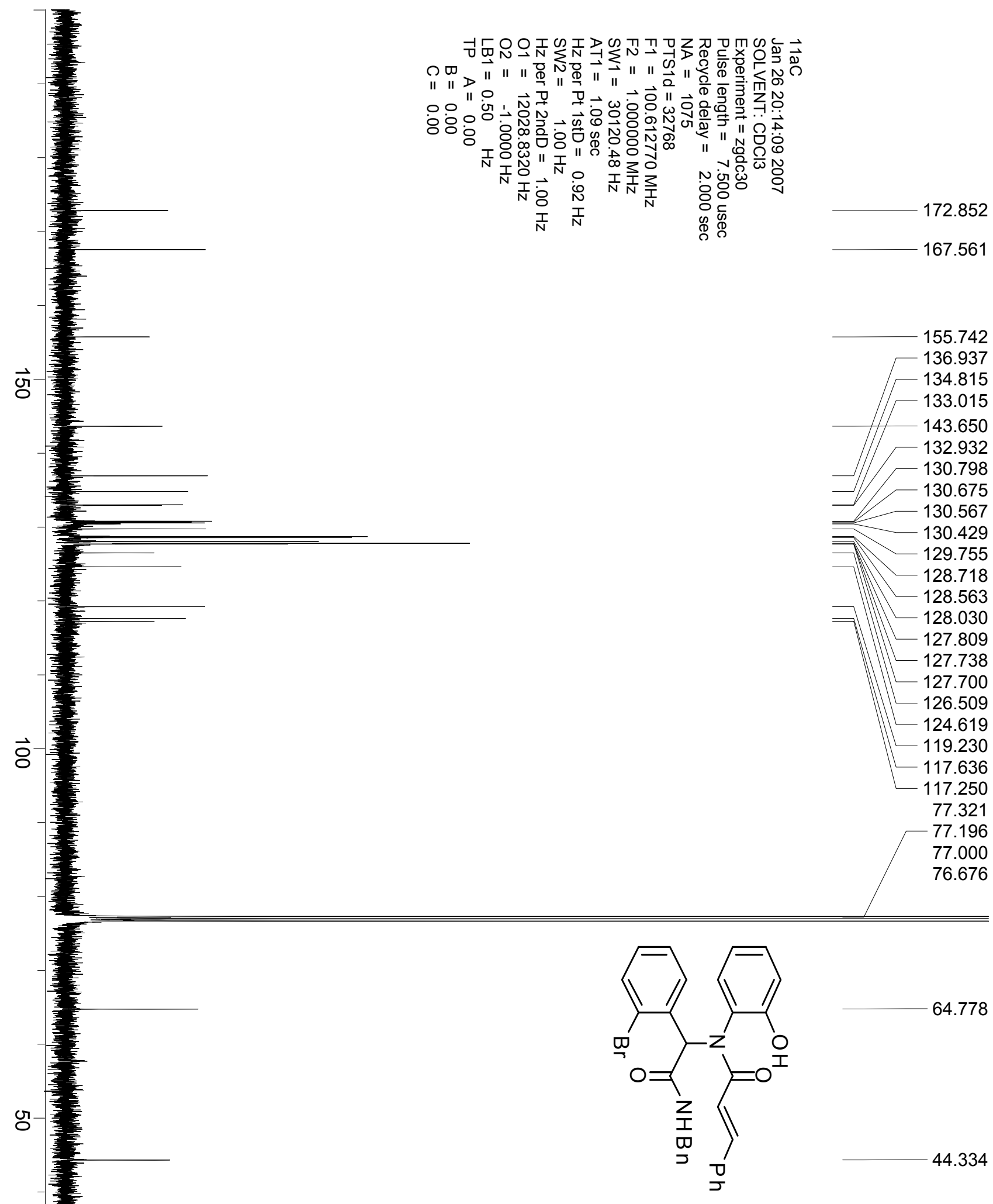



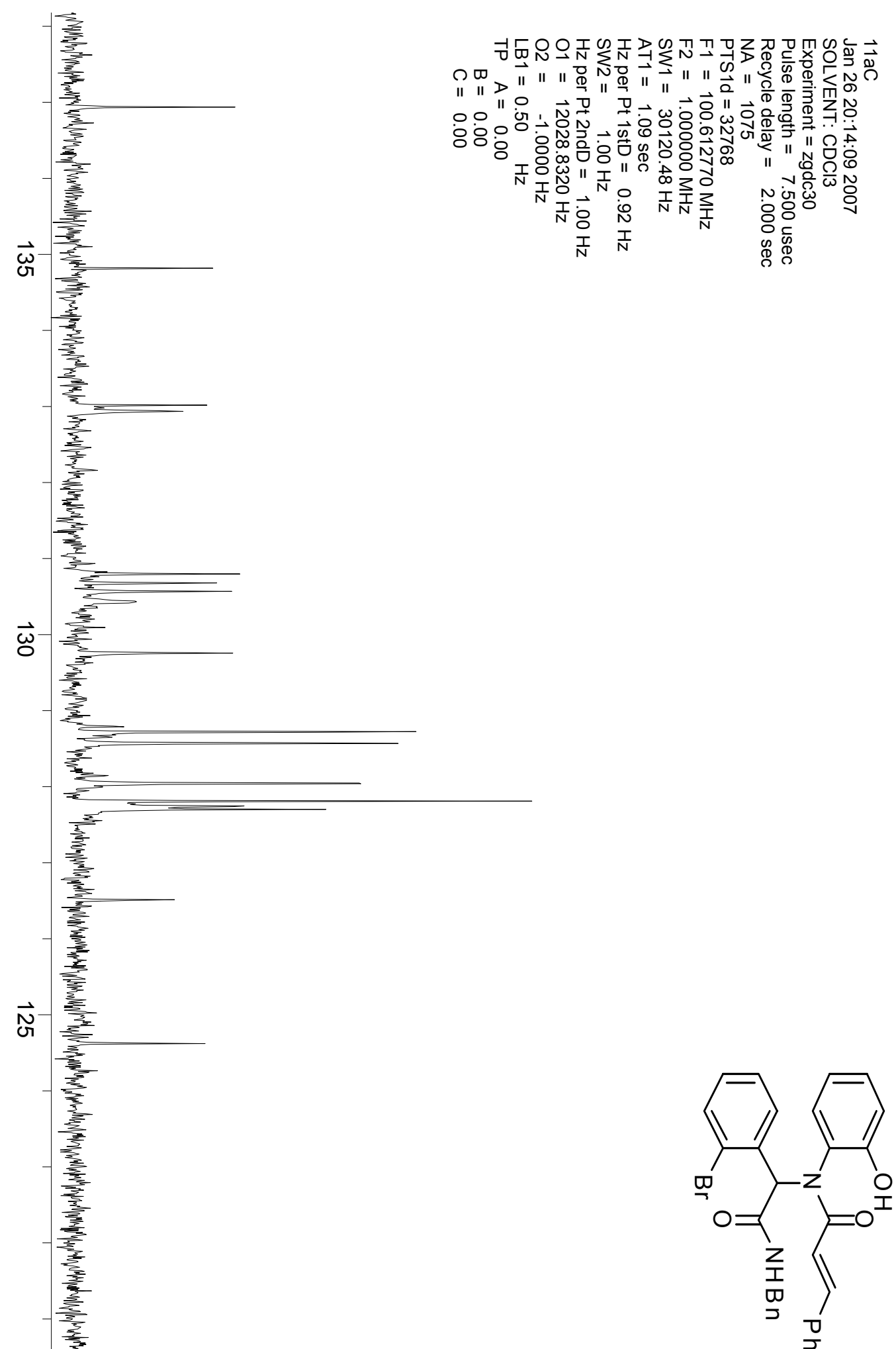


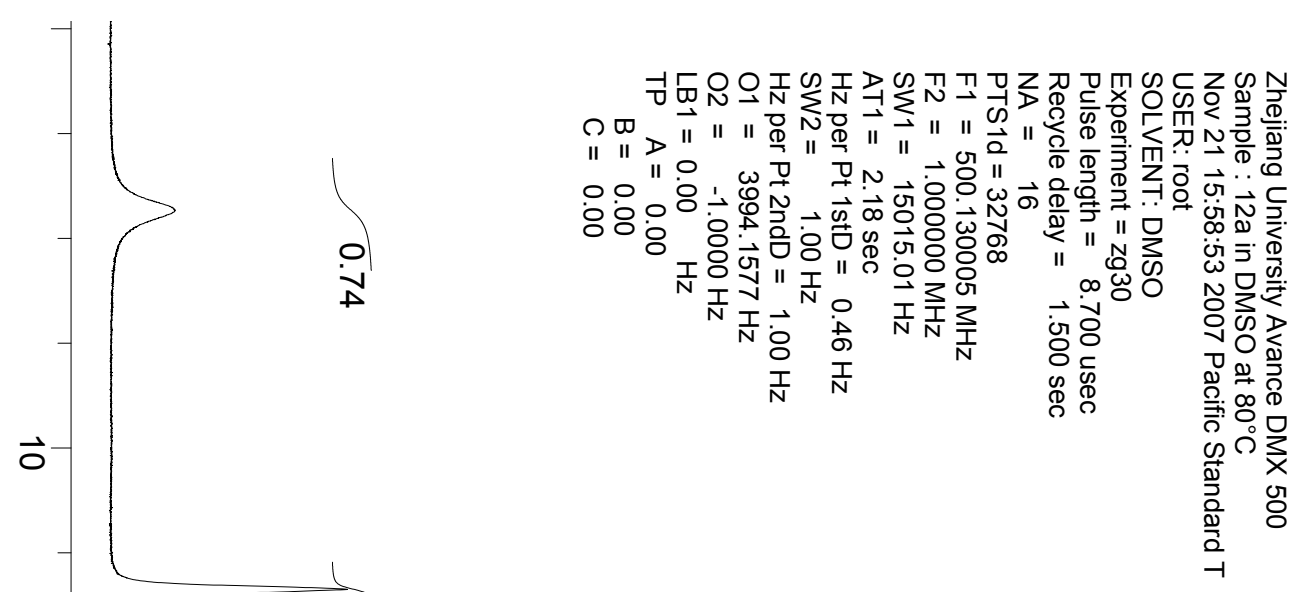

11.133

9.324
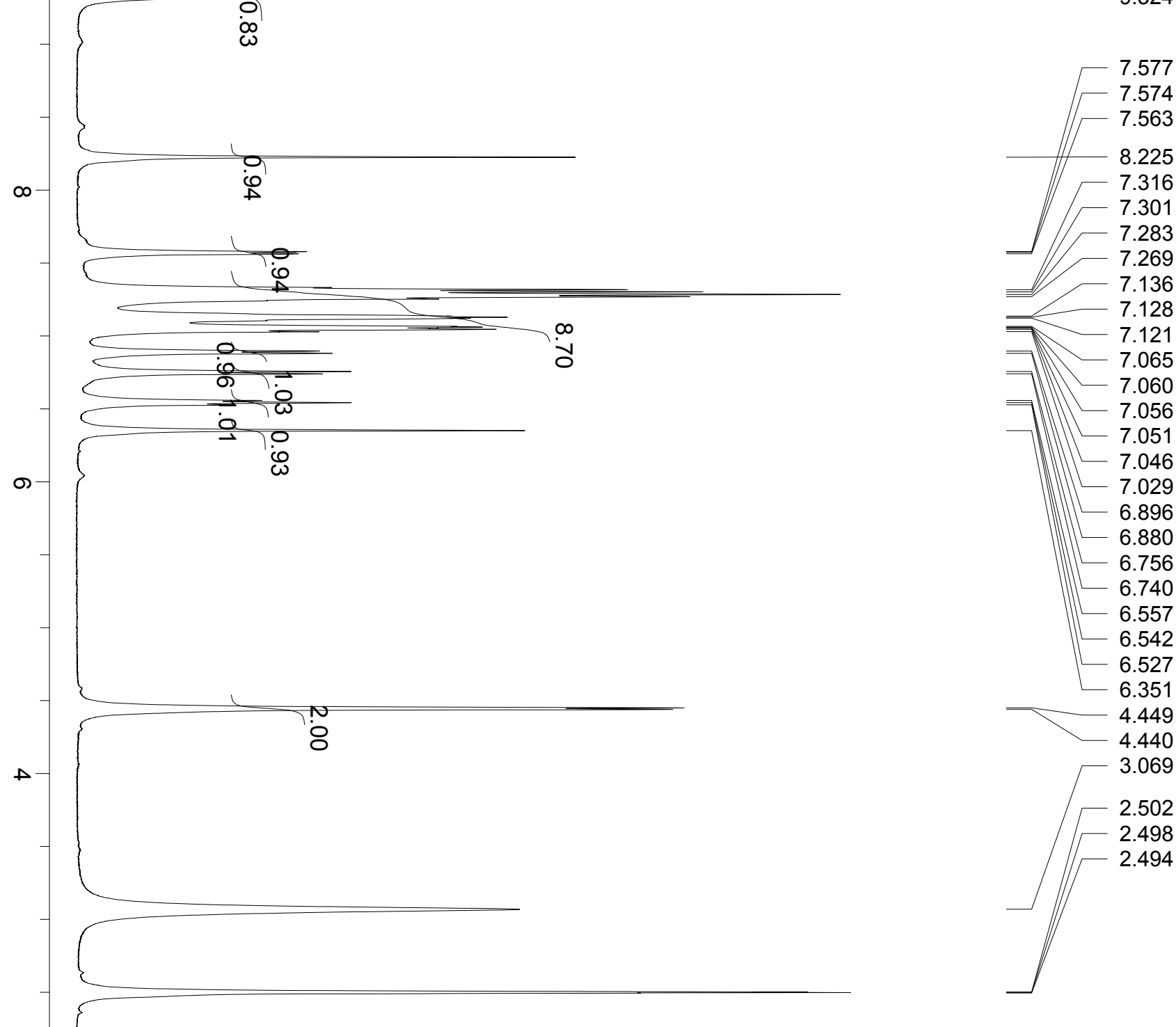

7.269

7.136

$-7.128$

$-7.121$

7.065

$-7.060$

7.056

7.051

7.046

$-7.029$

$-6.896$

6.880

6.756

6.740

$-6.557$

$-6.542$

6.527

6.351

4.449

4.440

3.069

2.502

2.498

2.494

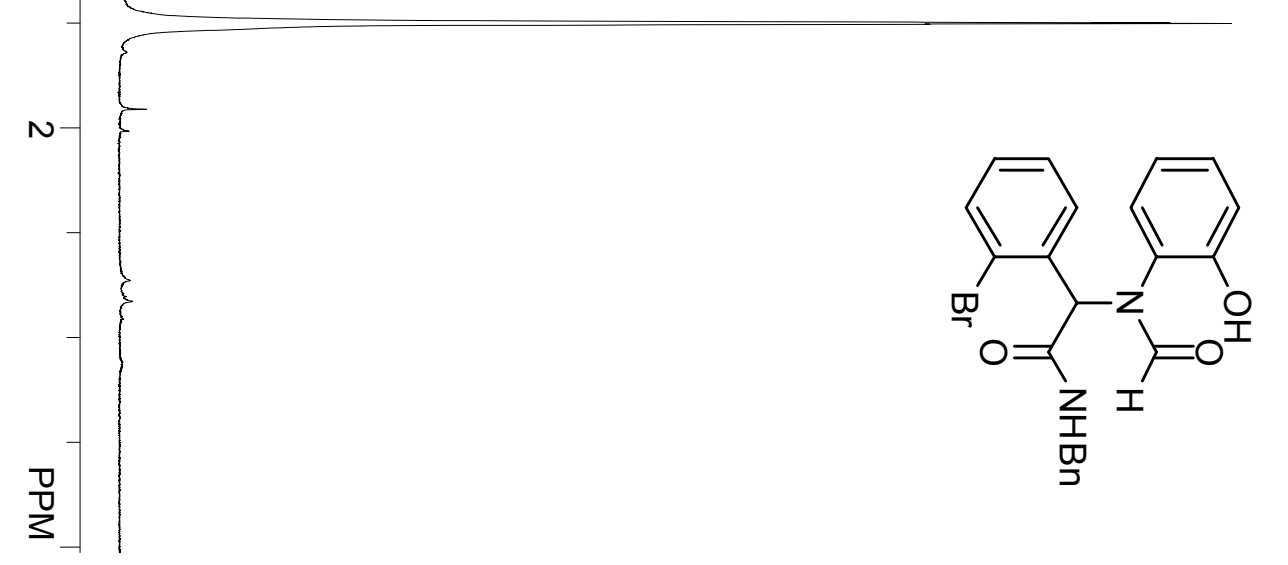



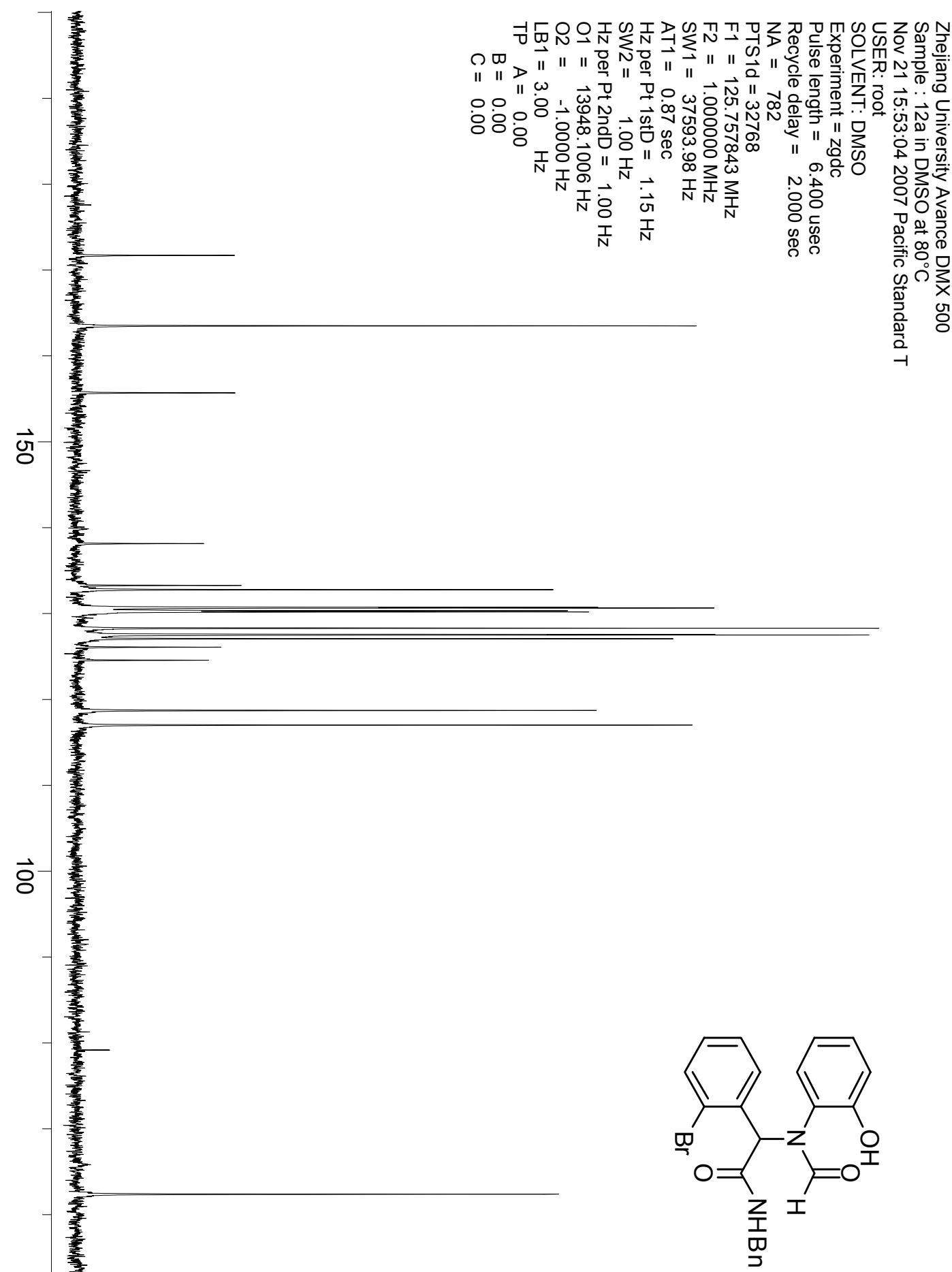


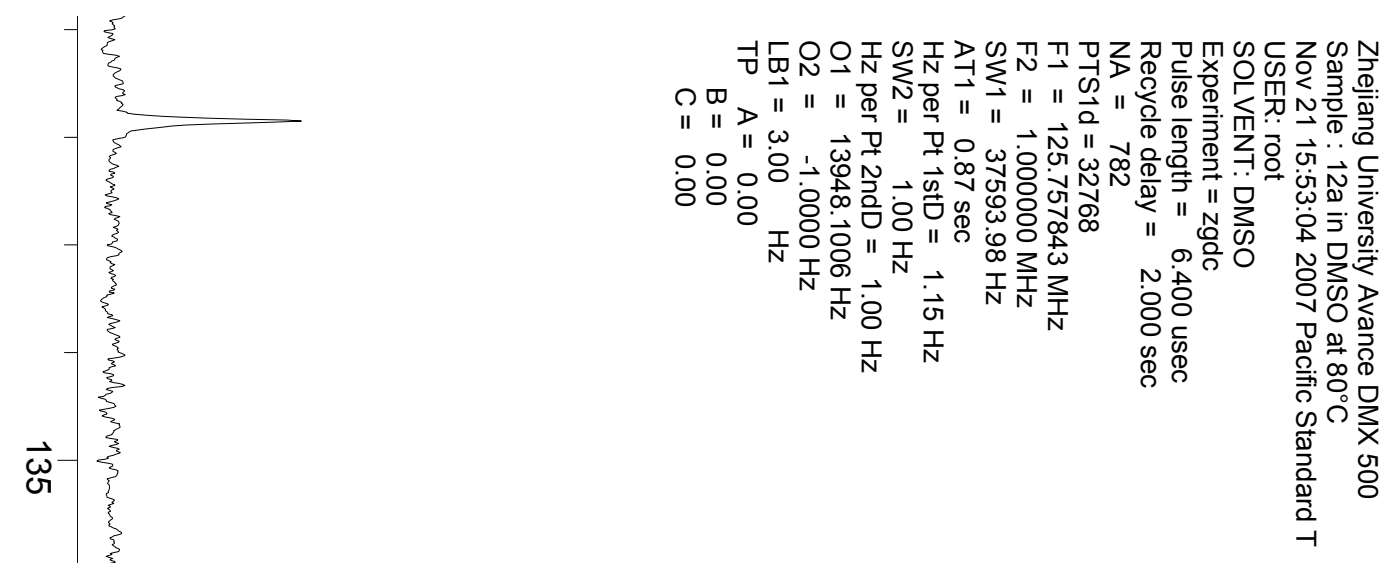

133.273

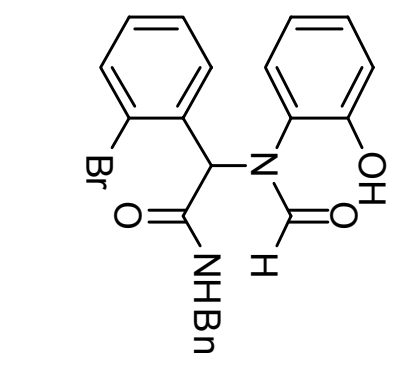

124.560 


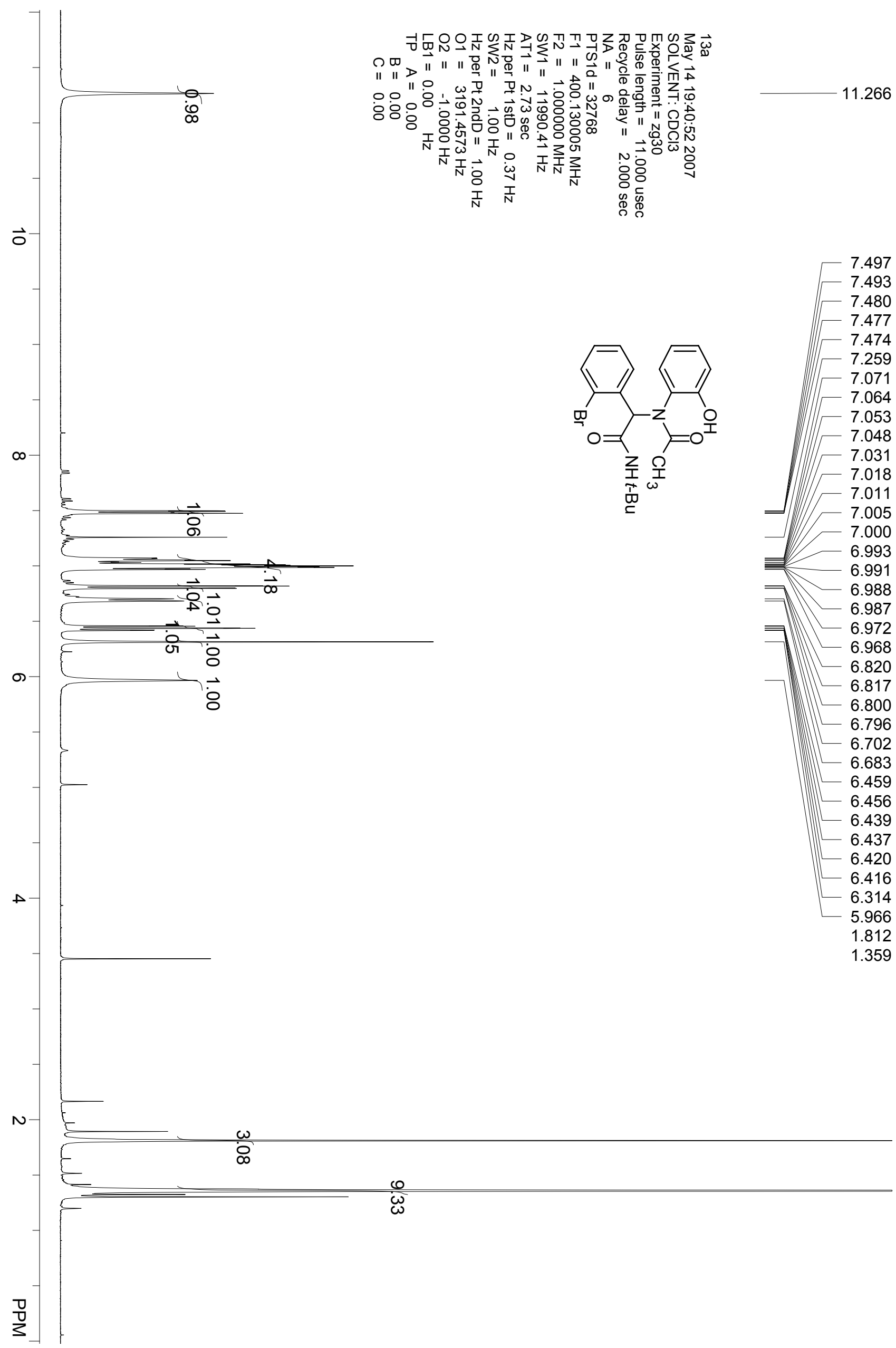



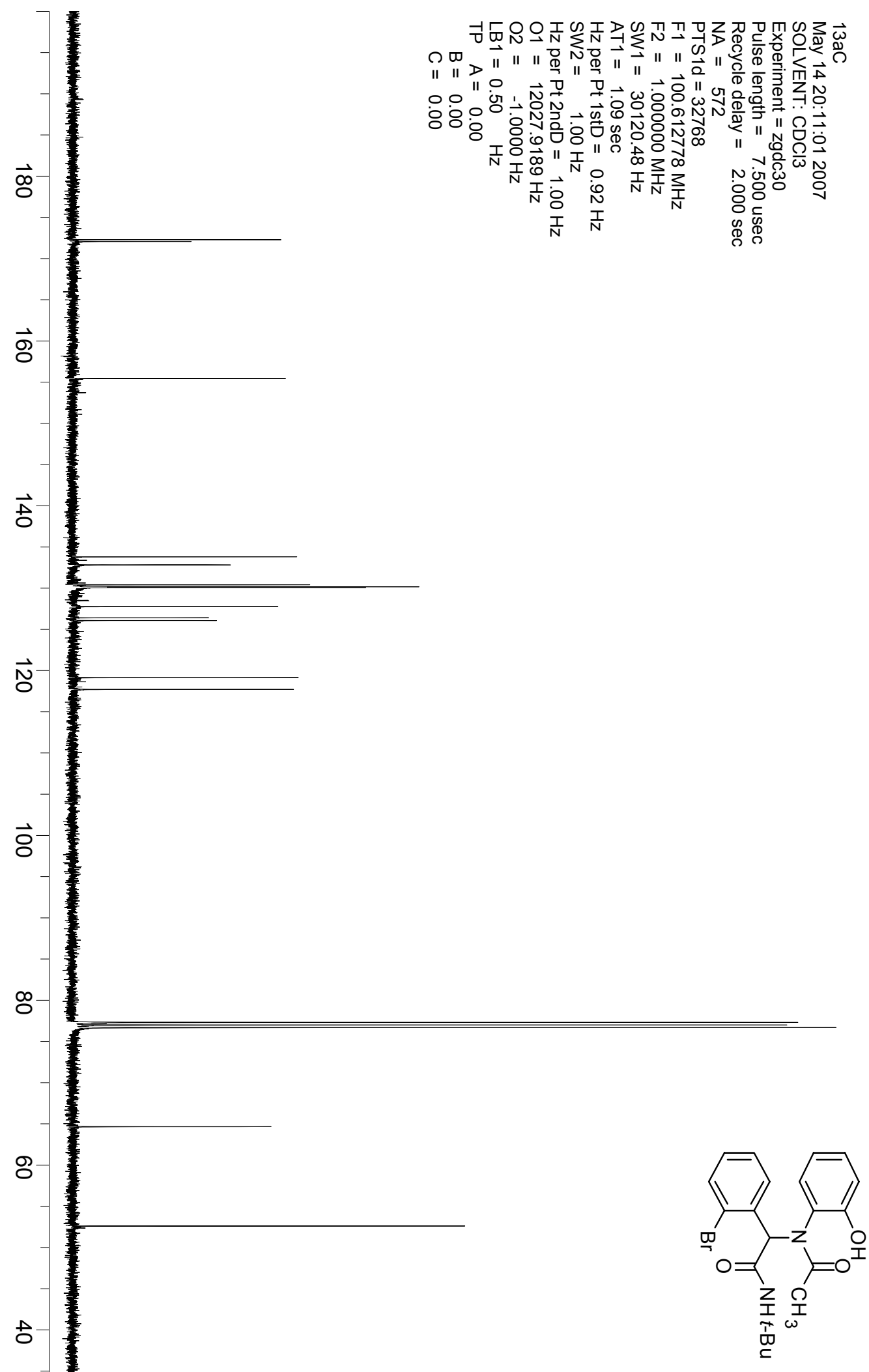

64.654 

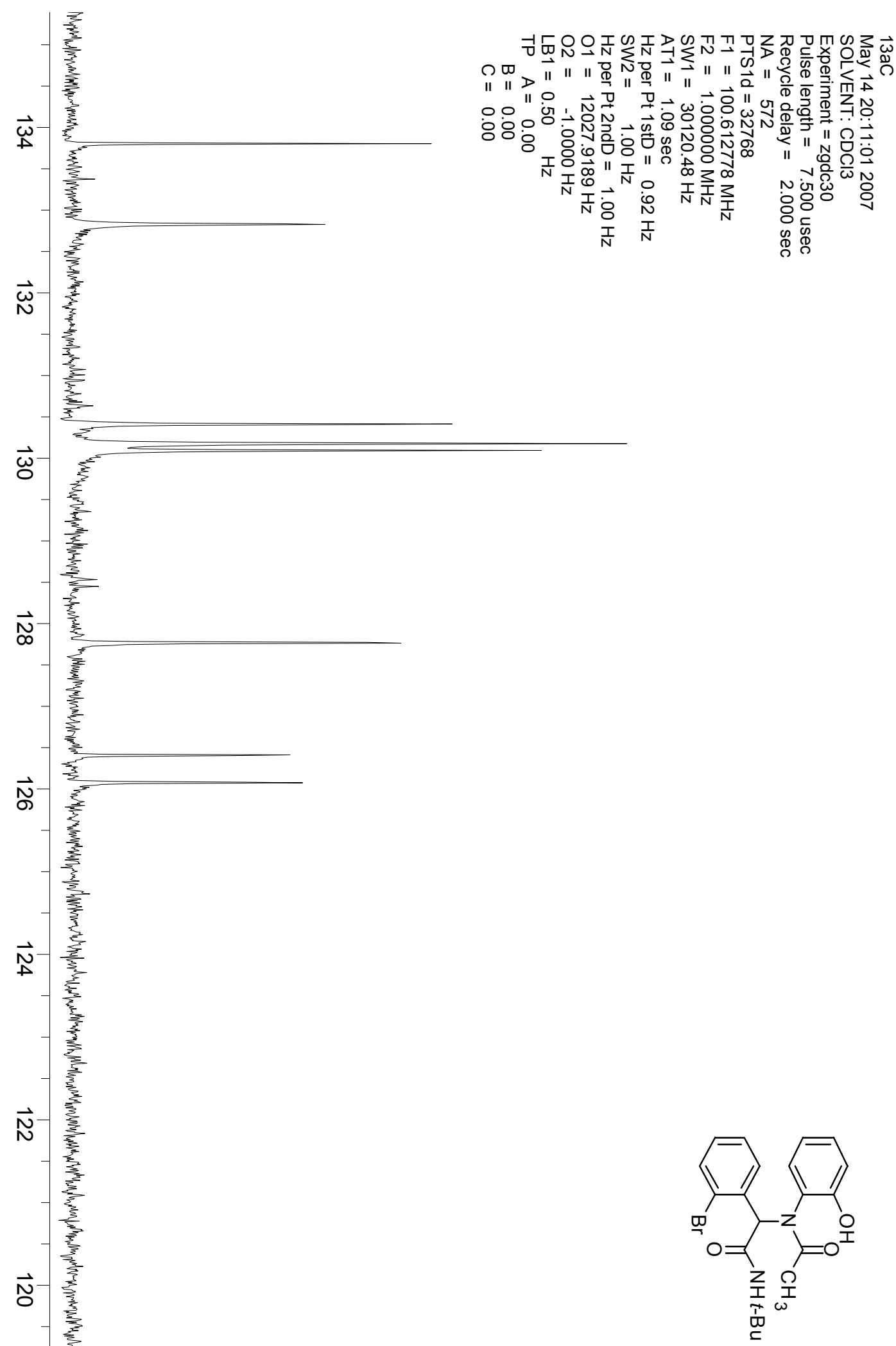


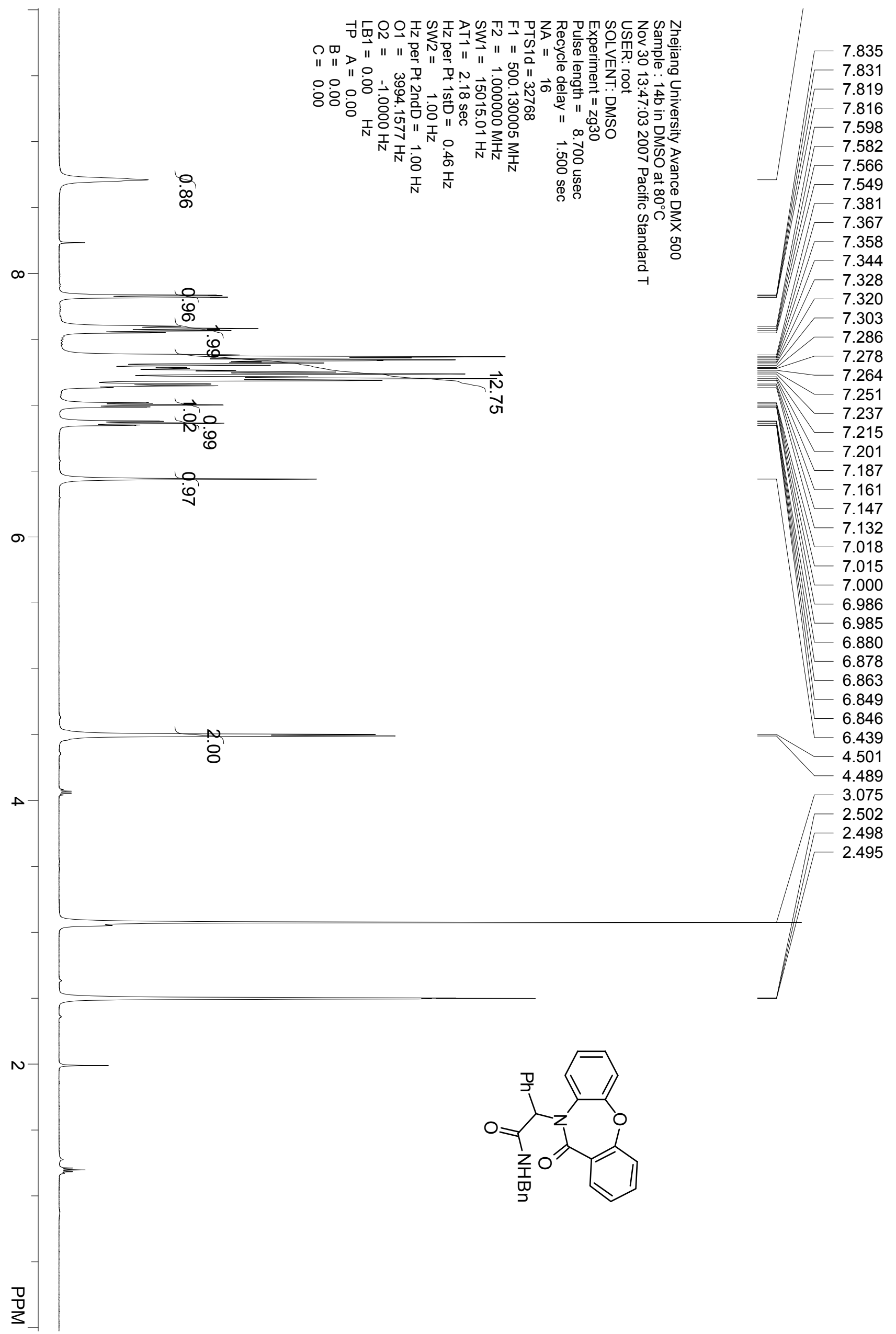




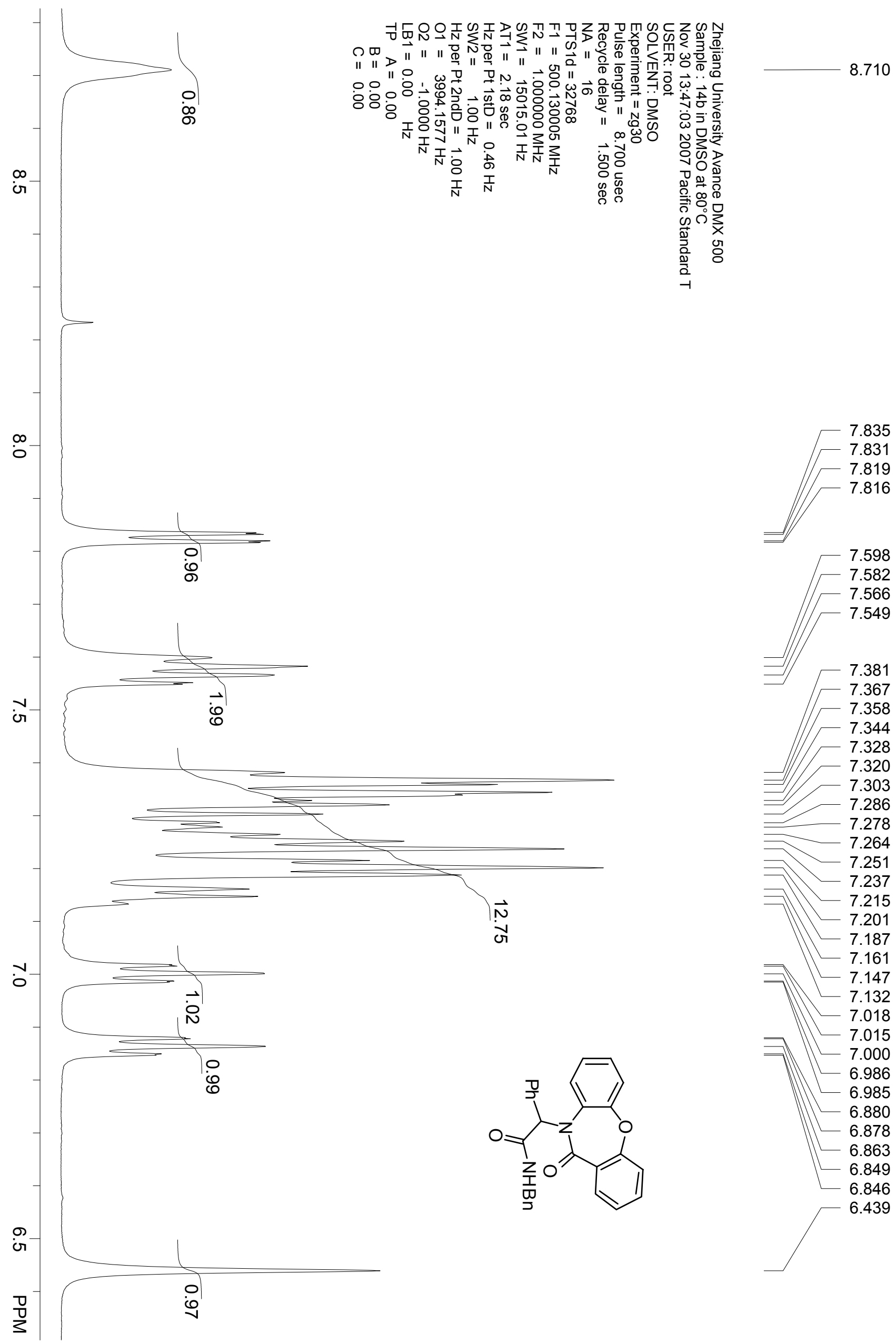




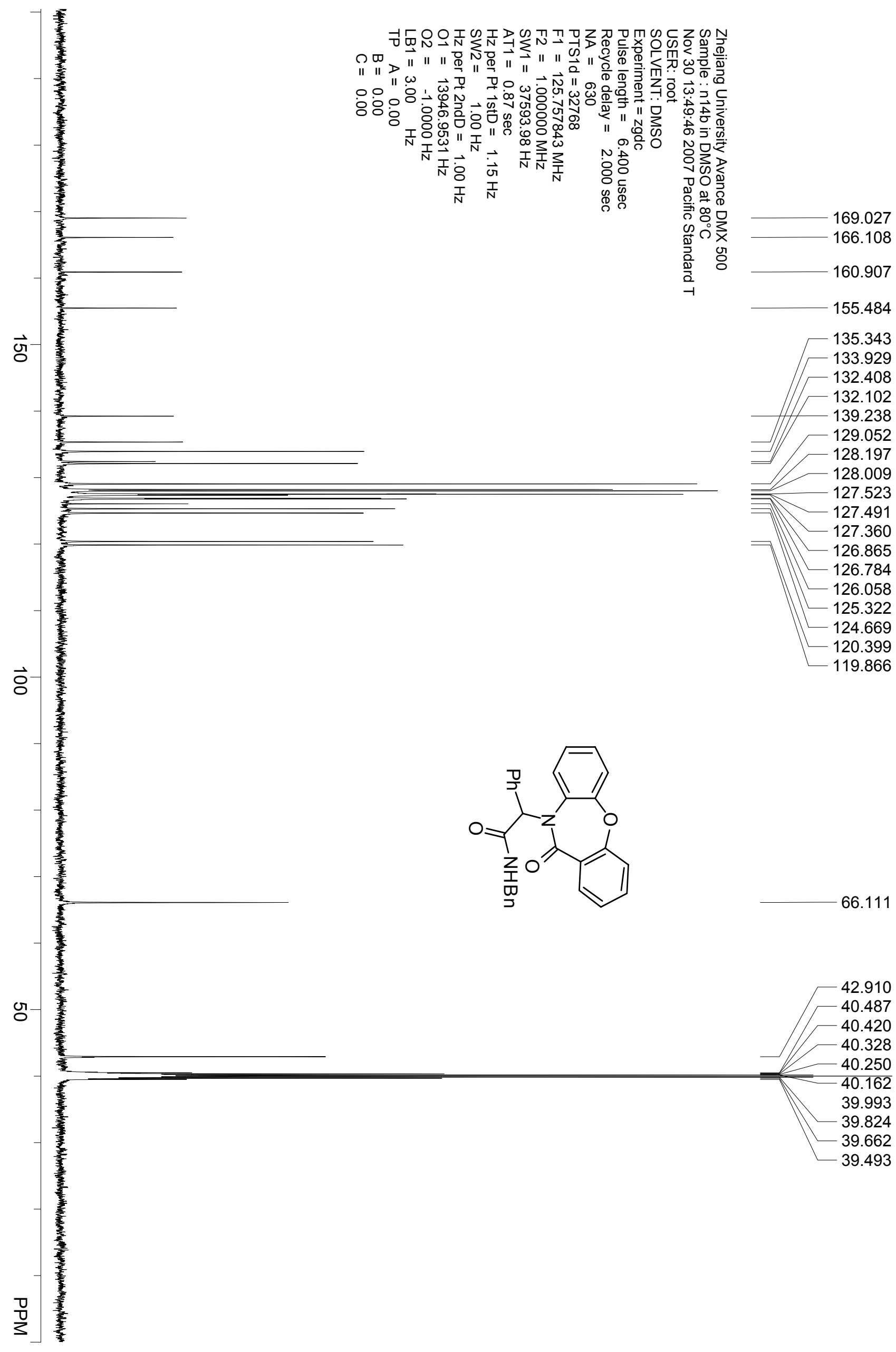




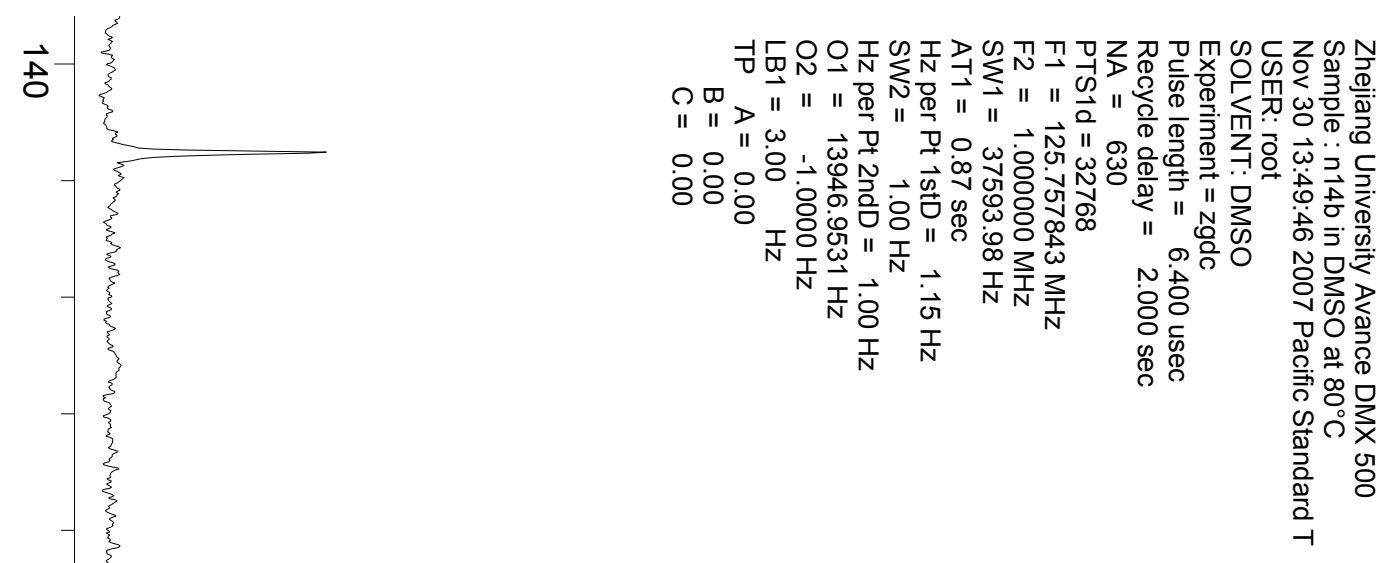

$\vec{\omega}$

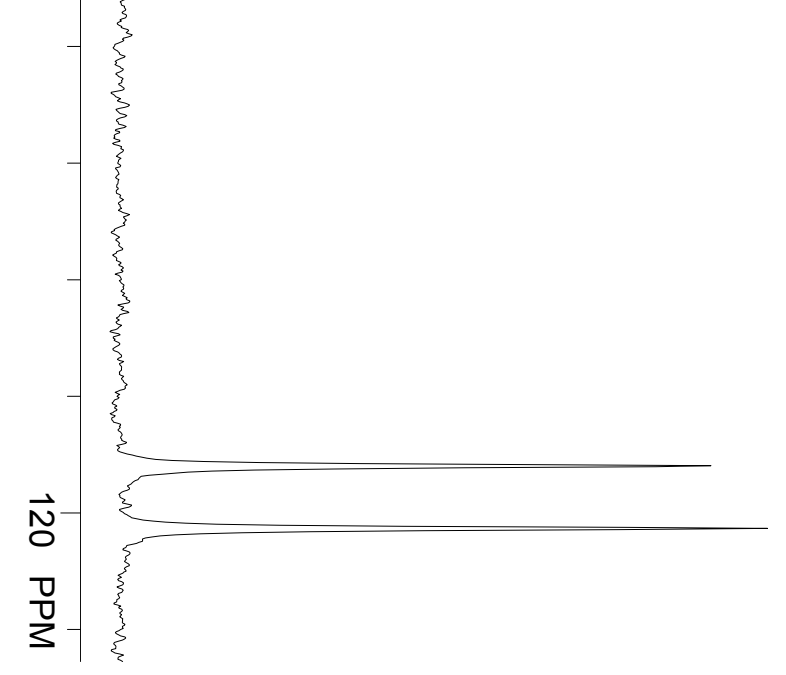

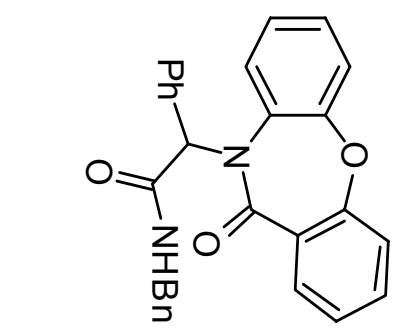




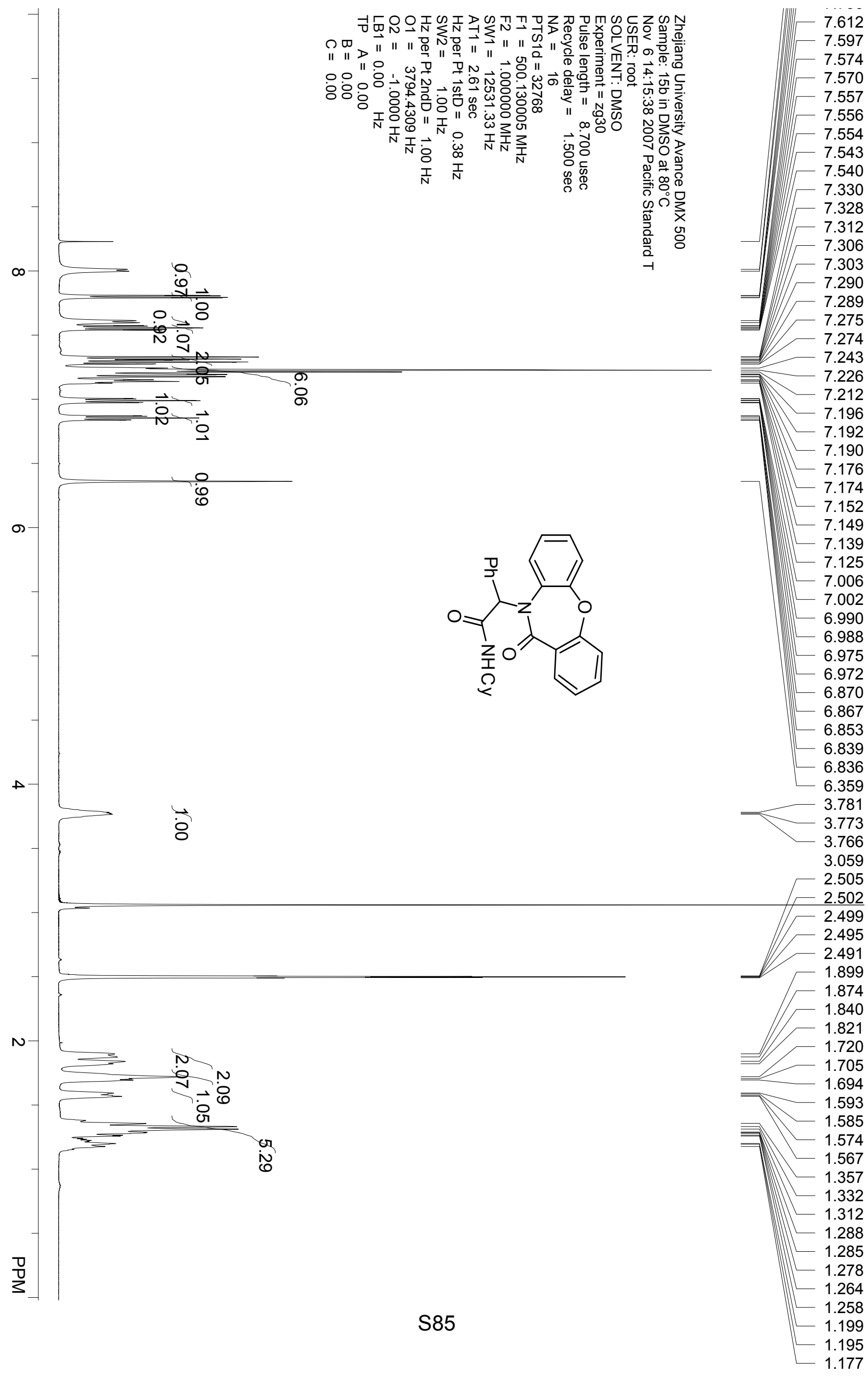




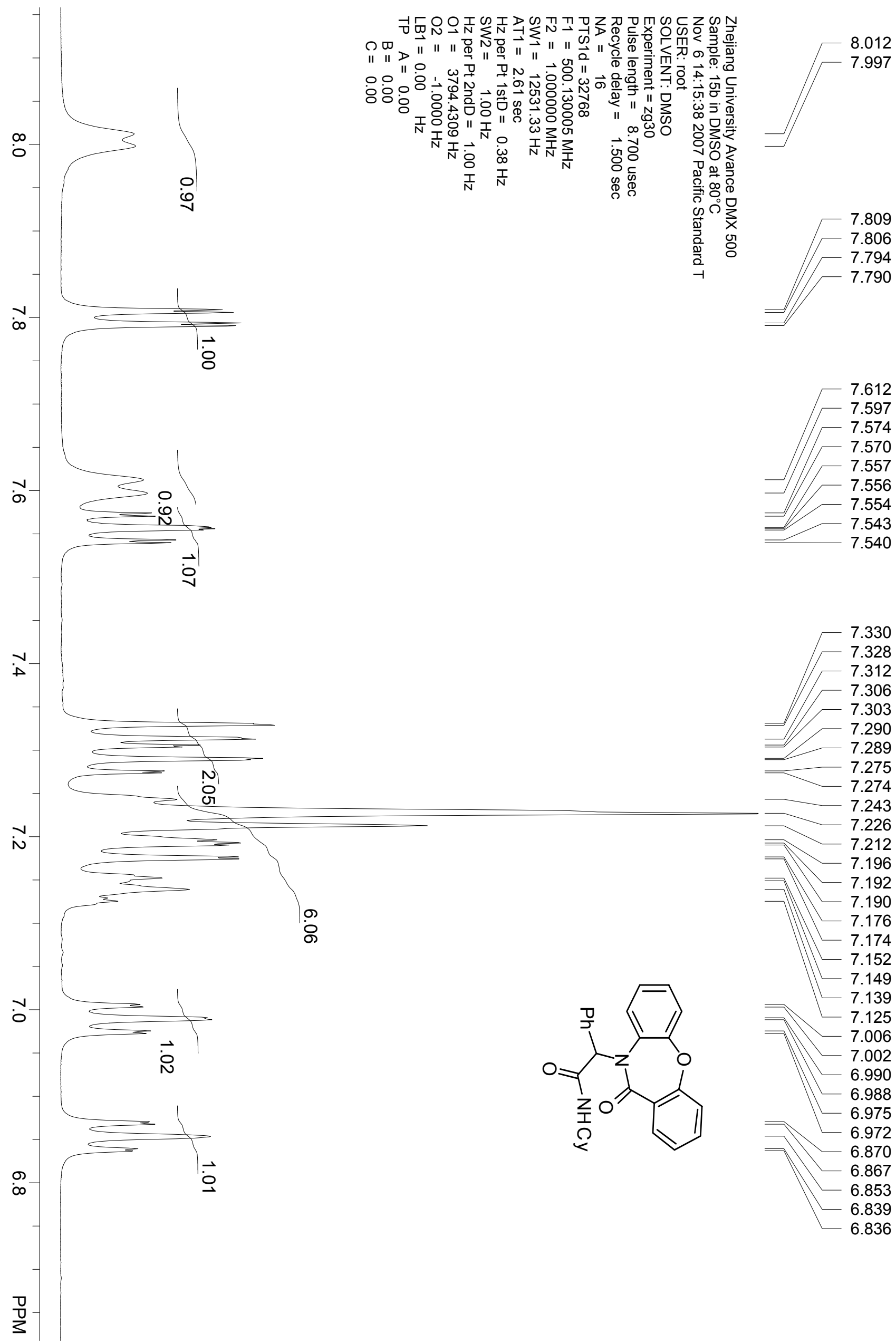




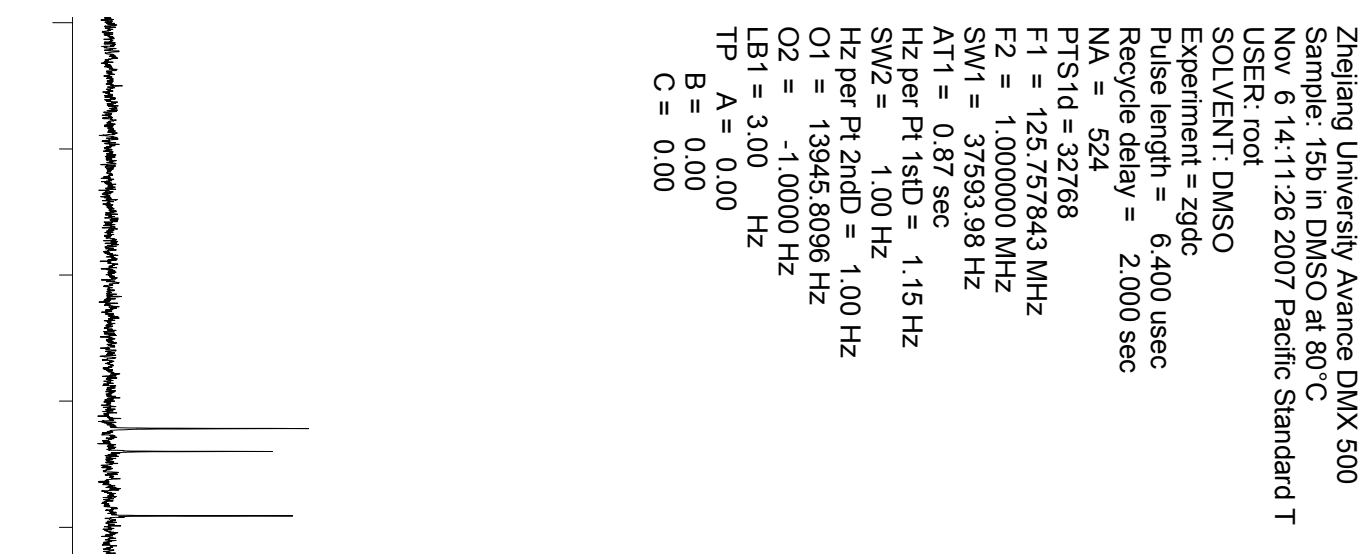

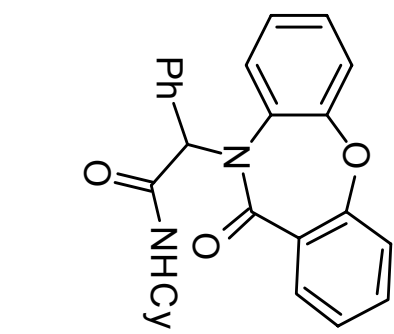




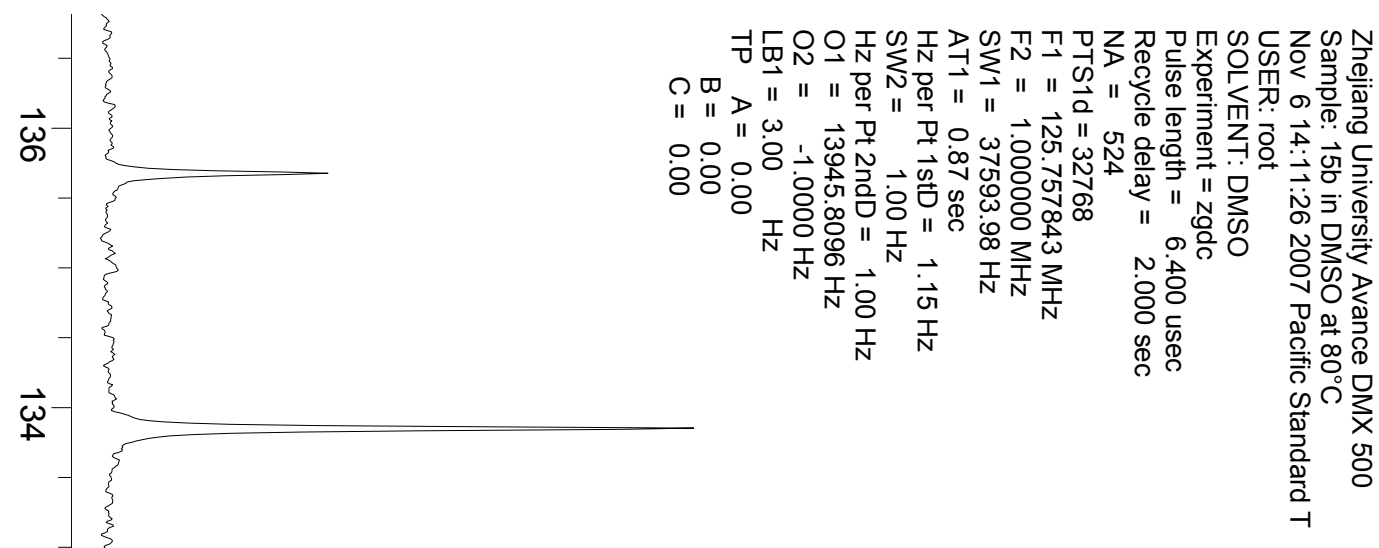

$\vec{\omega}$

$\vec{\omega}$

$\vec{N}$

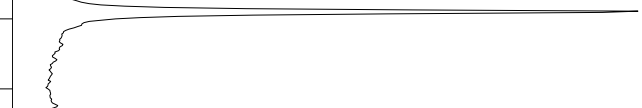

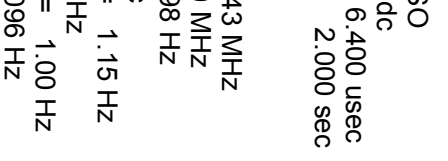

0
0
0
0
0

128.855

127.972

127.412

127.351

126.784

126.108

125.294

124.594<smiles>COC(=O)C(=O)C([Hg])C(=O)O</smiles>

$\overrightarrow{\mathrm{N}}$ 


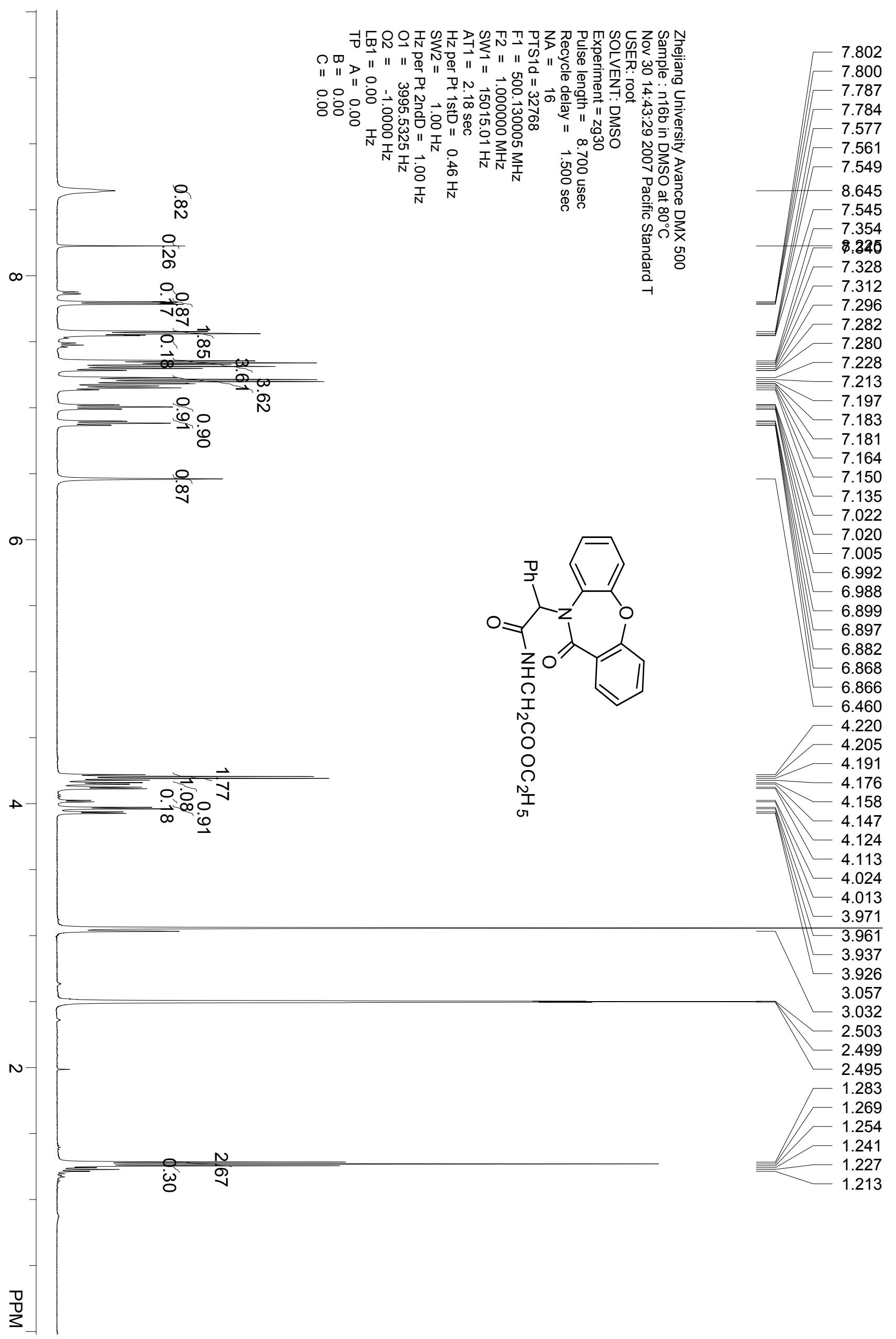




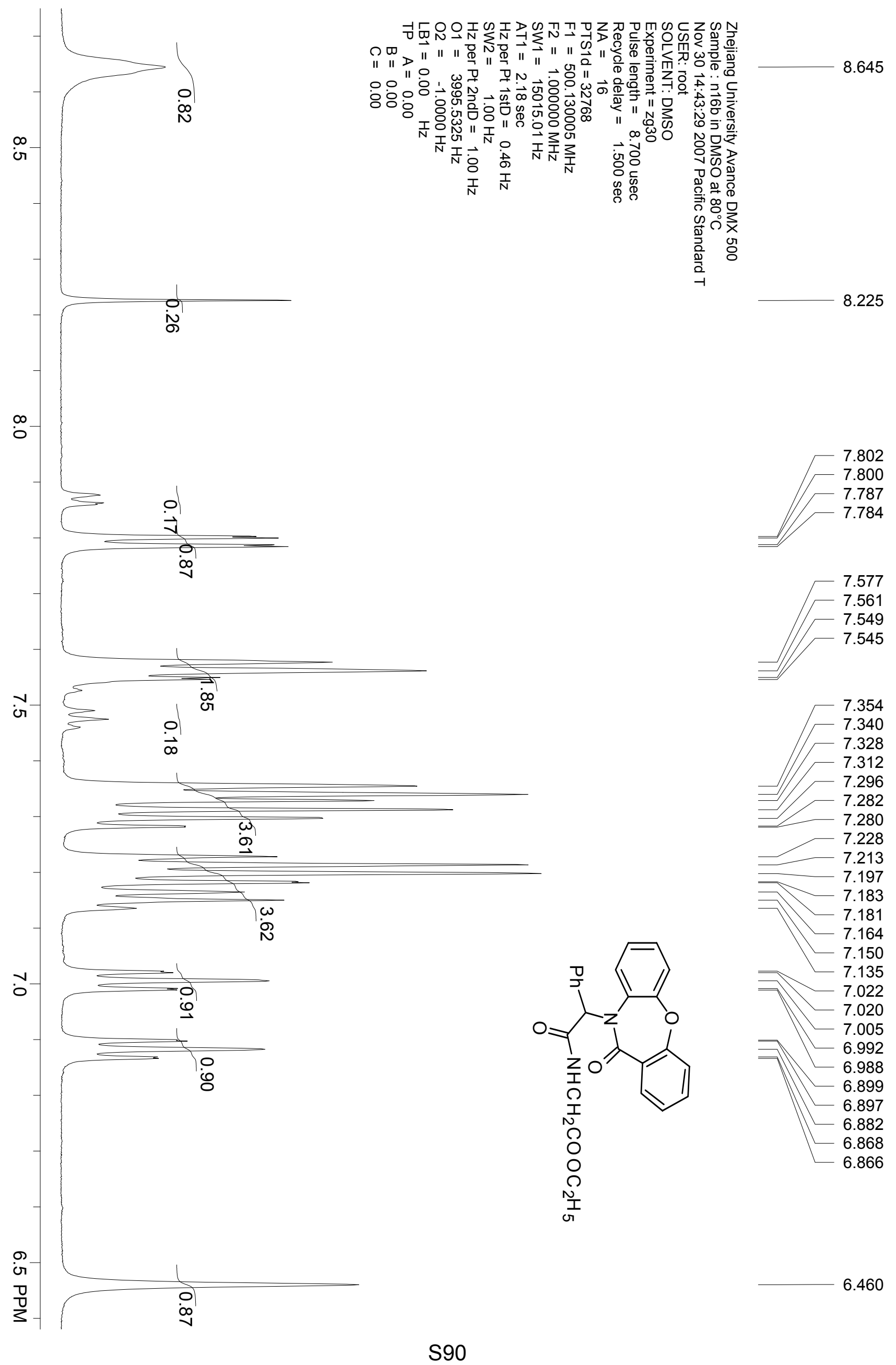



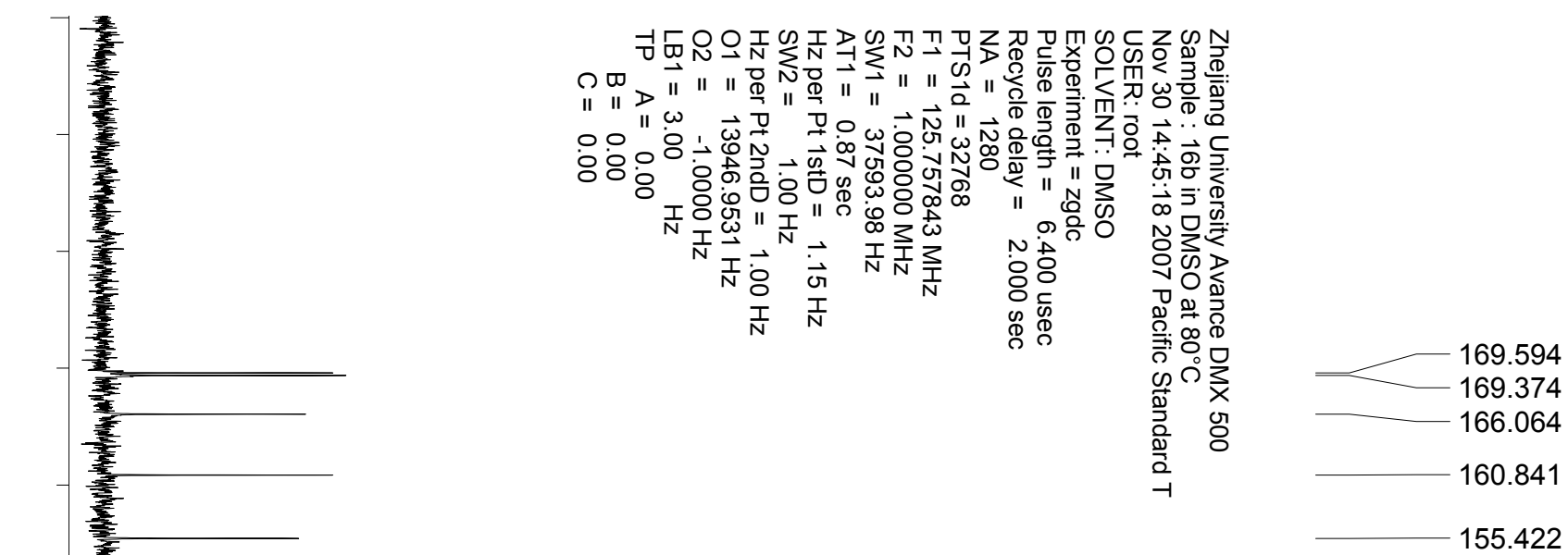

जे

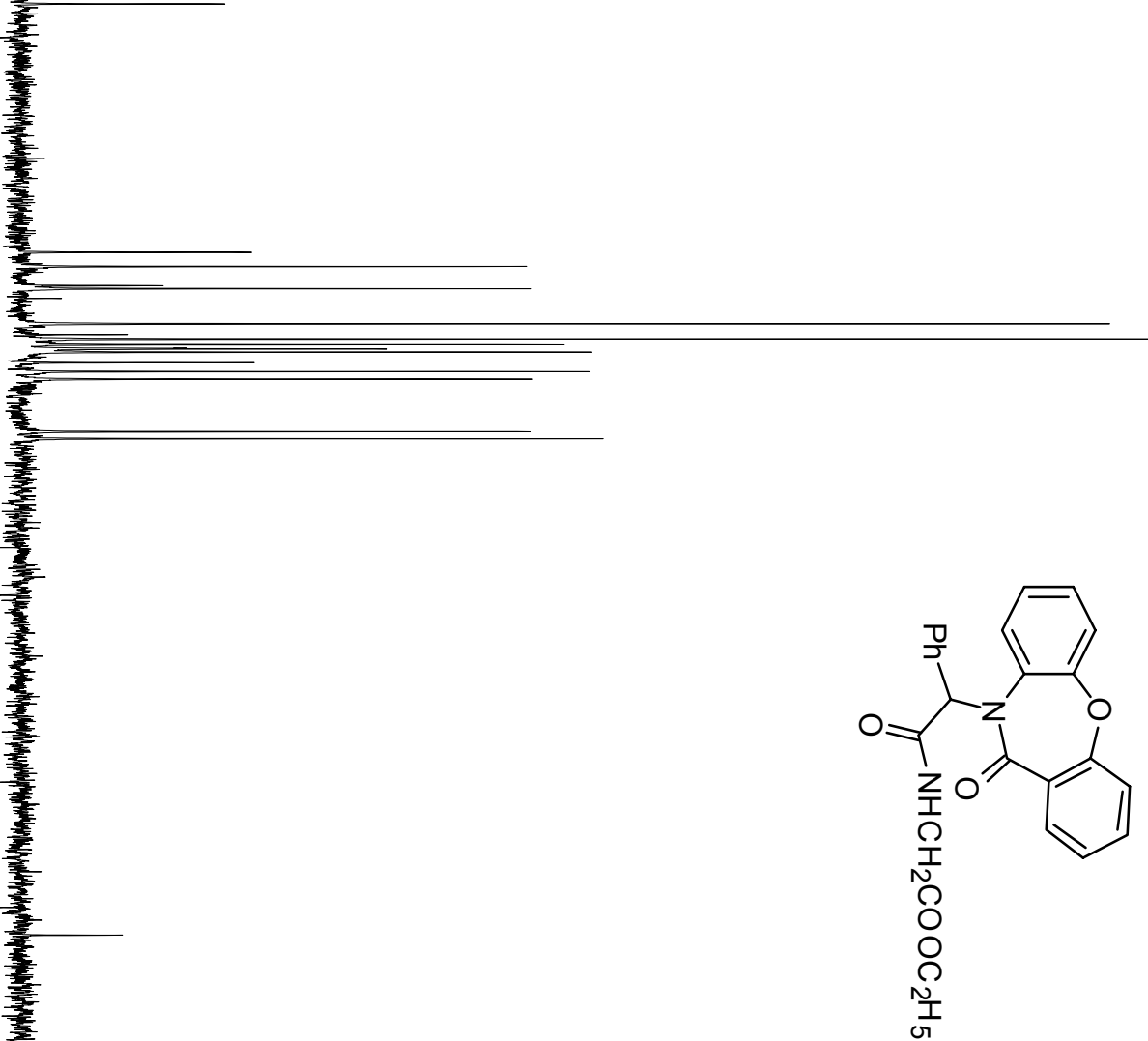

135.079

133.928

132.363

132.101

129.232

127.938

127.525

127.176

$-126.916$

126.038

125.321

124.711

120.397

119.839

$\overrightarrow{8}$ 


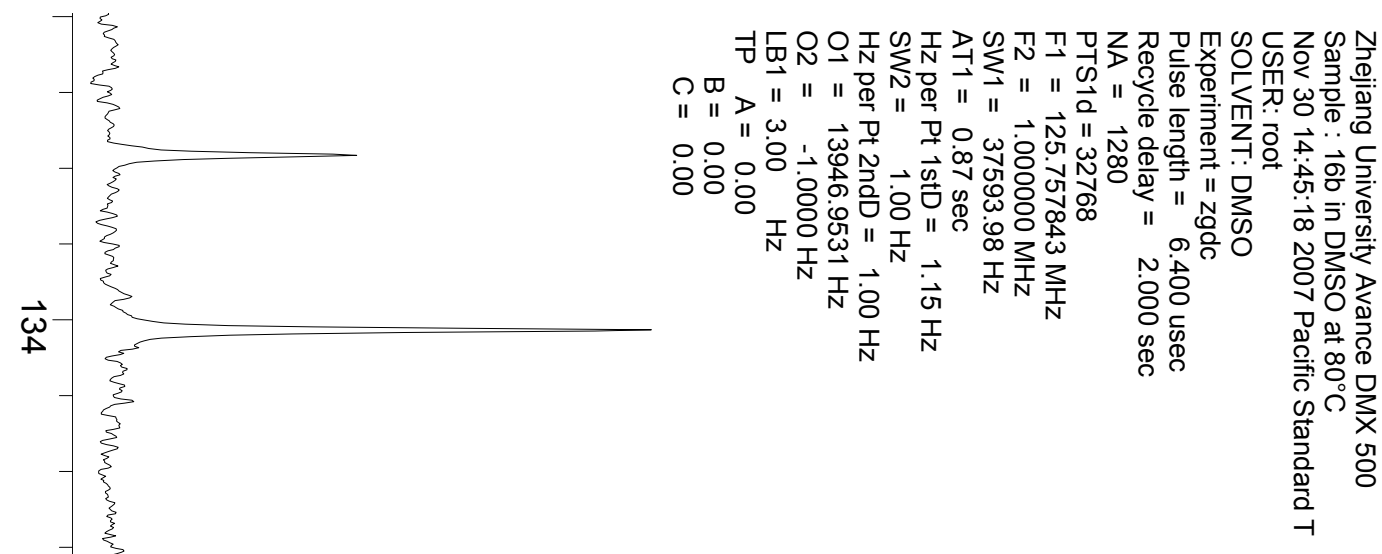

$\vec{N}$
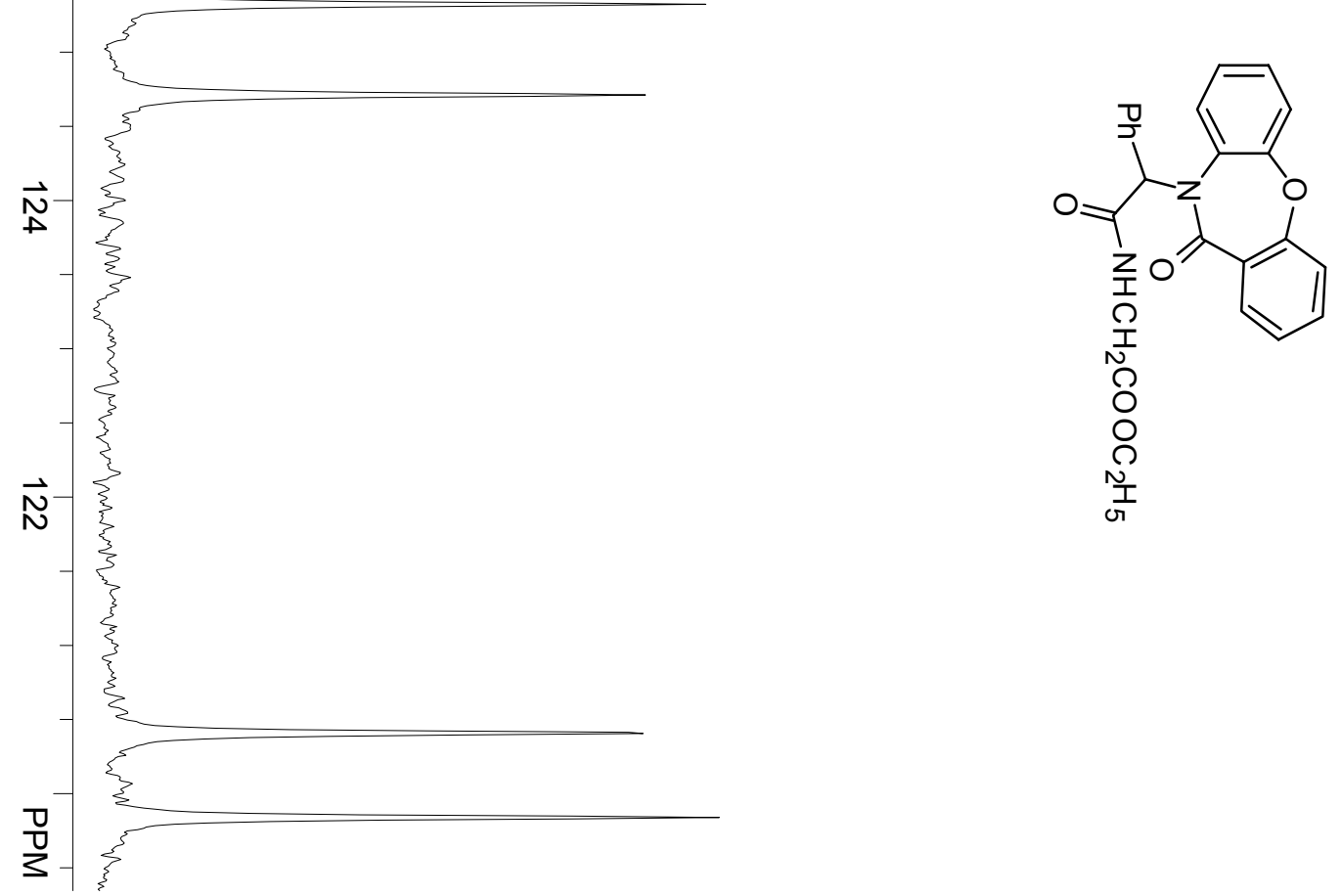

124.711 


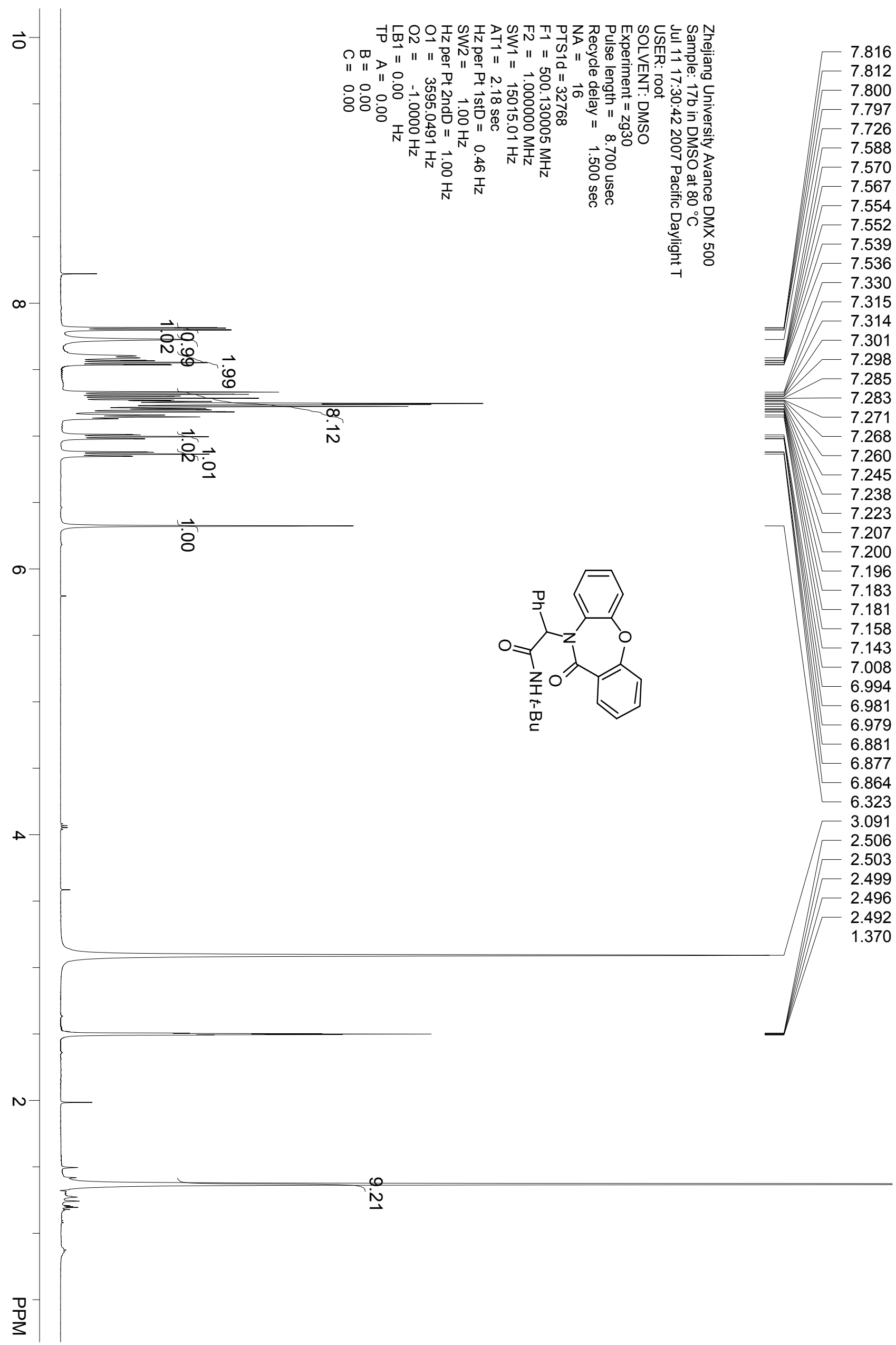




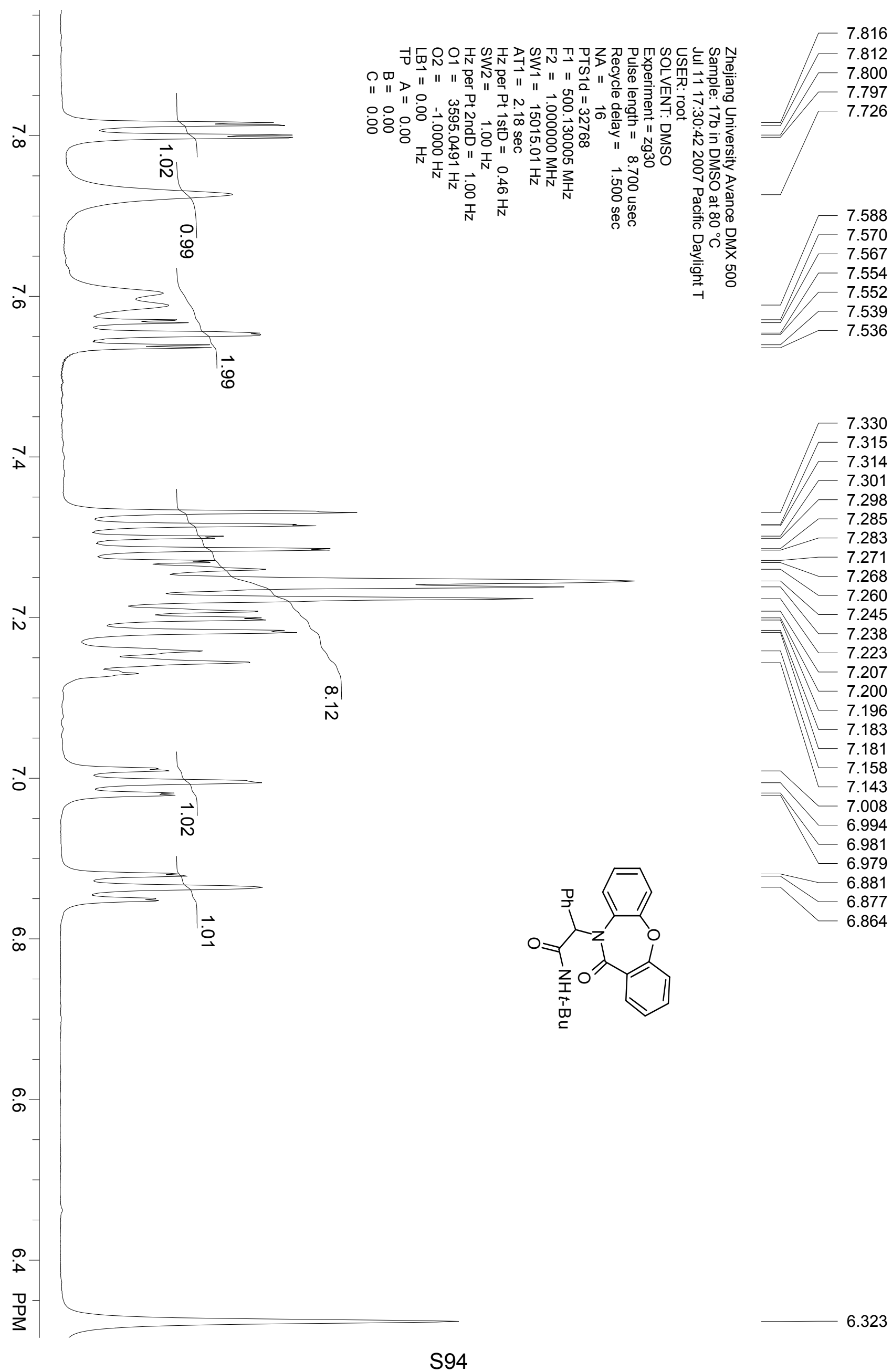




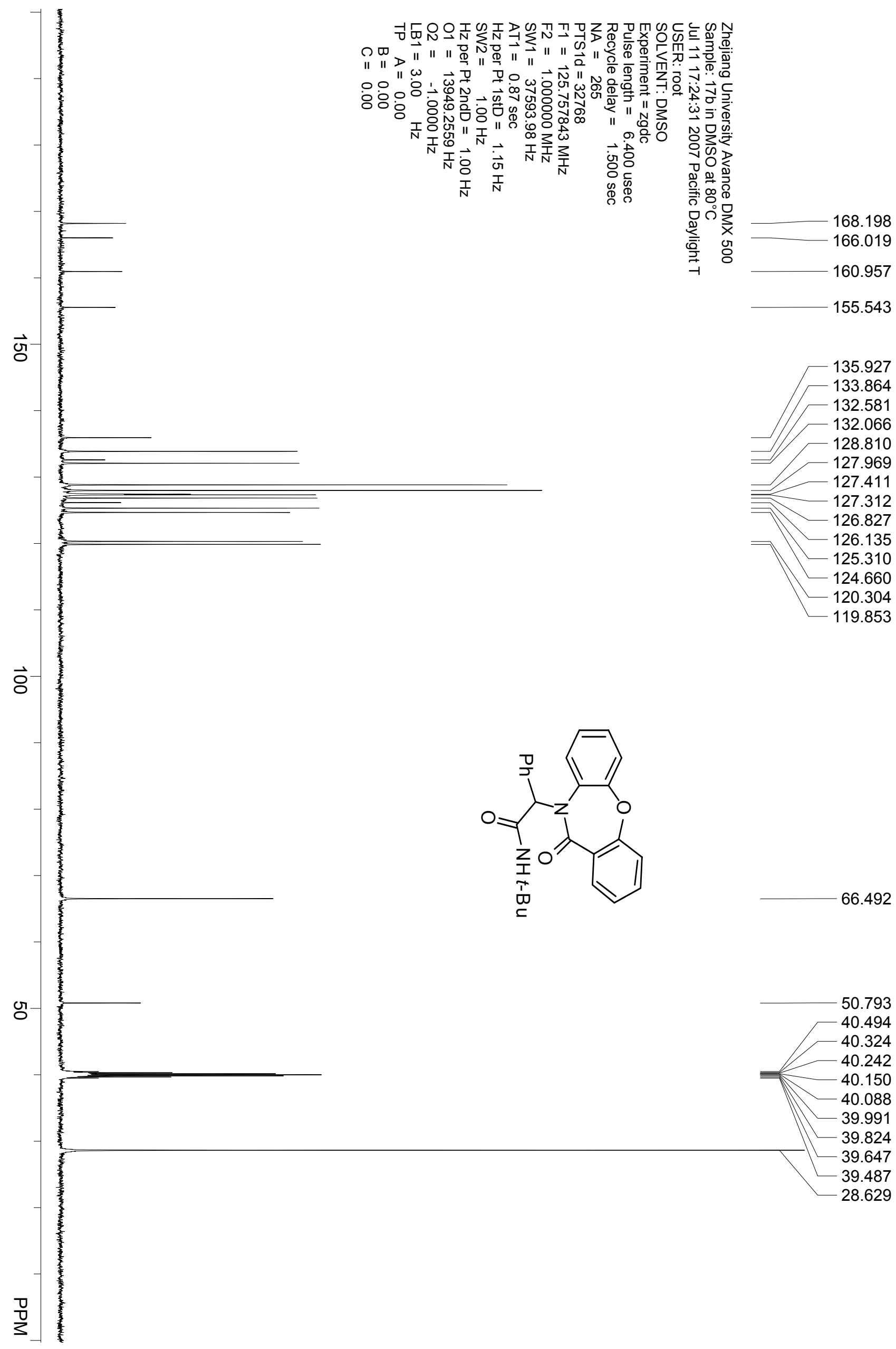




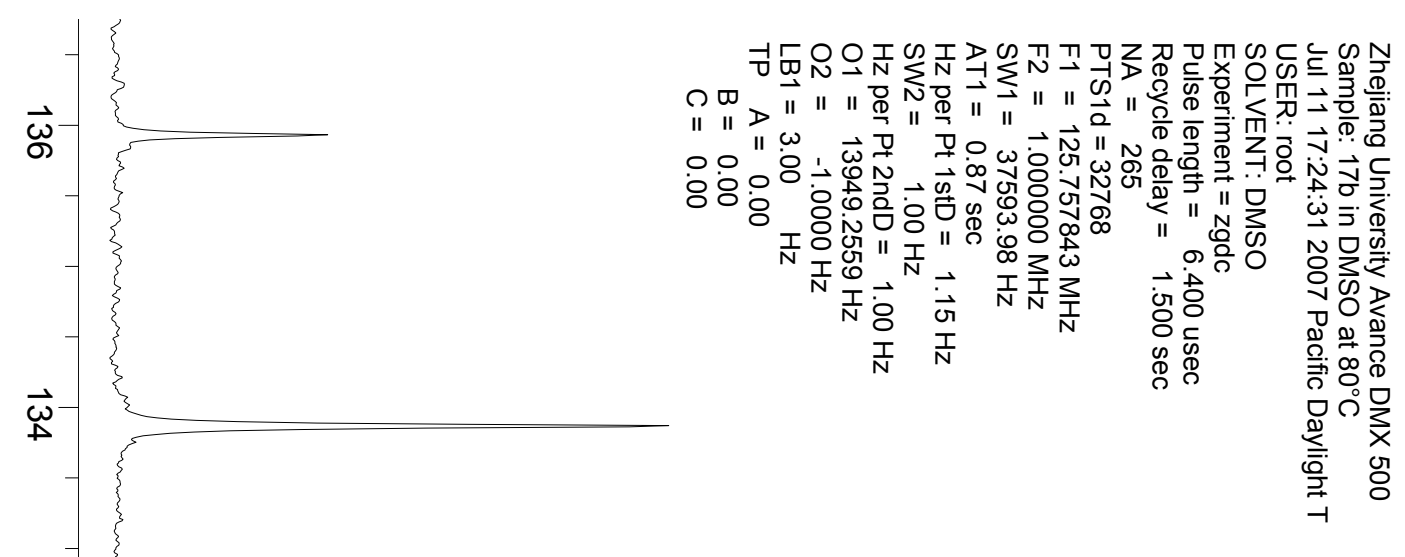

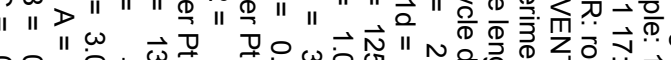

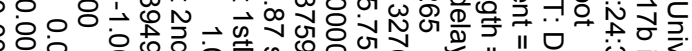
8 N I $\stackrel{N}{N}$

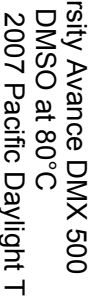
133.864 132.581 132.066

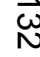

$\vec{\omega}$

$\vec{N}$

$\vec{N}$
$\vec{N}$

$-$
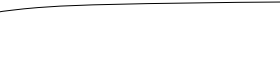

ran
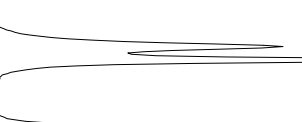

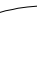

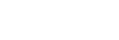

$\xi$

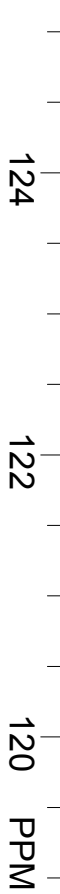
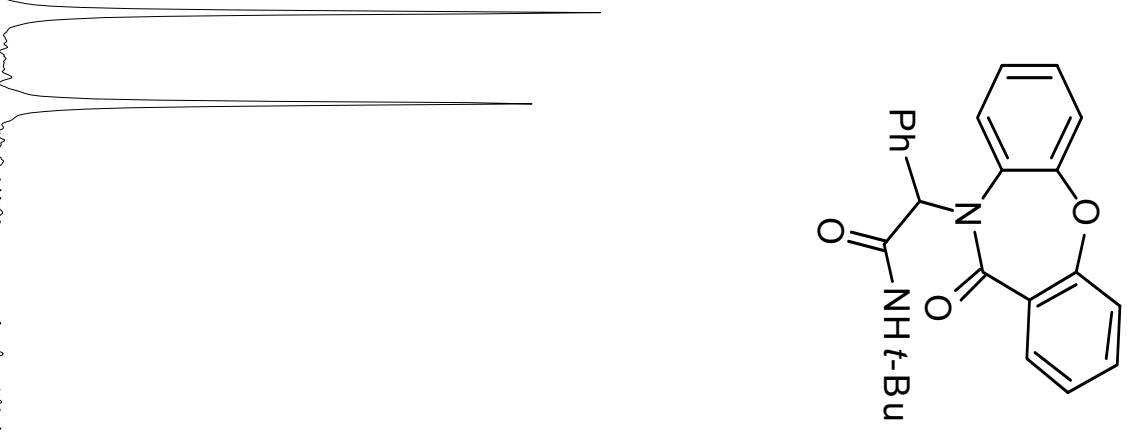

125.310

124.660 


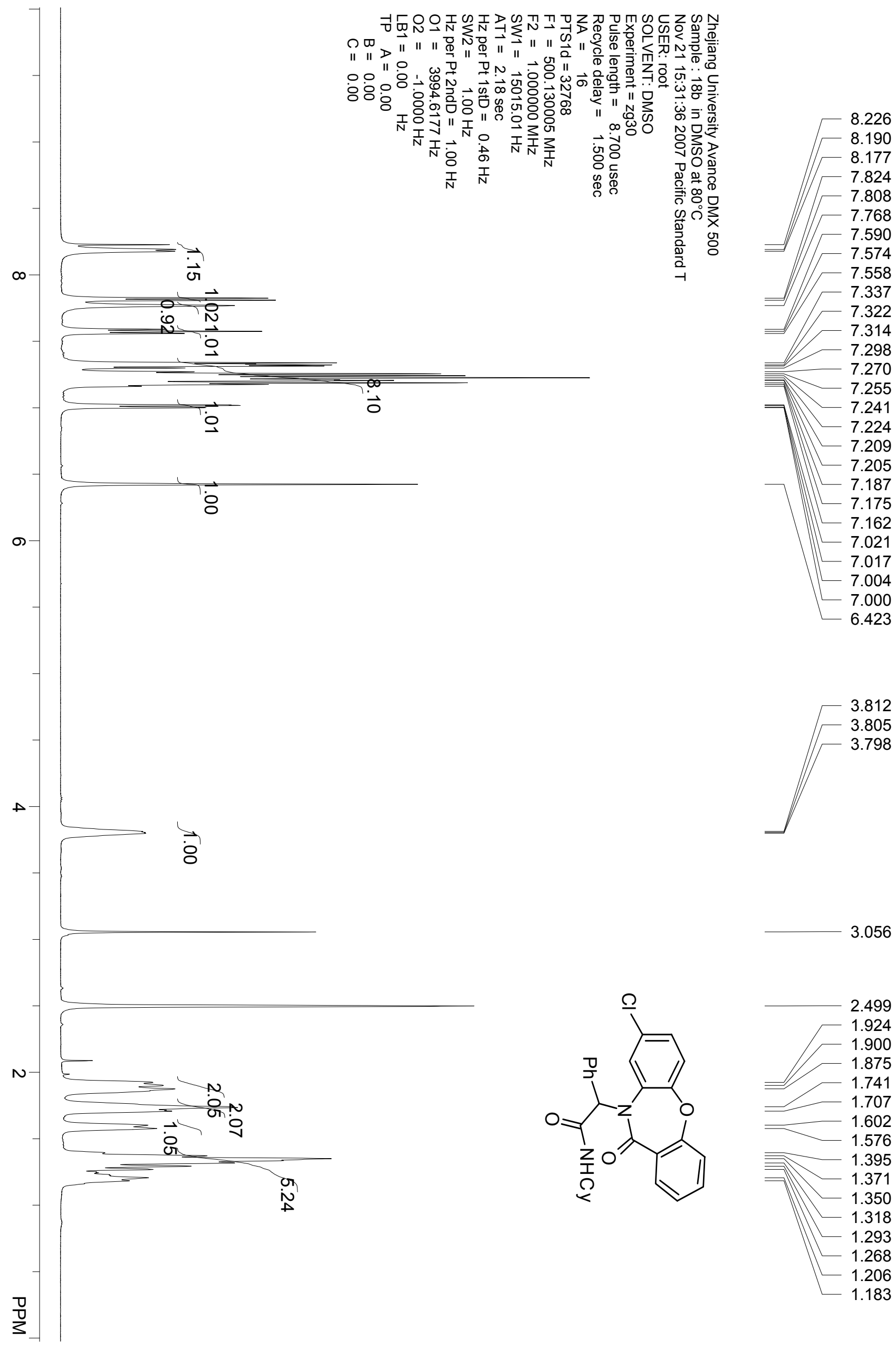




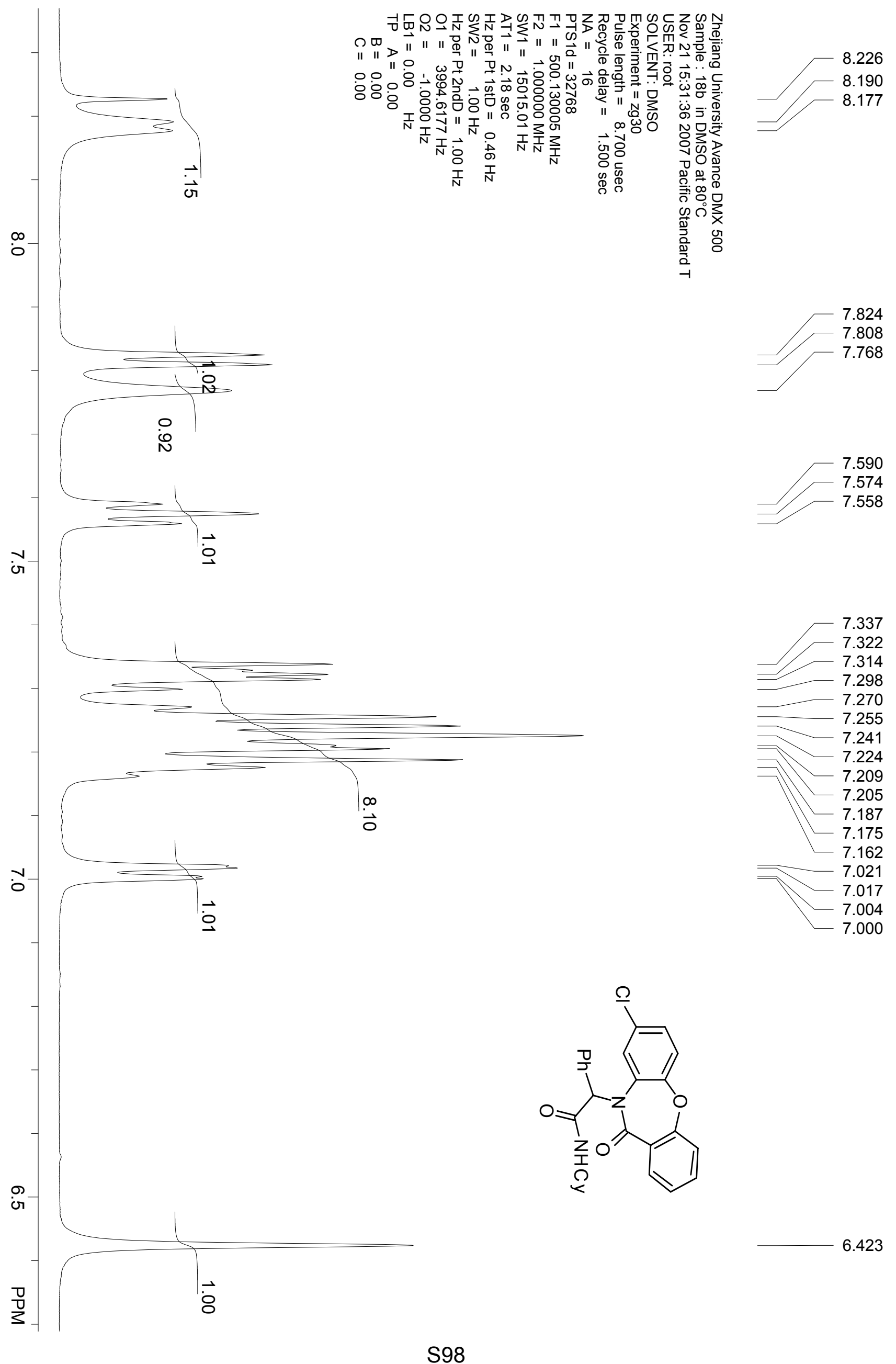




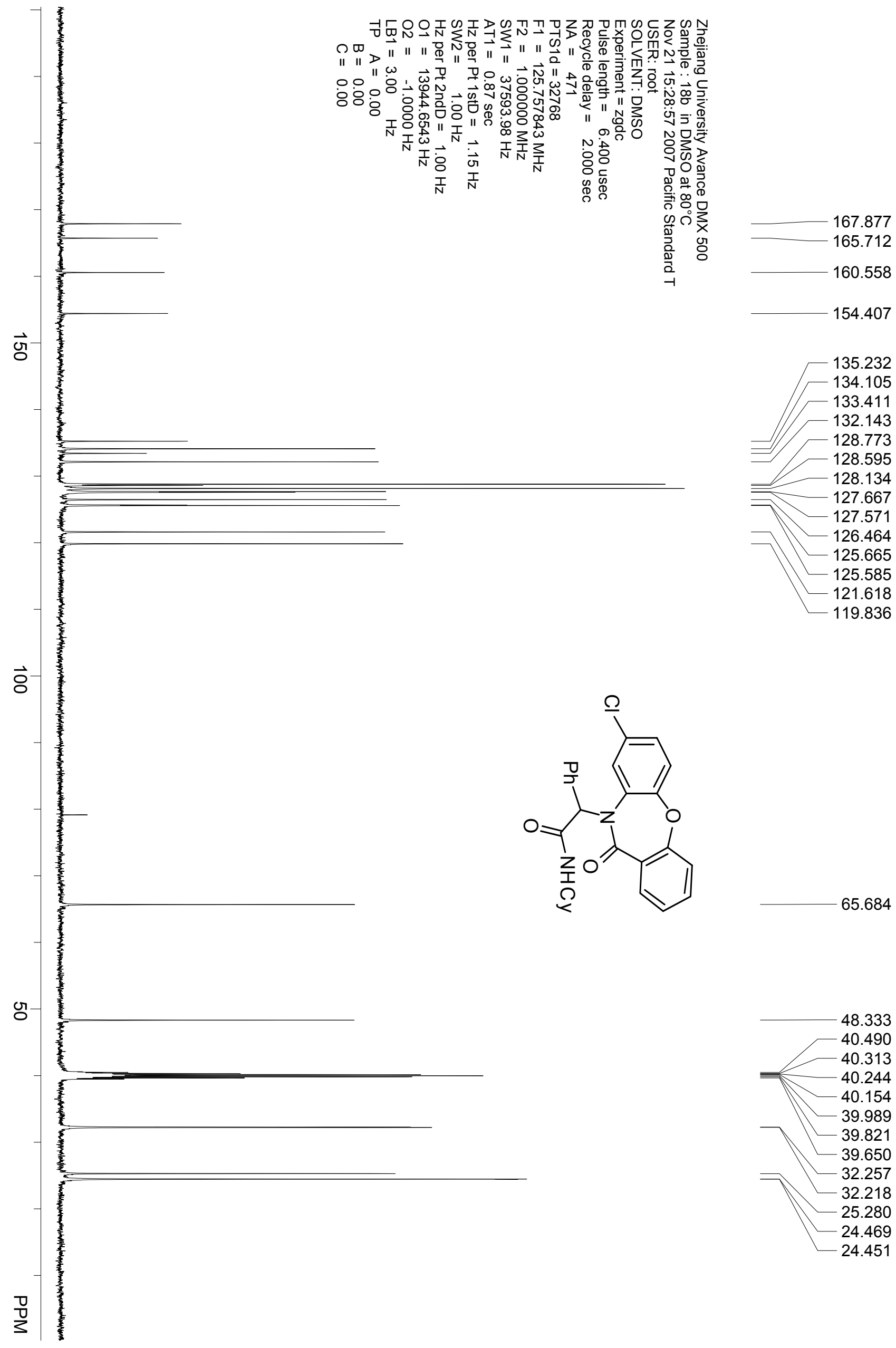




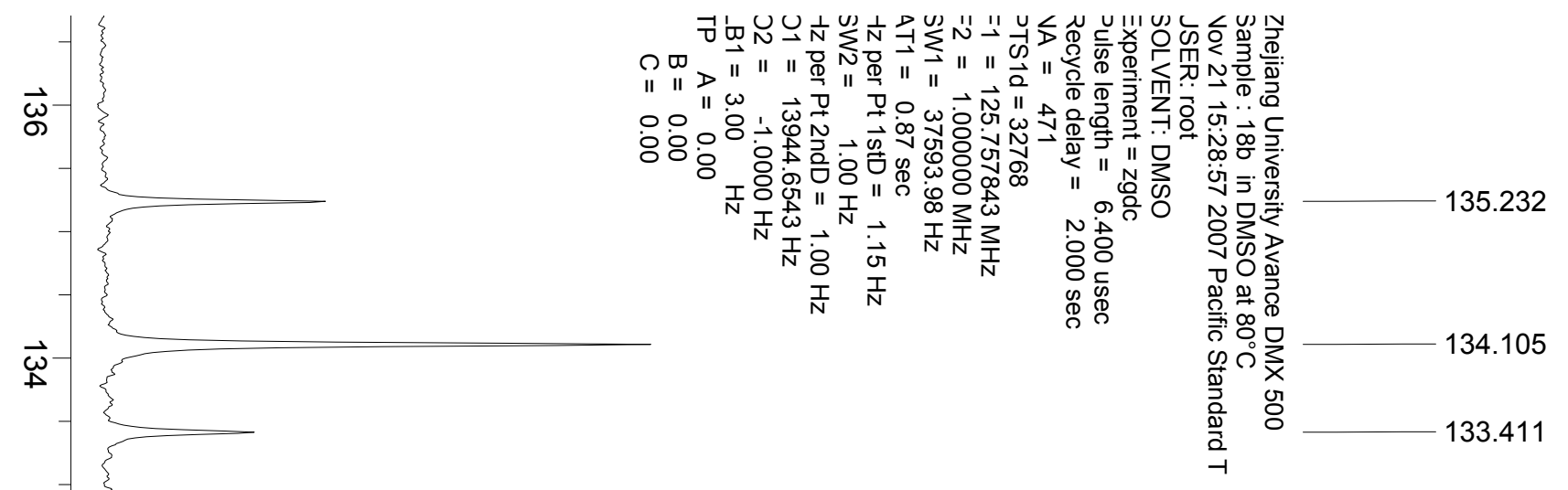

$\vec{N}$

$\vec{\omega}$

$\vec{\omega}$

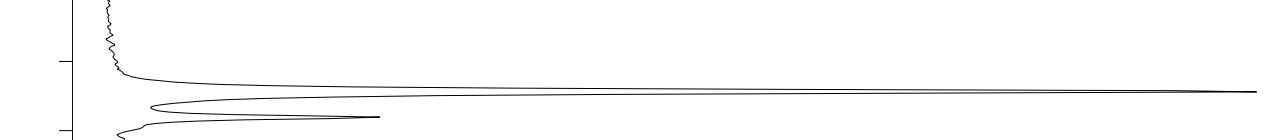

128.773

128.595

$\vec{N}$

128.134

127.667

127.571

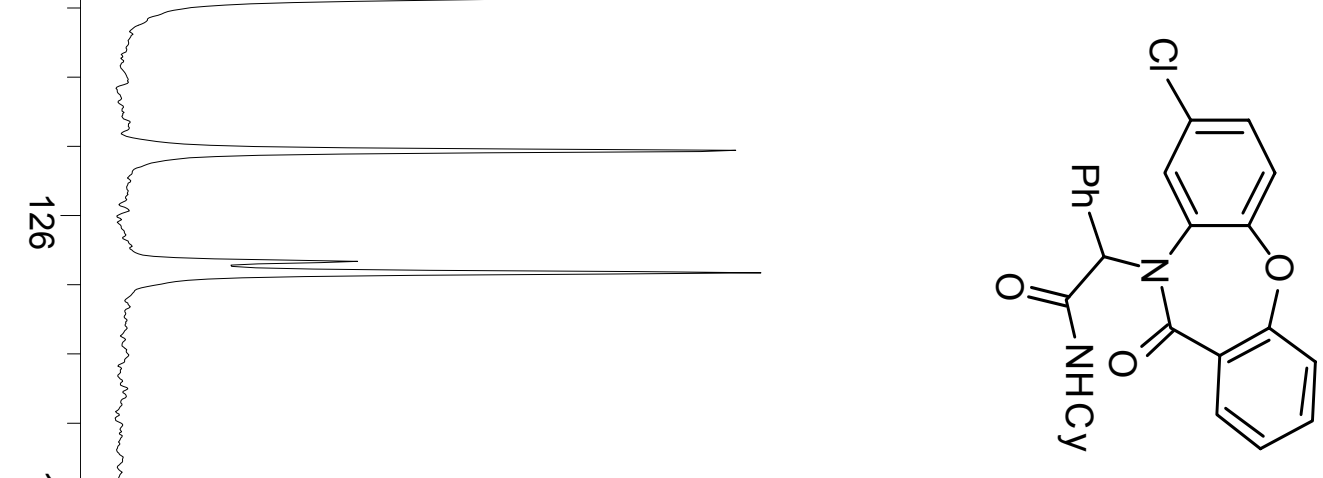

121.618

$\vec{N}-$
$\vec{N}$
$\overrightarrow{0}$
$\frac{0}{3}$

$\stackrel{N}{ \pm}$

$\vec{N}$

$\vec{N}$

$\stackrel{0}{0}$ 


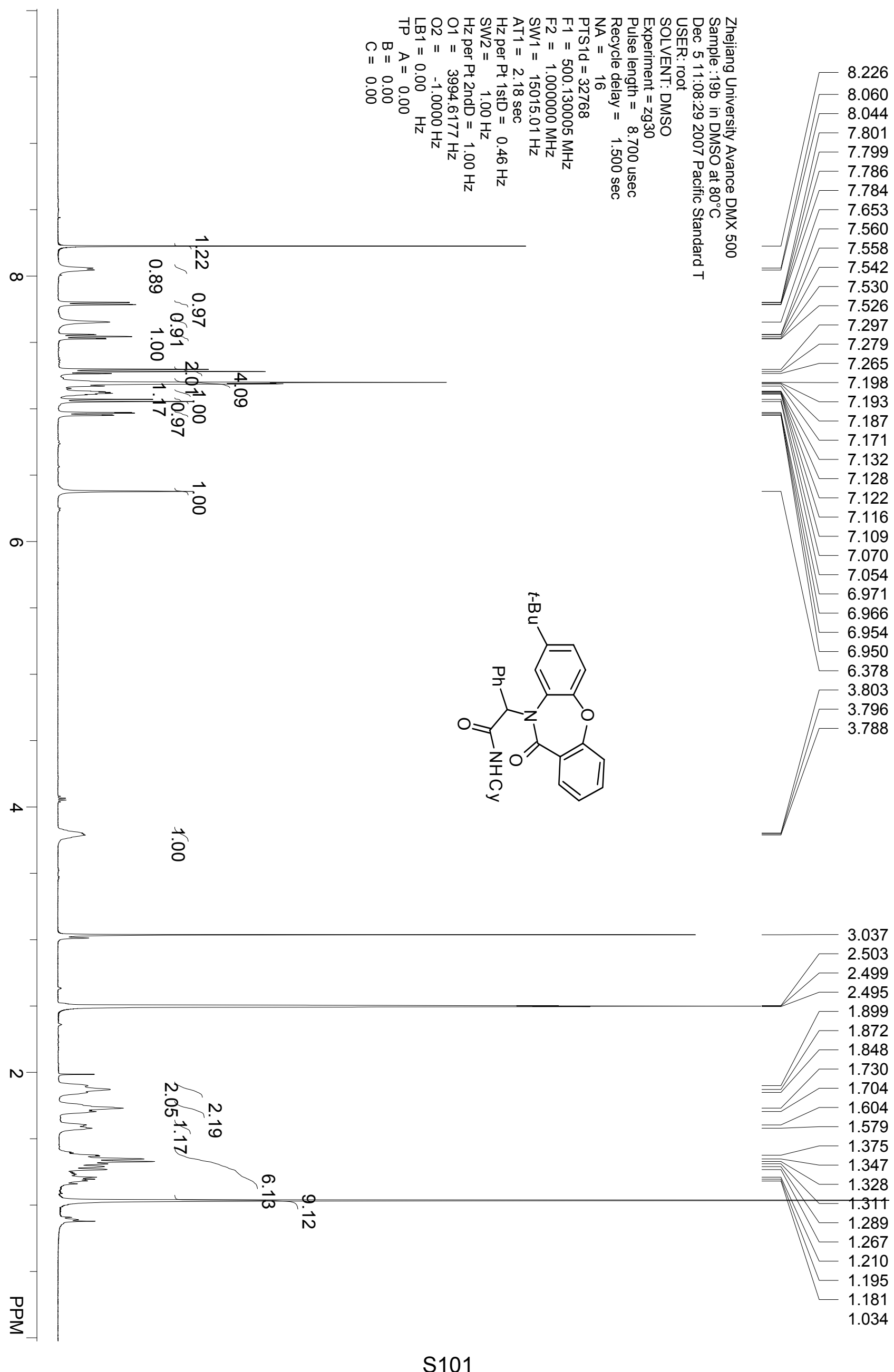




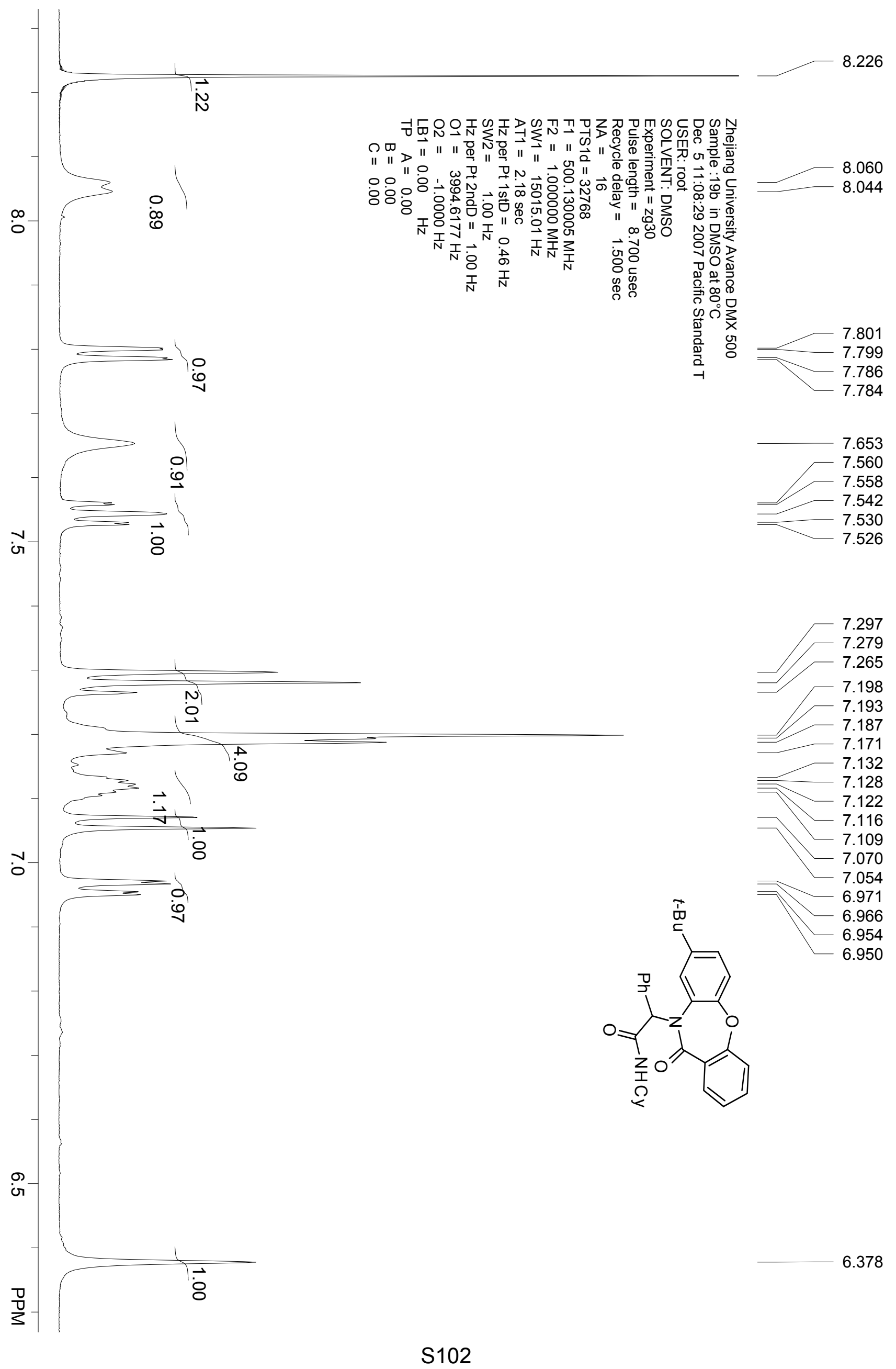




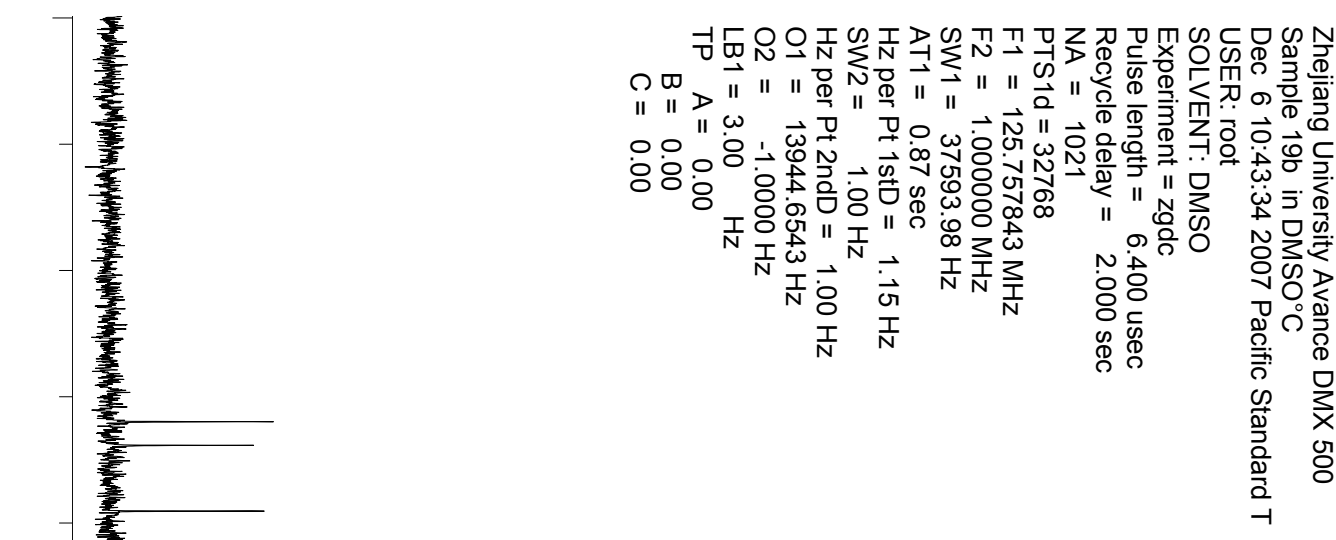

168.024

166.152

160.942

ज़

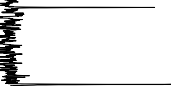

153.230

147.146

135.729

133.708

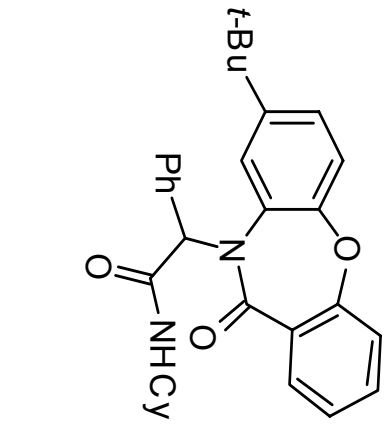

132.090

131.290

128.858

127.948

127.185

126.257

125.127

124.791

123.360

119.759

119.455

응

앙

$\frac{\rho}{\frac{\rho}{\Lambda}}$ 


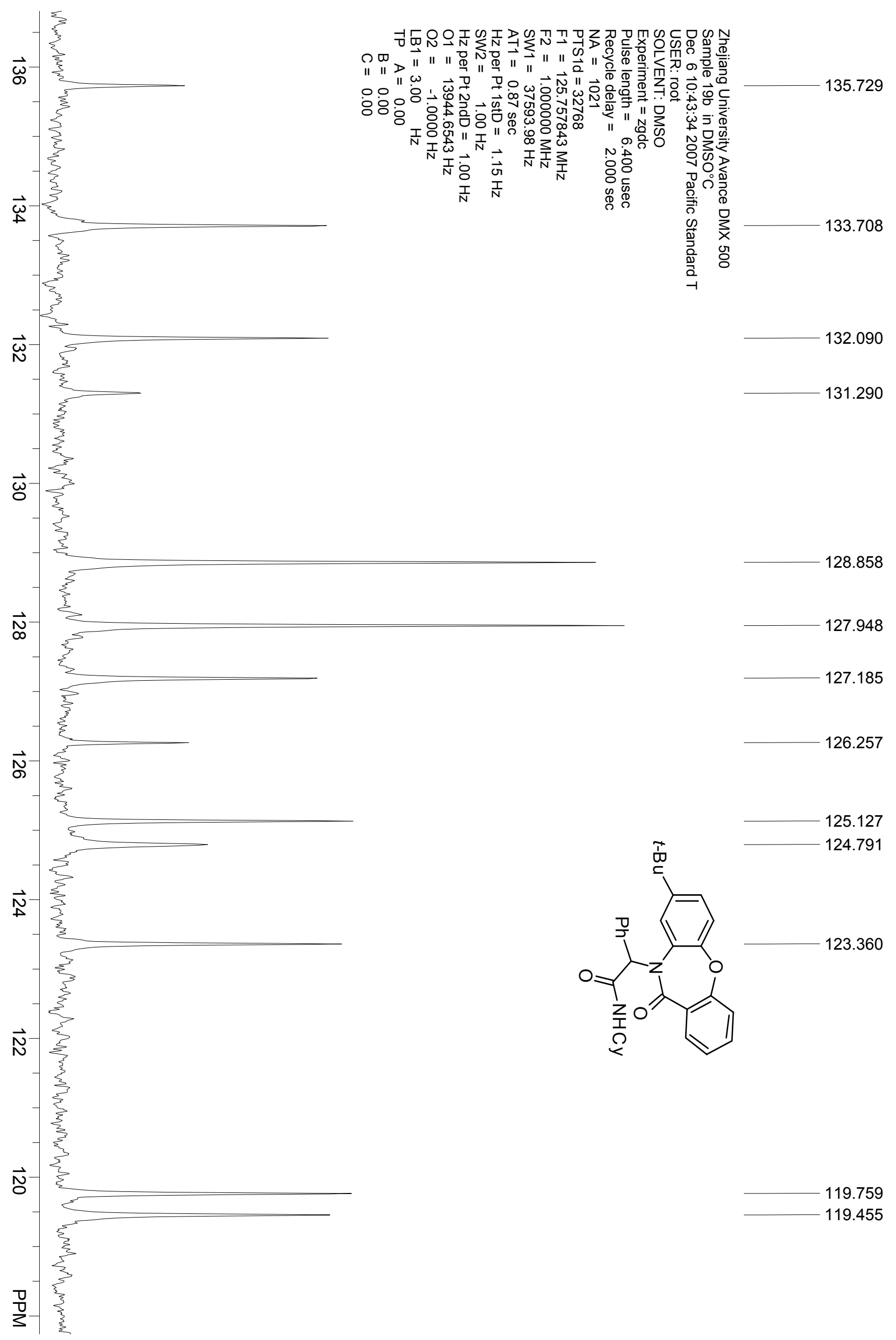




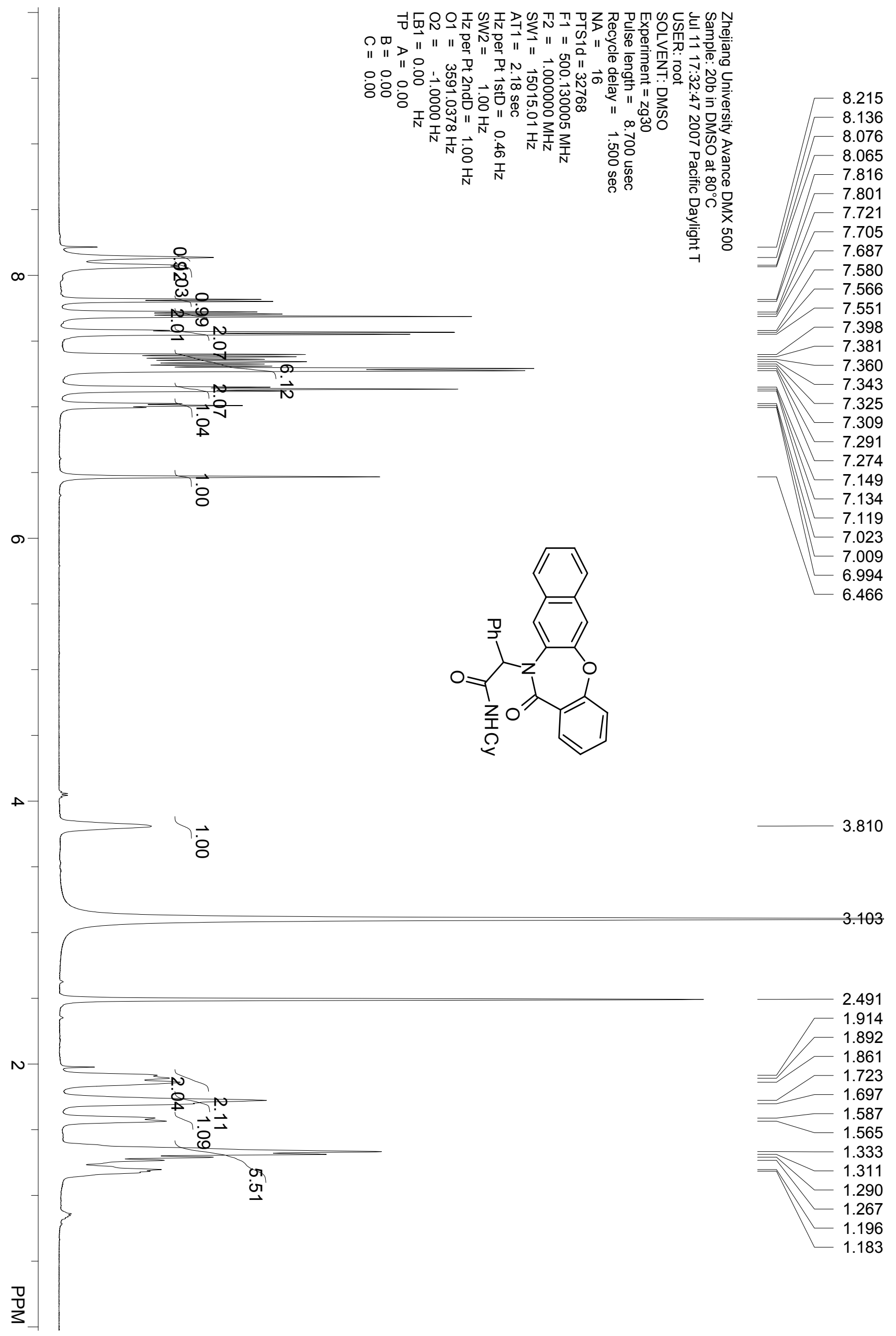



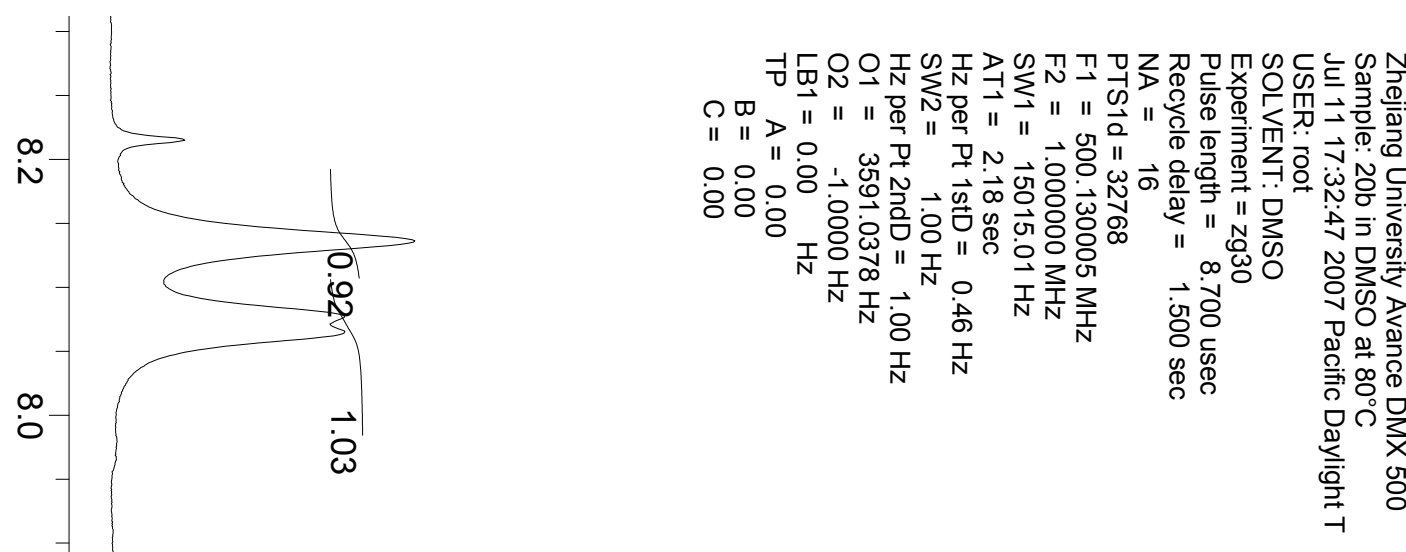

7.816

7.801

$\grave{\infty}$

8

7.721

7.705

7.687

N

ตे

$\stackrel{\circ}{\circ}$

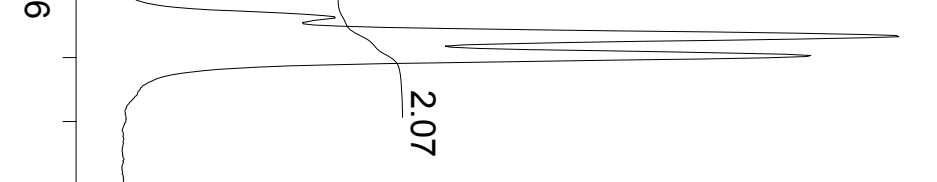

7.580

7.566

7.551

ì

7.398

7.381

7.360

7.343

$-7.325$

7.309

7.291

7.274

$\stackrel{\sim}{N}$

7.149

7.134

7.119

ำ

7.023

7.009

Oे

5

$\vec{\circ}$

$\infty$

ò

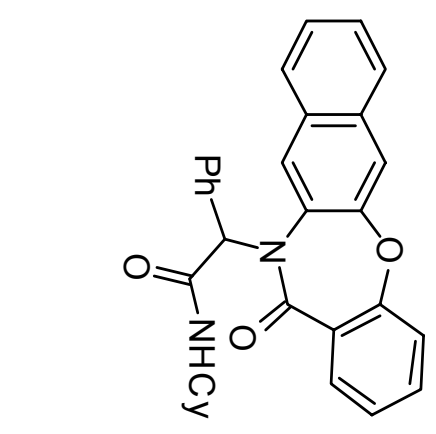




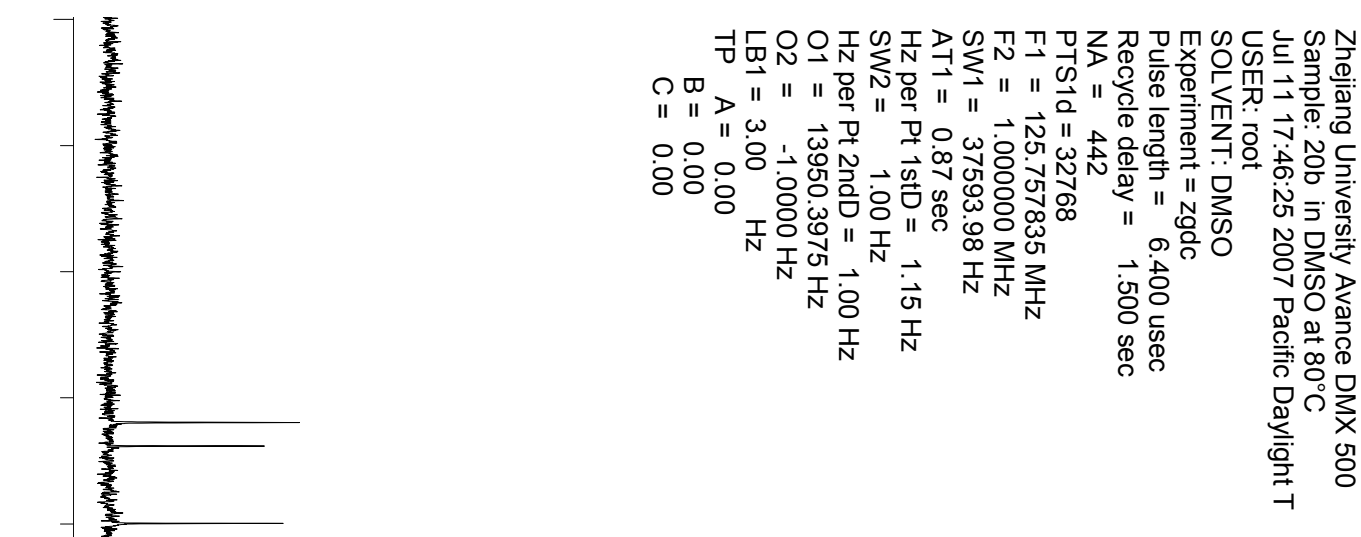

168.028

166.171

160.039

154.388

135.828

134.046

131.959

131.343

131.257

130.069

128.893

127.980

127.467

127.395

126.767

126.318

126.164

125.889

125.539

120.052

116.662

$\overrightarrow{8}$<smiles>C[C@H](O)C(=O)C([Hg])[C]1C(=O)c2ccccc2Oc2cc3ccccc3cc21</smiles>

66.525

앙

8335

40.330

40.250

40.160

39.986

39.827

39.659

32.334

32.276

25.340

24.518

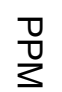




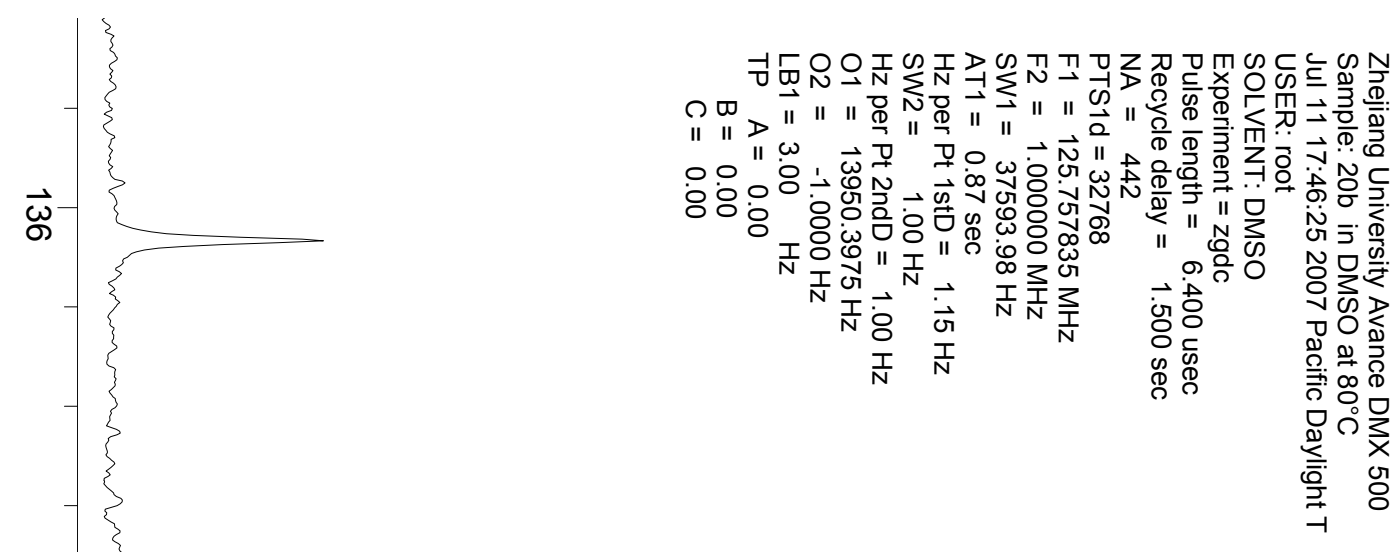

134.046

$\vec{\omega}$

131.959

$\vec{\omega}$

131.343

131.257

130.069

$\vec{\omega}$

128.893

$\vec{\infty}$

127.980

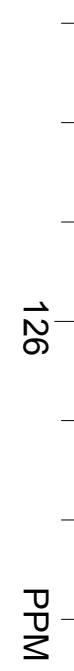

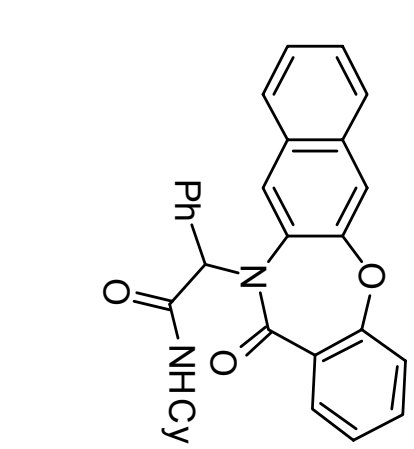

127.467

127.395

126.767

126.318

126.164

125.889

125.539 


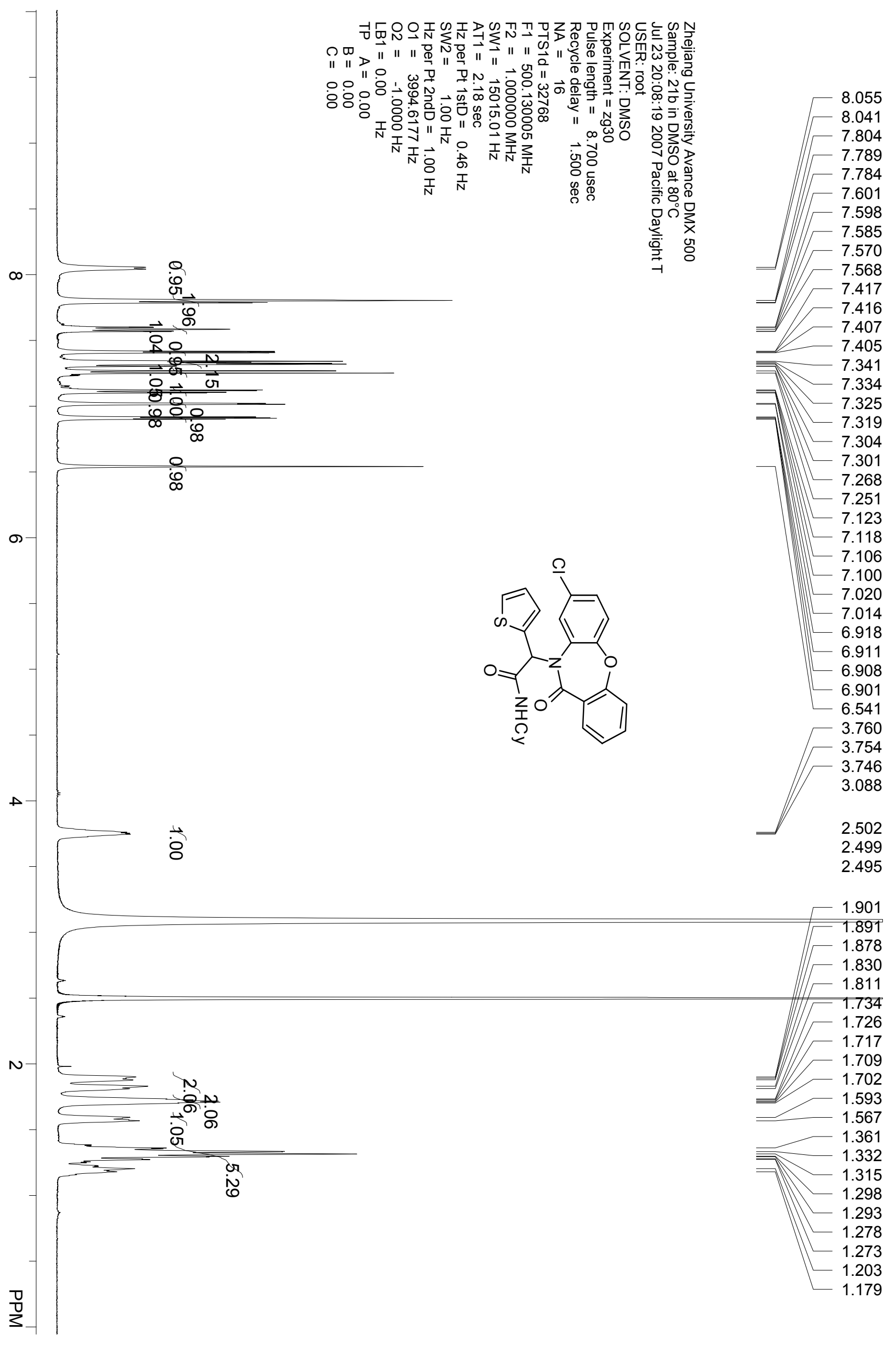




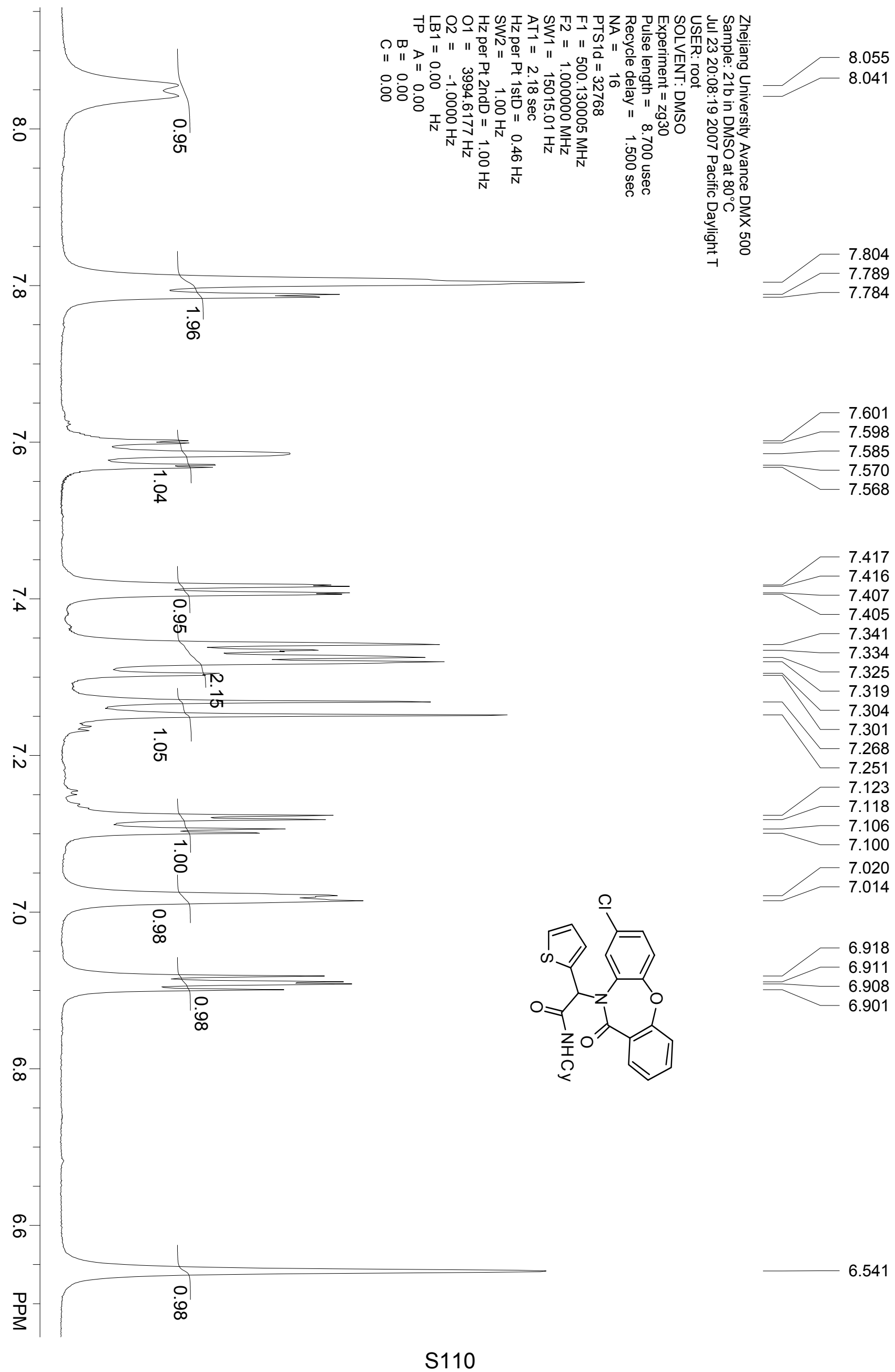




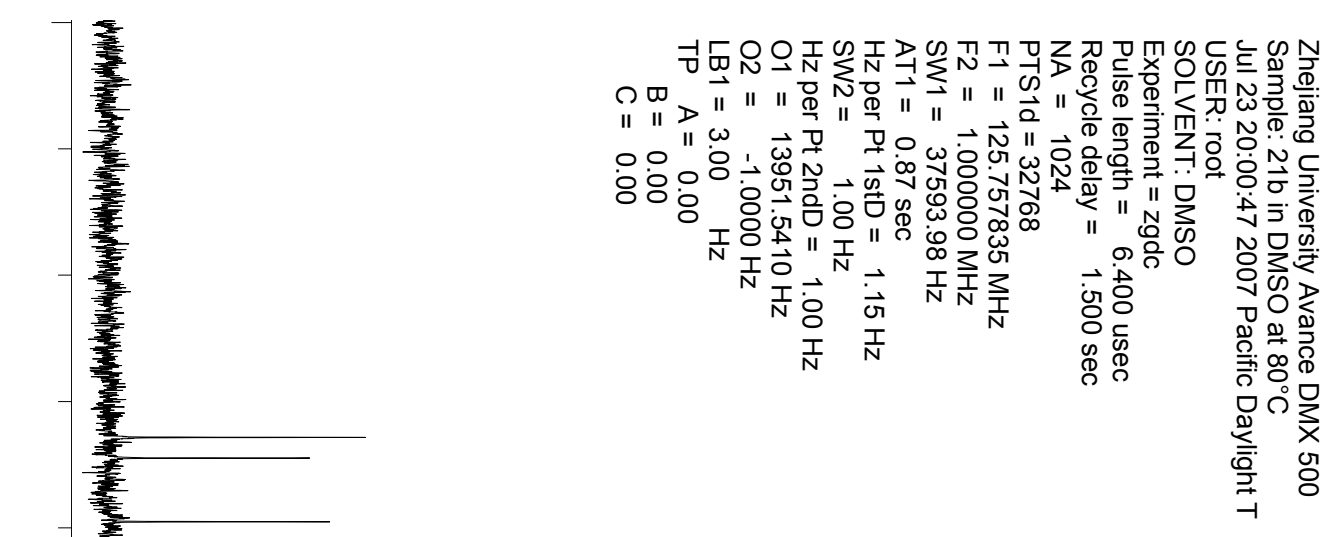

167.155

165.512

160.480

154.354

$\overrightarrow{0}$

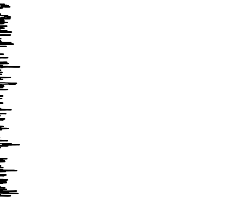

134.328

133.269

137.636

132.156

128.799

128.768

127.577

126.890

126.833

126.369

125.711<smiles>CO[C@H](C(=O)O)C(=O)[C@@H](c1ccco1)c1cc(O)ccc1Oc1ccccc1</smiles>

125.537

121.885

$-119.938$

$\overrightarrow{8}$

잉

61.500

40.578

40.490

40.405

48.528

40.313

40.247

40.153

40.080

39.990

39.821

39.650

39.490

32.157

32.108

$-25.293$

24.442 


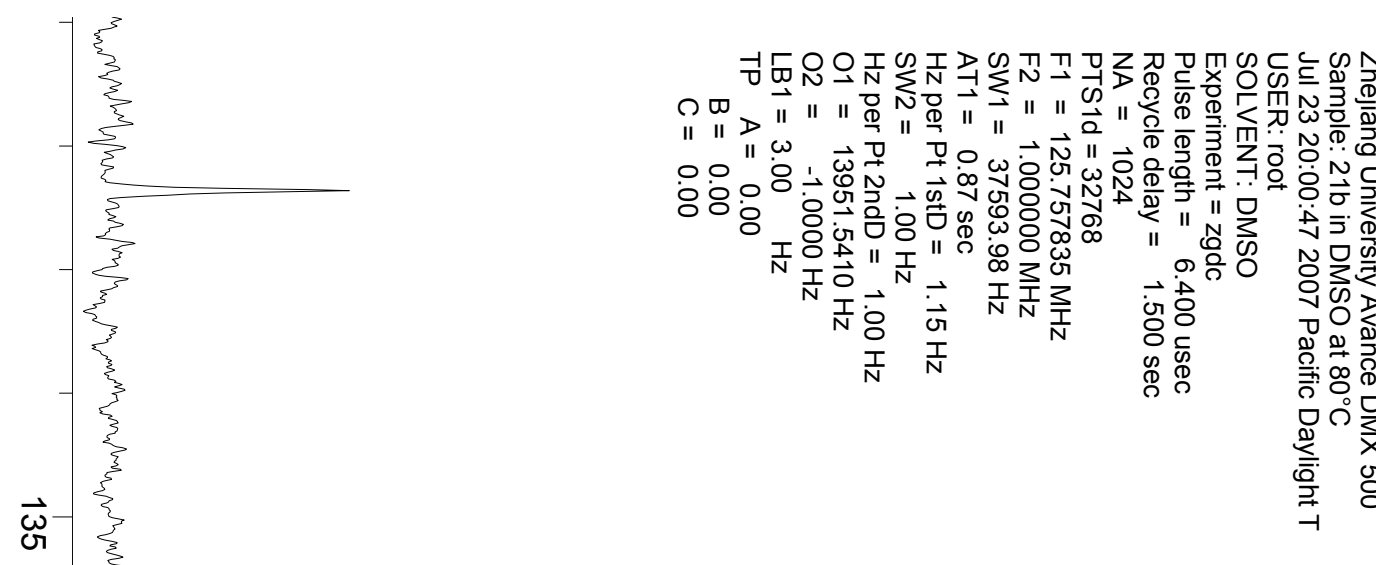<smiles>[CH]C(=O)C(C(=O)O)=C1C(=O)c2ccccc2Oc2ccc(O)cc21</smiles> 


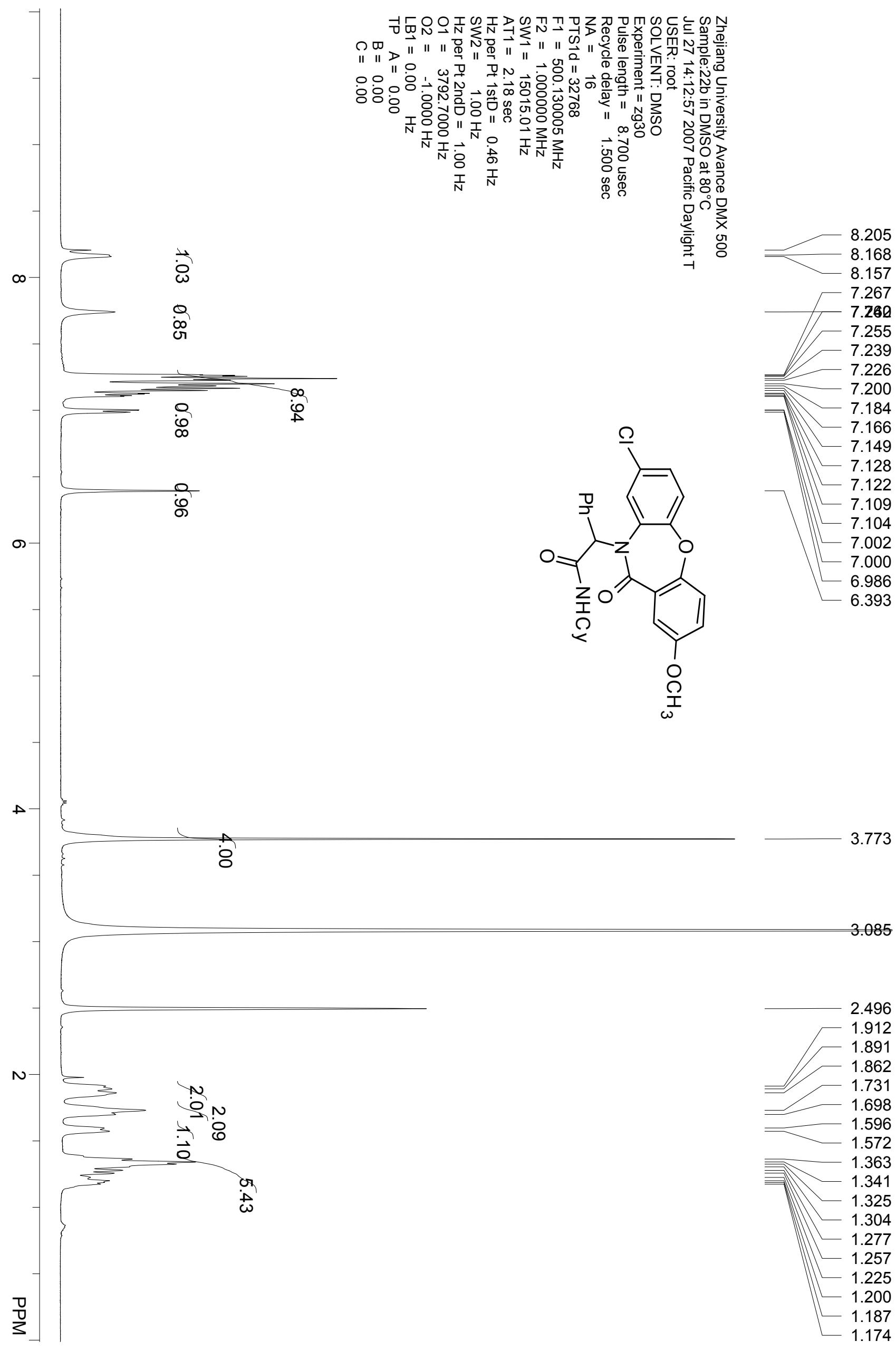



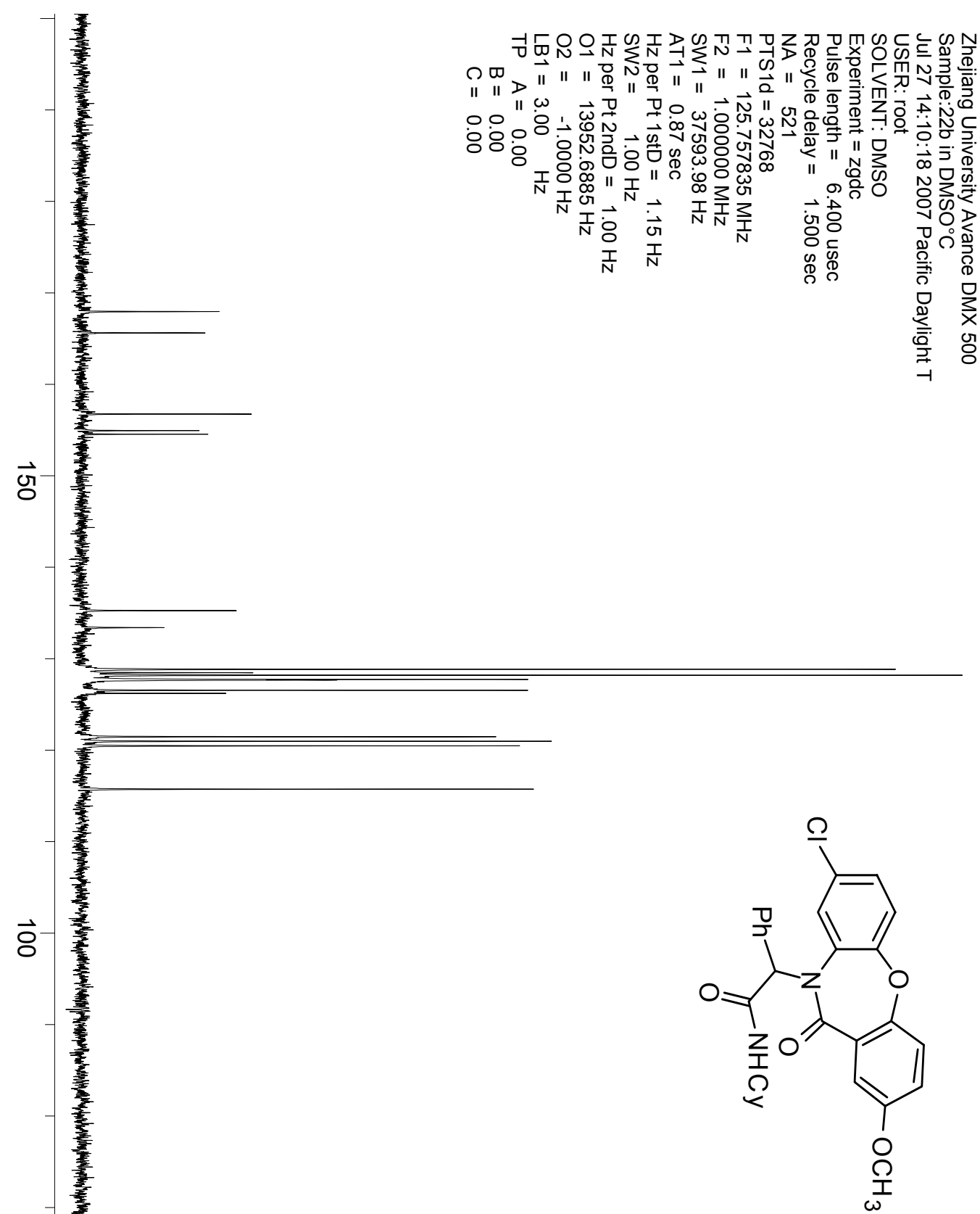

127.734

127.665

126.548

126.215

121.467

120.977

$-120.474$

$-115.736$

$\vec{\circ}$

긍

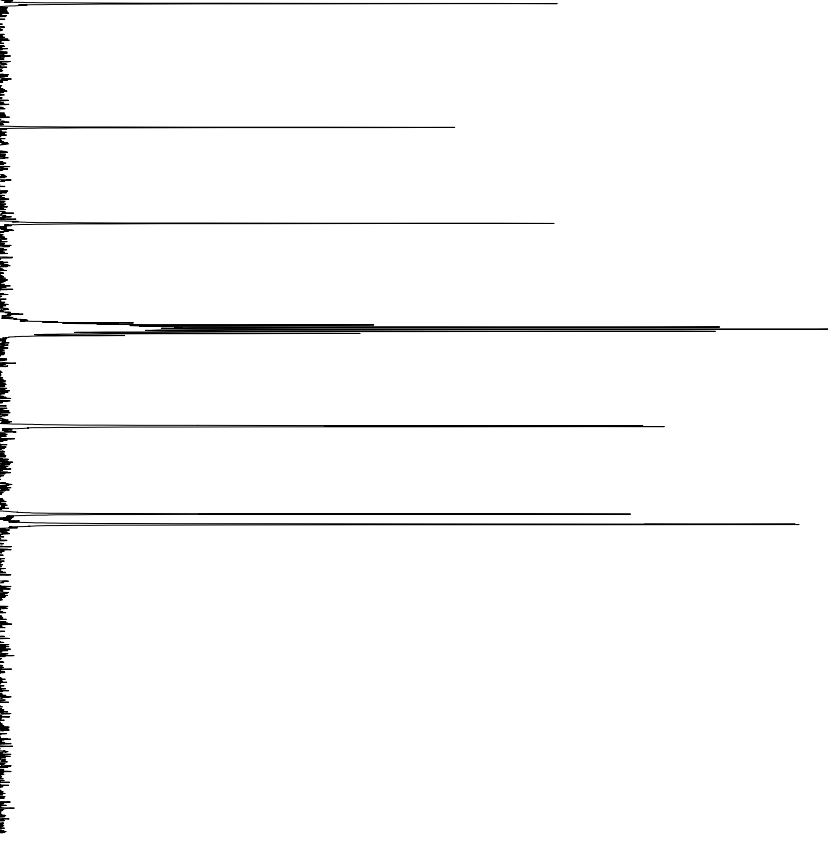

65.836

56.009

40.496

40.417

40.326

40.252

40.163

39.994

39.823

39.663

39.493

32.331

32.270

25.332

24.528

24.486 


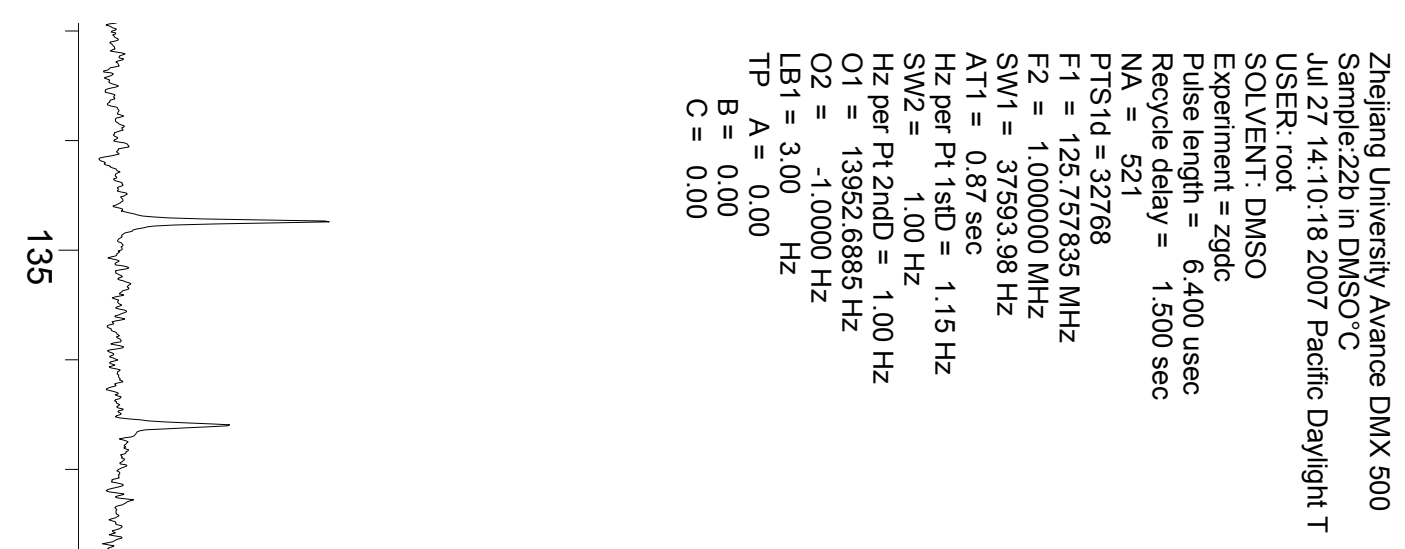

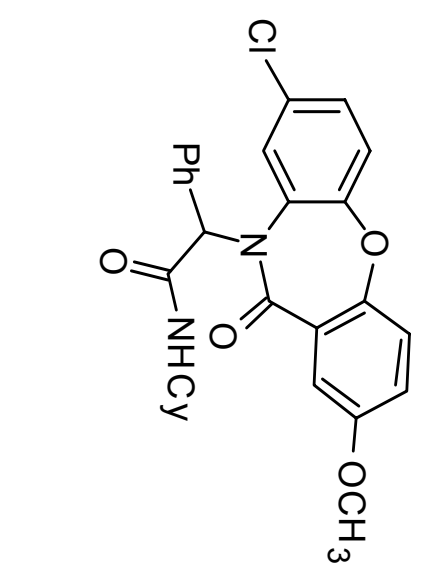




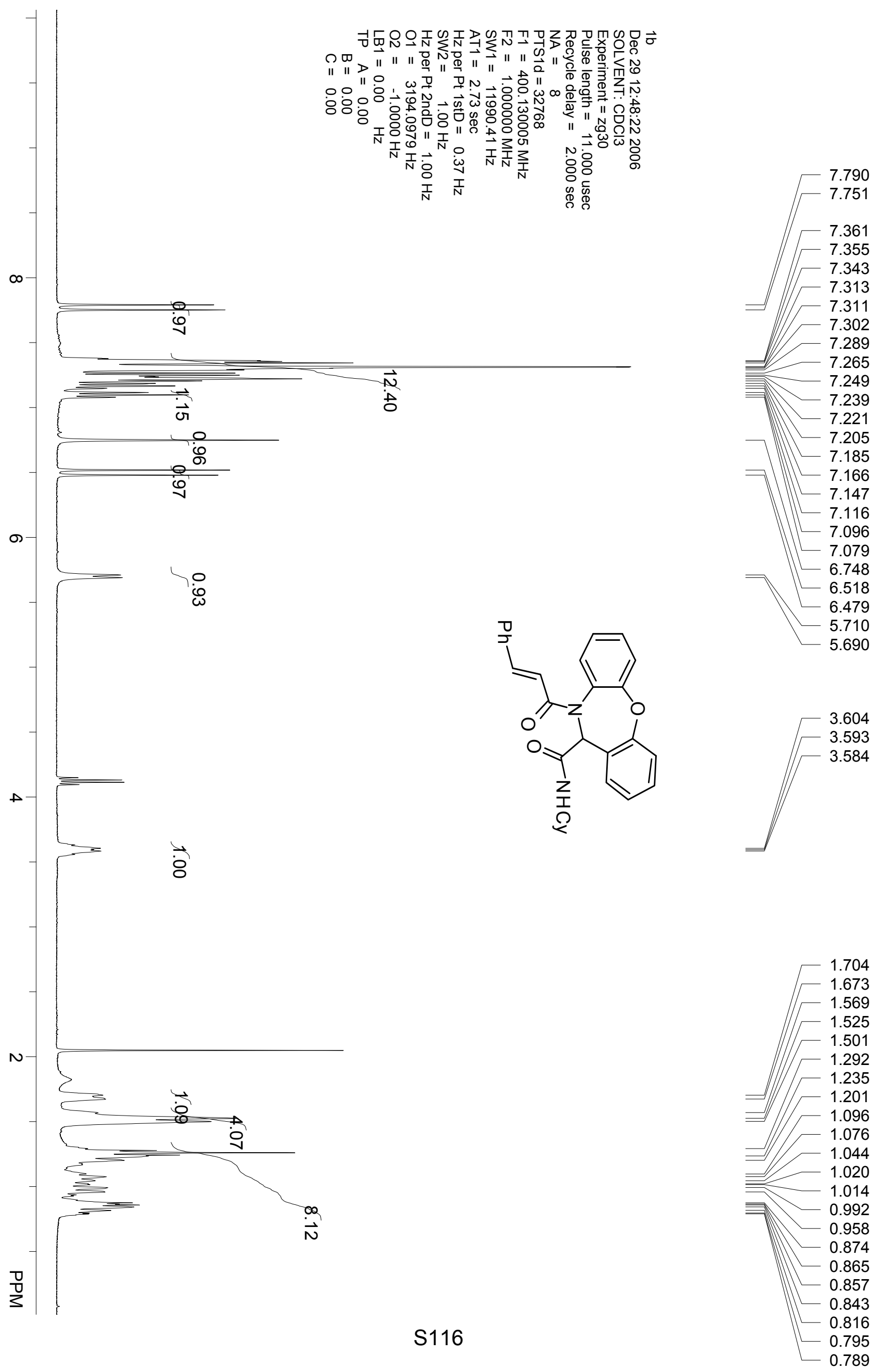




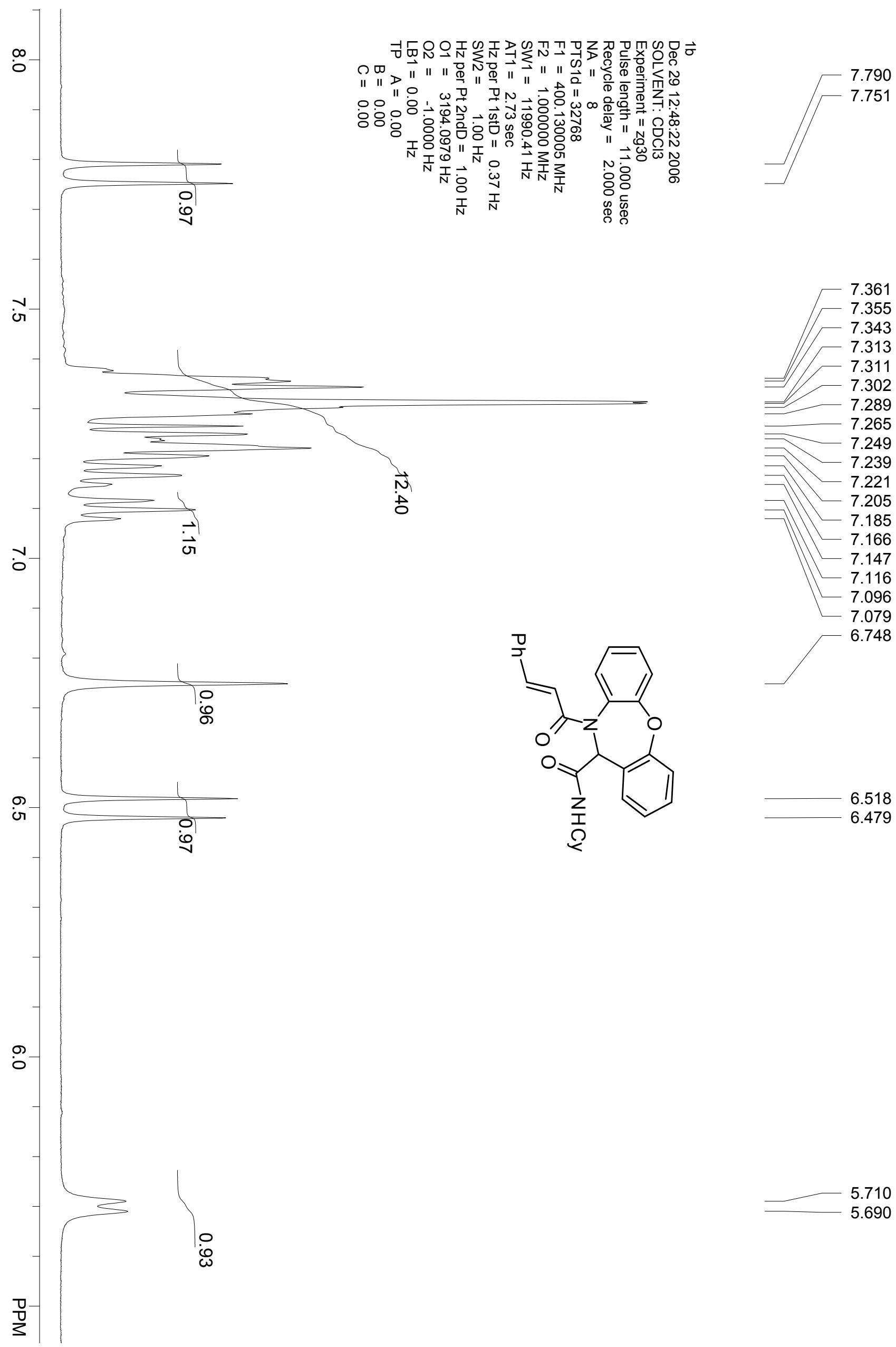




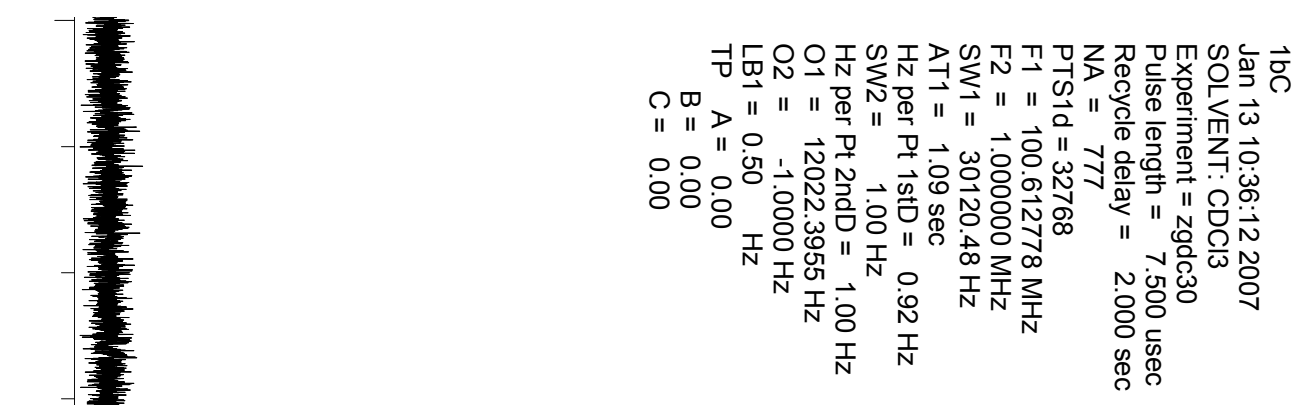<smiles>O=CC=CC(=O)C1c2ccccc2Oc2ccccc2C1C(=O)O</smiles> 


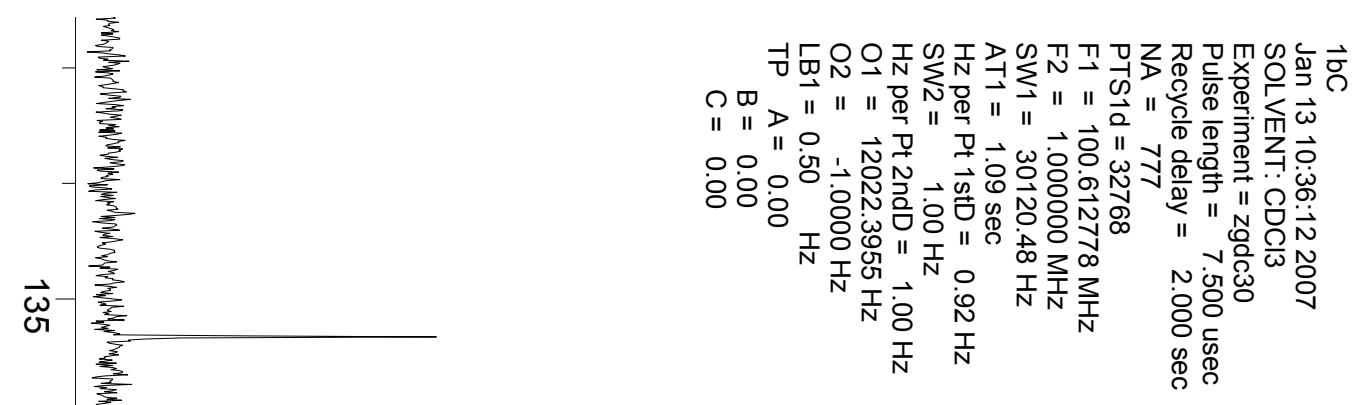<smiles>[CH-]C=CC(=O)C1c2ccccc2Oc2ccccc2C1C(=O)C=C</smiles>

122.538 


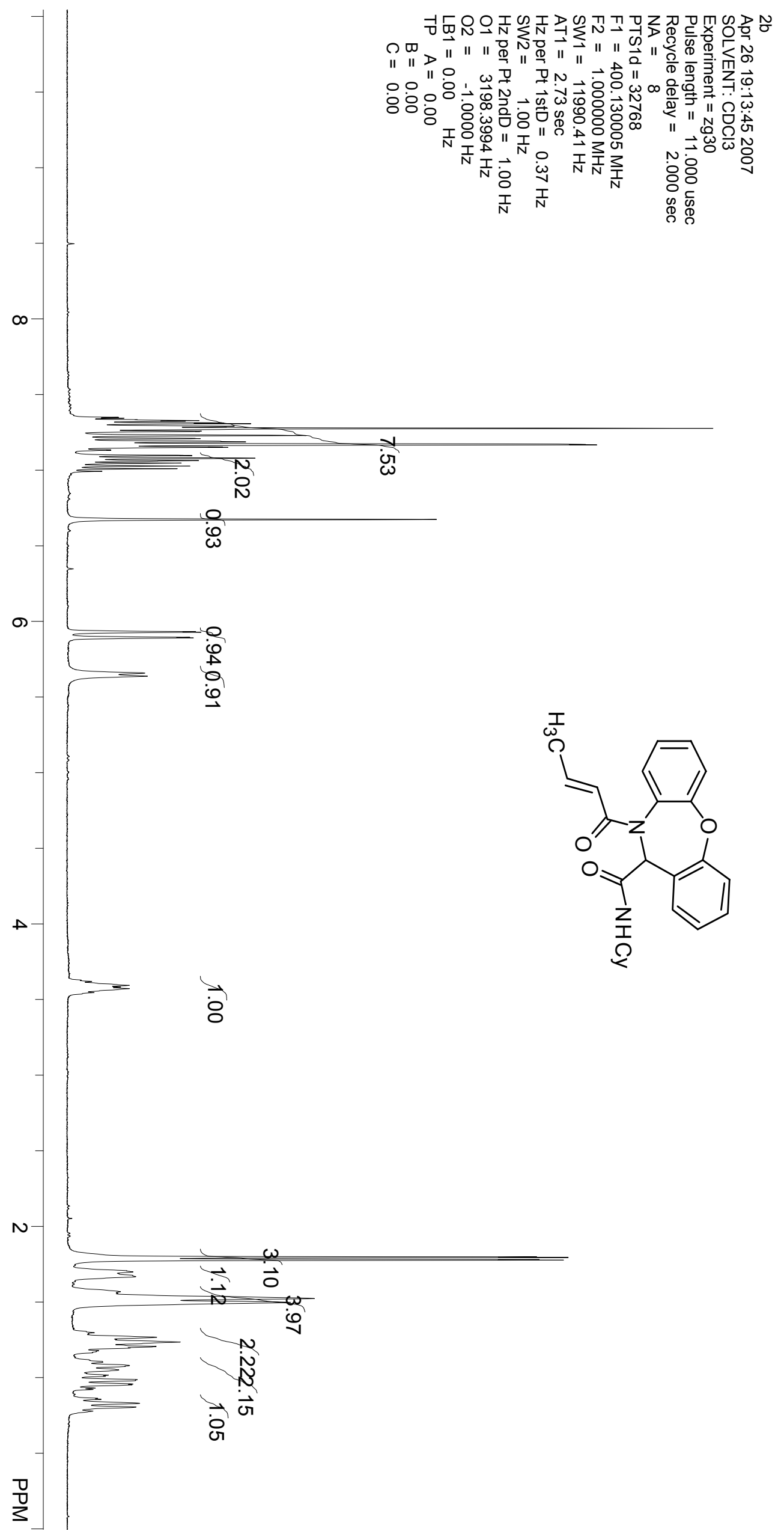

0 舟

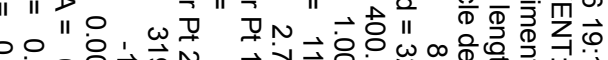

$\vec{w} \omega$

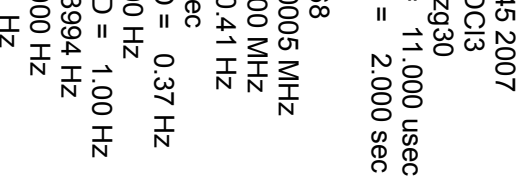



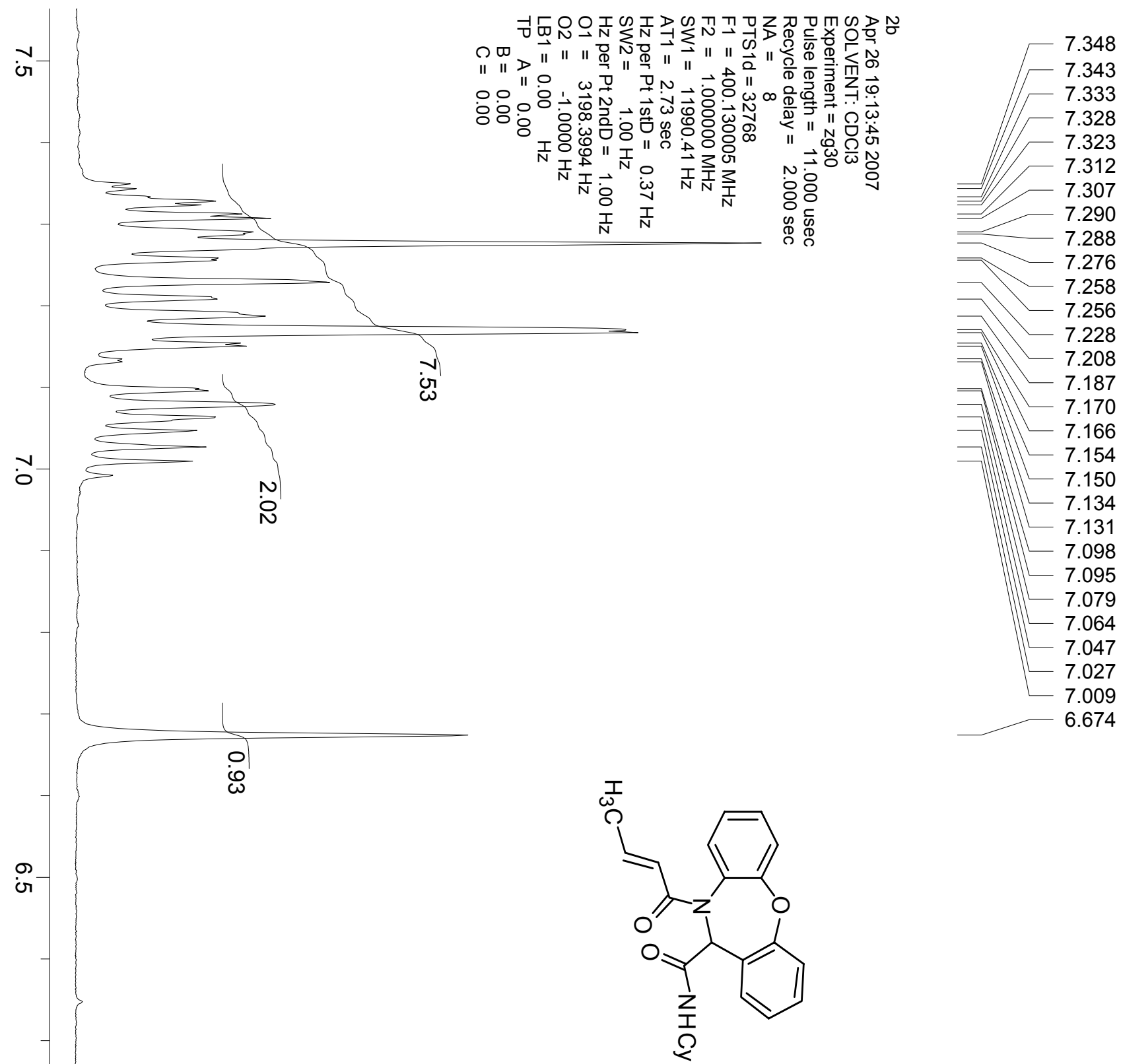

0
ஸे
$\omega$

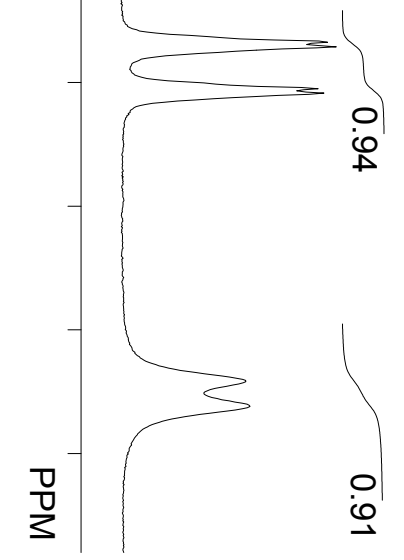




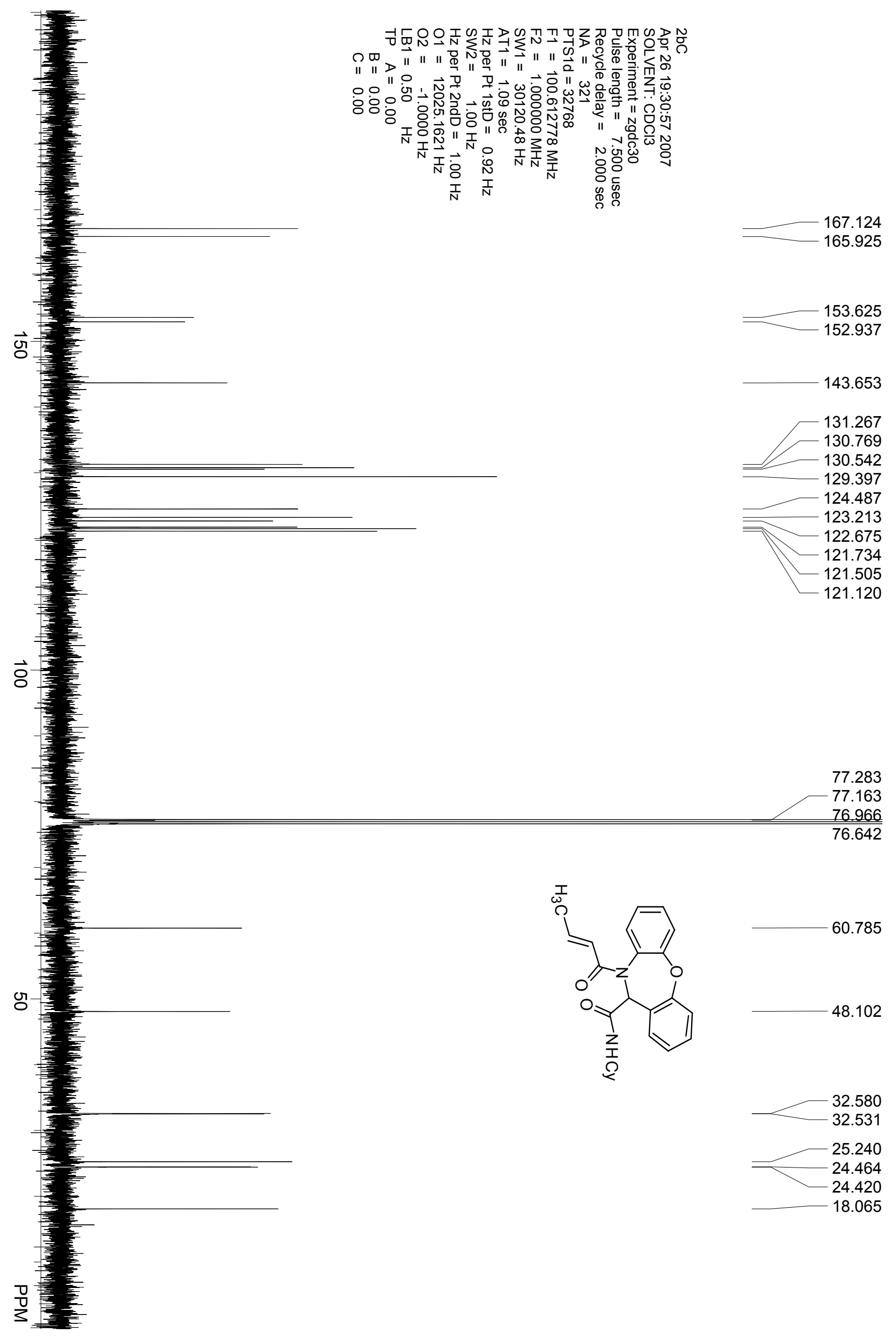



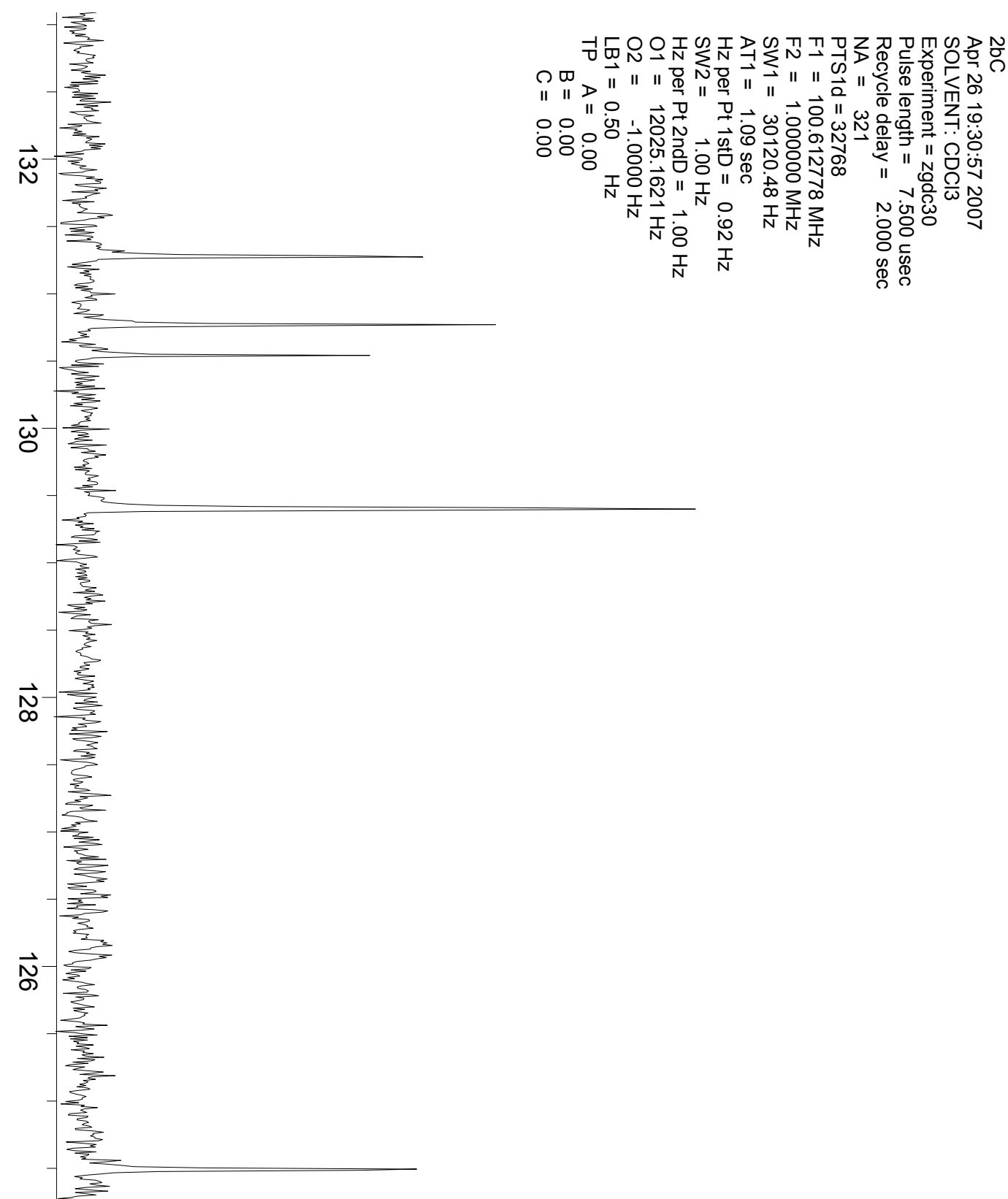


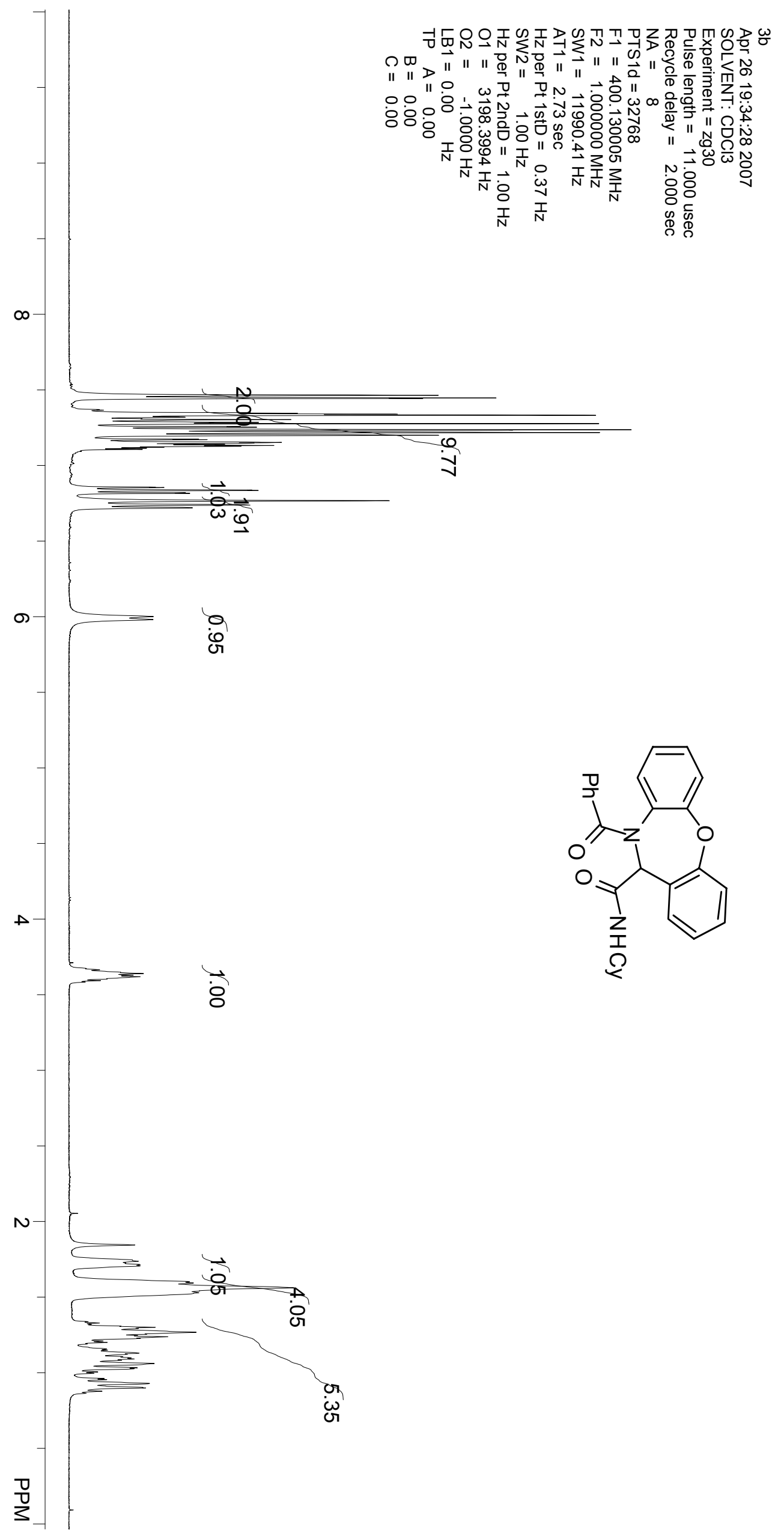

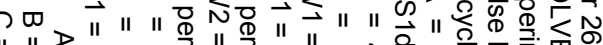




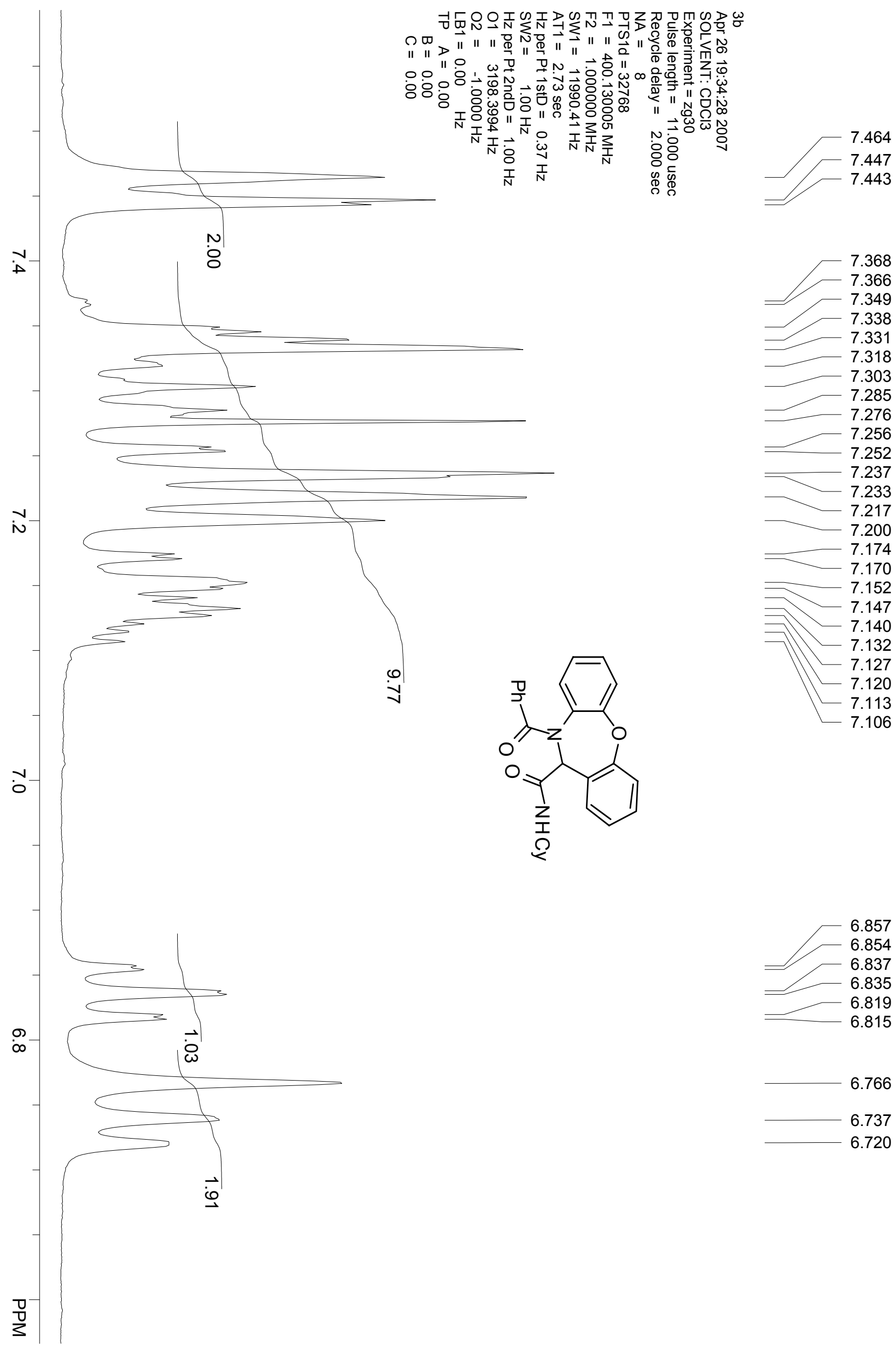




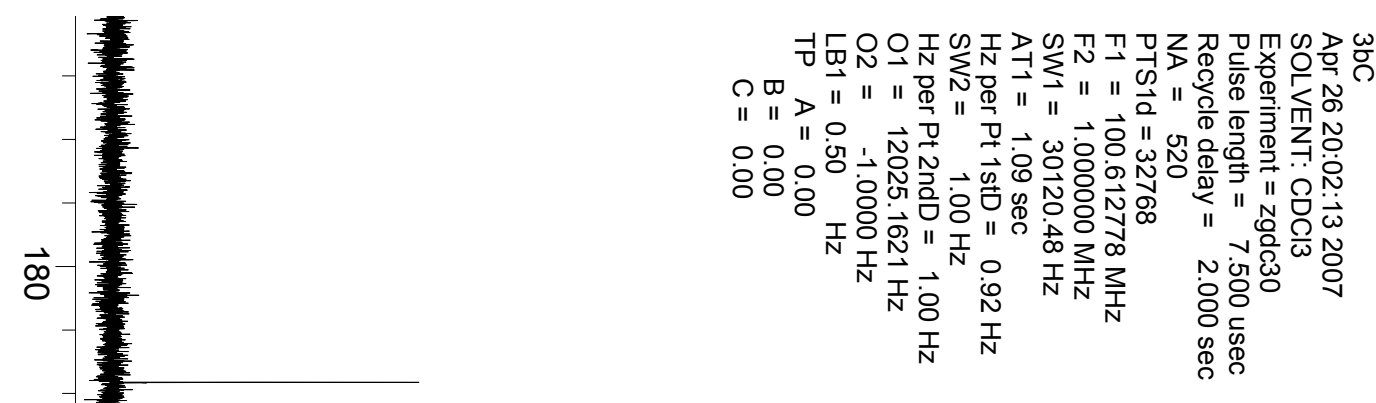<smiles></smiles>

61.454

8

-

$-$

+

-

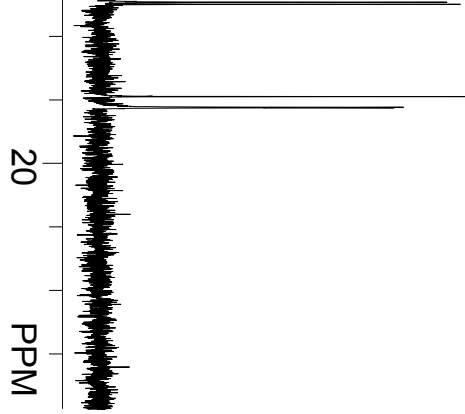

2.706

32.545

25.283 


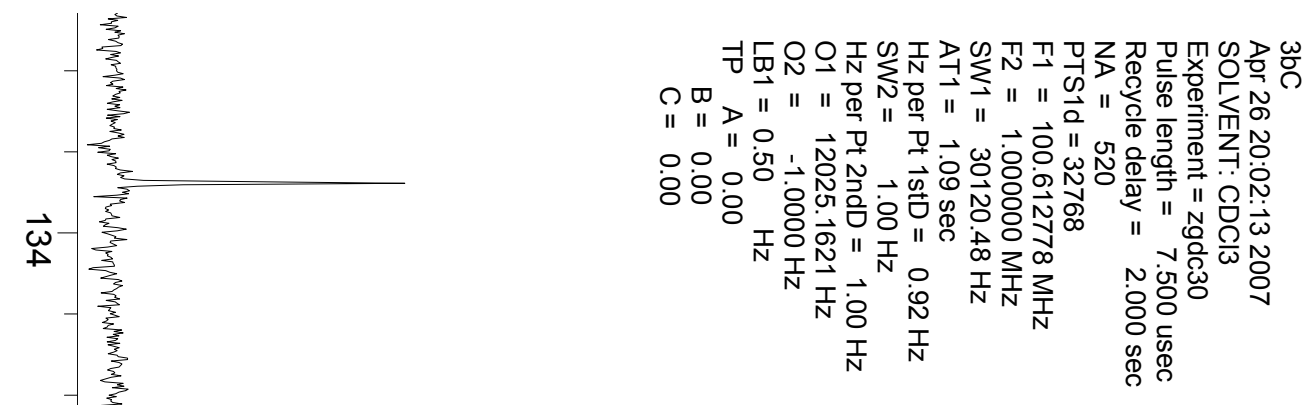<smiles>[CH]C(=O)C1c2ccccc2Oc2ccccc2C1C(=O)O</smiles>

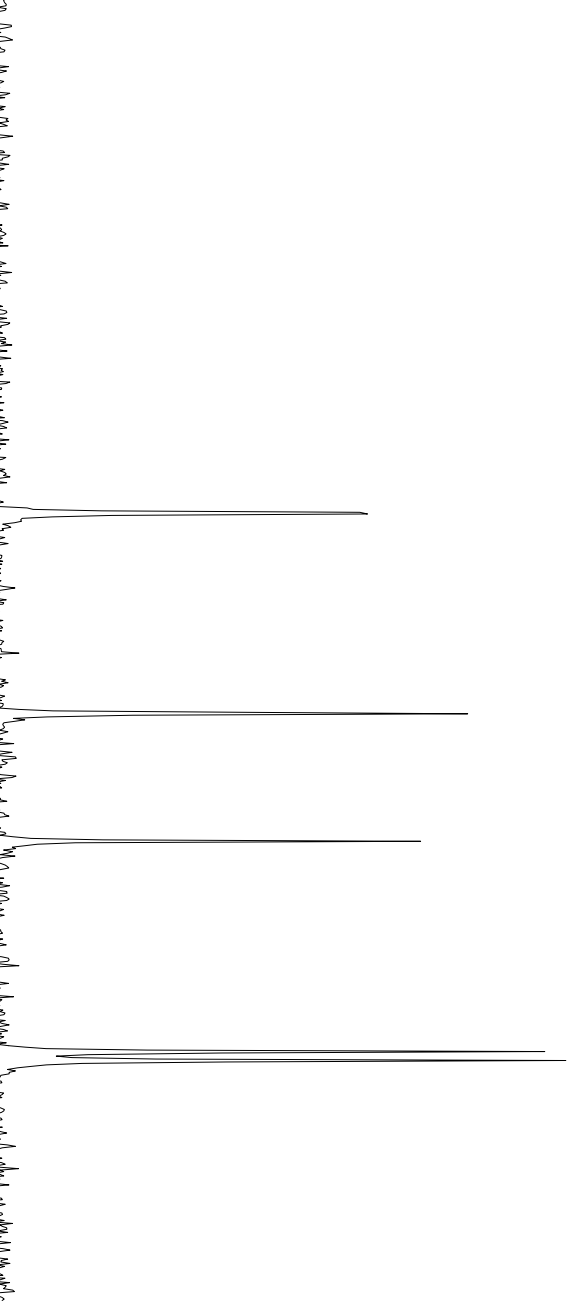




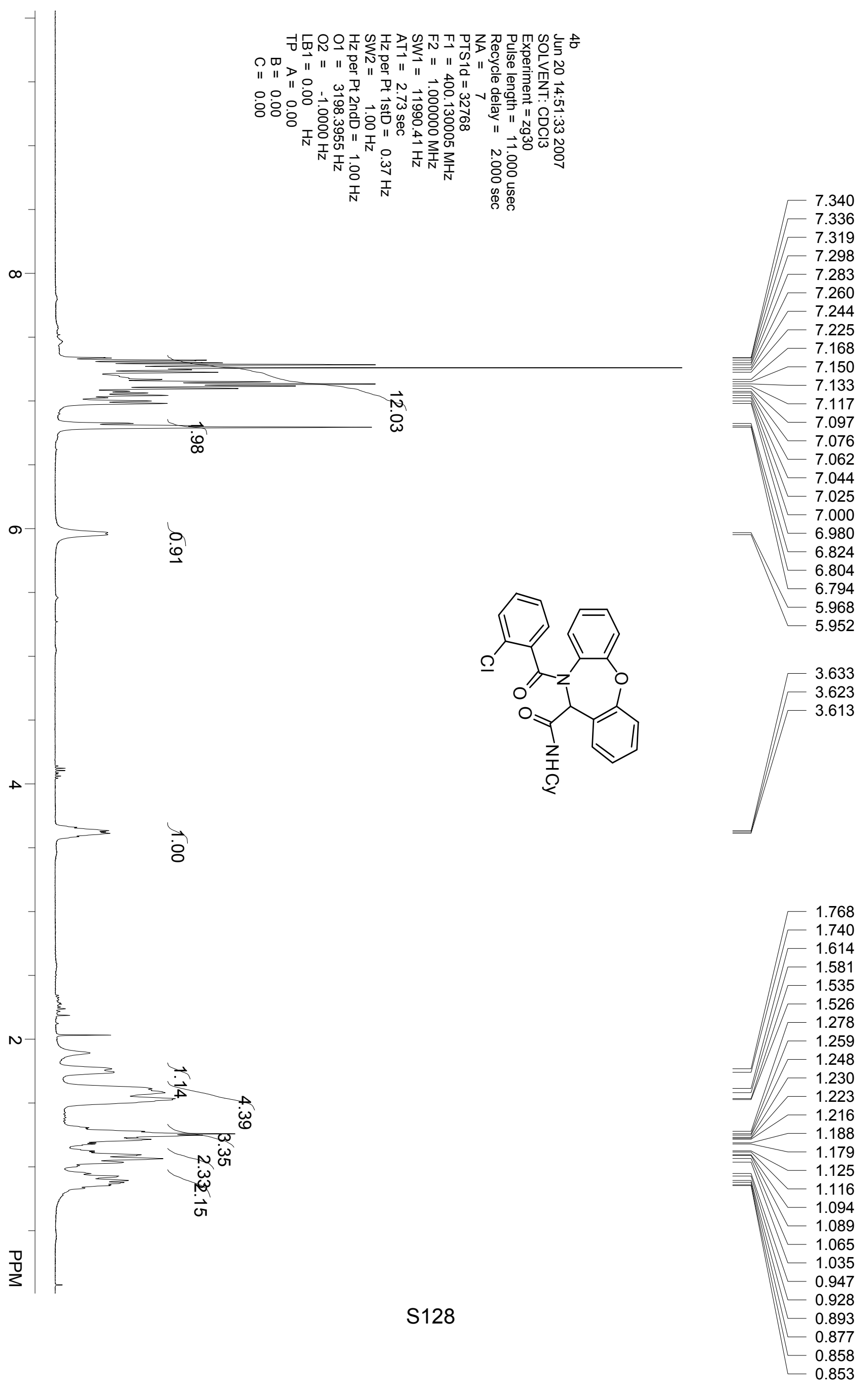




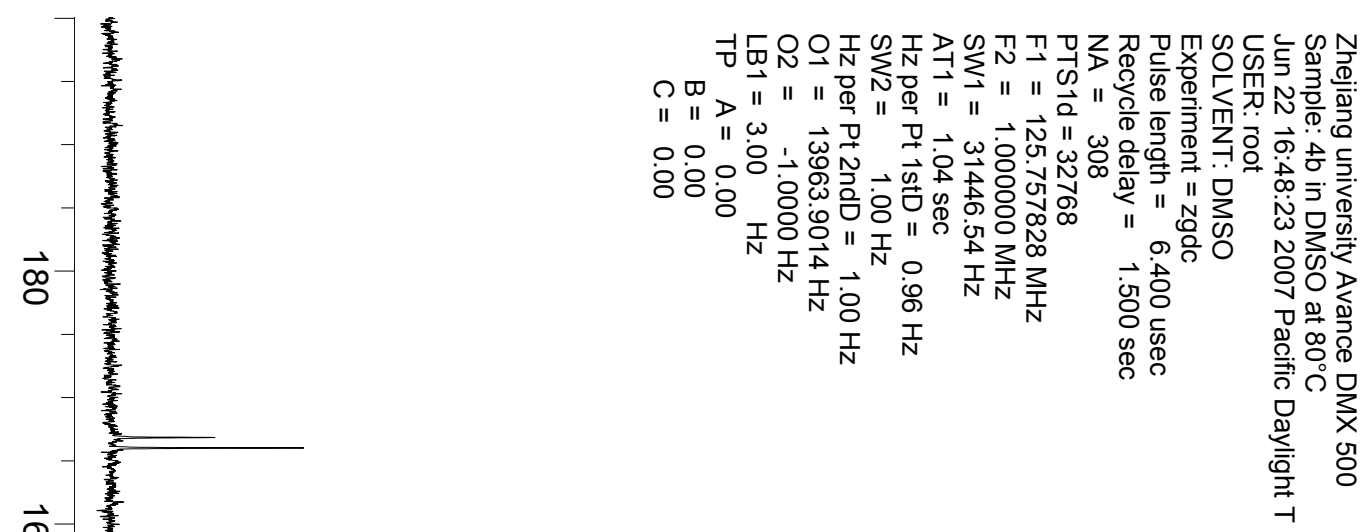

166.839 166.012

$\vec{\circ}$

웅

$\vec{N}$

$\overrightarrow{8}$

ᄋ

ㅇ-

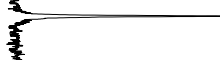

ज<smiles>O=C(OC1c2ccccc2Oc2ccccc21)C(=O)C1C(=O)c2ccccc2Oc2ccccc21</smiles>

153.978

152.573

130.933

130.695

129.890

135.663

129.697

129.332

129.238

129.179

128.688

126.863

124.348

123.241

122.894

120.668

120.582 

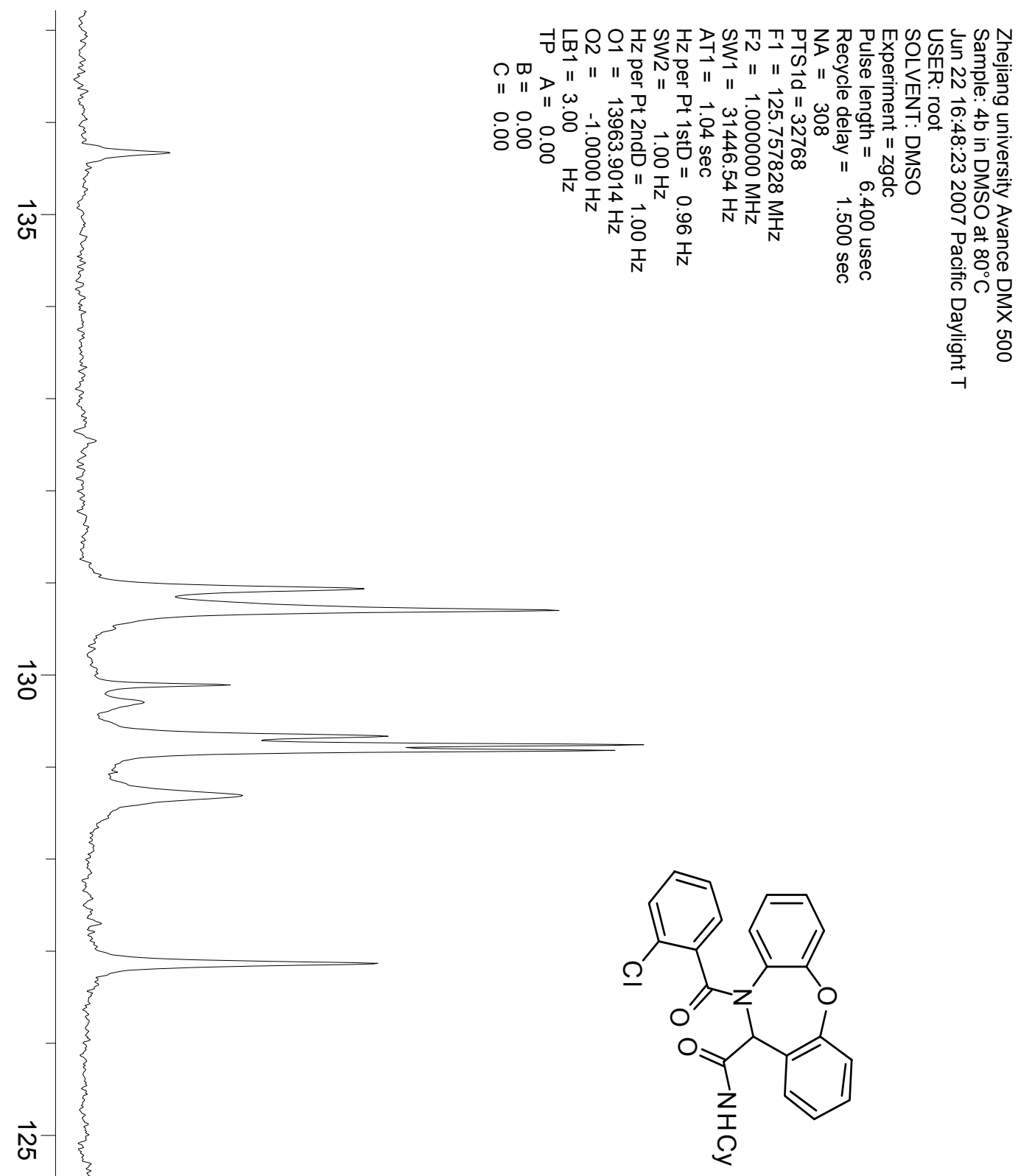

126.863 


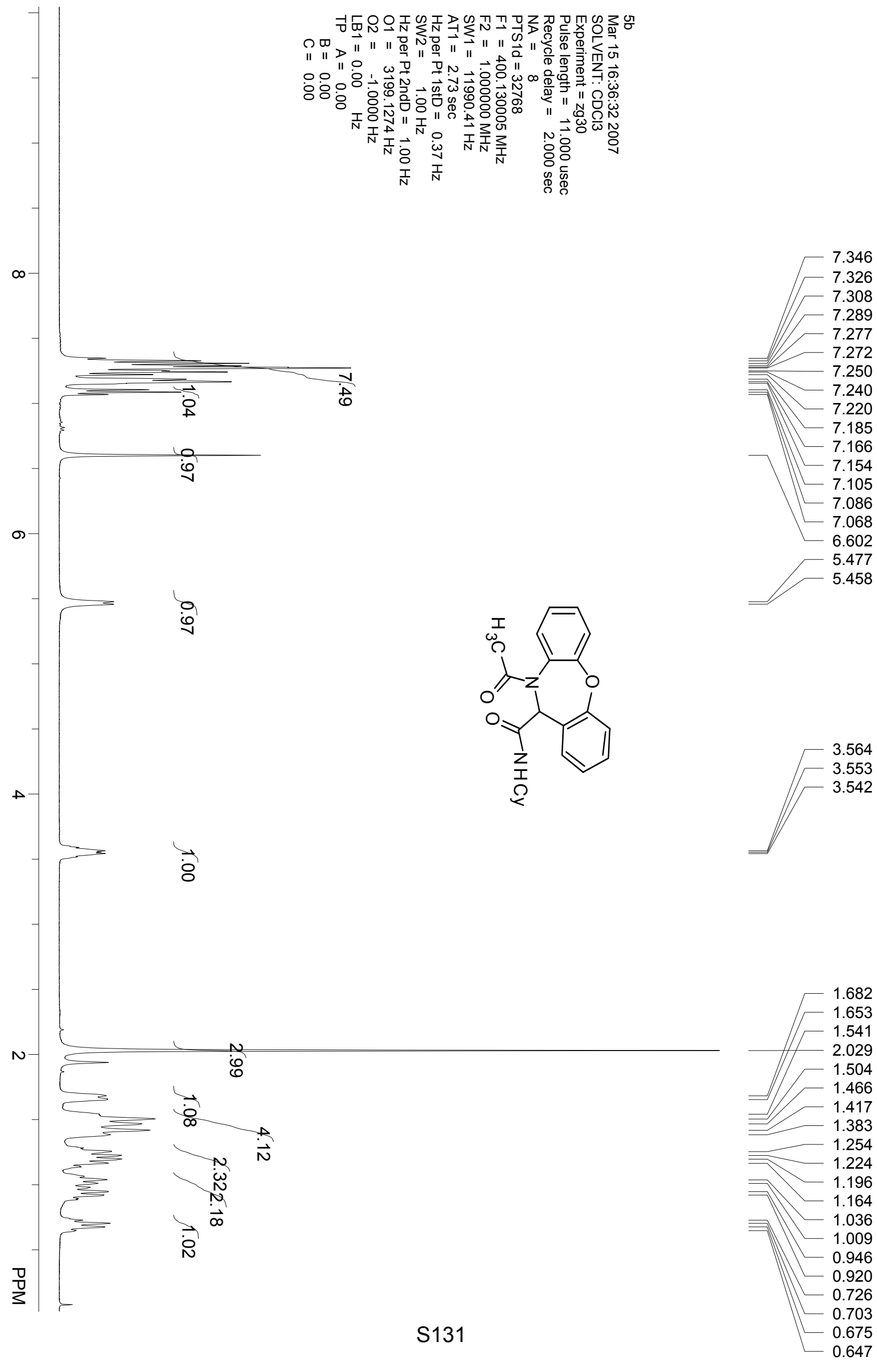




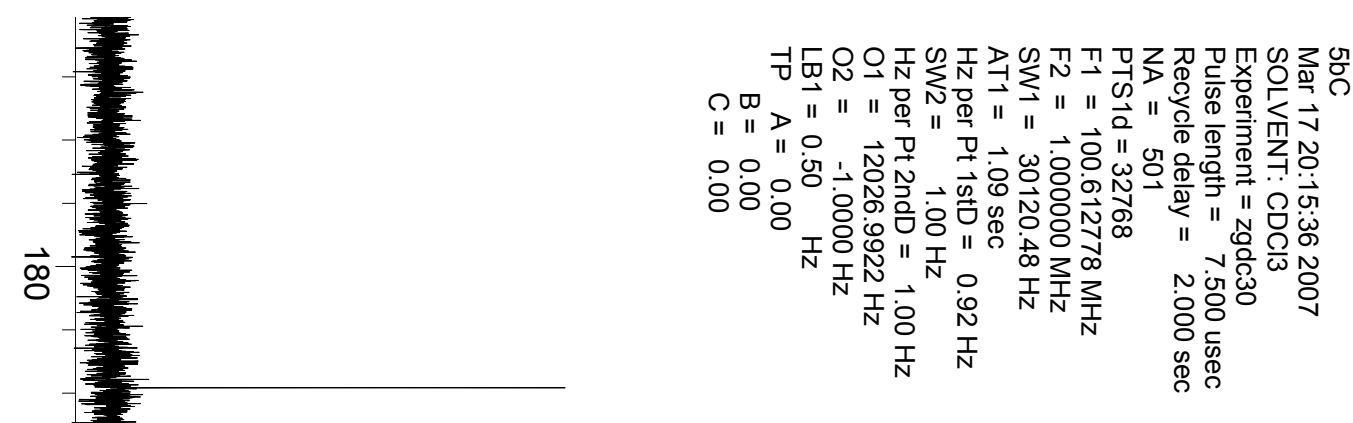

。<smiles></smiles> 

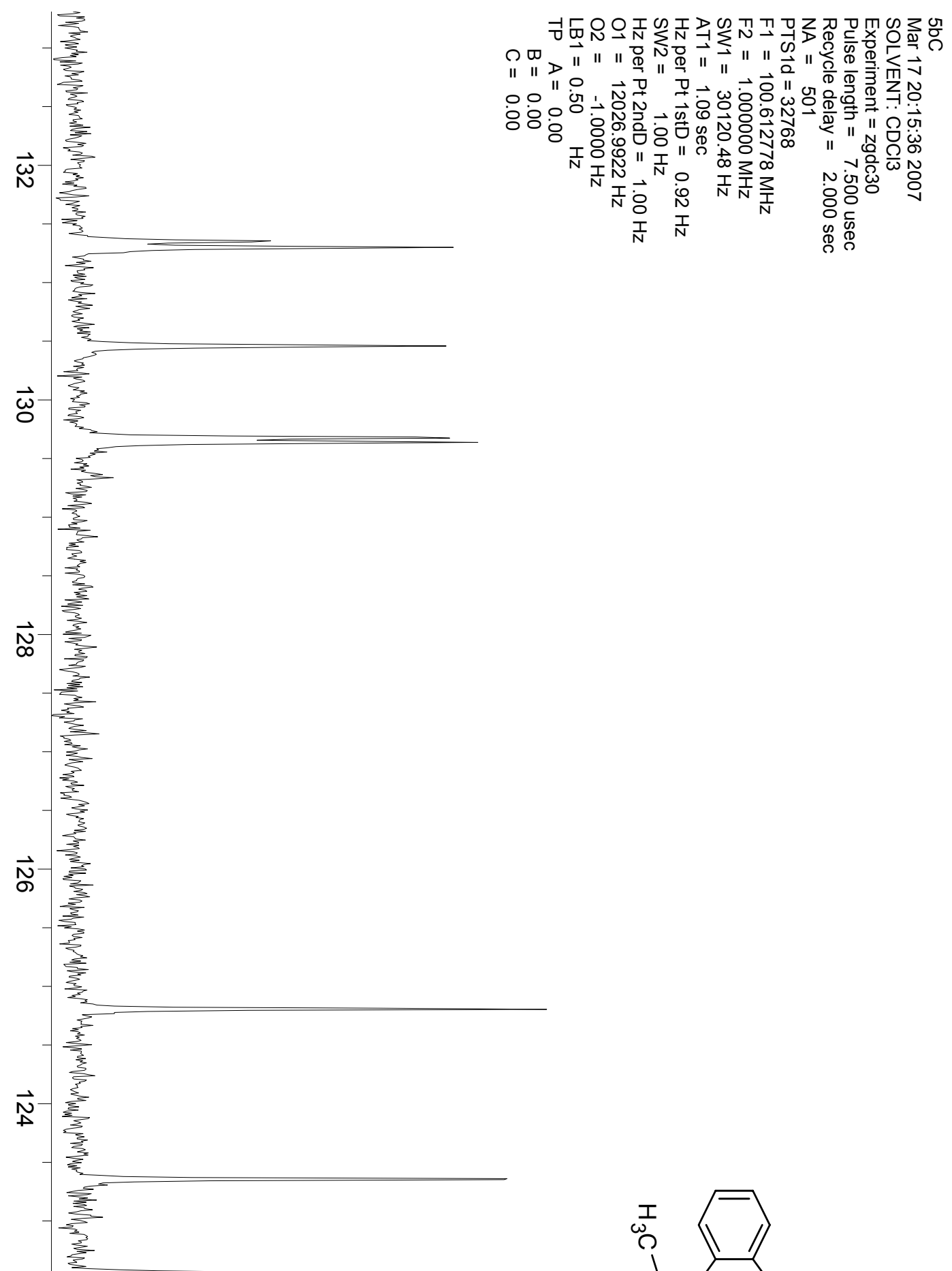<smiles>O=CC(=O)C1[C](C(=O)[O-])c2ccccc2Oc2ccccc21</smiles> 


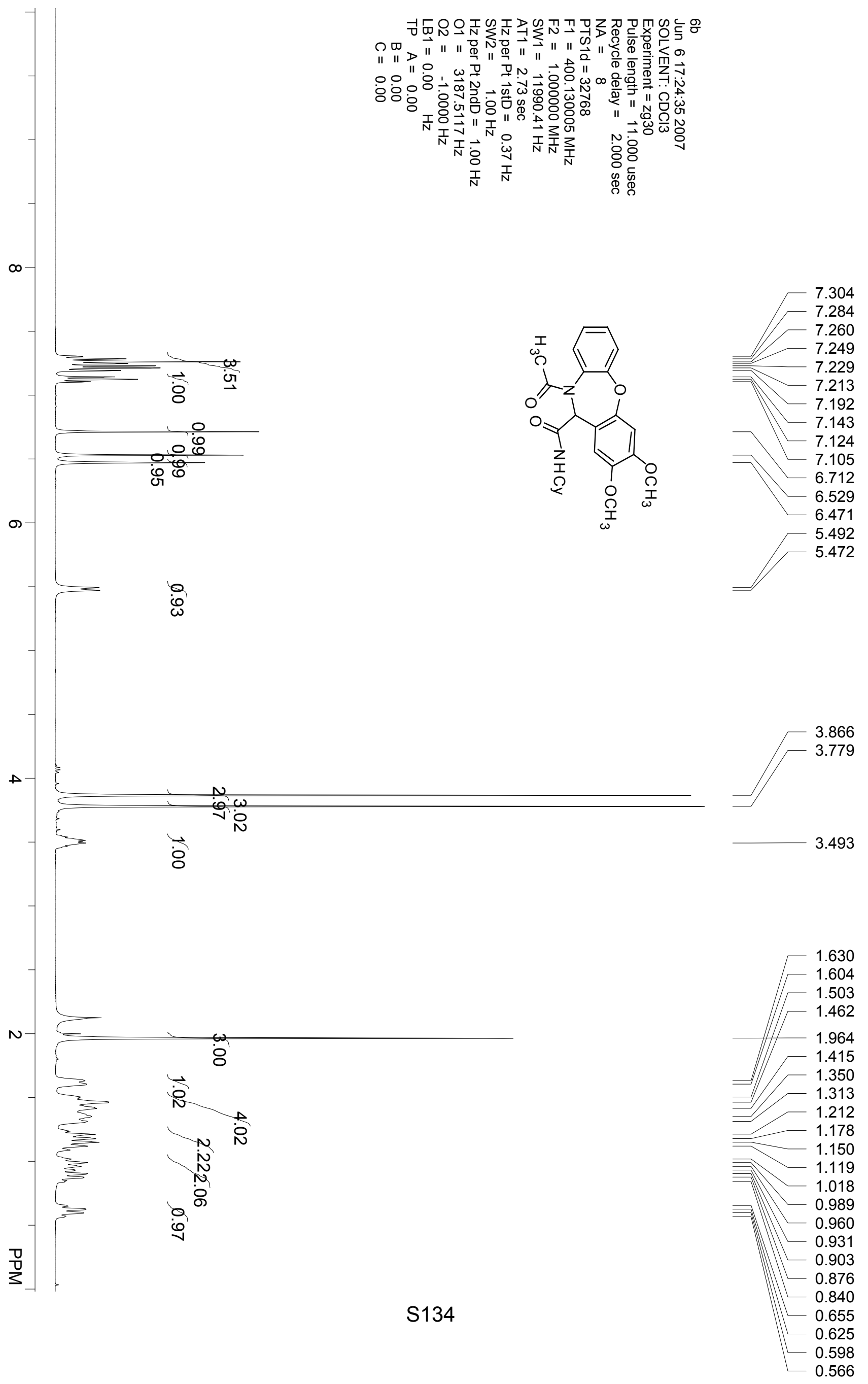




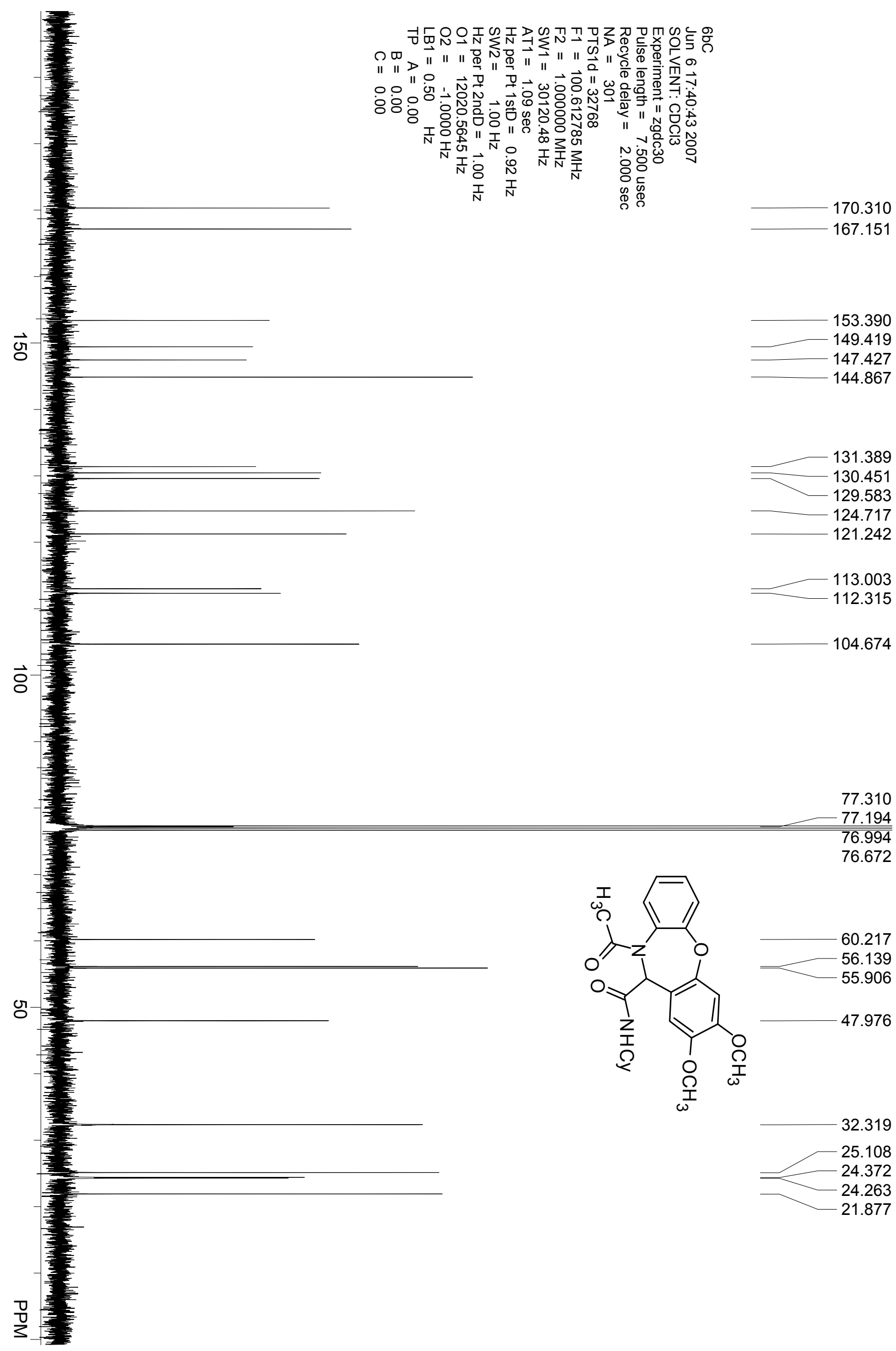




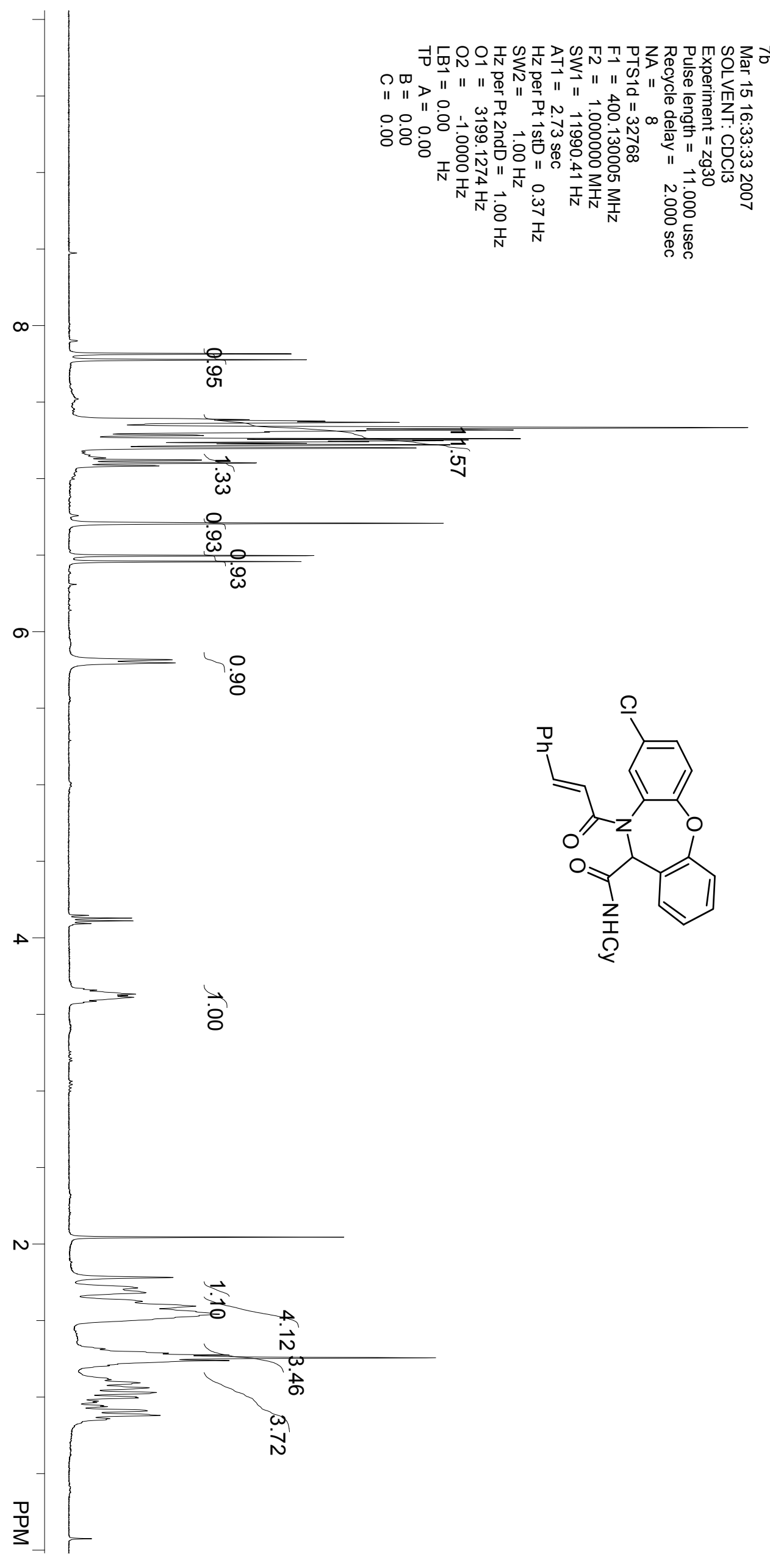




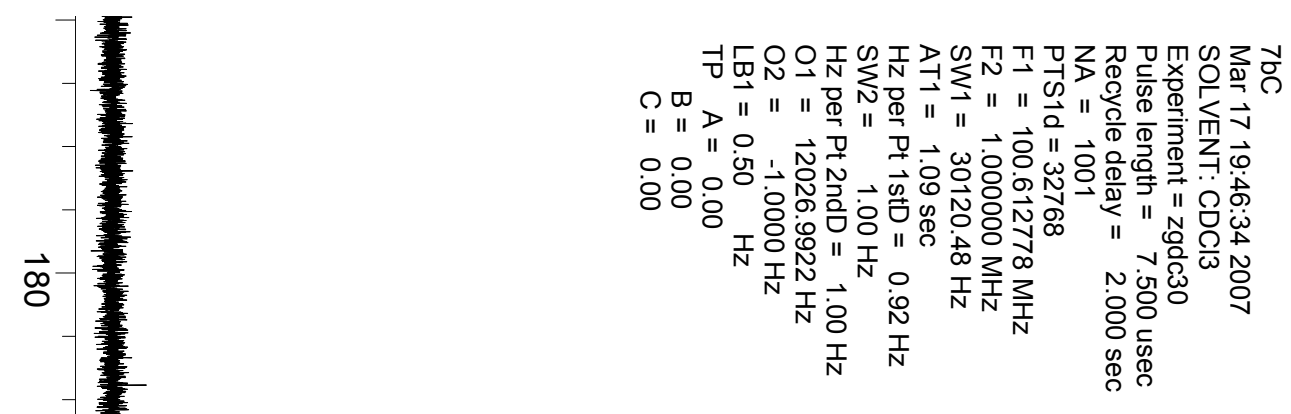<smiles>CC=CC(=O)C1c2cc(O)ccc2Oc2ccccc2C1C(=O)C=CC=O</smiles> 

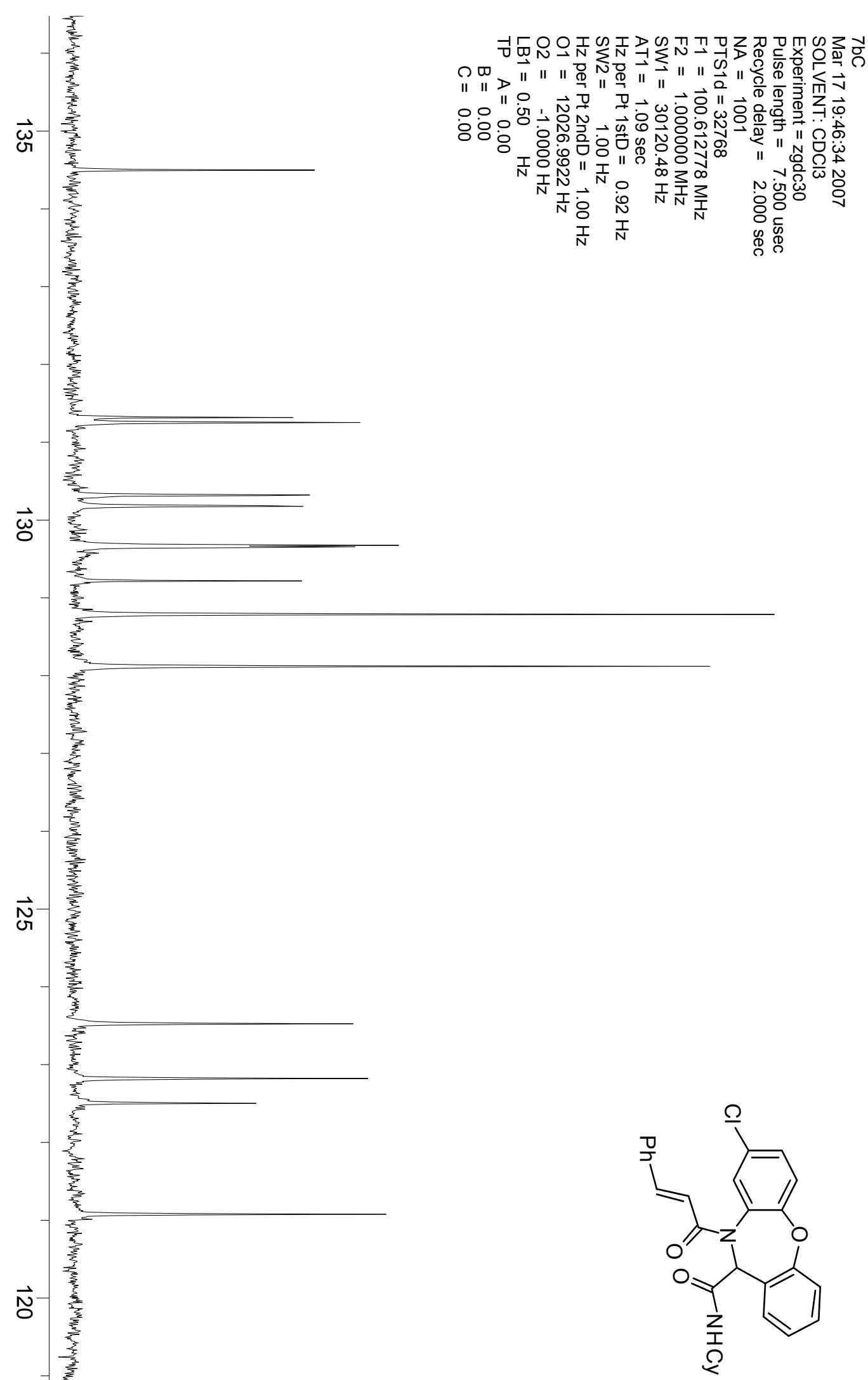

121.077 


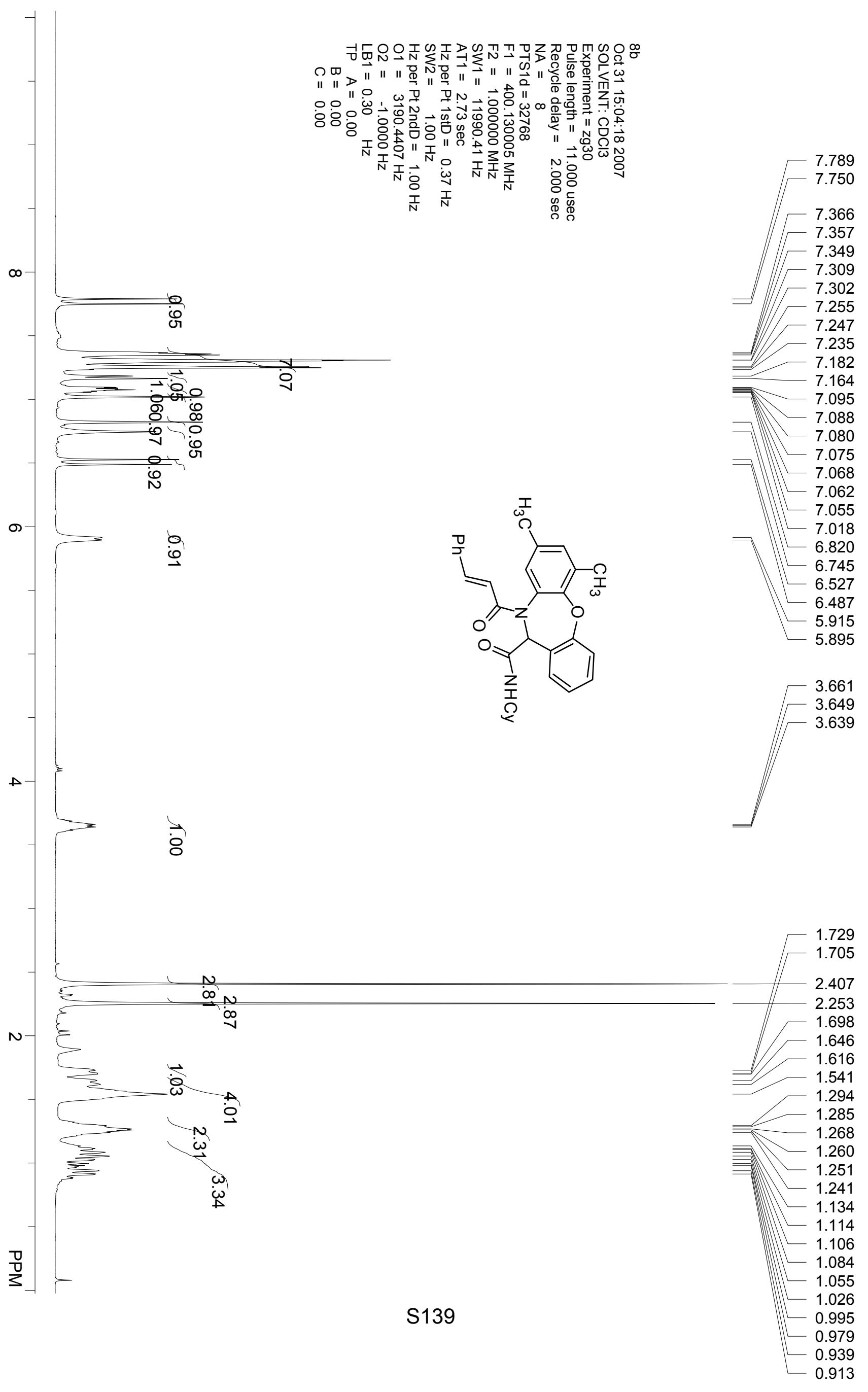




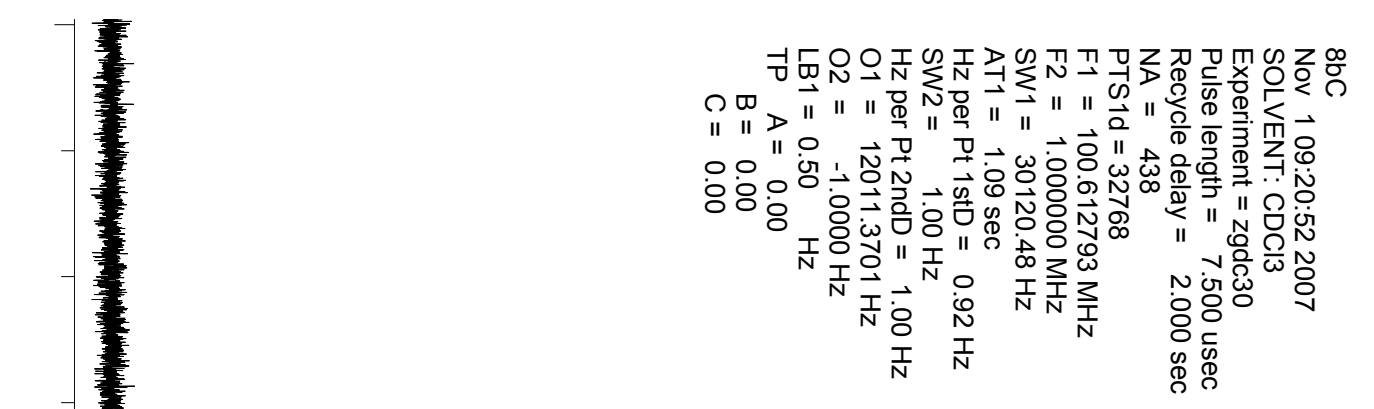<smiles>O=C(O)C(=O)C1c2cc([O-])cc([O-])c2Oc2ccccc2C1C(=O)O</smiles>

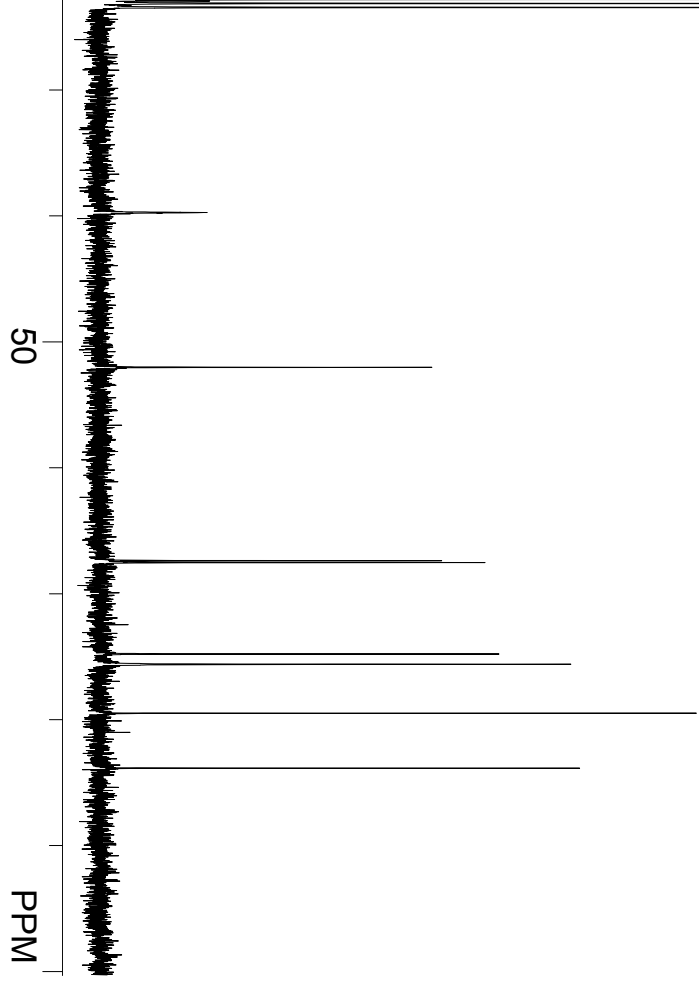



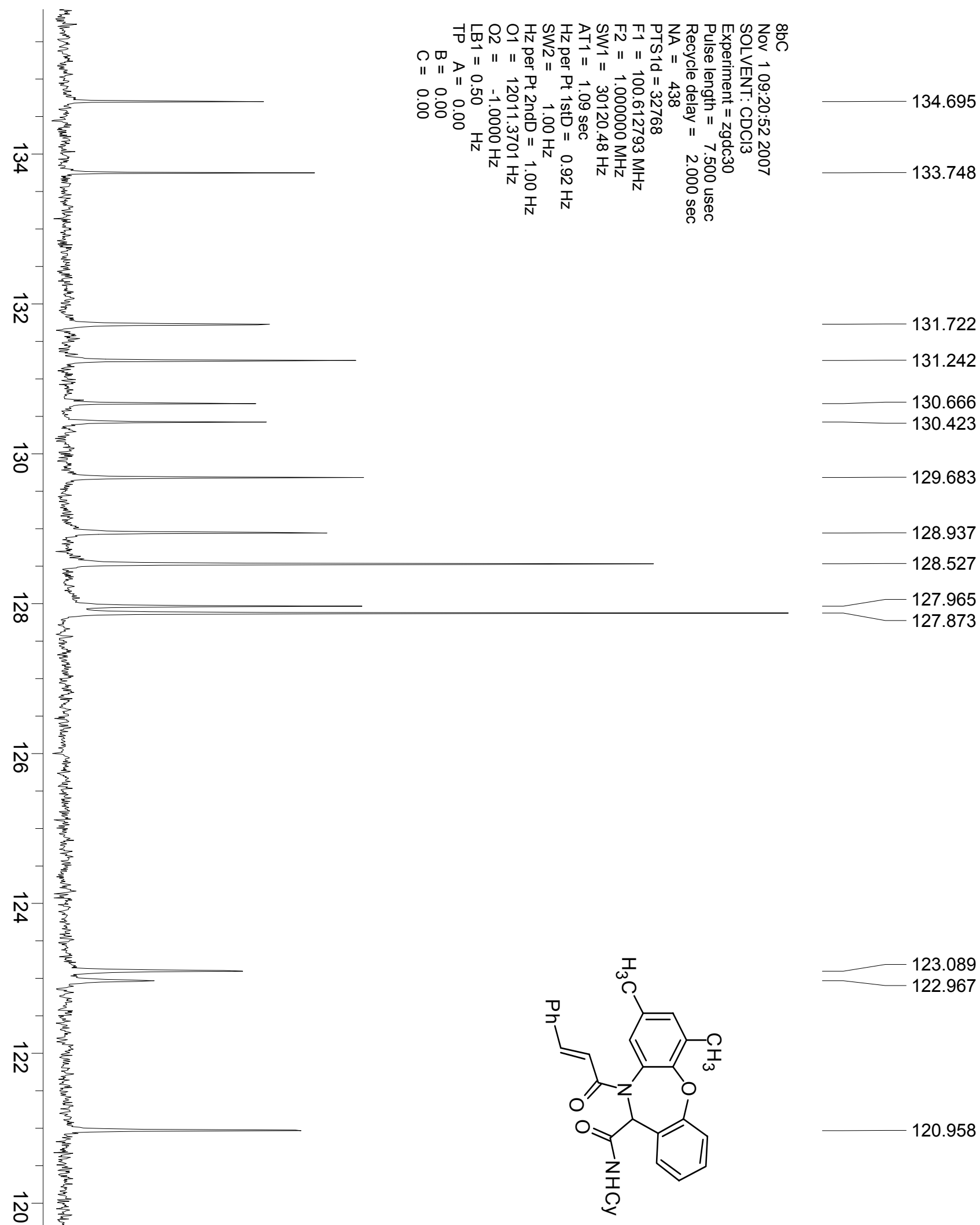

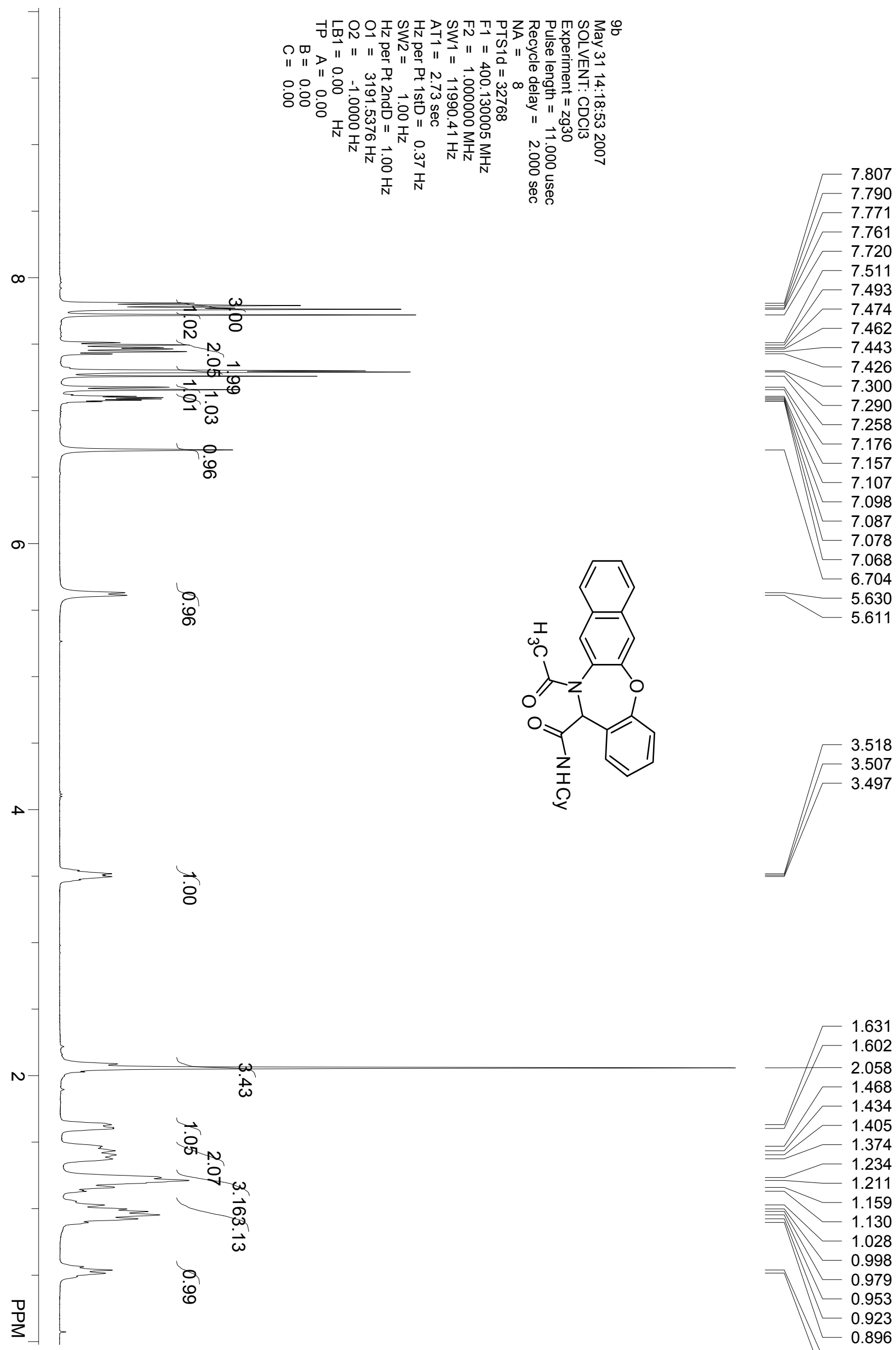


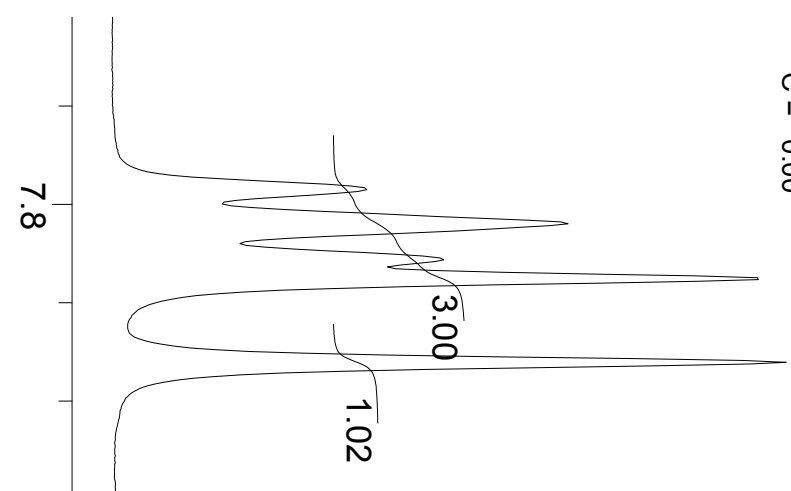

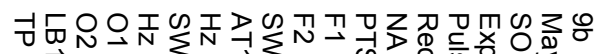

"

11"

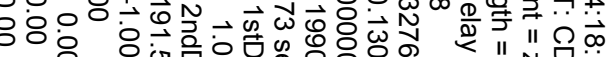
I T.

吕

7.761

7.720
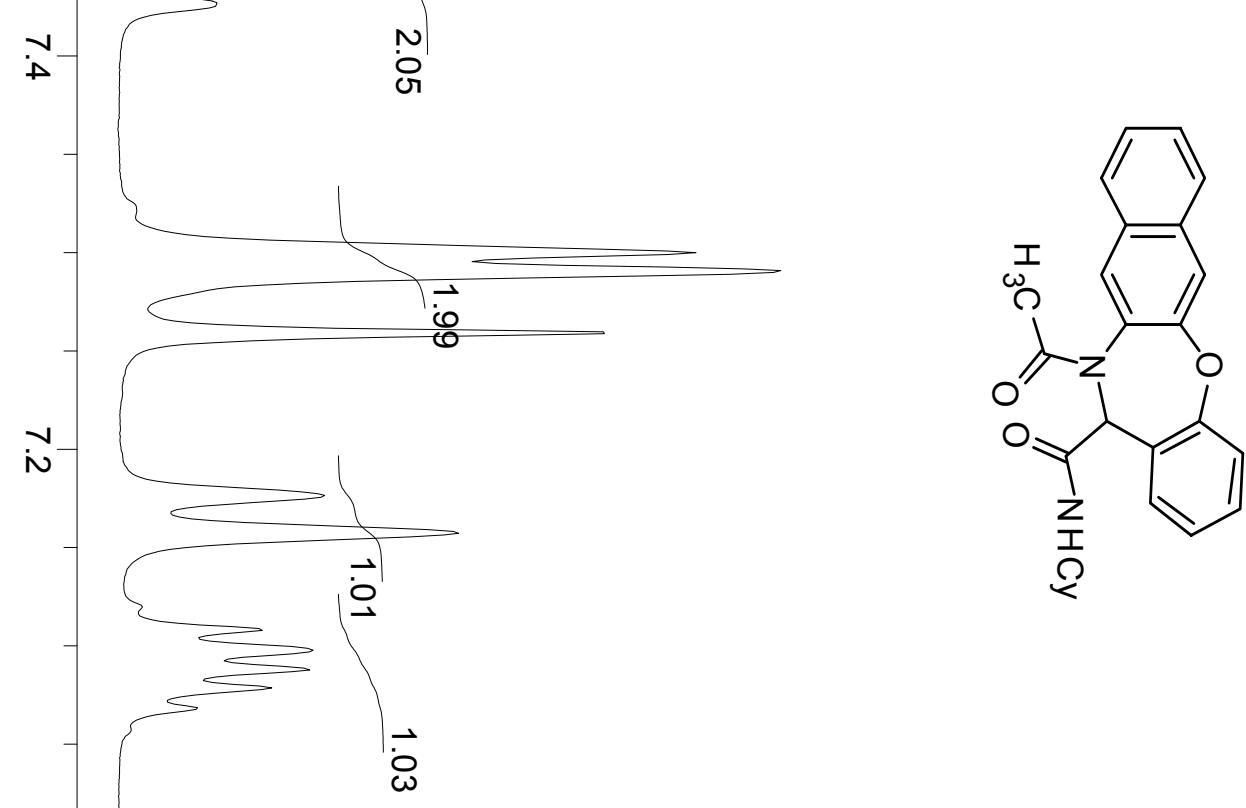

$\infty$ 


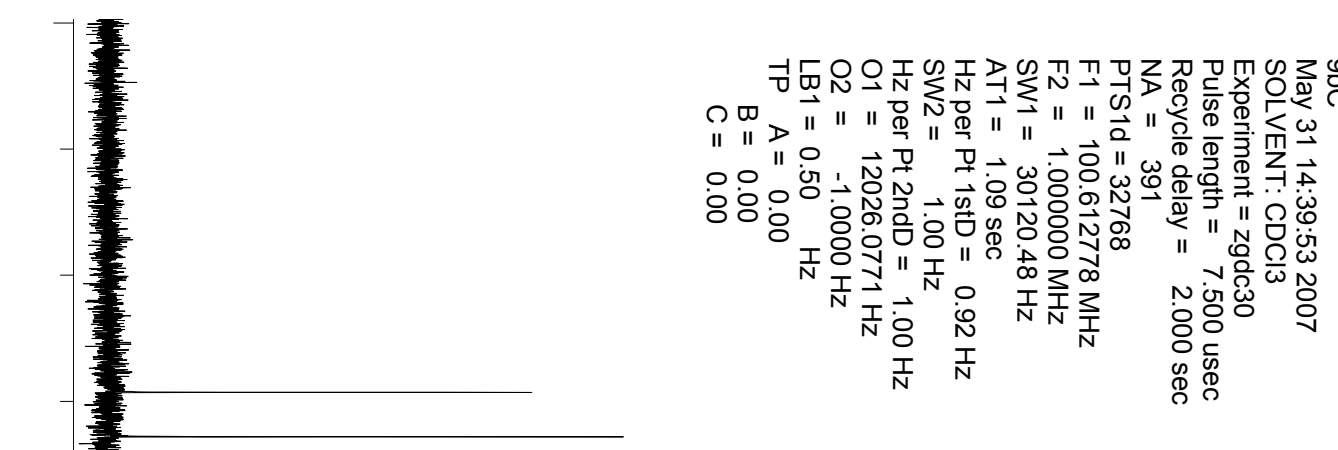<smiles>O=C(O)C1c2ccccc2Oc2cc3ccccc3cc2C1C(=O)O</smiles>

60.775 


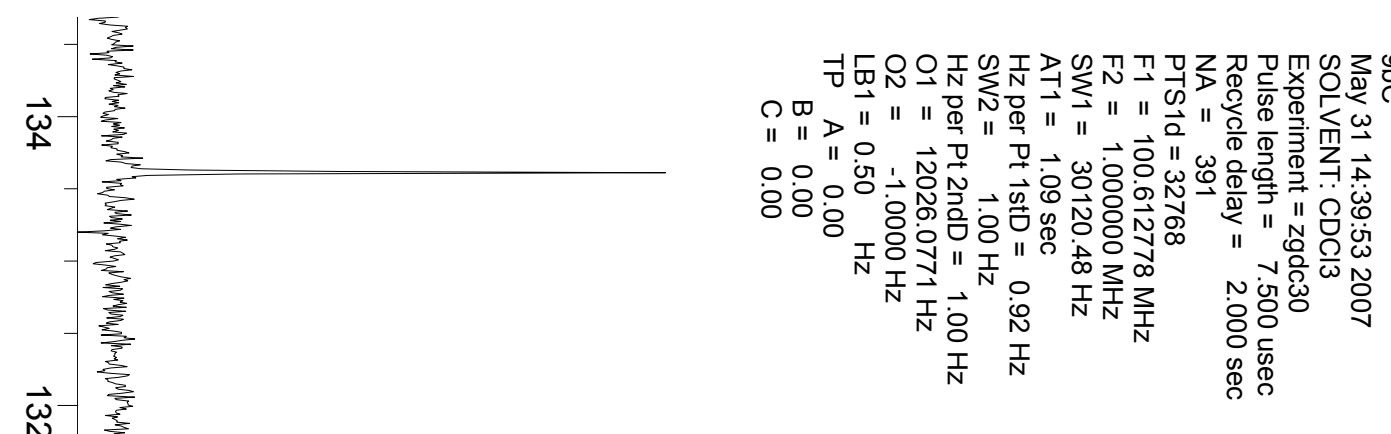

$\vec{\omega}$ 


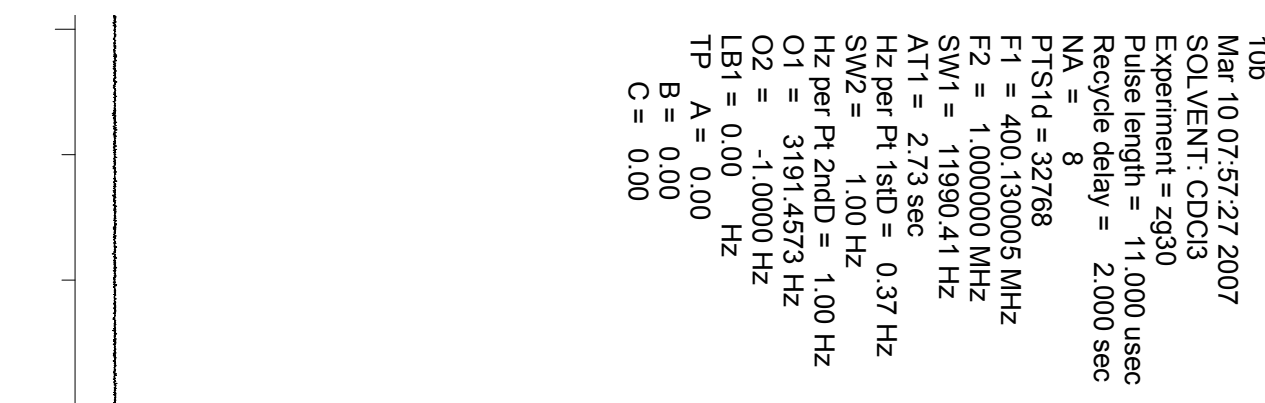

$\infty$

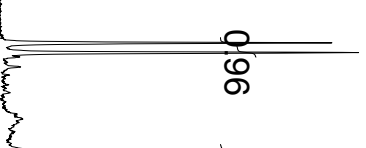

7.347 7.338

7.314

7.299

7.284

7.259

ㅁำ

7.235

7.171

7.154

7.134

7.115

7.097

6.878

6.597

6.491

6.451

4.170

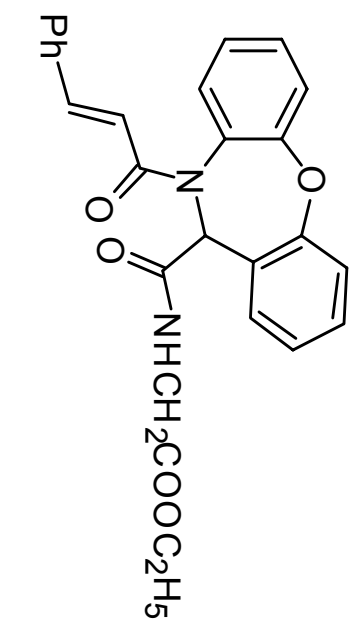

4.153

4.135

4.117

4.068

4.053

4.022

4.007

3.803

3.792

3.758

3.746

$\frac{0}{0}$ 

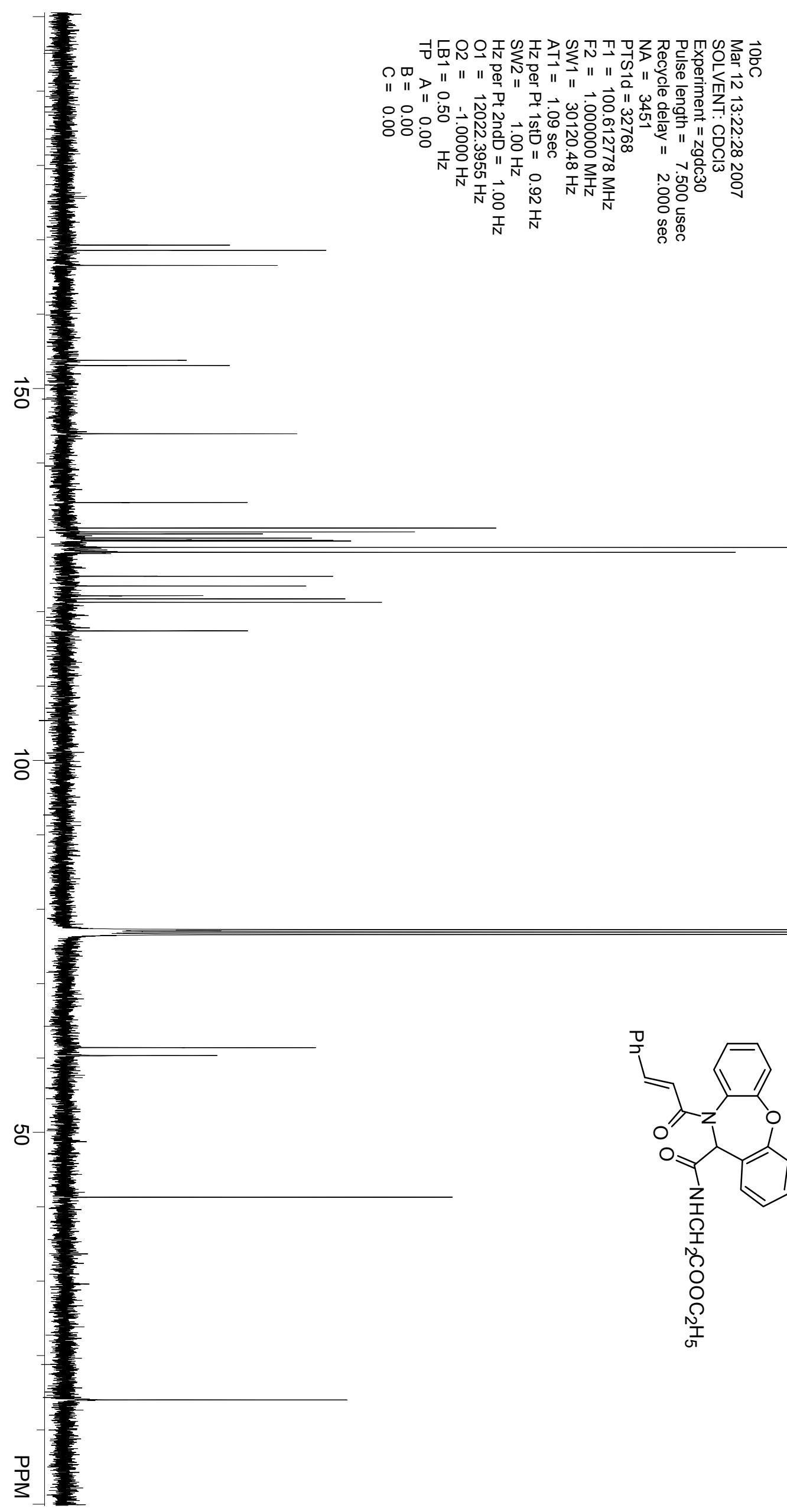

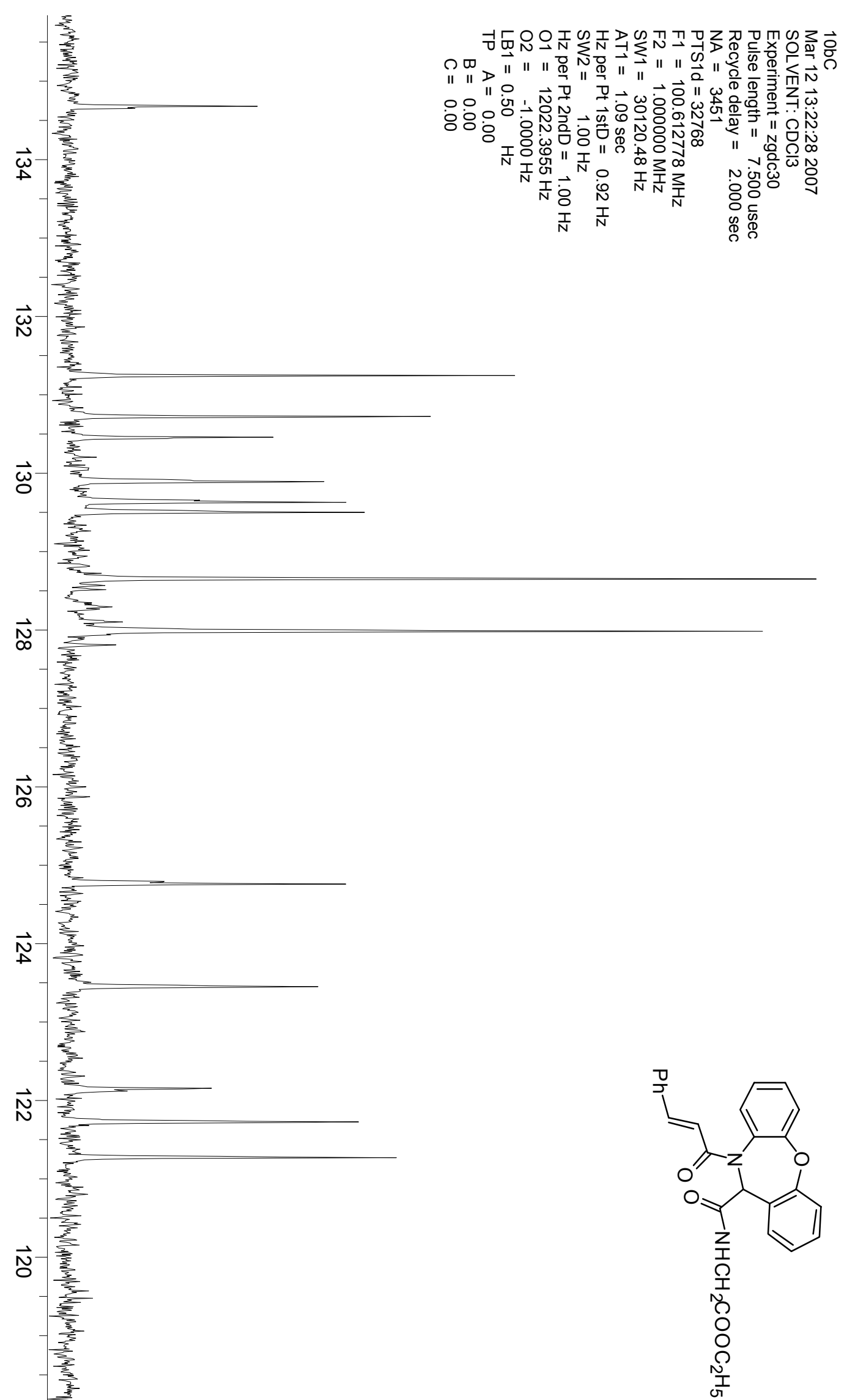

122.149 


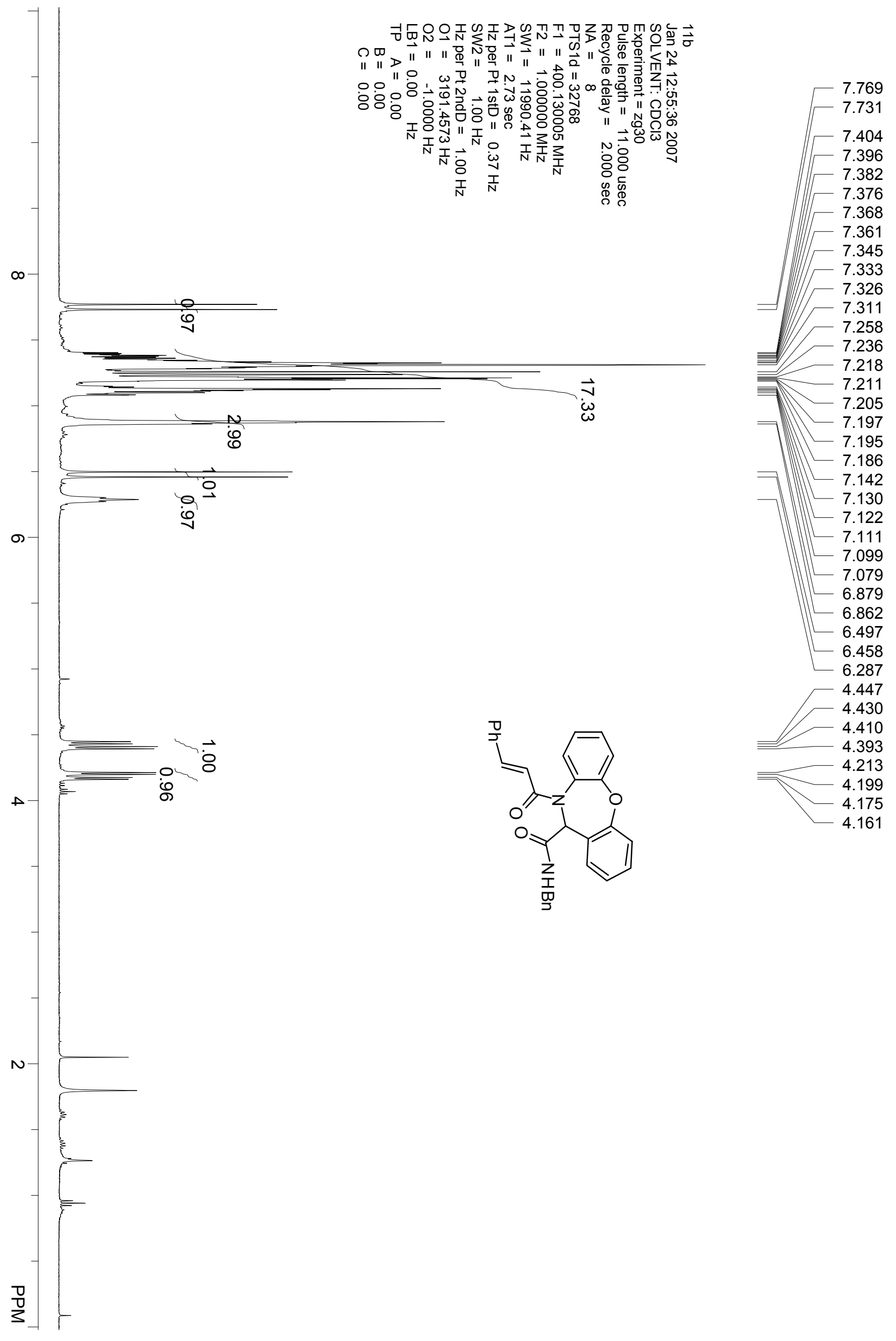




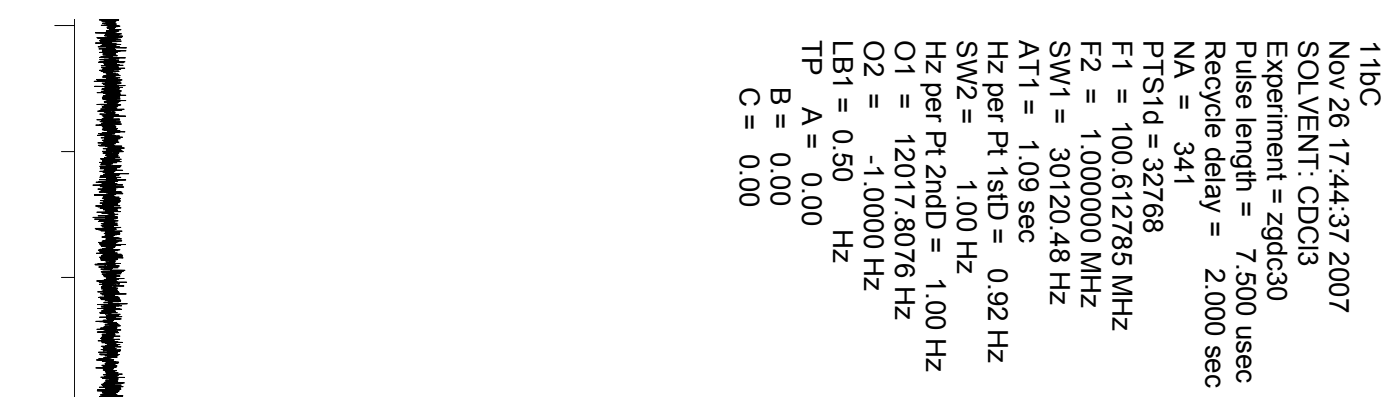

168.105

166.109

$\vec{\sigma}$

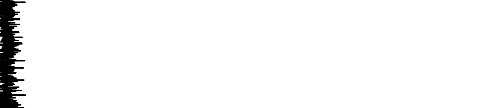

153.634

152.742

131.328

143.797

130.840

$130.28 \%$

134.625

129.861

129.626

129.537

128.632

128.400

127.925

$-127.315$

127.168

124.638

123.316

122.195

121.683

121.253

117.308

77.289

77.175

76.973

76.655

60.877<smiles>C=CC(=O)C1c2ccccc2Oc2ccccc2C1C(=O)C=CC</smiles>

43.399

$\frac{0}{0}$ 


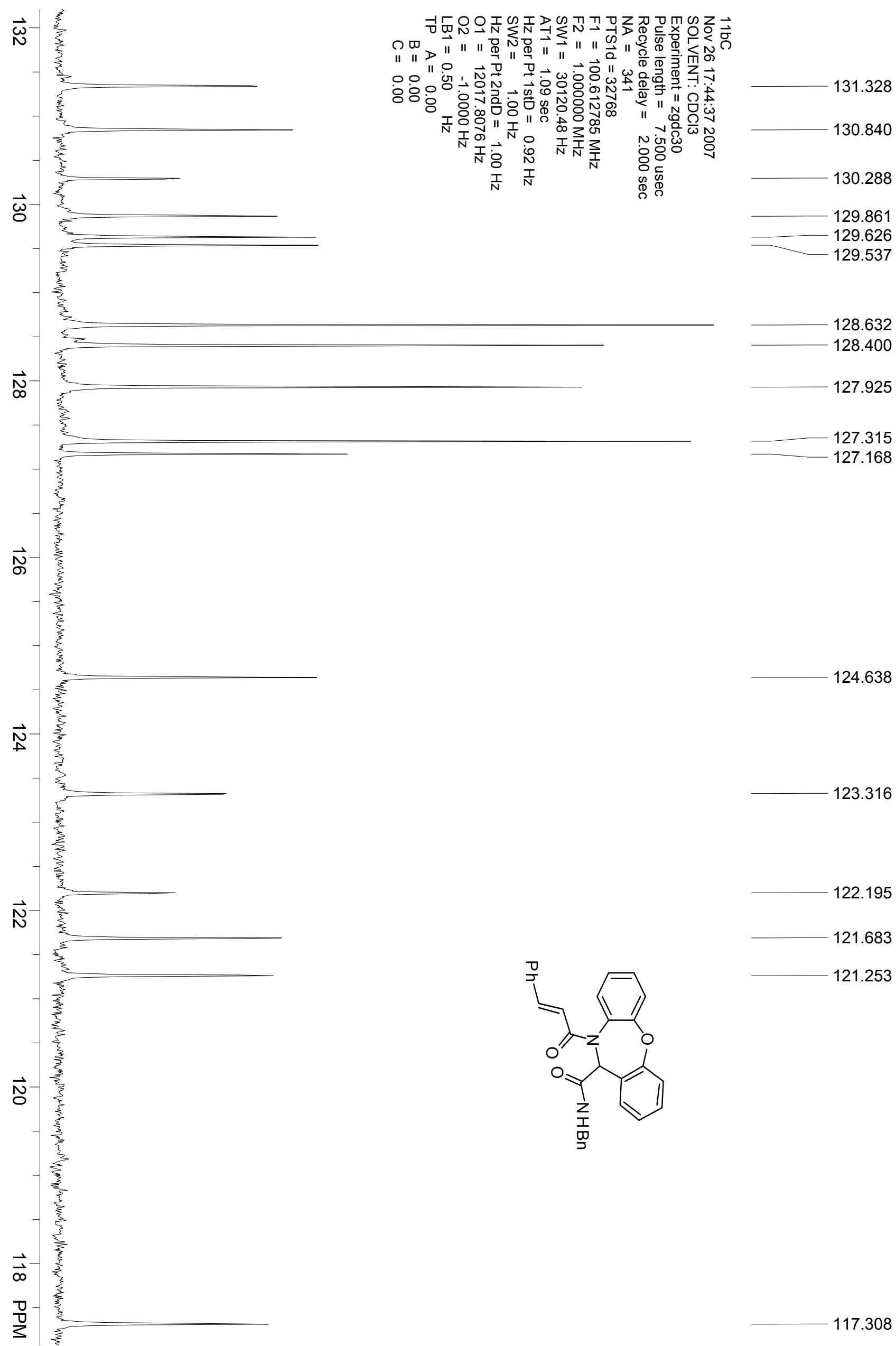




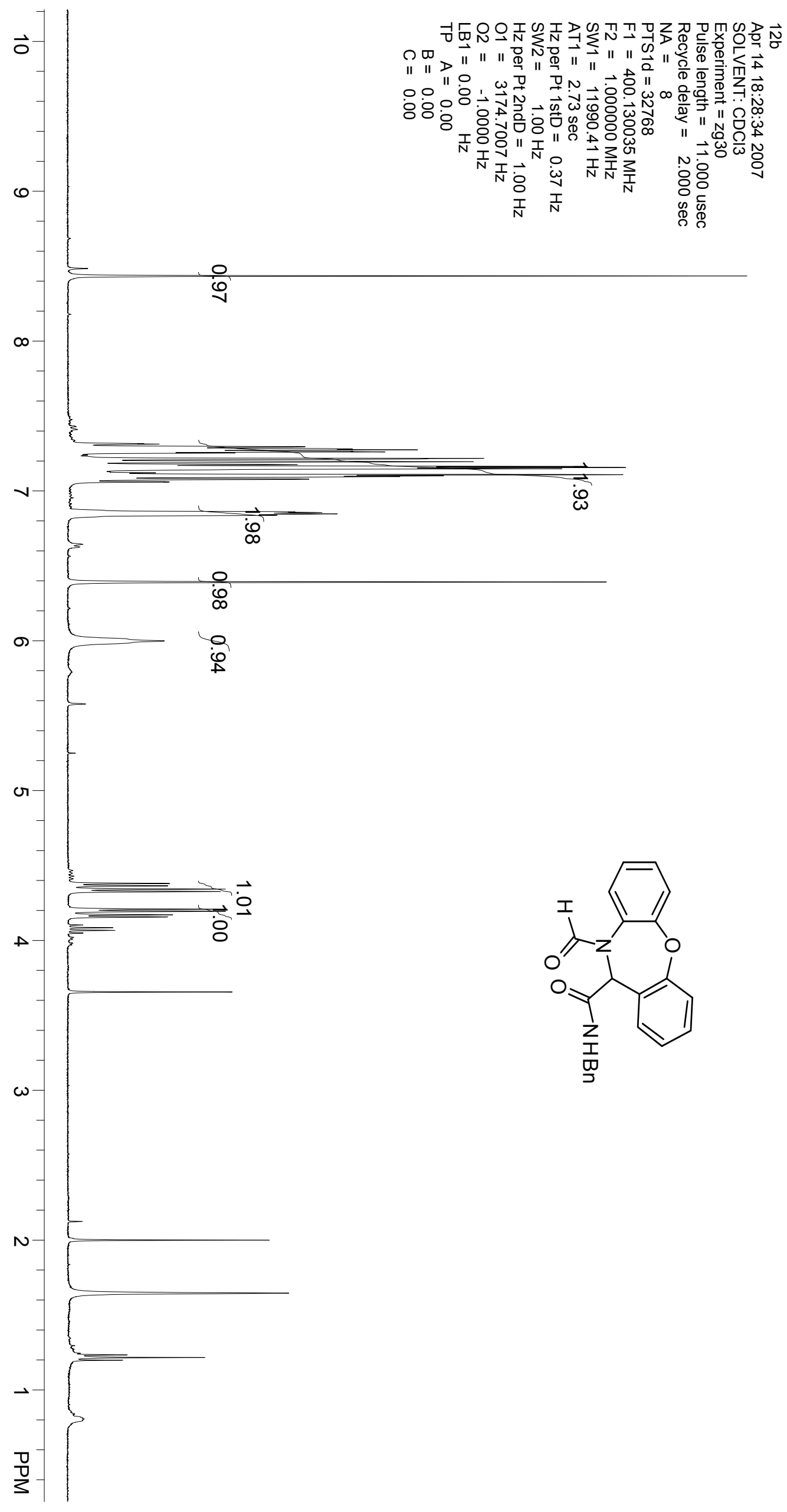




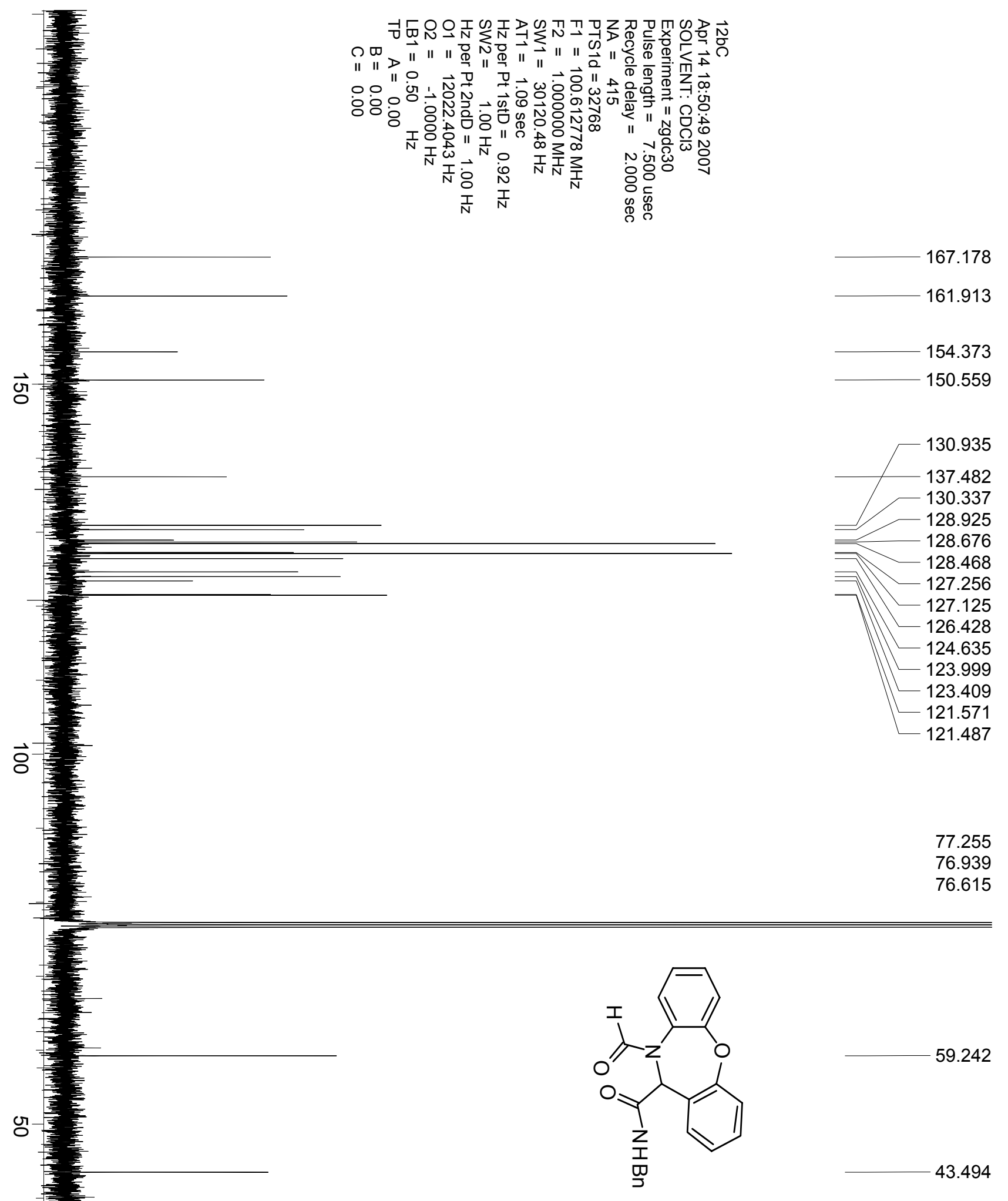




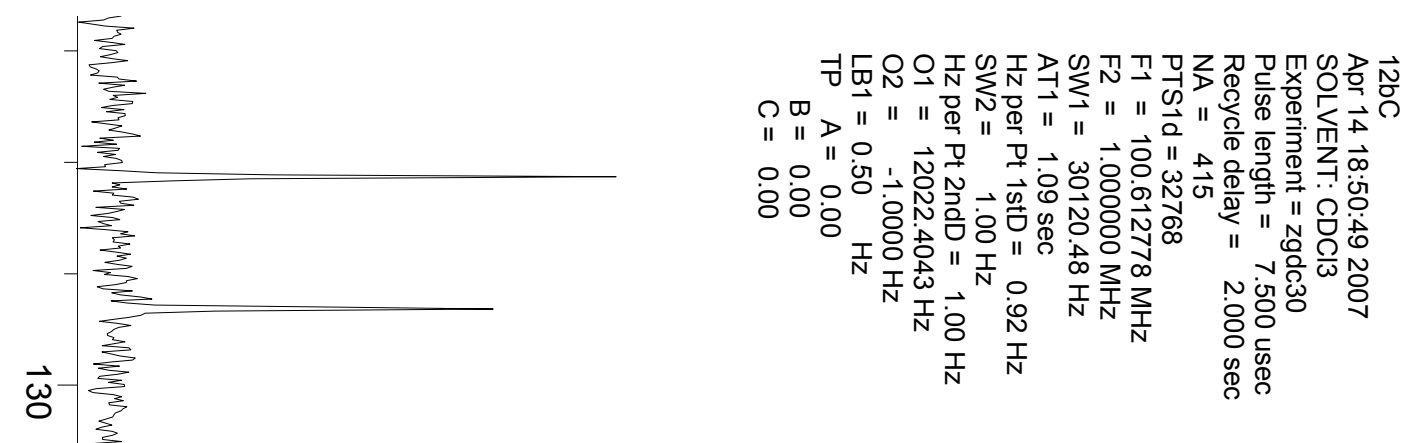

128.925

$\vec{N}-$

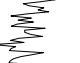

$\vec{N}$

$\vec{N}$

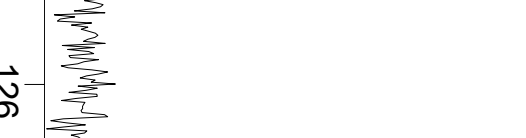

127.125

126.428<smiles>[CH]C(=O)C1c2ccccc2Oc2ccccc2C1C(=O)[Te]</smiles>

123.999

123.409 


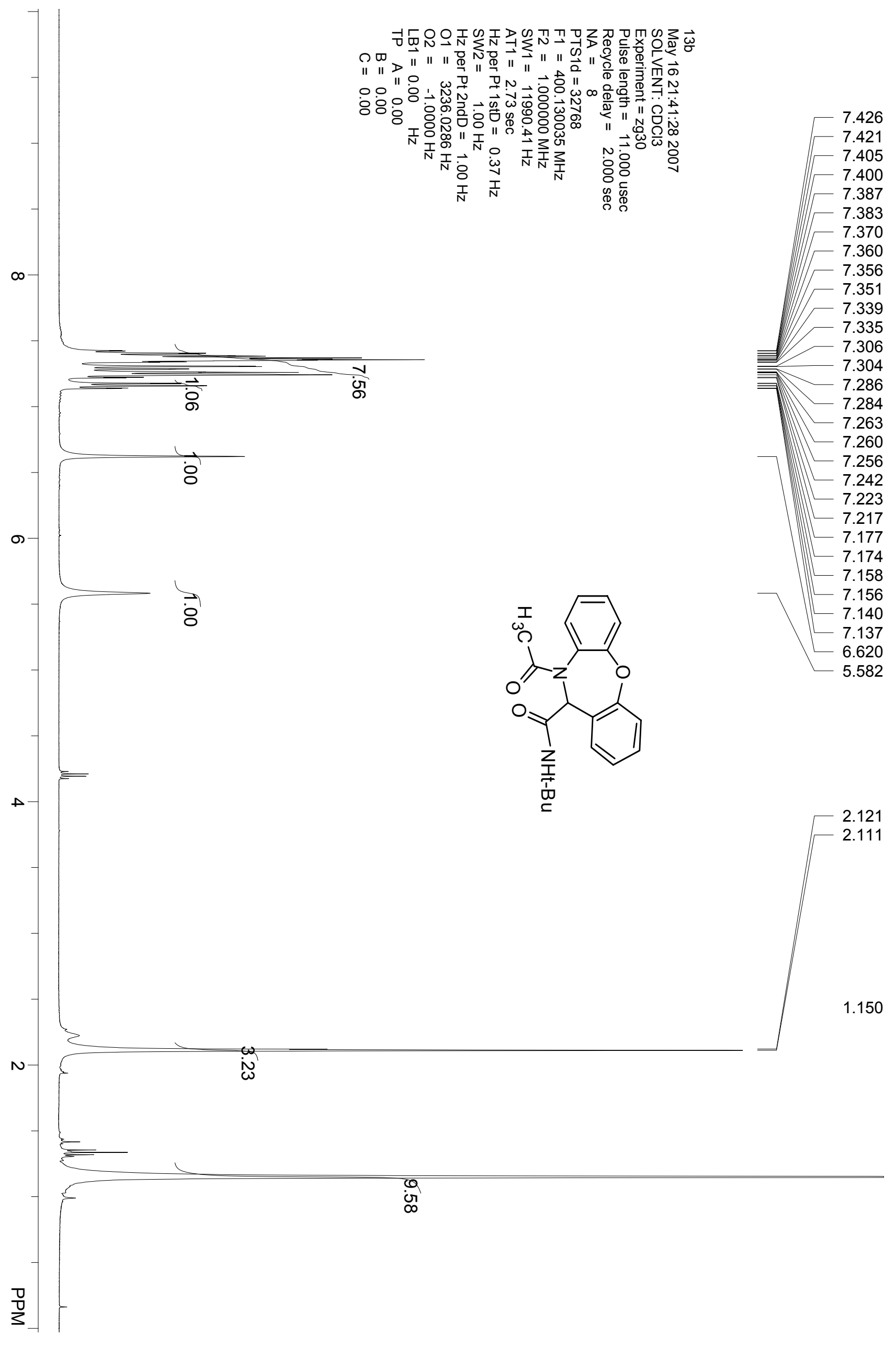




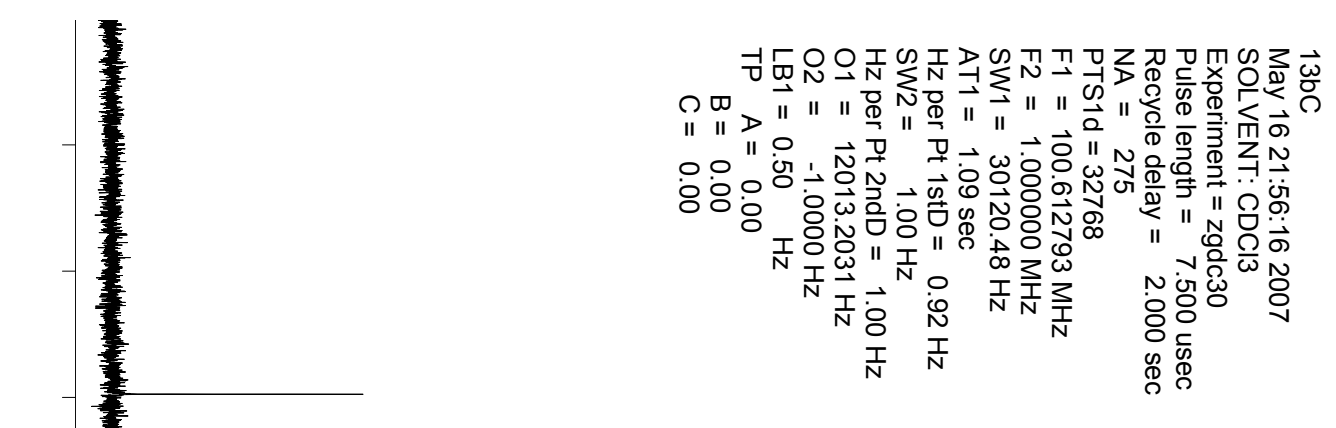

170.253

166.904

153.303

152.900

ज्ञ

응

잉

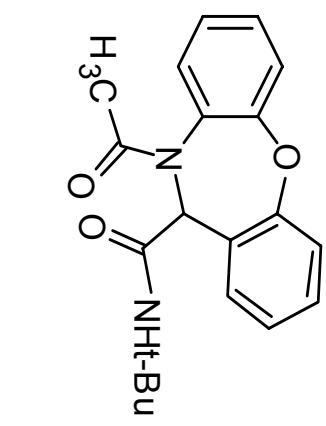

77.229

76.911

76.588

131.086

130.402

129.448

129.344

124.365

123.083

122.738

121.399

121.036

61.116

51.245

28.084

21.884

$\stackrel{0}{0}$ 


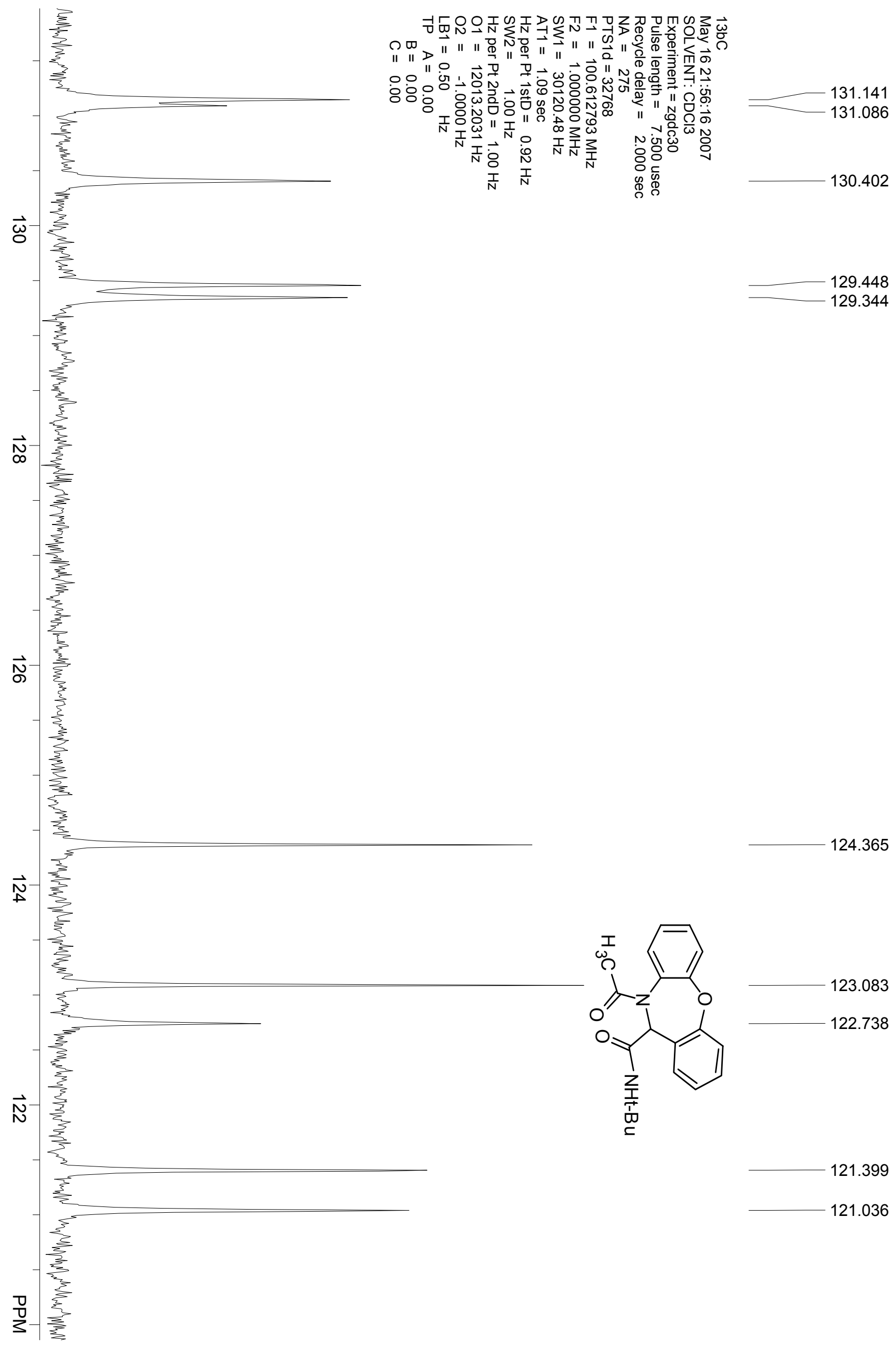




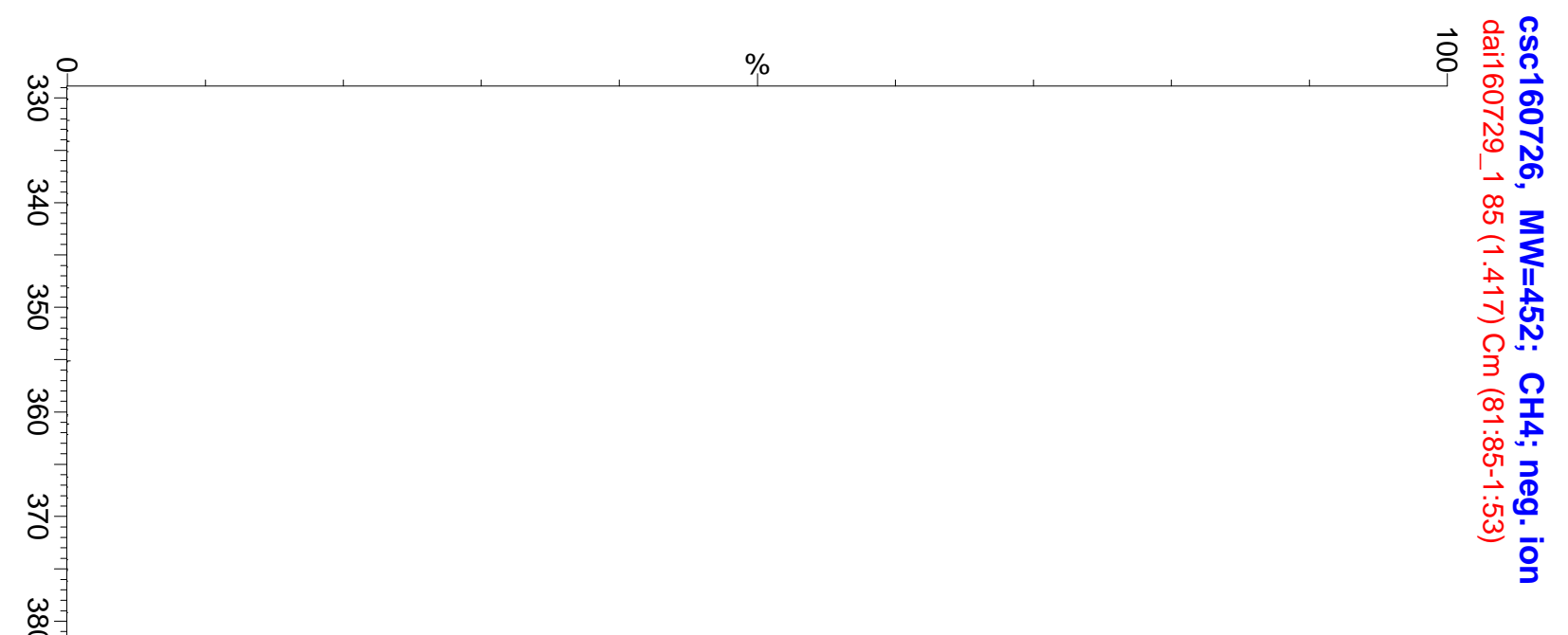

W

㝏

$\stackrel{ }{\circ}$

雚突

0

蛒走

克卷

방

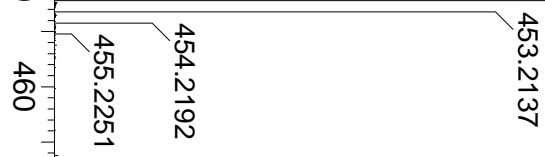

숭.

$\stackrel{+}{\circ}$

\&

용

or

Nั

ఱ్ట

잉

舁

용
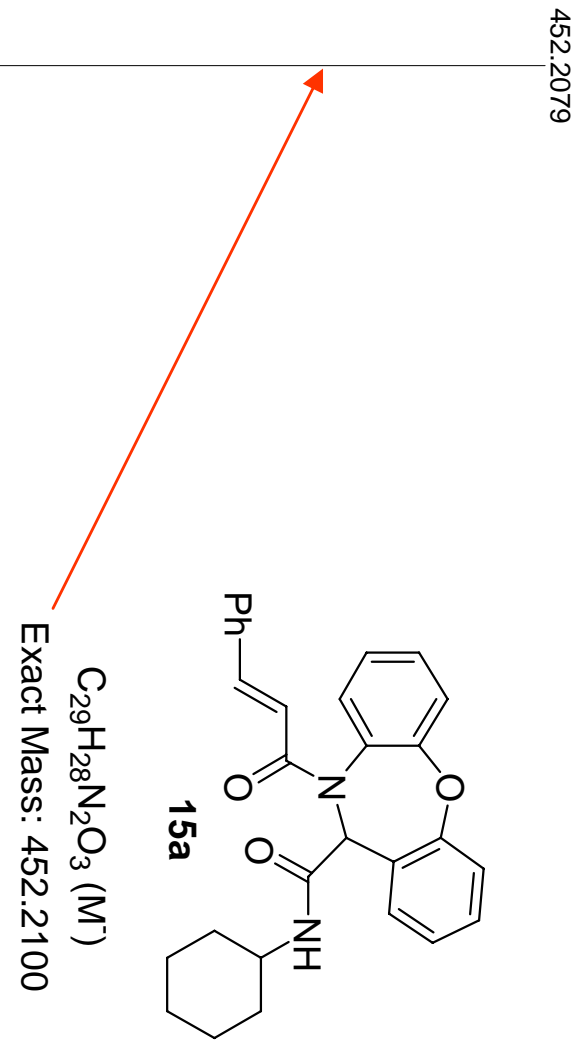

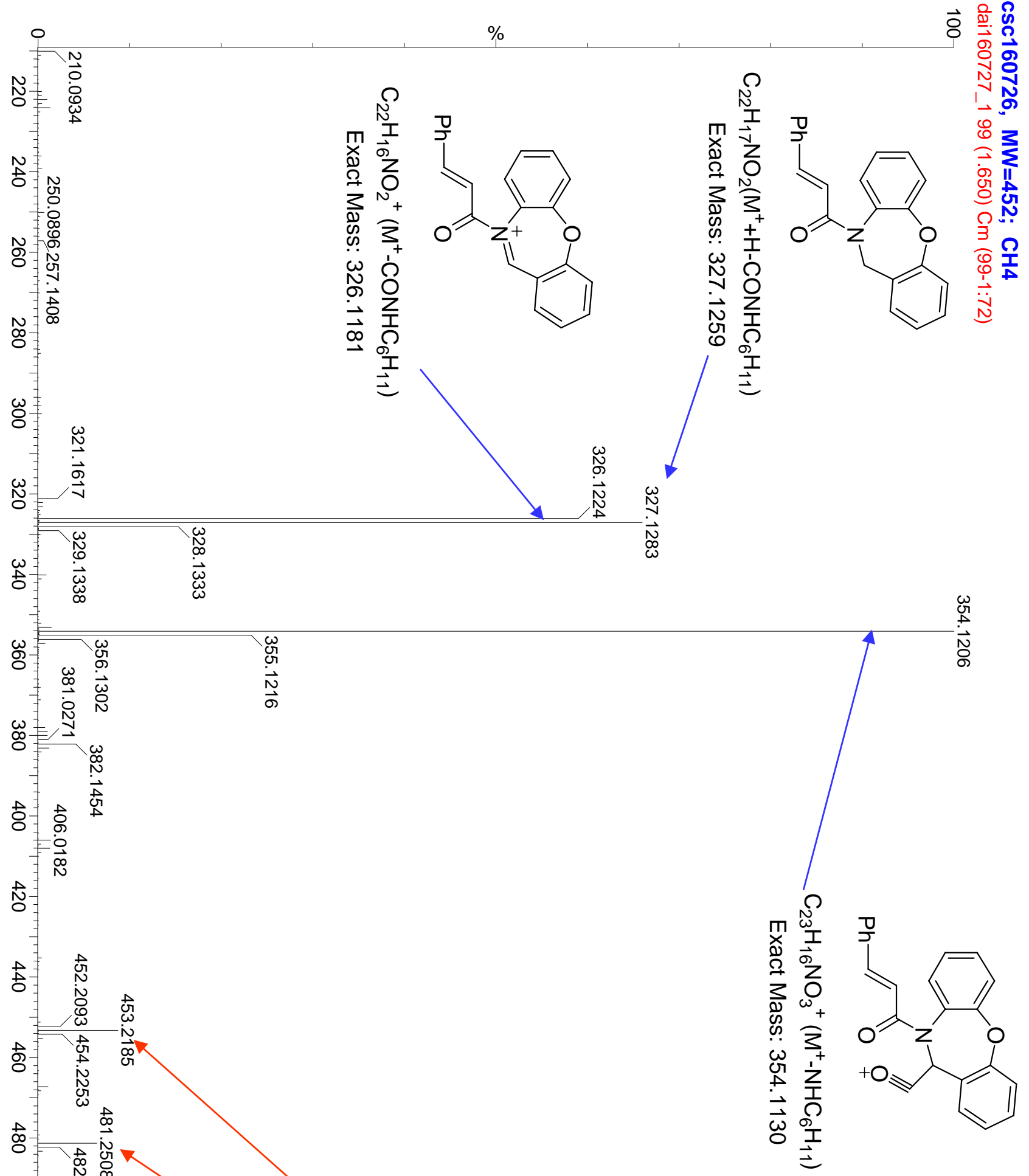

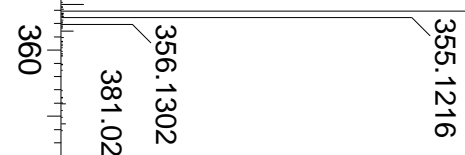

w

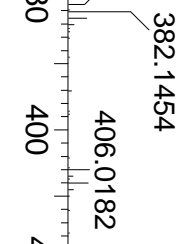

त्

寺青 空

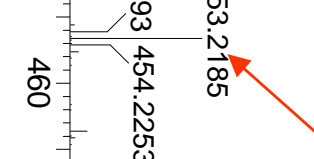

学 $\stackrel{+}{\stackrel{\infty}{\vec{N}}}$

ज्:

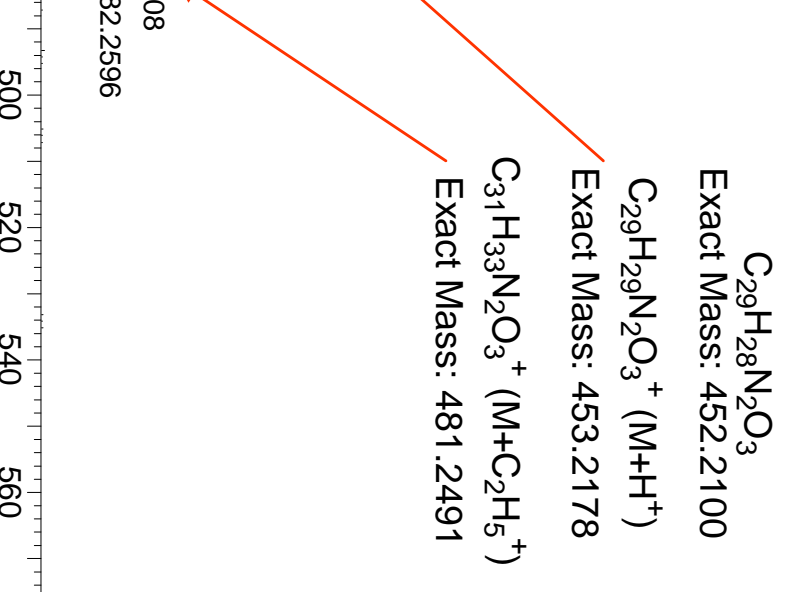

잉-<smiles>CC(C)(C(=O)C1c2ccccc2Oc2ccccc2C1C(=O)O)C1CCCCC1</smiles> 


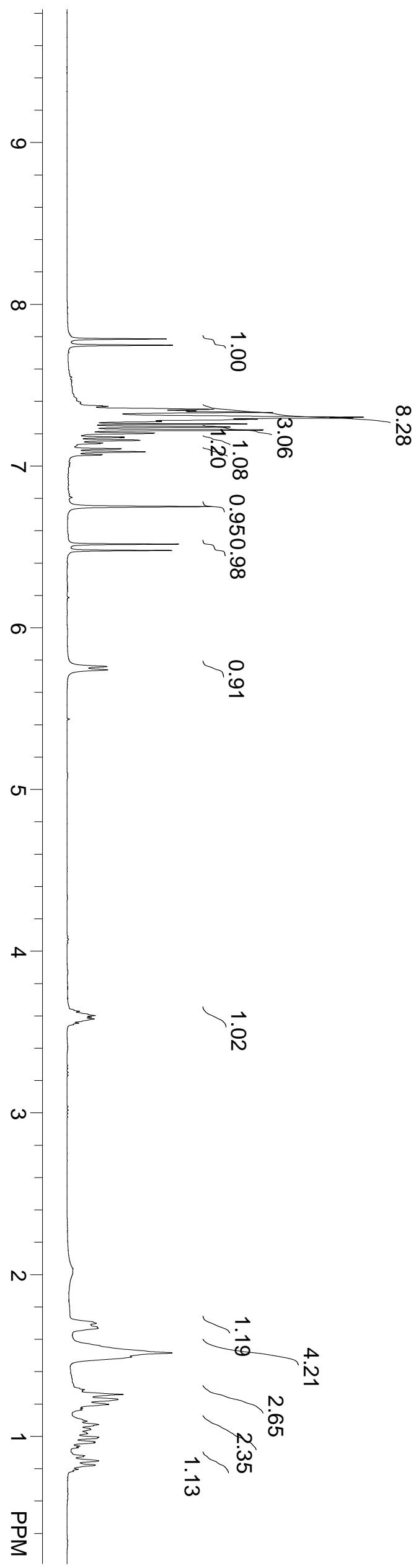

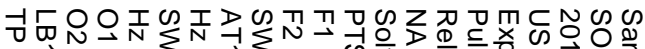

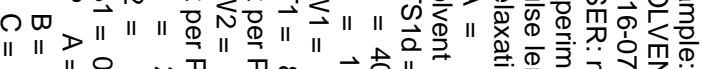
"1"

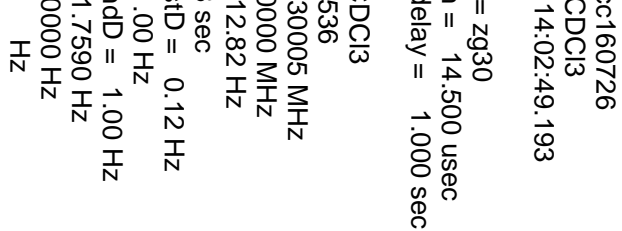

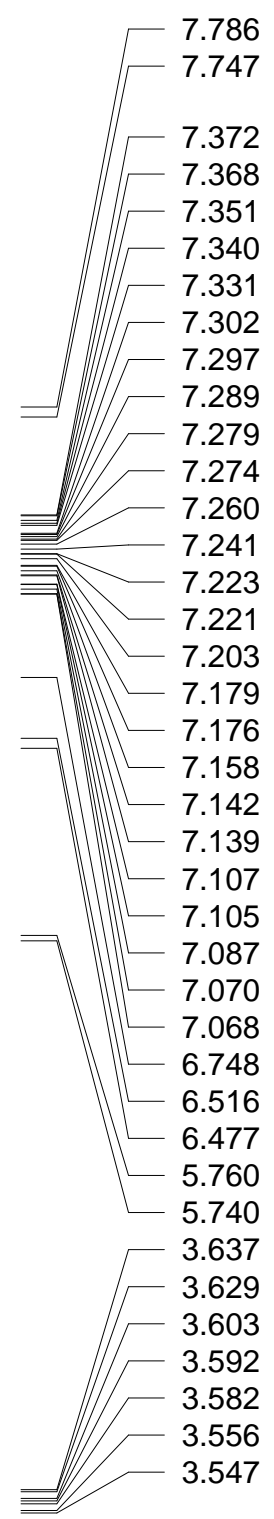<smiles>[CH][C](C(=O)C1[C](C(=O)/C=C/[Hg])c2ccccc2Oc2ccccc21)C1CCCCC1</smiles>

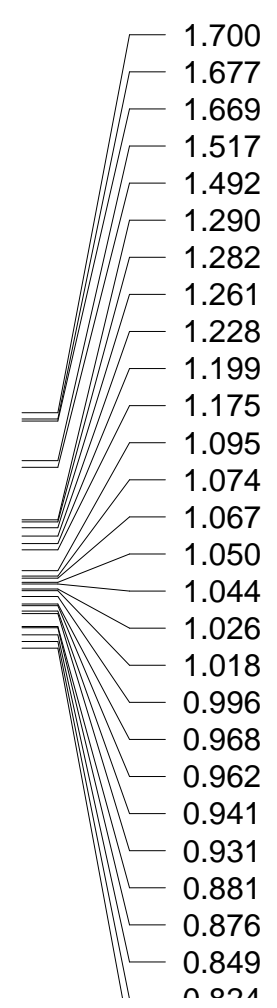




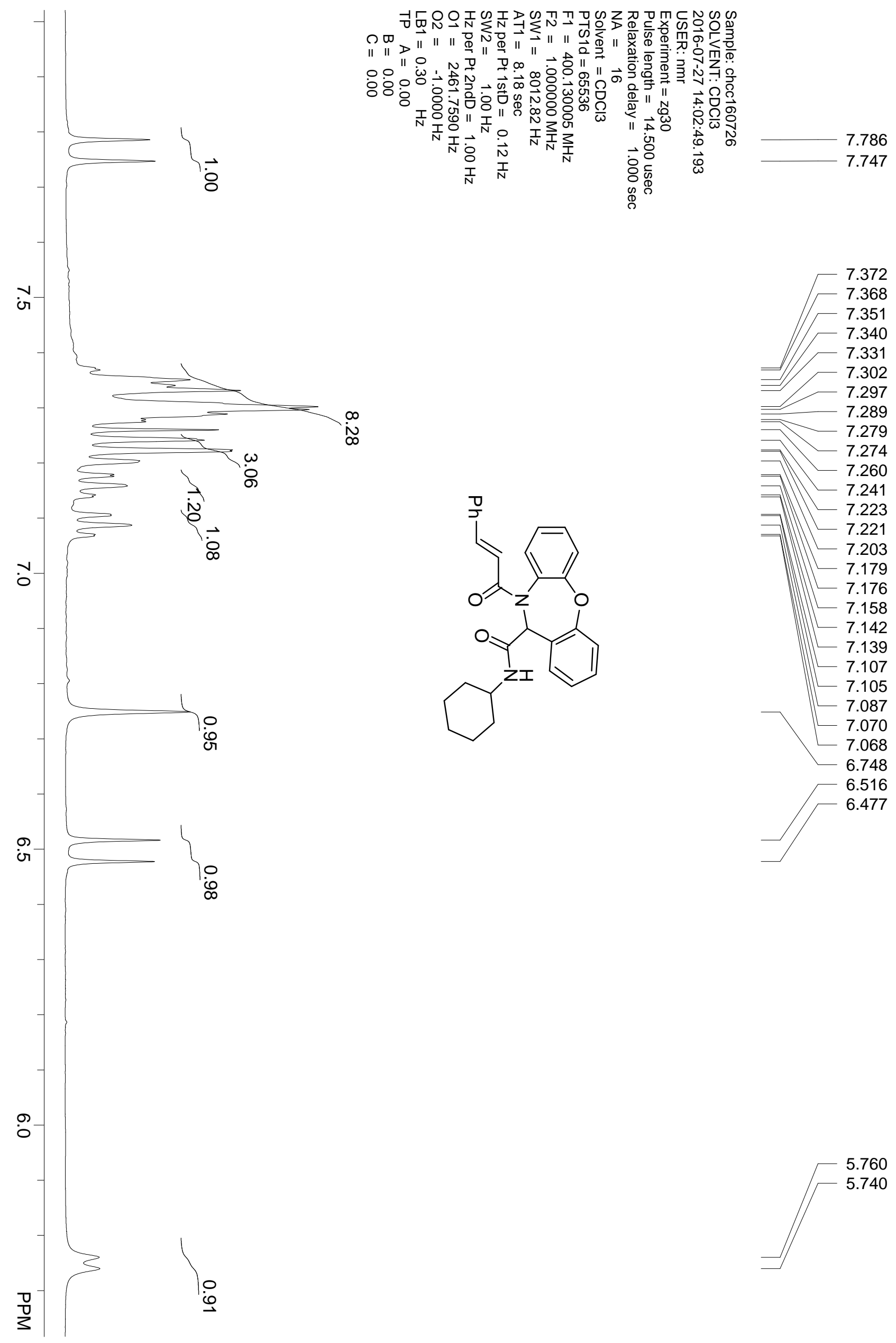




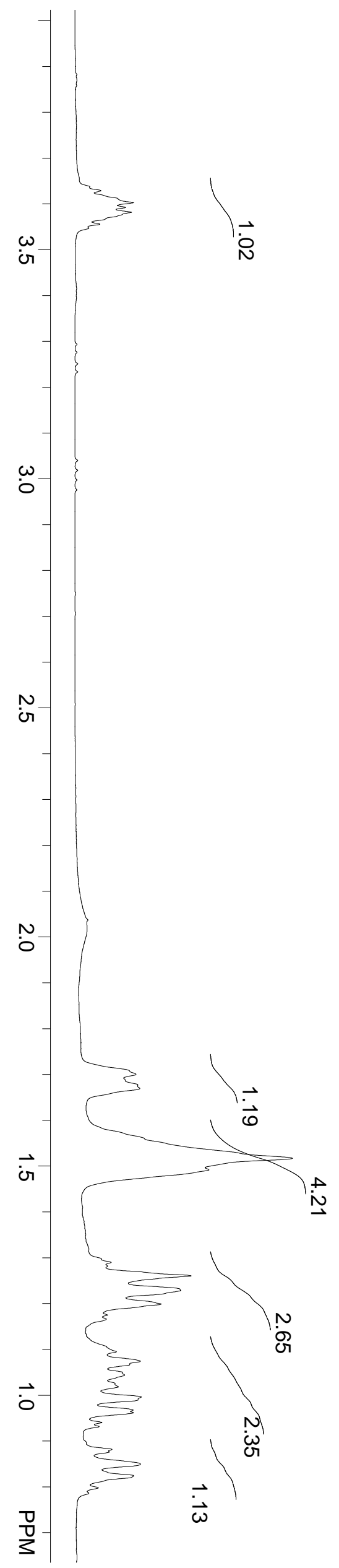

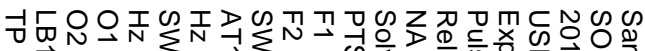

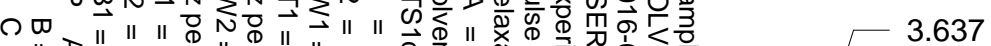
$\|$ \|

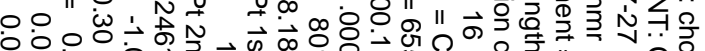

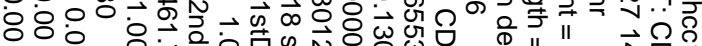
I

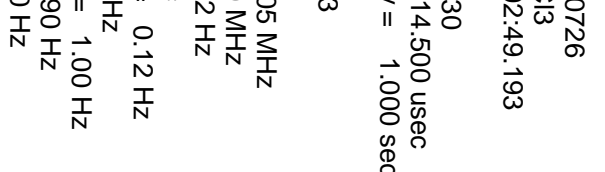

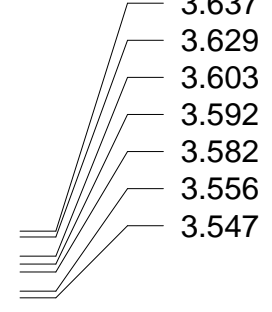<smiles>O=C(/C=C/[O-])[C]1c2ccccc2Oc2ccccc21</smiles>

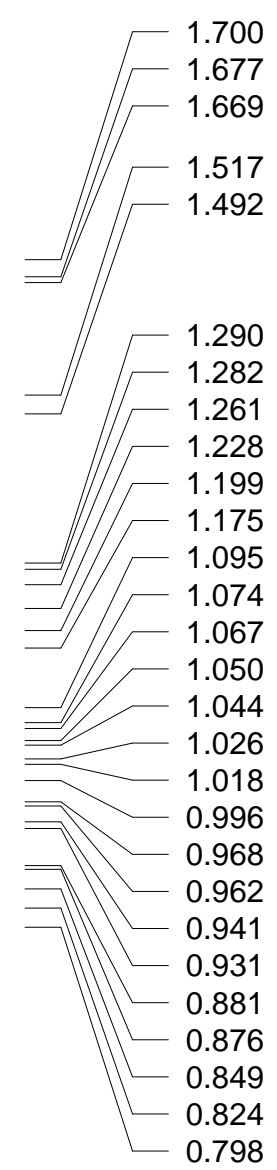




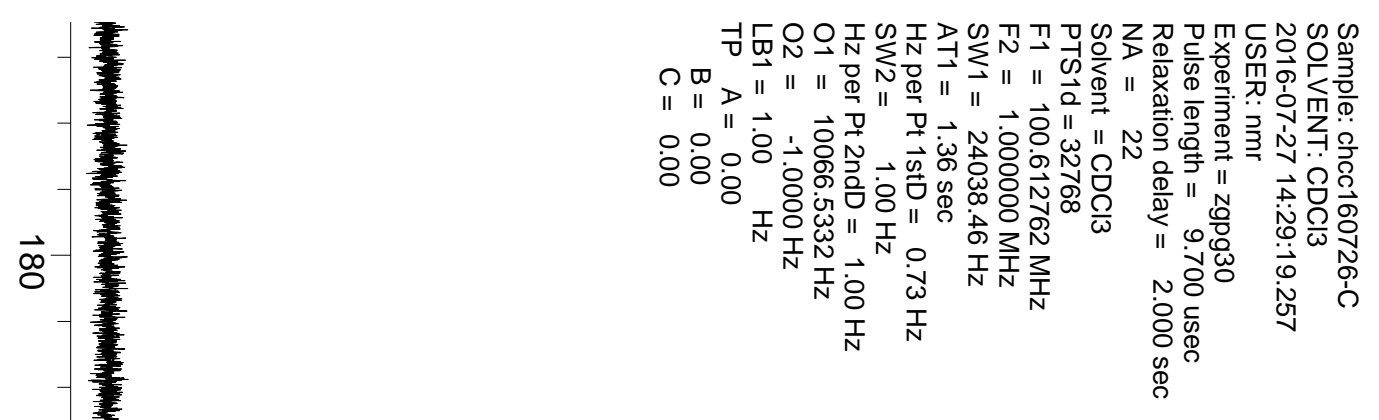

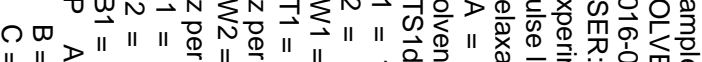

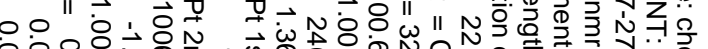

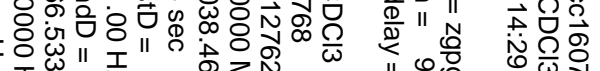

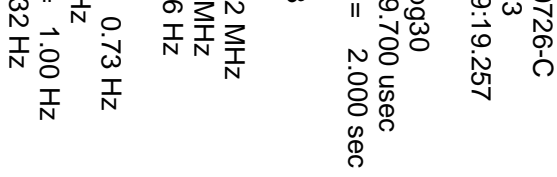

167.239

166.283

$\overrightarrow{8}$

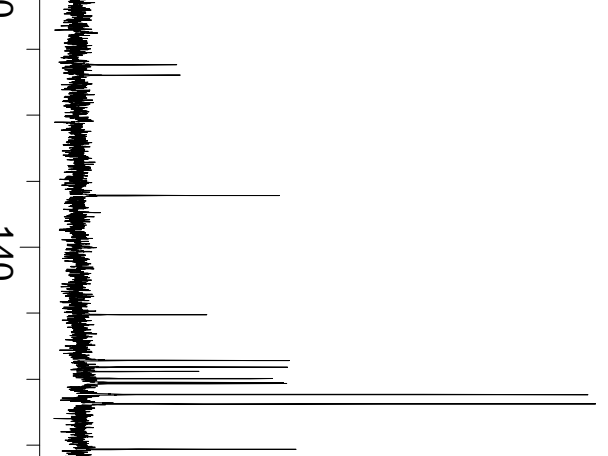

$\vec{N}$

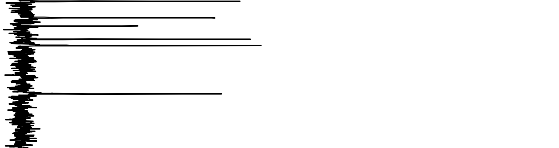

$\overrightarrow{8}$<smiles>[CH][C](C(=O)C1[C](C(=O)/C=C/[Hg])c2ccccc2Oc2ccccc21)C1CCCCC1</smiles>

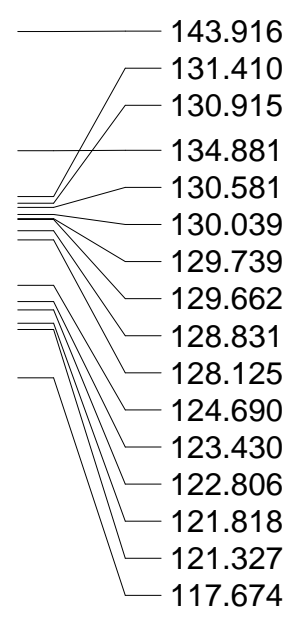

○

-

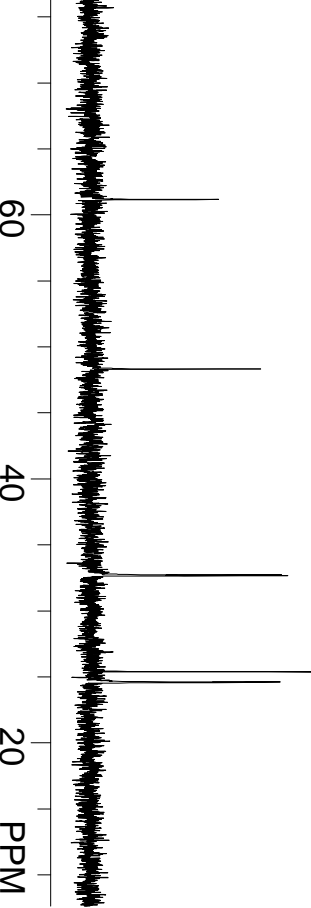

61.175

48.334

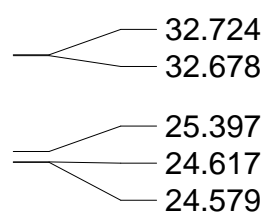



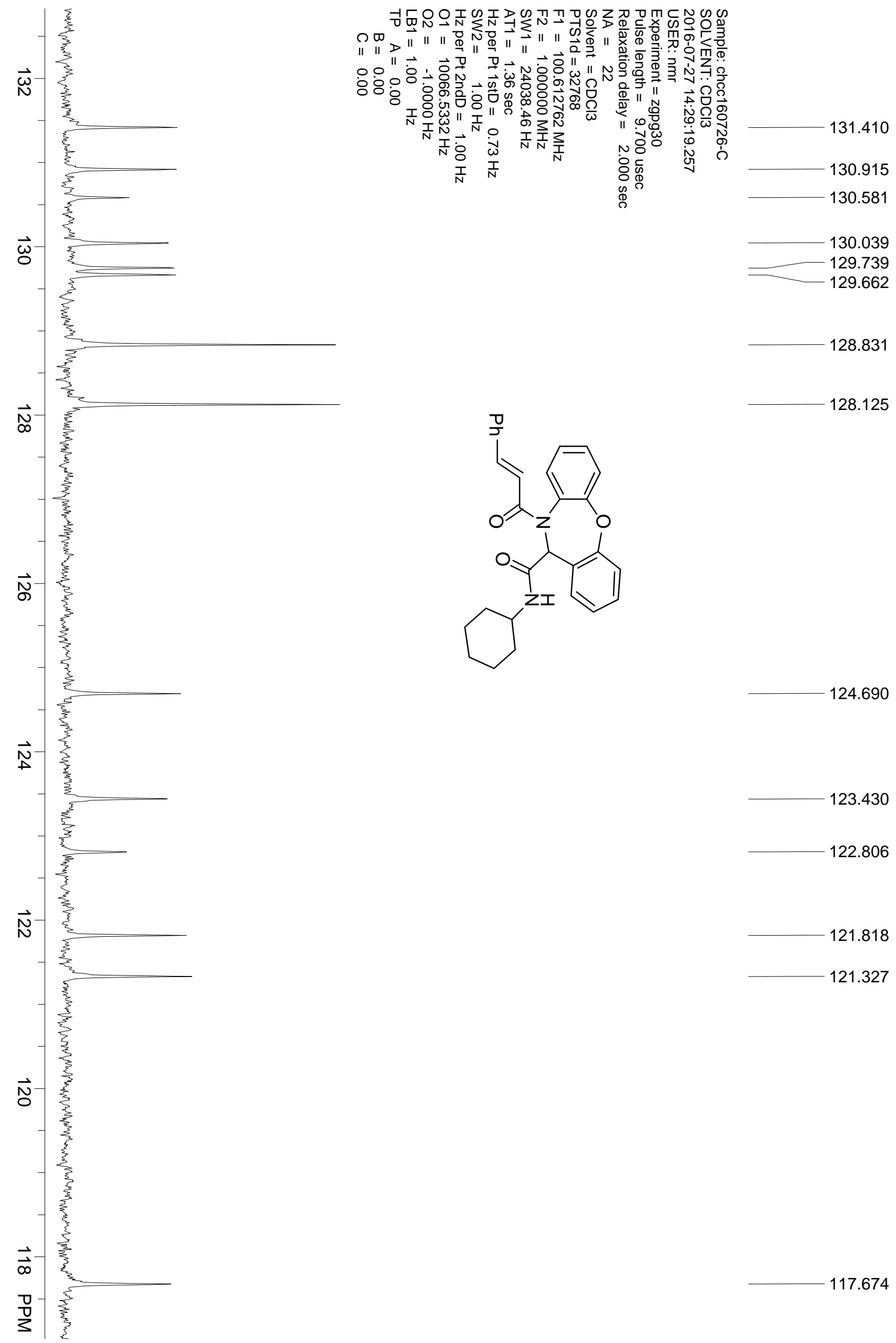

128.831

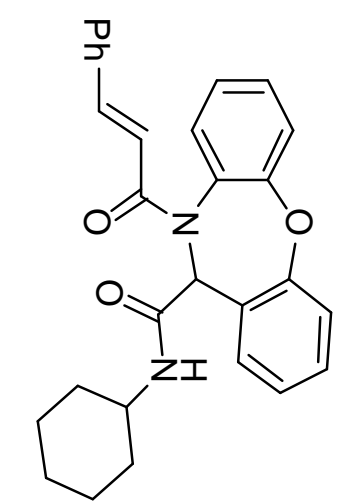

128.125

124.690

123.430

122.806

121.818

121.327 

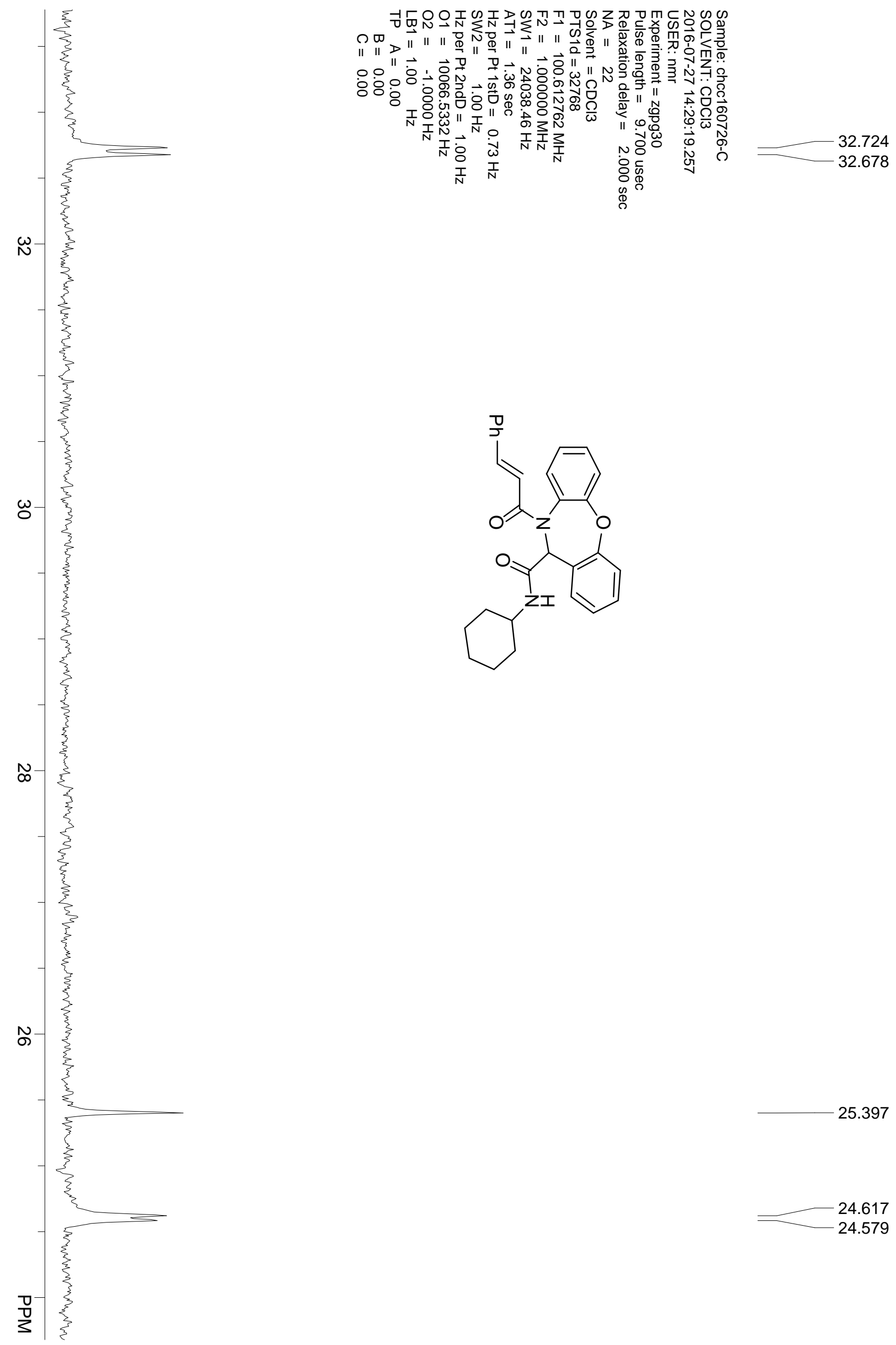

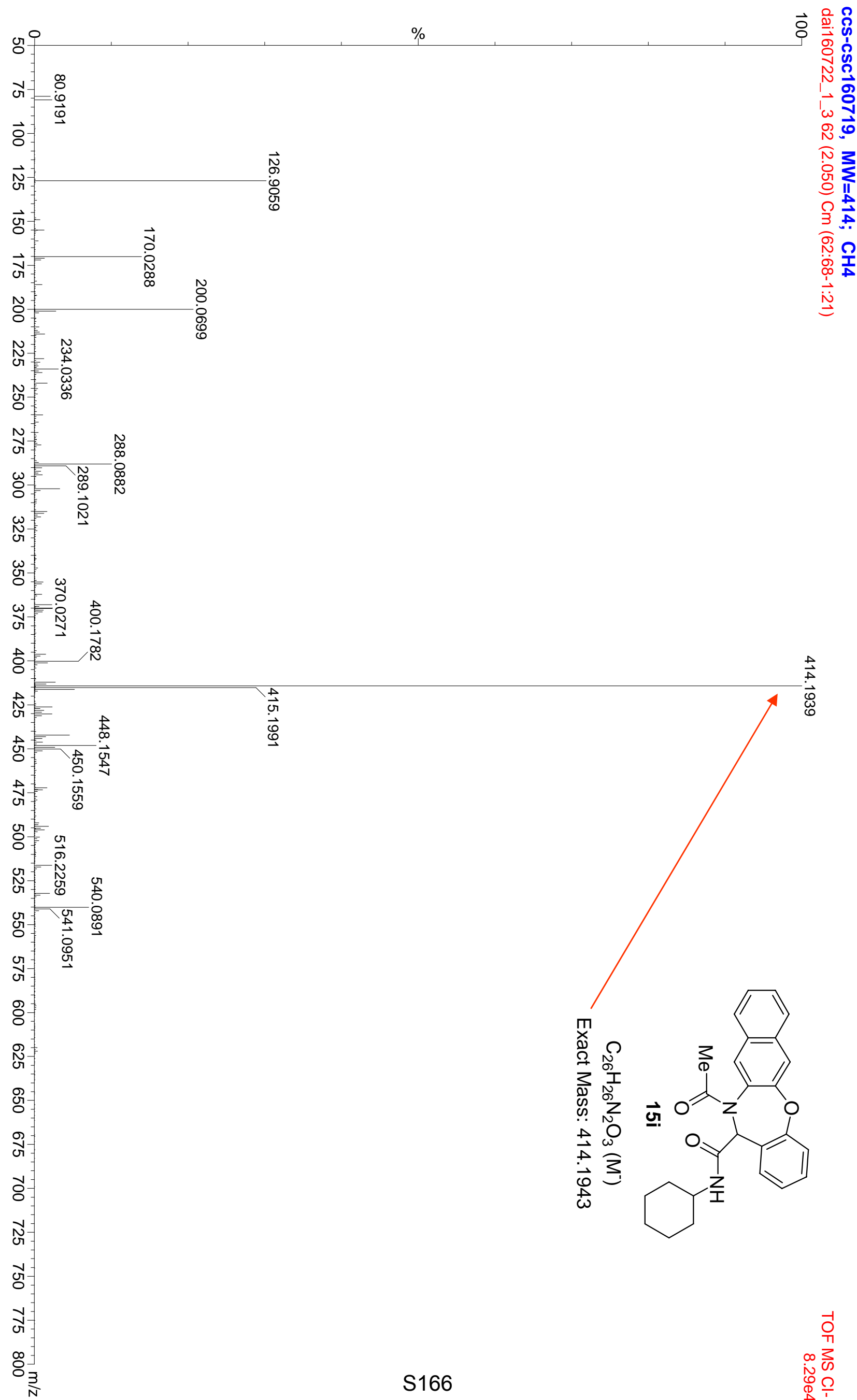

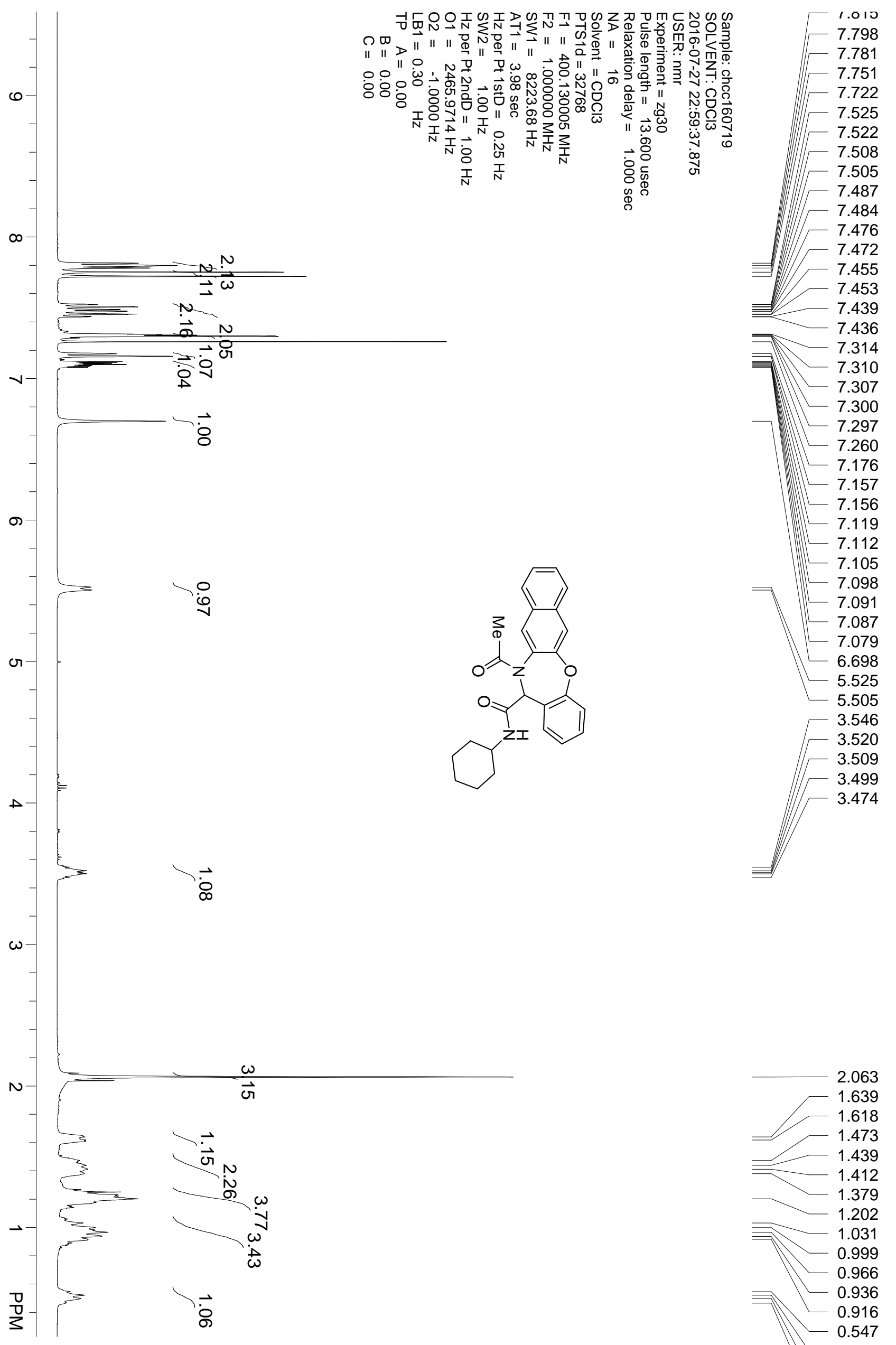


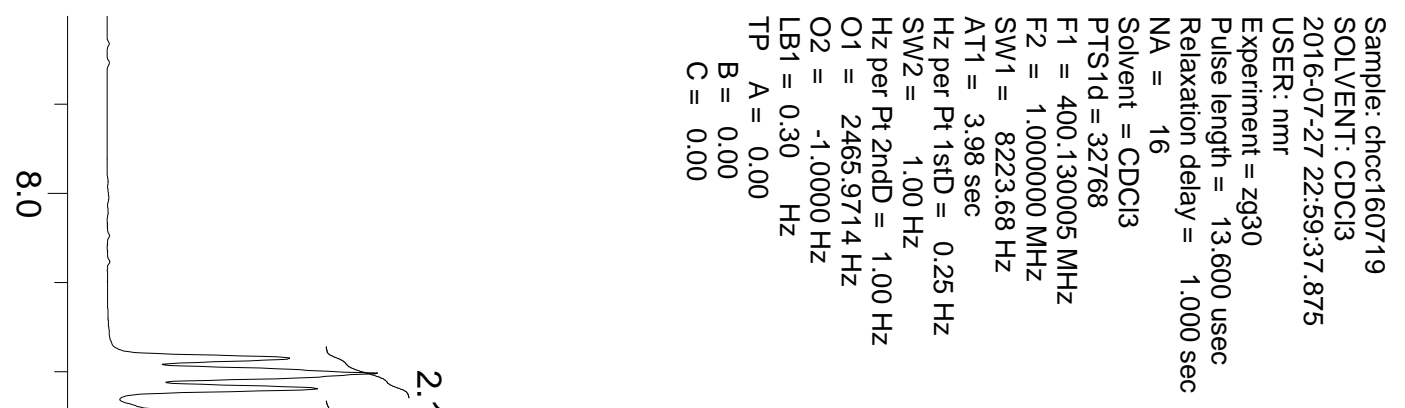

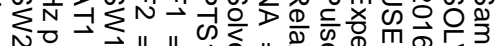

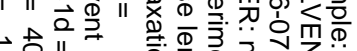
( 7.815

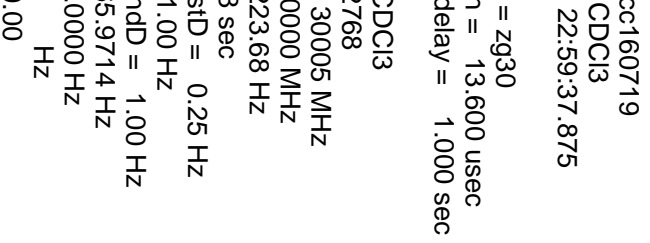
7.798 7.781 $-7.751$ $-7.722$
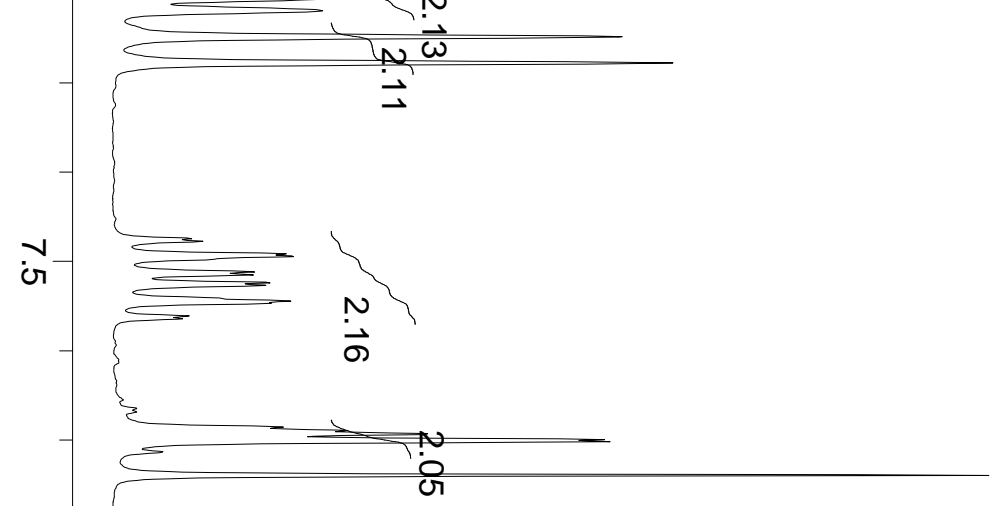

7.307

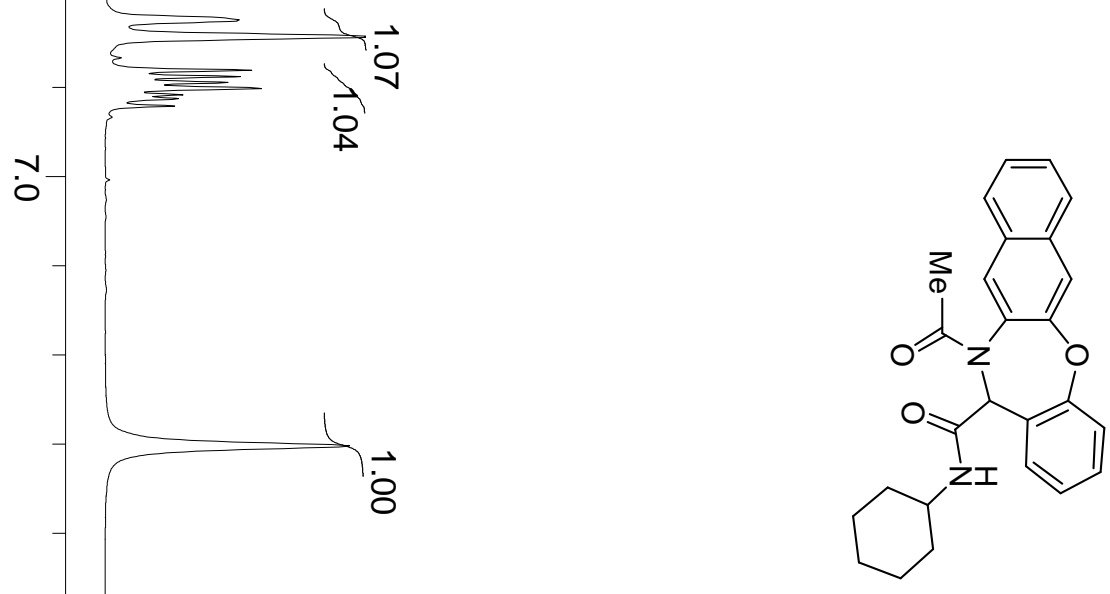




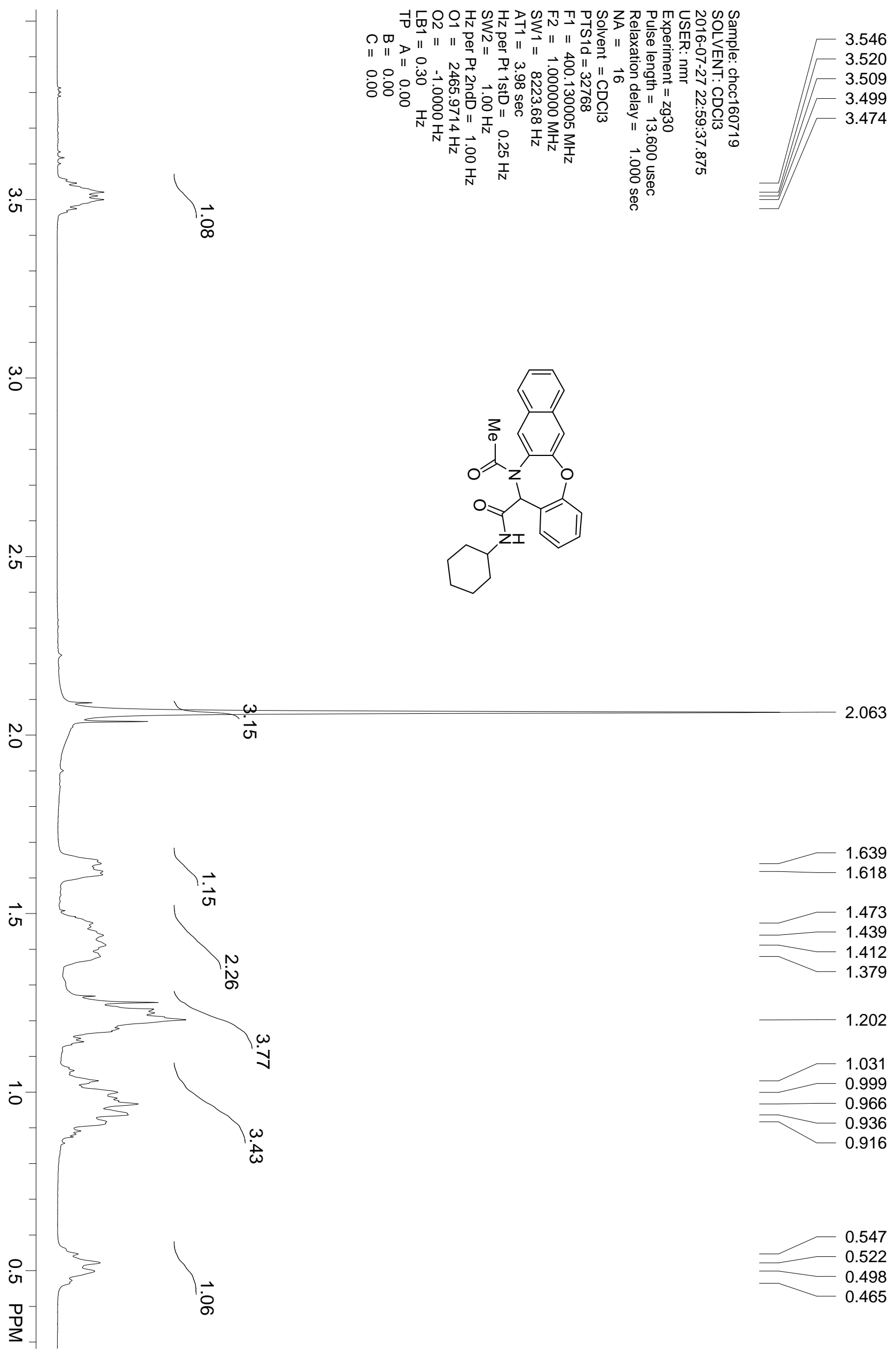



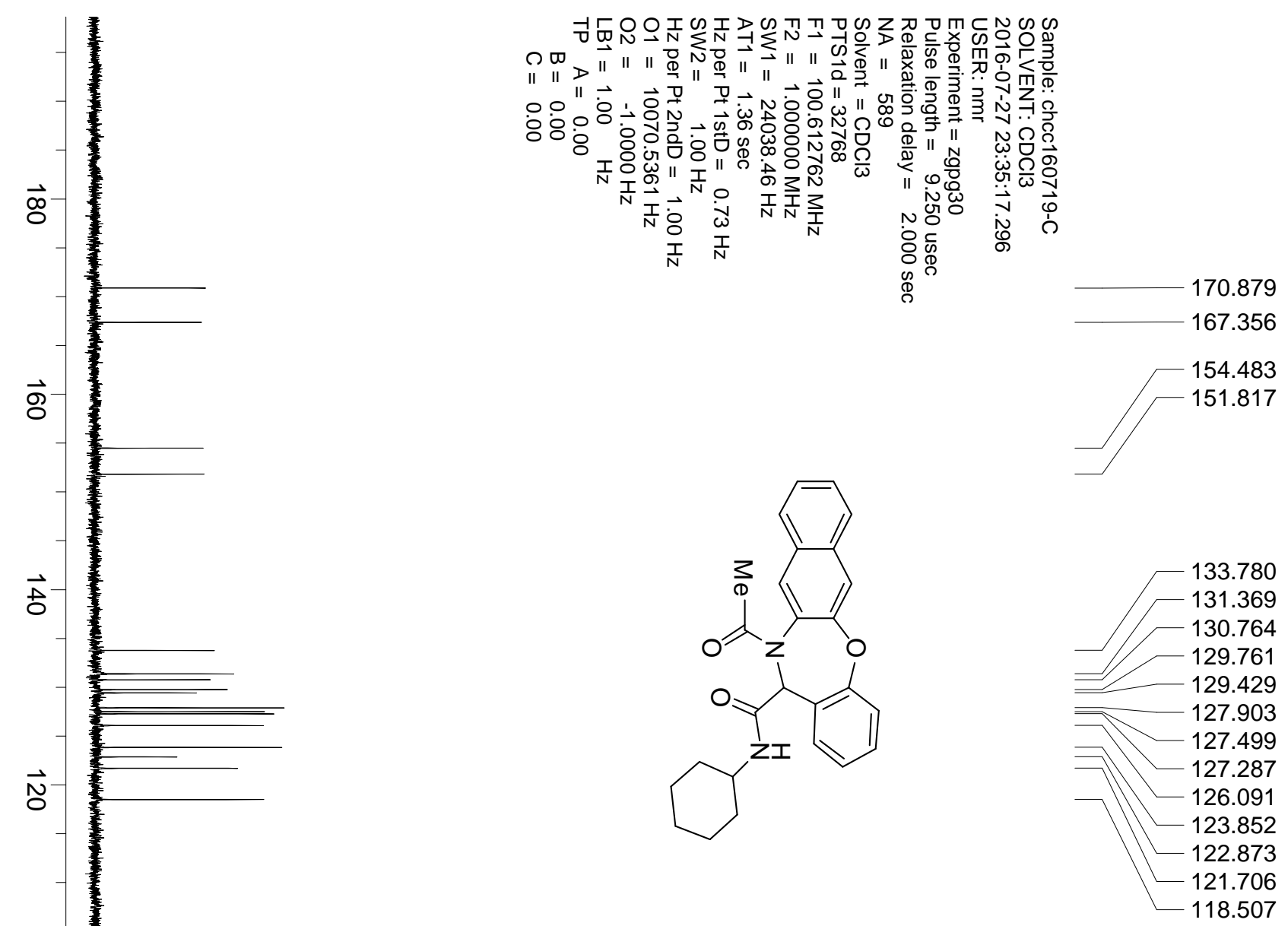

$\overrightarrow{8}$

ஜ

77.482

77.160

76.845

8

60.964

48.154

t

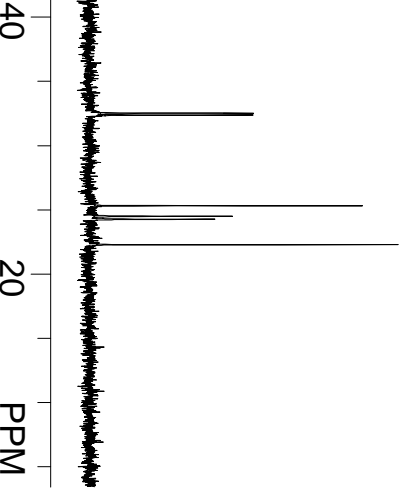

32.520

32.361

25.308

24.489

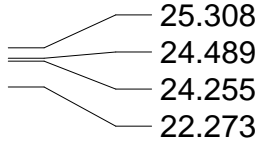




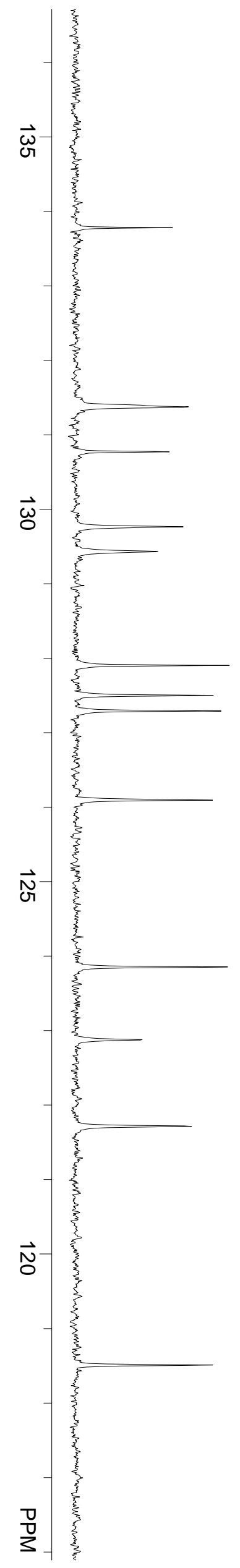

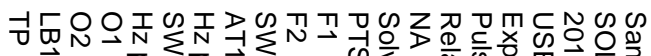

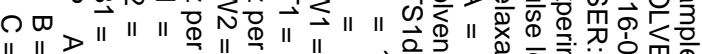

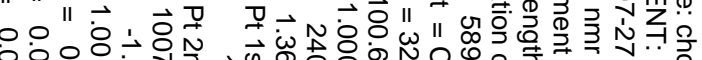

$\therefore 80.000$

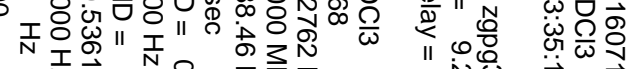

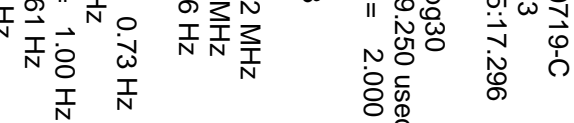

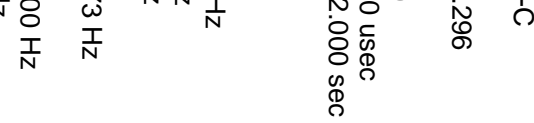

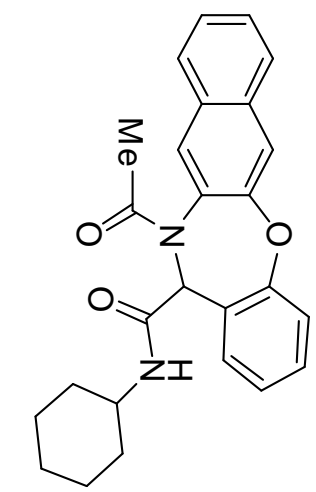

131.369

130.764

129.761

129.429

27.903

127.499

127.287

126.091

123.852

122.873

121.706 

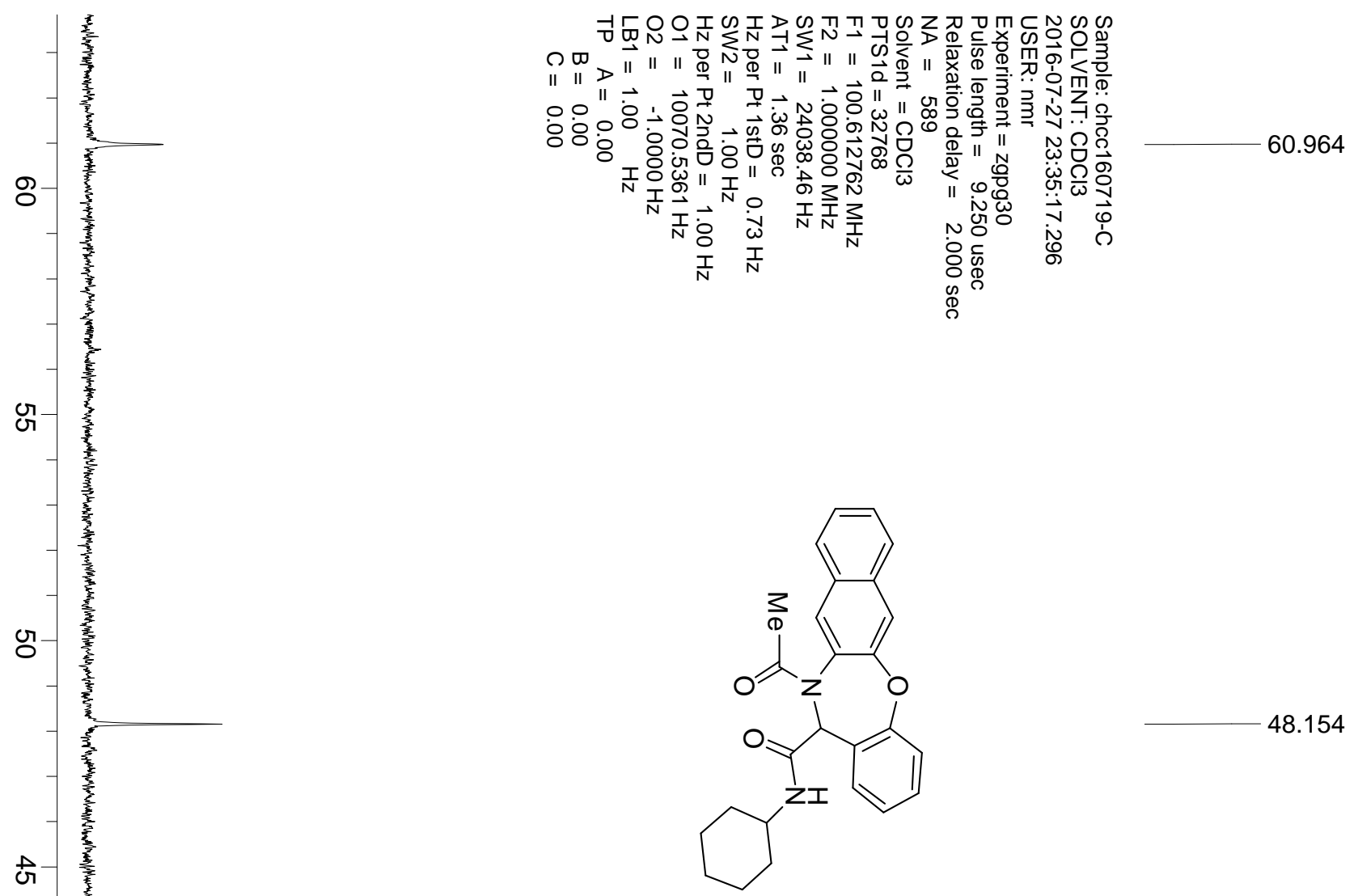

N

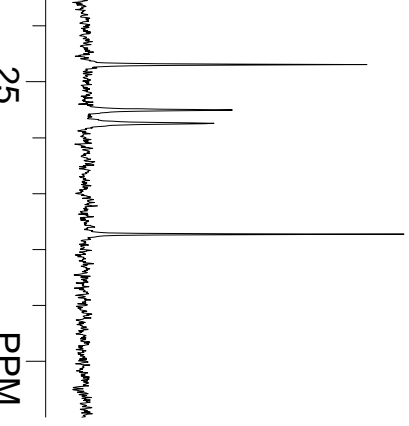

